Luminos is the Open Access monograph publishing program from UC Press. Luminos provides a framework for preserving and reinvigorating monograph publishing for the future and increases the reach and visibility of important scholarly work. Titles published in the UC Press Luminos model are published with the same high standards for selection, peer review, production, and marketing as those in our traditional program. www.luminosoa.org 

Anthropologies of Revolution 



\title{
Anthropologies of Revolution
}

Forging Time, People, and Worlds

\author{
Igor Cherstich, Martin Holbraad, \\ and Nico Tassi
}

\section{무}


University of California Press

Oakland, California

(C) 2020 by Igor Cherstich, Martin Holbraad, Nico Tassi

This work is licensed under a Creative Commons CC-BY license. To view a copy of the license, visit http://creativecommons.org/licenses.

Cataloging-in-Publication Data is on file at the Library of Congress.

Suggested citation: Cherstich, I., Holbraad, M. and Tassi, N. Anthropologies of Revolution: Forging Time, People, and Worlds. Oakland: University of California Press, 2020. DOI: https://doi.org/10.1525/luminos.89

ISBN 978-0-520-34379-5 (pbk. : alk. paper)

ISBN 978-0-520-97516-3 (ebook)

$\begin{array}{llllllllll}29 & 28 & 27 & 26 & 25 & 24 & 23 & 22 & 21 & 20\end{array}$

$\begin{array}{llllllllll}10 & 9 & 8 & 7 & 6 & 5 & 4 & 3 & 2 & 1\end{array}$ 
CONTENTS

Acknowledgments

Introduction. Multiplying Revolutions 1

Chapter 1. Revolution as Event: Ritual, Violence, and Transformation $\quad 18$

Chapter 2. State and Revolution: Nations, Tribes, and Lineages 41

Chapter 3. The Revolutionary Person: Penitence, Sacrifice, and the New Man 66

Chapter 4. The Revolutionary Leader: Charisma, Authority, and Exception

Chapter 5. Revolution and Ideology: Truth, Lies, and Mediation 113

Chapter 6. Revolutionary Cosmologies: Spirits, Myths, Worlds 134

Conclusion. Worlds in Revolution 155

References 171

$\begin{array}{ll}\text { Index } & 197\end{array}$ 

This book is the outcome of "Comparative Anthropology of Revolutionary Politics" (CARP), a five-year research project dedicated to developing a distinctively anthropological understanding of revolutions. The project was funded by a Consolidator grant of the European Research Council (ERC-2013-CoG, 617970, CARP) and led by Martin Holbraad at University College London from 2014 to 2019. For catalytic discussions on the anthropology of revolutions during the early stages of the book's development, we wish to thank Narges Ansari, Myriam Lamrani, and Charlotte Loris-Rodionoff, who were members of the project's core research team alongside the three of us. For illuminating discussions at various stages of the book's development, as well as for advice on relevant literature, we thank David Burrows, María Elena Canedo, David Cooper, Alice Elliot, Dan Hirslund, Caroline Humphrey, Bruce Kapferer, Nicola Miller, Morten Axel Pedersen, Mike Rowlands, Joseph Trapido, Kaya Üzel, and (particularly!) Lucia Michelutti. We are grateful to Pascale Searle and Suzanne Petrou for their dedicated administrative support throughout the project, and appreciate Michael Brown, Giles Machell, and Jen Morgan at UCL's EU Grants Office, Martin O'Connor, Paul Carter Bowman, and Rikke Osterlund at the Department of Anthropology, and Susanne Kuechler as Head of Department, for providing the basic administrative and institutional structures on which projects such as this depend.

We are enormously grateful to our undergraduate and masters' students in the course "Social Forms of Revolution," which we designed and taught together at UCL in 2016, and Cherstich continued to teach on his own in 2017 and 2018. The students' thoughts and comments during lectures and tutorials have been a constant point of reference for us in the writing of the book, the chapters of which 
are based on our lectures for the course. Some of the material that features in the chapters was also presented during the following conferences, workshops, and exhibitions: "Comparative Anthropologies of Revolutionary Politics" (UCL, London, 2014); "How Goes It with the New Man? A Comparative Approach to Revolutionary Subjectivity" (Cuban Institute of Philosophy, Havana, 2015); “The Revolutionary Process in Bolivia: A Comparative Approach" (Vicepresidencia del Estado, La Paz, 2016); "Morphologies of Invisible Agents" (Space Gallery, London, 2019); and "After the Event-Prospects and Retrospects of Revolution" (UCL, London, 2019). We thank those who helped to organize these events and also thank the participants for their contributions, and not least the personnel of the Centro de Investigación Social of La Paz as well as colleagues at the Instituto de Filosofia in Havana. We also give thanks to Hera Karagianni, Nikos Giannakakis, and particularly Panos Giannakakis (and Iris!) for their hospitality during a twoweek writing retreat in their house in Mount Pelion in June 2018. Kate Marshall at UCP has expertly guided this book to publication, and we are grateful also to the press's two reviewers for their detailed and insightful comments on the manuscript. Finally, our gratitude goes out to our families in Bolivia, Italy, and the United Kingdom for their support. 


\title{
Introduction
}

\author{
Multiplying Revolutions
}

\section{NOT MISSING THE REVOLUTION}

In his provocative 1991 article "Missing the Revolution," American anthropologist Orin Starn admonishes anthropologists of Peru for having allowed the insurgency of the Shining Path-the Maoist group whose violent revolutionary campaign dominated life in Peru in the 1980 s and 1990s-to take them completely by surprise. Hundreds of ethnographers had been conducting research in the Andes throughout the 1970s, often in the very parts of rural Peru where the Shining Path's uprising made its deepest inroads. Yet in their writings, Starn complains, they remained oblivious not only to the popular ferment that led up to the Shining Path's campaign from 1980 onward but also to the socioeconomic conditions that contributed to it. Little or no attention was paid to the developing impoverishment of the countryside and the unrest it produced, while the dynamics of internal migration that had created the pool of mobile youths from which the Shining Path drew its cadres also went unnoticed. Rather, anthropologists working there at the time stayed within the narrow confines of what Starn disparagingly calls "Andeanism," portraying peasant life as somehow immune to the flow of history, and focusing instead on such exotic and apolitical topics as environmental adaptation, ritual, and cosmology (see also Starn 1995).

Starn's critique is relevant well beyond the case of Peru. To be sure, it would be wrong to contend that anthropologists have in general ignored the revolutionary upheavals in their ethnographic midsts. As we shall explain in more detail 
presently, there are plenty of anthropological studies of revolution, including a number of substantial monographs, written by ethnographers who have been caught up in the action of revolutionary uprisings (e.g., Bourgois 1981, 1982; Hegland 2014; Armbrust 2019) or, perhaps more often, have sought to study their aftermath in particular ethnographic settings (e.g., Lan 1985; Donham 1999; Wilson 2016). Nevertheless, Starn's observation is pertinent on a broader level, since this literature is largely fragmentary. While studies of revolution are indeed scattered across anthropology, one is hard-pressed to find a set of debates or approaches to revolution that could be described as distinctively anthropological. There is no such thing as an "anthropology of revolution" (as there are, say, anthropologies of ritual, food, development, postsocialism, capitalism, and even, recently, protest movements) - no clearly discernible genealogy of writings with a sense of scholarly dialogue on the topic. ${ }^{1}$ As Bjørn Thomassen puts it in an article that helps to set the agenda for the kind of anthropology of revolutions we seek to develop, anthropologists have been "strikingly silent" on revolutions (2012: 680). Contributors to the debate about revolutions in the broader historical and social sciences "can hardly be blamed" for failing to cite anthropologists at all, "for the neglect comes from within anthropology itself" (680).

This book seeks to remedy such neglect by exploring systematically what anthropological thinking can contribute to the study of revolutions. In a field that seems saturated by the writings of philosophers, social and political theorists, historians, political scientists, and sociologists, not to mention emblematic works by revolutionary actors themselves (from Bakunin and Lenin to Guevara and Mandela), we seek to make space for a distinctively anthropological approach to revolutions. Our tack in this regard, however, is in a sense the opposite of what Starn had recommended. Rather than behaving more like political scientists or sociologists by paying attention to the distribution of resources, social and economic inequality, migratory pressures, and other structural conditions of local and global political economies, our intent is to take the study of revolutions deeper still into a distinctively anthropological terrain. A focus on quintessentially anthropological themes such as ritual, cosmology, and personhood, we propose, can help to deepen as well as refigure the study of revolutionary politics, unpacking the very notion of revolution in new ways, and taking the way we imagine it and study it in new directions.

At the heart of the book is an ethnographically driven experiment: What happens when we look at revolutions through the prism of the local social and

1. It is telling, for example, that contributors to two prominent online forums presenting quick-fire anthropological responses to the revolution of 2011 in Egypt, in the aftermath of the so-called Arab Spring, appeared to have had few anthropological theorizations of revolution upon which to draw (Elyachar and Winegar 2012; Abu-Lughod et al. 2012). Alongside the regional scholarship, in these essays one finds an array of references to philosophical, historical, and political scientific works on revolution, but hardly any to such works by anthropologists. 
cultural frameworks in which they are enacted? How might our understanding of revolutions be challenged, shifted, and augmented by looking at revolutionary phenomena in different ethnographic settings, in relation to varying social forms, notions of time, space, power, and personhood, religious cosmologies, indigenous mythologies, and ritual practices-contexts, that is, that are often quite different from standard understandings of revolution as a predominantly "modern" political phenomenon (e.g., Brinton [1938] 1965; cf. Scott 2004; Buck-Morss 2009)? What happens to revolution, for example, when it is enacted through idioms of tribal affiliation in Libya, ancestral spirit-mediumship in Zimbabwe, Shi'a martyrdom in Iran, Buddhist ethics in Mongolia, West African-derived animal sacrifice in Cuba, or Aymara cosmology in Bolivia? By experimenting with these conceptions and experiences of revolution that are often quite distant from what the script of influential political theorists predicted, we show the limits of often normative outlooks and add a new voice to the broader debate about revolution. In other words, we use the power of anthropological analysis to break out of standard assumptions and open up new ways of thinking about what revolutions are, how they operate, and why they matter to people.

To map out the scope of such an endeavor, in this book we ask questions such as the following. What might we learn about revolutions if we think of them in relation to anthropological debates about the dynamics of ritual transformation (chapter 1)? How might anthropologists' long-standing concern with kinship, clanship, and other localized forms of social organization inform the way we understand the role of the state, the party, and the vanguard in revolutionary projects (chapter 2)? How do varying conceptions of personhood in different ethnographic settings inflect the way revolutionary subjects are constituted (chapter 3), and what bearing do they have on how we understand the power and charisma of revolutionary leaders (chapter 4 )? How could debates about the role of ideology in revolutionary action be reoriented by taking into account the varying ways in which people imagine the relationship between reality and illusion in more localized revolutionary contexts (chapter 5)? How, more broadly, do differing cosmological frameworks in different social and cultural settings change the very horizons of revolutionary politics - how is revolutionary time, including its origins and ends, imagined and experienced; how are revolutionary projects spatialized; and how do revolutionary projects sit alongside other forces, relations, and entities that compose people's worlds (chapter 6)? Could revolutionary politics, ultimately, be understood as cosmogonic projects in their own right (Conclusion)? That is to say, how do we take seriously as anthropologists the notion, so often propounded by revolutionary protagonists, that what is most deeply at stake in revolutions is not just a desire to modify the conditions of people's lives, but the more radical aspiration of reconfiguring the very worlds in which lives unfold?

This book's central contention is that, when viewed anthropologically in this way, revolutions emerge as concerted attempts to radically reconstitute the 
worlds people inhabit. Unlike more gradual and piecemeal forms of political change, revolutions set themselves up as projects of total and radical transformation, expressed characteristically as a desire to bring about a "different world"- - sometimes an altogether "new" one. This all-embracing quality makes revolutions more than simply acts of violent political rupture-a feature on which political theories of revolution have tended to focus (e.g., Arendt [1965] 2006; Dunn 1972; Badiou 2009). From the holistic, ethnographically informed perspective of anthropology, revolutions emerge as processes of wholesale societal transformation that penetrate deeply into the fabric of people's lives, albeit in complex, often uneven, and invariably contested ways. They interact with localized social forms and structures, which they often seek to reconstitute. They make demands in people's most intimate spheres, promoting new forms of personal comportment, sometimes related to religious or quasi-religious ideals such as Islamic piety or the "New Man." They seek to refigure the relationship between past, present, and future, often through ritual practices and mythical narratives. All in all, we suggest, revolutions have a deeply cosmogonic character, in the classic sense of "cosmogony," understood as an act that brings about or otherwise reconstitutes a whole world. They unfold and refold in different ways the coordinates of human existence, recasting people, their relationships to each other and to the world at large, giving new roles not just to State, Leader, or Party, but also, for example, to divinities, ancestors, and spouses.

The notion of revolution as bringing about new worlds resonates with a modern and conventional political idea of radical transformation according to which human action can deliberately change the course of history, erasing the past in the name of a better future (Koselleck 1985; Scott 2004; Malia 2006). To paraphrase Claude Lévi-Strauss's anthropological comment on the French Revolution in particular, revolution is the "myth" of modernity. It provides "a coherent image on which our action can be modelled" (1966: 254), and indeed, deeper still, it provides a model for the very idea of what might count as an "action" at all, at least as far as the political arena of history, as we might imagine it, is concerned. If it is to paint revolution on a canvas larger than just "Western modernity," therefore, our anthropological approach must handle with care the idea that revolutions aim to bring about new worlds. In particular, encompassing the full diversity of revolutionary situations in different parts of the world, drawing into the fray ideas and practices that diverge from "modern" images of revolution, must involve critically interrogating assumptions about newness, historical rupture, progress, and indeed the very idea of a "world" as an object of human influence or control (Abramson and Holbraad 2014). To be sure, some form of rupture or upheaval is common to all of the situations we shall be treating as revolutionary (and we return to questions of definition presently). Part of our aim, however, is to allow the content we give to these notions- "rupture," "upheaval," indeed, "revolution"- to vary from one ethnographic 
situation to another (see also Holbraad et al. 2019). What the shape of any given revolutionary upheaval might be, how it may be understood and valued by the people involved in it, and how far it might converge or diverge from emblematically European ideas about revolution as a historical rupture are all questions we leave deliberately open to ethnographic scrutiny. So, yes: revolution as a cosmogonic process that seeks to bring about a different world. But only if what counts as a "world," what makes it qualify as "different" or even "new," and what the conditions and manners of "bringing it about" might be, are all treated as open anthropological questions.

Qualifying and presenting alternatives to the images of revolution that tend to dominate both public and scholarly commentary is one of our prime aims in developing a distinctively anthropological approach to the topic. Throughout this book we shall have occasion to enter into critical dialogue with historians, philosophers, social and political theorists, as well as revolutionary protagonists themselves, whose writings articulate, or at times simply take for granted, the central ideas that the "myth" of revolution as the modern form of politics par excellence has mobilized. To give a sense of where the fault lines of such a critical engagement lie, it is useful to consider as an example the ways in which revolution has been debated by political scientists in particular. After all, the frameworks that political scientists develop, and the questions they ask, tend to have a strong influence in wider public commentaries on revolutionary events and processes, by regional experts, journalists, and other pundits who comment on such developments in the media.

\section{QUESTIONS AND ASSUMPTIONS IN THE POLITICAL SCIENCE OF REVOLUTION}

A well-rounded, let alone exhaustive, account of the political scientific literature on revolution - a literature that is voluminous and in any case well reviewed (e.g., Kimmel 1990; Bauman 1994; Goldstone 2001; Meeks 2002) - is beyond the scope of our argument here. Our aim is only to illustrate how political scientific debates and approaches tend to ratify certain basic assumptions about revolutions, and then to show how an ethnographically driven anthropological engagement can serve to open these assumptions up, exploring ways in which they could be diversified and recast. In this connection, we should note that the literature on revolutions in political science tends to circle around two main questions: first, how revolutions ought to be defined and, second, what their causes and consequences are. These two questions are of course related, since the definitions of revolution that are proffered in these debates tend to be cast in terms of causes and, to a lesser extent, consequences. For example, are revolutions to be understood as outcomes of class conflict (e.g., Marx [1852] 2008), as examples of collective action borne of a competition for economic resources and political sovereignty 
(Tilley 1978), as responses to modernization (e.g., Huntington 1968), or as a function of weakened state structures (Skocpol 1979)? Should they be understood as singular events or as more drawn-out processes (Brinton [1938] 1965; Hobsbawm 1986; Stinchcombe 1999)? Is the emphasis on structural considerations enough to explain them (Goldstone 2001)? Should one not also take into account the agency of collectives (e.g., "the people," or particular classes or interest groups) as well as individual protagonists (Kimmel 1990; Foran 1997)? And what about all the other factors that contribute to revolutions, such as civil society (Dahrendorf 1997), gender (Olcott et al. 2006; Malmström 2012), domestic life (Johnson 1985), or, indeed, religious worship (Billington 1980)?

Reading the best that this well-developed body of work has to offer, it is hard not to be impressed by its attention to precision and the insight to which it can lead-although, admittedly, its self-consciously "scientific" tenor and tone can make one rather crave for more of the sentiment famously expressed by American journalist H.L. Mencken, that "revolution is the sex of politics" (cited in Selbin 1999: 1). Here, however, we want only to draw attention to two related characteristics that one can discern in the political scientific literature taken as a whole, which serve, by way of contrast, to pinpoint the kind of departure that an anthropological approach can offer. These have to do, first, with certain basic assumptions about revolution that underlie these accounts; and second, with the role accorded to definitions in their overall strategy and, particularly, to the normativity to which this strategy gives rise. Let us take the two points in turn.

Regarding the basic assumptions that undergird the political science of revolution, we note first that the idea that revolutions are essentially a modern phenomenon is prominent here, too. Many of the most central questions that political scientists debate in this context revolve around how best to articulate and specify ways of thinking about revolution that have become intuitive in Europe since the Enlightenment. The question of whether revolution is better considered an event or a process, for example, takes for granted a linear conception of history, consisting of a series of occurrences that can sometimes generate moments of historical rupture (cf. Palmié and Stewart 2016). So too does the very idea that revolutions can be understood in relation to the complex sequences of historical causation in which they are embedded, and from which explanatory frameworks can be abstracted to furnish more "generalizing" definitions and explanations. As we shall see in more detail in the next chapter, conceptual historian Reinhart Koselleck (1985) has argued that such a conception of history, and of time itself, is intimately bound up with changing notions of revolution in seventeenth- and eighteenth-century Europe.

These essentially cosmological assumptions about time as historical development are married in political science approaches to revolution with assumptions of a more sociological nature-in particular, a view of what kinds of entities and 
relationships compose the social and political world (i.e., a particular sociopolitical cosmology_cf. Collier 2011). The most overt of these are the mainstay categories of political scientific analysis, which tellingly coincide with the conduct of modern politics. Revolution is seen as a function of the interaction among "states," "institutions," "classes," "interest groups," and, indeed, that most marked category of revolutionary ferment, "the people" (see also Humphrey 2019). The historical contingency of these basic categories of contemporary political thought-the peculiarly European story of their emergence and the complex trajectory of their now global hegemony-is of course a topic for historians and theorists of political thought (e.g., Skinner and Stråth 2003, Thompson 1991; Arendt [1965] 2006). Deeper still, as we know from some of the most radical anthropological critiques of sociological thinking (e.g., Dumont 1981; Strathern 1988; cf. Hage 2012), the underlying, less marked, and therefore more thoroughly taken for granted distinction between, on the one hand, something imagined as "society" and, on the other, the "individuals" who supposedly compose it, is just as contingent. For example, in a remarkable feat of anthropological deconstruction, Marshall Sahlins (1996) has tracked the specifically Judeo-Christian trajectory of the image, so commonplace among economists as well as political scientists, of individuals self-interestedly competing over scarce resources. An anthropological approach to revolution, keen to explore conceptions and practices of revolution that go beyond what we (think we) already know about the topic, must involve a thoroughly reflexive interrogation of these assumptions with reference to ethnographic alternatives. In chapter 2, for example, we shall see how a rich array of other social entities and relations-dealing with kinship, clanship, and tribal organization-come to play a constitutive role in varying social settings in which revolutionary politics is played out.

Such examples, of which we shall see many throughout this book, speak to a broader point about our anthropological positioning in relation not only to political science but to all approaches that build their studies of revolution on categories they deem as "basic"-be they sociological ones (e.g., about class) or, more recently, to do with gender, ethnicity, or sexuality. To be sure, revolutions themselves most typically cast their central aims as extinguishing forms of inequality in those very terms: class, ethnicity, and, sometimes, gender and sexuality. We take it as read that studies that analyze revolutions in these terms have produced important insights into the dynamics of revolution. For example, studies adopting a feminist approach have sought to overcome the standard assumption that revolution is an affair primarily of men (staged as a matter of bold political action in the public sphere, involving technological know-how and of course violence), foregrounding the role of feminist movements in revolutionary struggles and countering the depoliticization of women's reproductive work (e.g., Federici 2012). Similarly, an approach to revolution that precluded an understanding of the racial and ethnic dynamics even of revolutions that do not-as so many have 
done-frame themselves primarily in those terms would be deeply questionable (cf. Moore 1989). Still, we contend that an anthropology of revolution can help us to bring forth categories and indeed forms of subjectivity that stand in a complex relationship to assumptions about class, gender, and ethnicity that are alreadyand rightly-prevalent in the literature, and which have often been excluded from well-known modern revolutionary narratives.

This brings us to our second point, regarding the normative role that definitions tend to play in the political science of revolution. While the strategies adopted on this score are of course varied and subject to debate in themselves (e.g., Abrams and Dunn 2017), the overall direction of travel is revealing, since it marks a fundamental point of contrast with the anthropological approach we develop in this book. As with other concepts on which they focus, political scientists make it one of their prime tasks to define revolution as an abstract category, be it in order to establish a rigorous (presumably historically and culturally "neutral"?) conception to add to the analytical armory of a science of politics (e.g., Goldstone 2001: 140-42), or, more flexibly, in order to "advance one's understanding of the term" (Selbin 1999: 4). Debates, then, often focus on whether a particular definition is sophisticated enough to shed light upon particular empirical cases, which in turn can serve as a pivot for a revision of the definition itself (e.g., Paige 2003). Definitions, in this way, come to act as a conceptual benchmark for understanding empirical cases, while empirical cases can also act reciprocally as benchmarks for assessing the merits of competing definitions. This is very much the stuff of social science debates on revolution.

Crucially, however, this kind of benchmarking lends a strongly normative quality to political scientists' competing definitions of revolution. Definitions are important because they are meant to specify what "counts" as a revolution in the first place, when a particular revolution might be said to have failed or succeeded, and how revolutions are to be distinguished from, say, revolts, protests, civil wars, or coup détats (e.g., Dunn 1972:13-16). Indeed, these questions can gain a great deal of traction in broader political commentary. Note, for example, the prominence of political scientists in the heated debates about the so-called Arab Spring and its aftermath, with pundits and commentators of various kinds appealing for their expertise on whether the events are to be considered as revolutions at all, not least in view of the course they have taken since (e.g., Bellin 2012; see also Noueihed and Warren 2013). The inherently normative character of political scientists' concern with definition-their disciplinary orientation toward sorting the wheat from the chaff when it comes to the central categories of political thought and action - can in fact be seen as an extension of the normative stakes of the very political practices on which they seek to comment.

By contrast, our concern with "opening up" the notion of revolution to critical ethnographic scrutiny, as already stated, leads us to put questions of definition firmly within brackets. To be sure, general definitions of revolution can help with 
identifying particular historical or ethnographic situations as revolutionary. For these purposes, however, we are happy to operate with a broad, loose, and intuitive understanding of revolution-for example, revolutions understood as large-scale upheavals, aimed at wholesale change of the political order, often involving violent conflict, in which, as we are keen to emphasize, the very constitution of the world is at stake. Other than for such "heuristic" purposes (Henare et al. 2007), however, our interest in revolution throughout this book is above all, and deliberately, ethnographic. This, we suggest, includes the question of definition itself: rather than proffering a definition of our own, we are interested in how revolutions are defined by the people who are involved in them. "Revolution," in other words, is interesting to us strictly as a local category, which is therefore inherently variable. How people's understandings of revolution may change from one empirical situation to another, and how this may serve to pluralize the ways in which revolution can be conceptualized analytically, are our abidingly anthropological questions.

Of course, this is in many ways standard anthropological fare. Anthropologists par excellence are those who like to take concepts that other disciplines may seek to render uniform, or even universal, in an abstract and generalized way, and try instead to open them up critically by showing the different ways in which they may be imagined and constituted in different ethnographic circumstances. In the case of a concept such as revolution, which as we have noted has such an emblematically modern European provenance, this tack involves two related sets of questions. On the one hand, the first anthropological reflex is to ask how revolutions might be understood in contexts other than the "modern" or the "European," whatever one might actually take these tags to mean (for these too are of course variable concepts-e.g., see Chua and Mathur 2018). If revolution as a political form is at least in part tangled up with the contingencies of its modern European roots, then in what sense can we speak of revolution in social and cultural circumstances that may be very different, and what insights might doing so yield for a broader, more pluralized understanding of revolution?

On the other hand, this forces us to confront immediately another set of questions, which are also explored by anthropologists addressing other phenomena that can be understood as having radiated globally out of Europe and its vicinities, such as Christianity, capitalism, and democracy (e.g., Cannell 2006; Miller 1997; Cook et al. 2016). Namely, how far can the varied manifestations of revolutionary politics we encounter around the globe be understood in relation to the modern European origins of the very concept? This is a question explored in great detail by one of the prime forerunners of our attempt to develop on anthropology of revolutions-Donald Donham's seminal historical ethnography (1999) of the interaction between "Marxist modern" conceptions and practices of revolution with local forms of traditionalism as well as Evangelical Christianity in Maale, Ethiopia, in the 1970s and 1980s. Following Donham, and painting this central question on a comparatively larger canvas, we suggest that answering it cannot 
come down to setting up a spurious (at least in this context) distinction between "modern" and "nonmodern" versions of revolution. Rather, the question is how a distinctively modern political form such as revolution is able to take hold in such diverse social and cultural contexts, and what local concepts and practices might be configured as part of its putative traction (see also Comaroff and Comaroff 1991, 1997; Tsing 2004, 2015; Englund and Leach 2000).

Once again, however, it is crucial to emphasize that these matters are interesting to us, analytically, above all because they are so alive for the people who participate in revolutionary processes. Our attempt to broach the question of revolution anthropologically does not primarily involve an attempt to chart the spread of ideas of revolution across the globe, although occasionally we shall be brushing against such questions of "diffusion" in a more incidental way. Rather, throughout the book we shall encounter varied localized interpretations, critiques, refractions, and contestations of the modern conception of revolution-for example, through the global projection of Marxist-Leninist texts and politics - and look at how these have fueled variable manifestations of revolutionary processes in different ways. The modernity of revolution, in short, is itself an issue for those involved in its action, and paying attention to this is part of the scope of our argument. Indeed, this reflexive quality of revolution as a political form - the fact that what a revolution is, and how it ought to be imagined and enacted, is a question that revolutions, and the people they involve, ask of themselves - is at the heart of what makes revolution so inherently variable, and therefore also so compelling from an anthropological point of view (see also Graeber 2009: 527-28).

To sum up, then, our categorically anti-normative stance on the question of definition marks a stark contrast between our approach and that of political science. We refuse to provide a definition of revolution, as already stated, because we are interested in all of the different ways in which people can come to understand it in different settings. This implies that, as anthropologists, we are happy to treat as a "revolution" any instance local actors conceive of as such-any political upheaval, that is, which, for variable reasons and in varied ways, participants brand as a "revolution" in their own terms. What they might mean by that, and how they might (or might not) relate it to what revolution might be taken to be in other settings, including in traditions of revolutionary politics emanating from Europe, are the questions motivating us. To a political scientist, such an approach may appear unprincipled or even chaotic, since it dissolves any hope of articulating analytically any kind of "essential" understanding of revolution, or even of identifying some kind of common denominator that might help to isolate it for cross-cultural comparison and analysis. From our point of view as anthropologists, however, that is precisely its virtue. We do not seek to "purify" revolution into some core concept, but rather critically to upend all such efforts, pluralizing and diversifying the very notion of revolution according to its contingent ethnographic instantiations at 
different times and in different parts of the world. In short, what excites us is not the possibility of finding out-once and for all perhaps-what revolutions really are and how they operate. Instead, we are bent on exploring analytically the different things revolutions can be-indeed, even, what they could be (see also Holbraad et al. 2014). As we shall discuss at length in the Conclusion, this does not constitute an effort to foreclose a universal notion of revolution but rather to open up more possibilities as to how revolutions' claims to universal aspirations-indeed their very claims to universality-may be understood.

\section{AN OVERVIEW OF ANTHROPOLOGICAL WORKS ON POLITICAL UPRISINGS}

Given the sudden and unpredictable nature of revolutions, it has been historically difficult to plan and execute thorough ethnographic studies of them. To be sure, the often all-embracing social and political effervescence that follows revolutions is by definition volatile and can present security risks for research, while revolutionary states such as the Soviet Union, Cuba, and Iran can be unwelcoming to foreign researchers. ${ }^{2}$ These constraints have tended to impede the ethnographic study of revolution and induced scholars to treat revolutionary phenomena more or less incidentally. They have also obstructed the consolidation of a body of anthropological knowledge on the subject, leading to the production of a set of scattered works that tend to tackle the question of political uprising and transformation from multiple and heterogeneous angles (cf. Worsley 1991).

To make things even more complex, in terms of heterogeneity, revolutionary processes are internally strongly differentiated, with a high degree of variation depending on the phase of the trajectory of revolution over time. The initial period of effervescence and social upheaval, for example, can be strategic in foregrounding insights on violence and imaginings of past and future (Schielke 2015; Mittermeyer 2014; Abu-Lughod 2012; Ghannam 2012). However, a focus on revolutionary statecraft, or the institutionalization of a society transformed by revolution, has constituted privileged terrain on which to visualize and understand how political ideas have been operationalized through sociopolitical structures and institutions, but also to comprehend the specific dynamics in the making of the revolutionary subject (Humphrey 1999; Verdery 1996; Wedeen 1999; Varzi 2006; Yurchak 2006; Holbraad 2017b). Finally, particularly in the case of the Soviet Union and former state-socialist countries, more recent ethnographic

2. Examples of vivid and, at times, harrowing accounts of the difficulties involved include Ruth Lewis's account of her and her husband Oscar Lewis's expulsion from revolutionary Cuba in 1970, accused of being CIA agents (Lewis 1977; see also Rigdon 1983), and Katherine Verdery's narration of her surveillance while conducting ethnographic research in socialist Romania, based on her subsequent review of her own Securitate files (Verdery 2018). 
studies have focused on what could be termed the "afterlife" of revolutions, exploring how subjects and societies instituted under a revolutionary framework respond to new circumstances in a postrevolutionary era, and how the ideas and practices of revolution have transmuted into newer forms (Steinmüller 2013; Ssorin Chaikov 2003, 2017; Pedersen 2011; Hann 2002).

In addition to broaching different phases of revolutionary processes, then, the heterogeneity of an anthropological approach to revolutions is exemplified by the different angles and topics through which radical sociopolitical transformations have been studied and conceptualized. To be sure, these thematic choices-from ritual to political forms, from religion to modernity-illustrate what a distinctively anthropological contribution to the study of revolution might involve. Nevertheless, when viewed collectively as a body of literature, these heterogeneous works do not coalesce into a coherent frame that systematically critiques, complements, or problematizes the set of definitions, assumptions, and norms about revolution we still often take for granted.

In what follows we provide an overview of these texts with two aims in mind. The first objective is to begin to systematize the existing literature by harnessing a number of different elements, ethnographic ideas, and practices that provide a sense of the many ways in which ethnography can refigure the concept of revolution, exemplifying what a specifically anthropological gaze has to offer. The second objective is to show certain shortcomings in these works in order to problematize certain habits and assumptions in the study of revolution and allow ethnographic materials to open up the way we think of revolutions. Most of these works will be further analyzed and discussed in the main body of the book, although, despite our outlining a multiplicity of anthropological works on revolution, the book is not to be understood as a compendium.

Pioneering works such as Evans-Pritchard's The Sanusi of Cyrenaica (1949) and Gluckmann's "Rituals of Rebellion in South-East Africa" (1963) have been held up as referents and ancestors of an anthropology of revolution (Worsley 1991). Evans-Pritchard's book describes the coalition between the Libyan tribes of Cyrenaica and the Sanusiya Islamic brotherhood in the battle for the liberation of Libya from Italian colonial invasion and occupation. Although EvansPritchard's work does not directly address the question of revolution, it demonstrates the relevance of social forms of tribalism, its alliances and control of territory, in Libya's liberation from colonial powers. Through their networks and alliances (saff), the tribes were able to crystallize forms of control of vast territories and/or the caravanserai in the proximity of the borders. Despite emphasizing the struggle of the tribes against foreign invaders, the book offers a series of reflections on the transition from the segmentary structure of the tribes to the modern and centralized form of the brotherhood that was able to do away with colonial powers and shape a cohesive political system. In fact, Evans-Pritchard tends to 
present the cultured Sanusiya brotherhood as a state-like organization capable of articulating, controlling, and educating the illiterate tribes through local tribunals and mechanisms of conflict resolution, thus reproducing political science's linear notion of political transition toward modern institutions and the inability of the traditional social forms to produce thorough transformations.

We encounter a similar bias toward modern forms and practices of political organization in the mentioned work of Max Gluckmann, described in detail in chapter 1. Gluckmann tackles a series of ritual forms that explicitly transgress ordinary social practices and political structures by visualizing and exacerbating the conflicts and sociopolitical hierarchies among different members. In line with an established tradition of thought in the anthropological study of ritual, however, Gluckmann observes that such ritual performances are unable to activate a radical transformation of the political order - such as in a proper revolution-but, rather, generate minor alterations necessary to reaffirm the legitimacy of the whole political system. In this sense, Gluckmann echoes the existing debate in political science at the time about the difference between "primitive rebels" (Hobsbawm 1959), fundamentally unable to shape a thoroughly new political order, and modern revolutionaries (see Wolf 1969). Although this conceptualization of ritual and "traditional" segmentary forms of political organization-of being able to activate transformations (Gluckmann 1963; Bloch 1992) that are yet sufficiently circumscribed as not to challenge the existing sociopolitical order-remains central to most ethnographic analyses, a number of works (Gibson 1994; Turner 1975) have plotted a series of correspondences between ritual and revolution or between revolution and segmentary forms of organization (Davis 1986; Hegland 2014). What we tackle in this book (see chapter 1 ) is the possibility of identifying "rituals of revolution" wherein ritual practices may become instrumental in the definition of specific forms and practices of revolutionary politics. We show that, rather than constituting forces obstructing processes of thorough political liberation, practices and forms ranging from spirit possession to kinship and segmentary organization may become strategic in the definition of the rhythms, strategies, and legitimacy of insurrectionary events (Lan 1985).

Although not always tackling the notion of revolution head-on, a series of anthropological works have been instrumental in foregrounding tribal ethos, kinship, ritual, and religion as strategic domains for the study and understanding of radical political transformations. In principle considered incompatible with revolution by political theorists, domains such as religion have been reintroduced and become instrumental in a number of anthropological analyses. In the case of the Bolivarian revolution in Venezuela, Michelutti (2017) points out that the late revolutionary leader Hugo Chávez is being turned into the figure of a spirit, a saint, a reincarnation of independence fighter Simón Bolivar (cf. Taussig 1997); thus, Chávez continues to shape Venezuelans' revolutionary selves by 
becoming an integral part of everyday social life. Moreover, these dynamics amplify the religious undertone of the revolution by creating a revolutionary system of divine kinship through networks of local politicians-each referred to as a "little Chávez" - whereby the legacy, charisma, and spiritual force of revolution are reproduced.

Martin Holbraad (2014) elaborates in his work on the notion of self-sacrifice as a constitutive dynamic of the Cuban Revolution, one clearly reminiscent of the Christian notion of renunciation of the self for the sake of a greater power and project. This downplays the role of political ideology as the main framework through which to interpret revolutionary phenomena and the ultimate aspirations of the Cuban people, presenting a notion of revolution as an all-encompassing entity capable of permeating all aspects of social life, thereby conflating the intimate (private) and the political. Alpa Shah (2014) similarly describes the role of the dedicated revolutionary cadres in the Maoist guerrilla movement in India as shaped and (re)interpreted on the basis of the religious principles and practices of the Hindu renouncer. While the renouncer seeks to end the eternal cycle of reincarnations, transcending cast and taboos in order to shape a parallel social path founded on radical equality, the ideology of the Maoist guerrilla fighter appears to be shaped by a similar aspiration to transcend binding social rules and impediments in the building of a liberated world.

All of these works present an argument which is highly relevant here, namely, that political projects and upheavals are often embedded in religious frameworks which, instead of jeopardizing the full realization of revolutionary change, become instrumental in defining the shape, the practice, and the horizon of political transformation (see also Humphrey 2003; West 2005; Varzi 2006; cf. Badiou 2003; Sewell Jr. 1996). Throughout the book we build on this type of scholarship and argument to question and reconfigure the conceptualization of revolution as a universal mold applicable to different sociocultural contexts.

Particularly the existing anthropological scholarship on the Arab Spring has revealed unexpected spaces and domains of operation of revolutionary forces and practices. In tension with Starn's article "Missing the Revolution" (see above), a series of emblematic ethnographic works have begun defying the conventional loci of study from which to examine and comprehend revolution. In the case of the Egyptian revolution of 2011, a set of mostly female anthropologists (Abu-Lughod et al. 2012; Mittermaier 2014) accentuated and analyzed a series of strategic spaces traditionally overshadowed by the conventional focus on the political, providing crucial insights into the workings of revolution. While the stereotypical representation of revolution often emphasizes effervescence, action, violence, and the convergence of a mass of fighting protesters, mostly men, in the central space of a large city, these authors began to signal a series of unexpected dynamics and places-from the intimacy of a home in the outskirts 
(Abu-Lughod et al. 2012) to the Islamic significance of food (Mittermaier 2014) traditionally overshadowed in mainstream accounts focusing on Tahrir Square. These authors begin to challenge the association of revolution with the classic loci and forms of political action, demonstrating that what is at stake in a revolution may not be fully visible in the emblematic uprising that signals its beginning, or in its explicit, public, and political dimension. This calls for broadening the focus and taking into account a set of often-overshadowed elements, from space and time to gender and religious notions, that remain crucial to understanding how revolutionary transformations are enacted and experienced, as well as sometimes impeded. Throughout the book we deploy this inherent tendency of anthropology to retrieve unexpected notions and ideas from neglected spaces and domains, but also its capacity to operate simultaneously on different scales in the examination of social phenomena: from the private and intimate dimension of a home away from the uprising to the political ideology and messianic aspirations of the fighter at the center of Tahrir Square (see also Loris-Rodionoff 2019; Malmström 2015, 2019; Elliot 2017, 2020).

Finally, one of the most interesting anthropological contributions on revolution results from the critical stance of some of these works toward the range of naturalized ideologies that come with the concept of questioning taken-for-granted narratives of change and modalities of transformation. Judith Scheele (2007), in analyzing the political practices and discourses of the Algerian people of Kabylia together with international rhetoric on revolution, singles out the need to look critically at the notion of revolution and its concurrent concepts of change, creativity, and newness. If anthropology has been instrumental in warning about the dangers of reifying tradition, Scheele concludes that an anthropology of revolution should be equally aware and critical of the intrinsic danger of treating revolution, newness, and change as universals and/or objective descriptions of societal transformations. In a time where newness and change have become social imperatives of our reality, revolution runs the risk of turning into a convention rather than a unique event irremediably breaking with the past and previous political forms.

Samuli Schielke (2015) describes the Egyptian uprisings of 2011 as spontaneous, emotional occurrences; yet these events have been reframed by intellectuals and political activists as oriented toward a future horizon of transformation along a defined trajectory of change, making this the official narrative of the Arab Spring. In Schielke's view, such a recasting of a spontaneous event into an aspirational trajectory of transformation is part of a process of co-option of an impulsive uprising into the conventional categories and frameworks of capitalism and, for that matter, Islamism. For Schielke, the formal religious and economic frameworks are both excessively concerned with newness and with the notion of the future as a horizon one always fails to reach. He points out that canonical conceptualizations of revolution may conceal the true nature of revolutionary events, while a 
supposedly new and transgressive political event may be reformulated according to the interests of capitalism.

These sometimes scattered works crystallize a specifically anthropological way of employing the concept of revolution from which we draw inspiration throughout this book. They generate resources for our project that range from a critique of naturalized ideologies — such as newness and linearity-in the conceptualization of political transformations, to ideas of the scale and shapes of revolutionary phenomena, thereby presenting a set of unexpected spaces and domains in which to examine the subject. This book constitutes an attempt to explore the consequences of addressing the process of revolution ethnographically and rejecting a priori definitions, norms, and recipes. In the following chapters we challenge established narratives and features of revolutionary processes by thinking them through indigenous cosmological categories, exploring the scope and limitations of reconfigurations of social, political, and cosmological coordinates according to local views in order to bring to light and comprehend emergent revolutionary forms. Bartering conventional notions and expectations for an explicit project of indigenization of revolution, we lay the foundations for an anthropology of revolution around which to rearrange coherently the set of scattered works outlined above.

\section{ANTHROPOLOGY OF REVOLUTION \\ AND ITS POLITICAL ENGAGEMENTS}

Having presented our proposal for a nondefinitional approach to the study of revolutions, an important clarification is in order-one that the reader should bear in mind throughout the book. Our call for an open framework does not negate the possibility of political engagement. In saying that revolutions can be radically different, and that one has to take each in its own right rather than measuring it against a normative definition or model, we do not mean to say that all revolutionary projects are equally desirable from a political point of view. Our intent here is not to advocate suspension of judgment, nor do we want to convey the message that there is no truth in the assumptions that characterize the current discussion on revolution. To be even clearer, we are not arguing that European revolutionary theorists and traditions should be discarded in favor of non-European versions. Ours is not a desire to do away with "linear upheavals"; if it were, we would still be proposing a "model for all." Nor do we wish to "open up" the concept of revolution by force. Rather, we want to problematize formulaic conceptualizations while knowing full well that we all have political opinions and stances. Ultimately, we wish to shed light on an inherent openness-a tendency to produce different versions of itself - that is already at the heart of revolutionary logic.

Revolutionary practitioners themselves also ask the question, "What is a revolution?" They continuously revise and adjust, either to ensure that they 
stay faithful to the original aim of their endeavors or to deal with unforeseen circumstances that demand fine-tuning, amendment, and even drastic rethinking. The depiction of the revolutionary leader or group gathering a committee to discuss the revolution-even years after it has succeeded in establishing itself-is not an exception in the revolutionary landscape. It speaks of a need to constantly redefine: a need for revolutions to preserve some recognizable traits while, at the same time, staying open, at least to some degree. It is a way for revolutions not to reify themselves-not to be obsessively attached to their own images of themselves, as they so often have been - to forestall their transforming into reactionary projects. Determining whether revolutionary movements actually manage to do so-that is, whether they are truly willing to cultivate openness-is beyond the scope of this work, however. What is important is to stress that the questions we ask are emic, not etic; they stem from established practice: from an openness that characterizes many of those who invest their lives in revolutionary activities. It is perhaps in this sense that, in the words of Thomassen (2012: 680), "anthropology has an unarticulated affinity with political revolutions," not only because, as he explains, anthropologists have often been ready to sympathize with revolutionary endeavors in the fight against colonial repression, but also-we feel-because both anthropology and revolution are open. They share a distrust for what has been statically predefined.

It is in this spirit that, throughout the chapters, we engage not only with lessdocumented revolutionary phenomena-hopefully in itself one of the virtues of this book-but also with a series of well-known thinkers who see, or have seen, revolution not simply as an object of intellectual inquiry but as a matter of personal, philosophical, and political involvement, from Karl Marx to Mikhail Bakunin, and Walter Benjamin to Slavoj Žižek. ${ }^{3}$ Although these renowned intellectuals have become part of the "revolutionary canon" we seek to problematize-and in that sense are often compared and contrasted with other forms of revolutionary thought and action in the pages that follow-we also capitalize, as much as possible, on their capacity for openness. In this sense, as will become clear particularly in the conclusion of the book, our project of "multiplying" notions of revolution is conducted in dialogue with the attempts made, at least by some of these thinkers, to open up the idea of what revolution is and what it could be.

3. We are aware that most of the references and descriptions of revolution by political theorists and philosophers we use throughout the text draw from the Marxist tradition of revolution. As an established, systematic, but highly diversified body of literature, Marxist debates are useful in exploring both discrepancies from and continuities with the anthropological approach we want to develop, thus allowing us to clarify the scope of our project. In the chapters we also touch upon various aspects and incarnations of the Anarchist episteme. As for other discourses, be it classical European liberal nationalism (Mazzini 1862), capitalism (Berger 1986; de Althaus 2007), National Socialism (Hitler 1925), or Fascism (Mosse 1999), we leave for future research a critical engagement with their claims to revolution. 


\title{
Revolution as Event
}

\author{
Ritual, Violence, and Transformation
}

\begin{abstract}
The relevance of the problem of beginning to the phenomenon of revolution is obvious. That such a beginning must be intimately connected with violence seems to be vouched for by the legendary beginnings of our history as both biblical and classical antiquity report it: Cain slew Abel and Romulus slew Remus.
\end{abstract}

- HANNAH ARENDT

It would seem uncontroversial to say that a revolution is, if nothing else, an event. A momentous event, a rupture in history, in time itself. We say "revolution" and we think of the storming of the Bastille or the Winter Palace, the occupation of Tahrir Square. And we put dates on revolutions: 1789, 1917, 2011 ... Emblematic moments in time, violent upheavals that bring about wholesale change in the prevailing political and social order, or at least seek to do so. And then we ask questions about their causes and effects: What brought such-andsuch a revolution about? How far back can we trace its origins? How long can it be said to have lasted? Did it develop in one fell swoop or were there different phases to it? And what were its consequences? Did the revolution change things as much as its protagonists had hoped? How long did the changes last? The notorious, if somewhat apocryphal and probably misinterpreted (e.g., see Plattner 2011: 12) dialogue between US president Richard Nixon and Chinese premier Zhou Enlai during Nixon's visit to China in 1972 captures this way of thinking. Prepped by Henry Kissinger about the Chinese leader's interest in French history, so the story goes, Nixon seeks to break the ice by asking Zhou Enlai what he thought the impact of the French Revolution had been on Western civilization. "It's too early to tell," goes the legendary response. If the story is meant to typify a sage-like Chinese proclivity to take the long view of things, in its irony it also exemplifies the underlying idea that revolutions echo through history as singular ruptures in time. 
The German conceptual historian Reinhart Koselleck offers a meticulous account (1985) of how this idea of revolutions as singular historical events has come to occupy such a central place in modern understandings of history itself as a forward-moving process. As do a number of other influential analysts of revolution and modernity (e.g., Arendt [1965] 2006; Berman 2010), he casts the emergence of revolution as a peculiarly modern concept at the time of the Enlightenment in contrast to earlier conceptions that identified revolution with the cyclical motion of heavenly bodies, to which the cycles of political change were also associated. If the French Revolution is sometimes deemed as the inaugural event of the modern era, according to Koselleck, that is also because the very notion of revolution that it transfigures is itself so modern, with two distinguishing features. First, instead of connoting a circle, revolution now begins to be understood as a singular break, making a rupture with the past for the sake of a future that is yet to be realized, and is in that sense open. Since the Enlightenment, Koselleck writes (1985: 46), "revolution obviously no longer returned to given conditions or possibilities, but has, since 1789 , led forward into an unknown future." Secondly, by unmooring itself from its natural reference in older usages, the concept of revolution is elevated to what Koselleck calls a "metahistorical" status (47). Rather than referring just to events within time (e.g., the French Revolution happened in 1789), revolution also refers to the form of time itself - an inherently asymmetrical line of development, in which the present stands at the cusp of a past that is forever gone and a future that is as yet unknown. Revolution, then, "assumes a transcendental significance; it becomes a regulative principle of knowledge, as well as of the actions of all those drawn into revolution" (46-47).

Somewhat surprisingly, Koselleck's conceptual history does not incorporate much discussion of the work of Karl Marx and its legacy in this connection. Given the enormous projection and influence that Marxist conceptions have had on revolutionary processes across the globe, however, it is important to note here that Marx's conception of revolution as a rupture in and with time is emblematic of the order Koselleck poses as the quintessence of modern ideas about the asymmetry of time. One of the most cited parts of the Eighteenth Brumaire, which is devoted partly to disparaging the "farcical" character of the 1848 revolutions when compared with the "tragic" quality of the French Revolution-"all great worldhistoric facts and personages appear ... [twice]: the first time as tragedy, the second time as farce" (Marx [1852] 2008: 5) - illustrates how for Marx the power of revolution turns crucially on the degree to which it is able truly to break with the past. Marx's writing is so vivid on this point that the famous passage deserves a fuller quotation than it is usually given:

Men make their own history, but they do not make it as they please; they do not make it under self-selected circumstances, but under circumstances existing already, 
given and transmitted from the past. The tradition of all dead generations weighs like a nightmare on the brains of the living. And just as they seem to be occupied with revolutionizing themselves and things, creating something that did not exist before, precisely in such epochs of revolutionary crisis they anxiously conjure up the spirits of the past to their service, borrowing from them names, battle slogans, and costumes in order to present this new scene in world history in time-honored disguise and borrowed language. Thus Luther put on the mask of the Apostle Paul, the Revolution of 1789-1814 draped itself alternately in the guise of the Roman Republic and the Roman Empire, and the Revolution of 1848 knew nothing better to do than to parody, now 1789 , now the revolutionary tradition of 1793-95. In like manner, the beginner who has learned a new language always translates it back into his mother tongue, but he assimilates the spirit of the new language and expresses himself freely in it only when he moves in it without recalling the old and when he forgets his native tongue. ([1852] 2008: 5)

This tension-between a desire for a clean break with the past, on the one hand, and, on the other, the past's ability nevertheless to "haunt" the present and thus restrict the scope and character of revolutionary transformation-is one that persists in writings on revolution, not least in the Marxist tradition. For example, in recent years the French philosopher Alain Badiou (2009) has put forward an intricate metaphysics of "the event," seen as a rupture that creates basic incommensurabilities between the past and the future. As an active Maoist himself (Badiou 2006; cf. Bosteels 2005; Laruelle 2017), Badiou is particularly interested in the political potentials of such a conception of the event, which he associates with iconic moments of revolution in Europe (e.g., Badiou 2007: 180-83; see also Hallward 1998). ${ }^{1}$ However, as we shall see in later chapters when discussing the parallel Badiou draws between revolution and Christian conversion, even this arch theorist of rupture finds continuities that connect the new order brought about by revolutionary ruptures to the times

1. Marxist thinkers have developed different understandings on how the revolutionary event unfolds. Some have favored the notion of a speedy and tempestuous rupture, as in the case of Polish Marxist thinker Rosa Luxemburg (2006: 191): "either the revolution must advance at a rapid, stormy and resolute tempo, break down all barriers with an iron hand and place its goals ever farther ahead, or it is quite soon thrown backward behind its feeble point of departure and suppressed by counterrevolution." Others have conceptualized revolution as a slower, subtler process, as with Italian Marxist philosopher Antonio Gramsci, whose theories will be analyzed in chapter 5. In particular, borrowing from military jargon, Gramsci traces a difference between "war of movement" and "war of position." The former refers to rapid revolutionary events aimed at immediately destroying old structures. The latter indicates gradual, seemingly uneventful processes in which revolutionary forces slowly erode old structures by strategically influencing public discourses and by creating tactical alliances (Gramsci 1992a: 216-19). Even though Gramsci did not completely dismiss the revolutionary benefits of the war of movement (Gramsci 1994), he saw the war of position as a more efficient strategy for revolution in modern Western societies (Hall 2018: 38). 
that came before them. In particular, as we shall see, the analogy Badiou makes between revolution and Paul's conversion to Christianity-politically motivated and, in that sense, normative as it is-invests the concept of revolution with distinctly Christian sonorities. In later chapters we shall be developing a broader argument about what we call the "cosmological" character of revolutionary transformations.

For now, however, we seek to set an argument in motion by focusing on the more narrow, though absolutely central, idea that revolutions are to be conceived, if nothing else, as events-violent ruptures that are meant to inaugurate a new order of things. As we shall see, the notion of event that Koselleck (descriptively) and Badiou (prescriptively) find at the heart of revolution as a modern political form never ceases to be relevant in the diverse ethnographic settings that we shall be exploring. By the end of this chapter, however, it should be clear that standard conceptions of revolution as a singular event that arrests and changes the otherwise ineluctable course of history cannot on their own do justice to the sheer diversity of temporal assumptions, concepts, and practices that different revolutionary projects have relied upon across the world. Indeed, our aim here is not only to make an inductive argument about the temporal diversity of revolutions-this being exactly what one would expect anthropologists to say about most things. More ambitiously, we also present a more "deductive" argument about the purchase that anthropological thinking can have on the analysis of revolutions and their temporal "shape" as events-an argument from first anthropological principles, as it were, bringing some of the most basic anthropological tools to bear on the question.

In particular, what we have in mind here is the study of ritual-an all-time anthropological classic that has furnished some of the most sophisticated analytical frameworks the discipline has to offer. Ritual theory is the obvious anthropological starting point for thinking about revolutions as events, since so many of our standard assumptions about how revolutions occur in time are central also to what anthropologists have had to say about ritual action. Rituals too, after all, are treated as events (unlike myths, say, which are more like abstract narratives); they are deemed to be transformative, having lasting effects on the people who participate in them (think of initiation rituals, for example); and often, as with revolutions, rituals involve significant doses of violence (the classic instance here would be the various hazing-type "ordeals" that initiations so often involve). As we shall see, however, this obvious affinity between revolution and ritual also serves a critical purpose. If key insights from the study of ritual can shed light on the understanding of revolution, then, by the same token, some of the critical perspectives that can be taken on ritual theory can stimulate alternative ways of thinking about revolutions, and not least ways of thinking of it as something other than an event. 


\section{REVOLUTION AS RITUAL: A TRAJECTORY \\ IN BRITISH SOCIAL ANTHROPOLOGY \\ Gluckman on Ritual Rebellion versus Revolution}

The suggestion that the study of ritual might provide the tools for developing an anthropology of revolution has a history-one that is bound up most particularly with the development of British social anthropology in its heyday, and its central concern with social order. The link with ritual is tellingly captured in the title of what, as we mentioned in the introduction, is anthropology's most celebrated early engagement with the topic of revolution, namely Max Gluckman's famous essay, "Rituals of Rebellion in South-East Africa" (1963), delivered as a Frazer Lecture in Glasgow in 1953. Admittedly, the thrust of Gluckman's argument is to distinguish from revolutions proper the kinds of "rituals of rebellion" he surveys in his essay-including Zulu agricultural first-fruit rites for the goddess Nomkubulwana, for example, in which women transgress their ordinary social roles and temporarily affront the males, or the Zwasi incwala ceremony, in which the king is for a period subjected to the disdain of his subjects, before he reemerges triumphantly as master of the forces of cosmic and social renewal.

As Gluckman writes:

[T] hese ritual rebellions proceed within an established and sacred traditional system, in which there is dispute about particular distributions of power, and not about the structure of the system itself. This allows for instituted protest, and in complex ways renews the unity of the system. (1963: 112)

Gluckman's distinction rests on an argument about time and its structure. Qua rituals, the rebellious performances he reviews are quite different from revolutions, which "question the system of institutions ... . [and aim] at altering the existing social and political order" (127), because they are "repetitive":

Every social system is a field of tension, full of ambivalence, of co-operation and contrasting struggle. This is true of relatively stationary-what I like to call repetitive-social systems as well as of systems which are changing and developing. In a repetitive system particular conflicts are settled not by alterations in the order of offices, but by changes in the persons occupying those offices. ... [The] ceremonial enactment of this order states the nature of the order in all its rightness. The ceremony states that in virtue of their social position princes and people hate the king, but nevertheless they support him. ... [I]n their prescribed, compelled, ritual behaviour they exhibit opposition to as well as support for the king, but mainly support for the kingship. This is the social setting for rituals of rebellion. (127-28, footnotes omitted)

So, for Gluckman, rituals (including rituals of rebellion par excellence, despite the apparent paradox) and revolutions are strictly speaking antithetical to each other (see also Gibson 1994). Taken as one-off historical events that take place in 
societies oriented toward change and development, revolutions can only happen if the constraints of ritual cyclicality are broken-this, for Gluckman, being yet another mark of the fabled transition from tradition to modernity. Indeed, Gluckman's example of a modern noncyclical counterpart to traditional cyclical rituals of rebellion vividly pinpoints the antithesis:

In Europe we can no longer ritually reject the king alone ... it is the Crown itself, and not its incumbent, which is resented. Some South Africans desire independence from the Crown: throughout the Commonwealth there are revolutionaries who wish for republics organized in quite different orders. On the whole no one struggles against a particular sovereign. (129)

In some basic ways, Gluckman's analysis of ritual rebellion, and the contrast he draws between it and revolutions proper, is exemplary of the focus on social order that was prevalent in British social anthropology at the time, as well as the role given to ritual as one of its prime expressions. Following Durkheim's basic idea that ritual is a prime arena in which society is constituted, both "functionalist" approaches associated with Malinowski and "structural-functionalist" ones developed by Radcliffe-Brown and his students at Oxford saw ritual as a mechanism for strengthening and integrating social bonds. At regular periods, social groups come together to perform rituals that reflect the shape of their organization and invest it with sacred legitimacy (e.g., Fortes 1945).

What Gluckman added to this, and substantially developed with his students in Manchester as one of the signatures of what came to be known in the discipline as the "Manchester School" of anthropology, was the focus on conflict (see Evens and Handelman 2006). Indeed, if Gluckman's argument about ritual rebellions has become such a standard reference, that may be because it encapsulates the central tenet of the Manchester School approach; namely, that the integrative role of ritual is achieved not by denying social tensions and conflict but rather by dramatizing them and staging their resolution. Notwithstanding Gluckman's emphasis on the question of order and its reproduction, his depiction of ritual as a conduit for (rather than just a shield against) social tensions and conflicts opened the door for subsequent anthropologists to explore the socially transformative dynamics inherent within ritual. By tracing this particular line of thinking within British social anthropology, we suggest, we can arrive at a position that in some ways is profoundly un-Gluckman-like; namely, seeing ritual not as the opposite of revolution, as he did, but as its avatar.

\section{Turner on Revolution and Liminality}

The towering figure in this trajectory is Victor Turner-the most influential among Gluckman's students in Manchester to explore the dynamics of conflict and its resolution within ritual. To be sure, Turner's earliest studies of the relationship between ritual and social change, conducted on the basis of his fieldwork among the Ndembu of then Northern Rhodesia (now Zambia), were very much in the 
mold of Gluckman's approach, emphasizing the homeostatic effects of ritualized "social dramas," as Turner called them (e.g., 1957). However, as his studies of the inner dynamics of rituals developed, delving also deeper into the symbolic characteristics of ritual action, Turner became increasingly interested in the subversive elements lying at the heart of ritual. Indeed, the three concepts most associated with Turner's analysis of ritual-liminality, communitas, and antistructure-all speak to Turner's conception of the inner dynamism of "the ritual process," as he called it, and its socially transformative potentials (Turner 1969). Building on Dutch-French folklorist Arnold van Gennep's (1960) famous three-phase model of rites of passage (according to which neophytes are first separated from ordinary social structures, then enter a liminal state characterized by social ambiguity, and are finally aggregated back into society with a new social status), Turner homes in on the dialectical relationship between the ambiguity of the liminal and the social and symbolic structures it temporarily suspends:

It is as though there were two major "models" for human interrelatedness, juxtaposed and alternating. The first is of a society as a structured, differentiated, and often hierarchical system of politico-legal-economic positions with many types of evaluation, separating men in terms of "more" or "less." The second, which emerges recognisably in the liminal period, is of a society as an unstructured or rudimentarily structured and relatively undifferentiated comitatus, community, or even communion of equal individuals who submit together to the general authority of the elders. ... [This gives] recognition to an essential and generic human bond, without which there would be no society. Liminality implies that the high could not be high unless the low existed, and he who is high must experience what it is like to be low. . . . From all this I infer that, for individuals and groups, social life is a type of dialectical process that involves successive experience of high and low, communitas and structure, homogeneity and differentiation, equality and inequality. (Turner 1969: 96-97, emphasis omitted)

Turner's analysis is consistent with Gluckman's basic structural-functionalist idea that the apparently "revolutionary" characteristics of many rituals, which Turner calls "anti-structural," ultimately bolster existing social structures: what liminality reveals, "however fleetingly," is communitas as the "generalised bond" upon which the heterogeneous structures of ordinary social life are based (96). Nevertheless, Turner's analysis goes considerably deeper than Gluckman's. Beyond the specific characteristics of rites of rebellion, discussed by Gluckman as a particular class of rituals, Turner's model of ritual articulates nothing less than the inner structure of the constitution of all society. Accordingly, if liminality is "revolutionary" in its tendency, albeit temporarily, to undo existing social structures (and therefore also the reigning political order), this is a potential that is built into the constitution of society itself. The notion that the (social, political) world could be otherwise, which is at the heart of that political impulse one is tempted to call 
revolutionary, from Turner's perspective emerges as a horizon that is always implicit in social phenomena, and is made regularly apparent as a referent for social actors in periods of liminality.

In his later writings, Turner often alludes to the possibility that the antistructural potentials of liminality may contain the seeds for more permanent social transformations, passing from the "subjunctive" mood of the liminal, as he calls it (1990: 11), to more declarative programs for more lasting social transformation. Rather than just a horizon undergirding the existing social and political structures, then, liminal process can also be the source of new ones. Millenarian or other social movements oriented toward utopian goals are for Turner a prime example, since they turn the existential condition of communitas into an ideology, and seek to institutionalize it as a normative order in its own right-an argument that in some ways runs parallel to Eric Hobsbawm's famous analysis of millenarians as "primitive rebels" (1959).

Indeed, for Turner, political revolutions more broadly can also be understood in this way, expressing the transformative dynamics of liminality "in times of radical social transition, when society itself seems to be moving from one fixed state to another" (1969: 133), as he writes in a different context. The most detailed example of this is Turner's sustained historiographic study of the Hidalgo insurrection of 1810-11, which initiated the Mexican revolution of independence against Spain, acting as "the limen between the colonial period of Mexican history, ... [and the] period when Mexico became, in the blood and turmoil of colonial and civil wars and revolution, a nation" (1975: 98-99). To be sure, much of Turner's analysis is sociological, looking at key events and protagonists in terms of the unfolding "social drama" of conflict between different constituents of Mexican society at the time-representatives of the Spanish Crown, local criollo elites, ordinary mestizos, and the indigenous populations from whose ranks the uprising drew much of its force. When it comes to analyzing the deeper sources of this force, however, Turner draws on the concepts he developed in his analyses of ritual liminality. Combining this with Freudian studies of revolutions as "moments of madness" (Zolberg 1972), he brands as "primary process" the violence that swept up indigenous as well as mestizo participants in the insurrection, under the leadership of Miguel Hidalgo, the local priest who initially uttered the "cry" (grito) of revolution in his local parish, Dolores, on 16 September 1810, during the course of festivities in honor of the Virgin of Guadalupe. Turner writes:

[Primary process] arises from deep human needs for more direct and egalitarian ways of knowing and experiencing relationships, needs which have been frustrated or perverted by those secondary processes which constitute the homeostatic functioning of institutionalized social structure. ... Men caught up in a primary process are mad to establish the kingdom (or republic) of heaven on earth, and they proceed compulsively to eliminate whatever they feel to represent obstacles to this ... desire for communitas. (1975: 111) 
The role of the Virgin of Guadalupe as figurehead for the insurrection was catalytic, according to Turner. On the one hand, the liminal dynamics of the ritual festivities provided propitious conditions for the equally liminal impulse of popular insurrection. On the other, the ecumenical character of the "Brown Virgin" herself, as a Catholic figure with indigenous characteristics, cut across the ordinary structural divisions between the indigenous population and mestizos as well as white "criollos," providing a poignant symbolic expression of an underlying communitas among them. The confusion in the historical record as to whether Hidalgo's initiating Cry was in her name ("Long live, then, the Virgin of Guadalupe! Long live America for which we are going to fight!") or in that of the nascent nation of Mexico ("Mexicanos, viva México!" as presidents of the republic have proclaimed in the annual commemorations of the event ever since) is indicative for Turner of the confluence of religious and political liminality in this context (1975: 99-101).

Beyond the initial Cry of Hidalgo, however, for Turner the Virgin of Guadalupe's role as liminal symbol of national communitas freed of the structures of Spanish colonialism speaks to a deeper sociopolitical dialectic between structure and antistructure. Following the Cry, he explains, the "roused and militant communitas" (112) of the insurgents swept away the more tempered military plans drawn up by Hidalgo's criollo allies, and the mass of rebels turned increasingly violent and reckless in a series of battles that have themselves, subsequently, become potent symbols of the force of Mexicans as a "people." By the same token, however, when Hidalgo's undisciplined campaign began to dissipate in the face of the Crown's more organized army, and Hidalgo himself was forced to flee and removed from military command, "the insurgence lost its mythic, primary processual character and faded into the light of a common day in which it had little hope" (122). With Hidalgo's trial and execution a few months later, the structural hierarchies of the colonial government were reasserted, and only ten years later was independence from Spain negotiated. Nevertheless, Turner suggests, "in taking up the banner of the Brown Virgin of the oppressed many-centuries-dominated Indians, [Hidalgo] was seizing a sign of wholeness and prophetic pan-Mexicanness that his opponents could not really counter" (152). While the Hidalgo insurrection itself was abortive, then, the liminal communitas that it projected symbolically onto the Virgin of Guadalupe left a "symbolic deposit in actual historical time [with] potent effects on subsequent dramas and revolutionary process" (102). Throughout Mexico's subsequent history and still today, "[o]ur Lady of Guadalupe lives in scenes of action ... a a multivocal symbol of popular powers in times of major social crisis" (153-54).

Nevertheless, there is something tragic about Turner's account of liminality in general, as well as the particular image of its revolutionary potential he presents in a political key. For while his model may be presented as a dialectic, it behaves more as a kind of oscillation. Reigning structures are lifted temporarily, whether in ritual or 
at times of broader social transition, such as revolutions, but only to give way to the mold of structure once more as the antistructural power of liminality fades. Turner himself admits as much when he observes that attempts to turn spontaneous communitas into an ideology, or to institutionalize it normatively, are themselves "already within the domain of structure, and it is the fate of all spontaneous communitas in history to undergo what most people see as a 'decline and fall' into structure and law" (1969: 132). As we shall see in subsequent chapters, this is certainly a problem that revolutions run into time and again. However, as far as Turner's theory is concerned, we may note that this problem of "tragic oscillation," if we may call it that, is as much as anything a problem with his model of liminality. If the power of the liminal is inherently and in principle antistructural, after all, it is hard to see how it could translate itself into lasting structural transformations. At most, liminal periods can leave enduring "symbolic deposits" that can act as a spur for further antistructural moments, as in Turner's analysis of Mexico. To the extent that liminality and structure are mutually exclusive in his model, however, to think of liminality as an ingredient, rather than just a spur, of structural change is a contradiction in terms.

\section{Bloch on Rebounding Violence}

This is a problem that Maurice Bloch is able to address in his own model of ritual transformation, elaborated in the decades following the publication of Turner's classic studies (Bloch 1992; see also 1974, 1986). Bloch's model deploys Turner's Van Gennepian three-phase structure, involving a contrast between, on the one hand, the world of everyday experience and, on the other, an extraordinary world into which rituals propel their participants, much as with Turner's notion of the liminal phase. Unlike Turner, however, Bloch does not see the central phase of ritual as rescinding ordinary social structures to reveal an underlying social continuity. Quite the opposite. For Bloch, the everyday world or ordinary experience refers to what all human beings most basically have in common, namely "natural transformative process[es] of birth, growth, reproduction, ageing and death" (1992: 3) - a kind of natural communitas, if you like, owed to "universal human constraints" (4). The phase of ritual Turner would call liminal, by contrast, is geared toward representing an alternative to this natural fluidity, reversing it symbolically to produce an image of transcendent structures that can be imagined as permanent. Far from collapsing social and political structures, for Bloch ritual is all about instituting them. His model, in other words, provides a renewed version of Durkheim's classic idea that ritual provides a prime mechanism for organizing the messy facts of individual human lives into enduring social and political structures:

The social and political significance of [ritual] is that by entering into a world beyond process, through the passage of reversal, one can then be part of an entity beyond 
process, for example, a member of a descent group. Thus, by leaving this life, it is possible to see oneself and others as part of something permanent, therefore lifetranscending. (Bloch 1992: 4)

To see how this suggestion bears on the question of revolution, we may note first the central role that Bloch's model gives to violence in particular-a matter that remained largely incidental in Gluckman's and Turner's analyses, but which to us is of immediate relevance. For Bloch violence is the prime means through which the two crucial transitions of the ritual sequence are enacted-the passage from ordinary life (in Van Gennep's and Turner's models, the "pre-liminal" phase) to the transcendent realm beyond it (the "liminal"), and then the return from the transcendent realm back to ordinary life (the "post-liminal"). Both passages are marked by violence, for Bloch, because they turn on the conquest or consumption of vitality. That this should be so for the first transition follows directly from Bloch's idea that ritual transcendence reverses the terms of ordinary life processes. For the ritual participants to be propelled into a realm that transcends ordinary life, this life must be symbolically vanquished. Elements and processes associated in any given ethnographic context with people's inherent vitality, to do with birth and growth, are violently negated and substituted with representations of decay and death. Thus the destruction of participants' "inner vitality", as Bloch calls it, is their passport to the "world beyond," since such a world is precisely one in which ordinary life processes are suspended.

The violence of the second transition, from transcendence back into ordinary life, also follows logically from that of the first, although the argument here is more complex. If the transcendent condition of the ritual participants takes the form of a symbolic death, then their return to the everyday realm must involve a process of revitalization-a rebirth of sorts. It is in this step of the argument that Bloch provides a solution to the problem of "tragic oscillation" that we saw earlier in relation to Turner's model of liminality. If participants leave ordinary life behind in order to enter a transcendent world of permanent structures, then their subsequent return from this transcended order cannot be conceived merely as a return to life, for then their experience of transcendence would make no lasting difference. The "problem posed by the politicosocial requirement of constructing a totality consisting of living beings, which is, unlike its constituent parts, permanent," Bloch explains, requires a solution "which rejoins the here and now and the transcendent units which the rituals create" (1992: 4-5). Therefore,

[Participants'] return into this world [must be made into] something quite different from their departure from it. In the first part of the ritual the here and now is simply left behind by the move towards the transcendental. This initial movement represents the transcendental as supremely desirable and the here and now as of no value. The return is different. In the return the transcendental is not left behind 
but continues to be attached to those who made the initial move in its direction; its value is not negated. ... The return is therefore a conquest of the kind of thing which had been abandoned but, as if to mark the difference between the going and coming back, the actual identity of the vital here and now is altered. Vitality is regained, but it is not the home-grown native vitality which was discarded in the first part of the rituals that is regained, but, instead, a conquered vitality obtained from outside beings, usually animals, but sometimes plants, other peoples or women. In ritual representations, native vitality is replaced by a conquered, external, consumed vitality. It is through this substitution that an image is created in which humans can leave this life and join the transcendental, yet still not be alienated from the here and now. They become part of permanent institutions, and as superior beings they can reincorporate the present life through the idiom of conquest and consumption (5).

The manner in which Bloch's model of "rebounding violence," as he calls it, brings together rituals' capacity to conjure alternatives to ordinary reality (the potential Turner saw as "liminal") with an inherent investment in violence speaks directly to our effort here to use ritual theory as a point of departure for developing an anthropological account of revolutions. Revolutions, after all, also conjure alternative orderings of the world in characteristically violent ways. Indeed, while Bloch's model is primarily aimed at explaining how ritual serves to institute and bolster existing sociopolitical structures, there are inklings that his model of rebounding violence can also allow for more subversive situations, reminiscent of revolutions, in which rituals are pitted against the prevailing order. In line with Turner's earlier suggestion, his prime examples are millenarian movements, which, as he shows with reference to the anticolonial character of the popular performance of royal Merina circumcision rituals in nineteenth-century Madagascar (1992: 85-90), can become the bearers of explicitly political projects of resistance and change. The problem with millenarianism for Bloch, however, is that, as an essentially world-renouncing phenomenon, it cannot fully consummate the alternative orders it envisages. Turning into a kind of virtue the problem of tragic oscillation we encountered earlier, the revolutionary potential of millenarian movements is by their very nature exhausted by the first phase of ritual transformation, namely the negation of life in favor of a realm that transcends it.

In the Madagascan case, for example, Merina commoners frustrated with their king's submission to French and British invaders in 1863, manifest in his decision to suspend performances of the royal ritual of circumcision, began defiantly to abandon their ordinary agricultural tasks and spontaneously to become possessed by ancestral spirits on a mass scale. According to Bloch, this denial of vitality in favor of the world of the dead ancestors was the commoners' way of enacting the first phase of the royal circumcision rituals, which involved "killing" the royal child at the moment of circumcision by ridding him of "wet" and "feminine" elements that constitute his youthful vitality, in order to allow him to be infused by 
the "dry" and "masculine" characteristics of the life-transcending order of their agnatic ancestors. In its proper royal performances, however, the circumcision ritual would be consummated by a second round of violence, in which the "external" vitality of plants, animals, and women would be consumed collectively by the participants, sometimes in conjunction with military conquests of neighboring groups. By contrast, participants in the rebellious ancestral possessions of 1863 refrained from completing the sequence of rebounding violence in this way. Their aim, rather, was only to deny the authority of rulers they felt had failed them, and assert instead the prior authority of the ancestors by enacting their timeless world.

Still, it is curious that Bloch refrains from extending the political efficacy of ritual, as he conceives it, to more fully fledged revolutionary movements since, we would argue, his model of rebounding violence lends itself perfectly to the task. ${ }^{2}$ For while the Merina mass possessions and other such millenarian phenomena might limit themselves to evoking alternatives to the reigning political order, as far as the model of rebounding violence is concerned there is no principled reason why such alternatives could not be consummated ritually, with a violent transformation of the political order of the here and now. Other than practical circumstances (e.g., their military weakness), for example, what was there to stop the Merina commoners from ending their life-transcending trances with a "rebounding" attack on the British and French colonists and their local collaborators, emulating the military expeditions with which their leaders had culminated the circumcision ceremonies in the past? Albeit rear-guard, in this case (and we shall see later that many revolutions are rear-guard in one sense or other), this would indeed be a way of putting into revolutionary use the violent power of ritual as Bloch conceives it.

An example of just such a case of ritual and fully fledged revolution coming together is provided by David Lan's marvelous ethnographic account (1985) of how the revolutionary freedom fighters of the Zimbabwe African National Liberation Army (ZANLA) joined forces with local spirit mediums in the Zimbabwean struggle for independence from British colonial rule in the 1970s. Supervised by Bloch, as it happens, Lan conducted his doctoral fieldwork with Shona-speaking inhabitants of Dande, in the northern part of the country, which was the young rebels' entry point into then-Rhodesian territory from their military and ideo-

2. Bloch in fact devotes the final chapter of Prey into Hunter to exploring "truly radical challenge[s]" (1992: 99) to the kinds of permanent institutions rituals support, ending the book with a reflection on how it might be possible "to analyse and criticize the very basis of our ideologies, to begin to demystify ourselves and to search for fundamentally different solutions" (105). But for him this possibility is to be found in myth, which, following Lévi-Strauss, he sees as a space in which alternatives to existing social orders can be explored imaginatively. It would seem that ritual, for Bloch, is inherently conservative and only myth can be truly subversive. 
logical training camps in Mozambique, Tanzania, and elsewhere. Lan's central concern is to explain how, during the course of their guerrilla campaign in Dande, these gun-wielding cadres, who called each other "comrades" and fought in the name of Marxist-inspired revolutionary ideals, were quickly incorporated into local society, gaining local support for and even participation in their campaign. A crucial part of Lan's ethnographically nuanced answer concerns Dande practices of spirit possession and their role in the conferral of ancestral authority.

The political circumstances the ZANLA freedom fighters encountered at Dande were in some ways similar to the situation Bloch described for the Merina in nineteenth-century Madagascar. In precolonial times, Dande society had been organized according to royal lineages whose members derived ritual and political authority as rainmakers and "owners of the land" from their association with local royal ancestors, the mhondoro. Crucial to this political configuration was the relationship between chiefs and the spirit mediums through whom the mhondoro made themselves manifest, since matters of chiefly succession, and therefore of the chiefs' authority over their territory, were decided by the ancestors themselves through the mediums. During colonial times, however, from the late nineteenth century onward, the chiefs' authority was severely curtailed. Authority over the distribution of the land was taken over by the Rhodesian state (systematically divesting Shona people of their land and turning large numbers of them into wage laborers in the white-owned plantations), and chiefs were slowly turned into state functionaries, collecting taxes from their putative subjects in exchange for a salary and other perks. In the eyes of ordinary people, this drastically reduced the authority of the chiefs and, as Lan describes in detail, for such crucial matters as agricultural fertility rituals, local dispute resolution, and the persecution of dangerous witches, people began to turn to the authority of the ancestors themselves. Similarly to Bloch's Merina case, then, dissatisfaction with their leaders' collusion with white colonists led local people to shift "their political allegiance from the chiefs of the present to the chiefs of the past, the mhondoro" (Lan 1985: 140). However, unlike the Merina case, this shift to the ancestors did not take the form of spontaneous, millenarian-style possessions on the part of the commoners themselves, but rather of an increase in the authority of the spirit mediums as presentday mouthpieces of the mhondoro, who effectively absorbed many of the political and ritual roles the chiefs had held in the past. In this way, the mediums came to occupy a position in Dande society that was structurally opposed to the colonial authorities - an opposition that was expressed in the aversion of the mhondoro to all things white.

This explains why in this case anticolonial sentiment did not limit itself to a millenarian denial of the here and now in favor of ancestral transcendence, spurring instead a military campaign to replace the colonial order with the political alternative the ancestors came to represent and actively promote, namely the 
anticolonial emancipation for which ZANLA was fighting. For a start, the rebels' emancipatory goal of taking control of the land back from the colonists and redistributing it to the peasants coincided closely with the mhondoro's ancestral authority as "owners of the land," effectively scaling it up from the level of local territories to a Zimbabwe-wide struggle against the white landowners. Indeed, this basic affinity between the rebels' anticolonial ideals and the mhondoro's stance against the betrayals of the chiefs was affirmed and consolidated by both sides, so that the rebels soon became associated with the mhondoro themselves. Under the spirit mediums' guidance, the rebels took on both ritual and social roles associated with the mhondoro. For example, they observed ritual prohibitions that called for sexual abstinence and forbade the killing of both animals and humans, and took on many of the duties with which the chiefs, as the mhondoro's descendants, had traditionally been charged but had recently abandoned, such as the persecution of harmful witches. On their part, the spirit mediums used their king-making role as mouthpieces of the mhondoro to confer political authority onto the rebels, treating them as the rightful heirs of the mhondoro, as they had done with the chiefs in the past. Rapidly, then, the ZANLA fighters were transformed from strangers into autochthons, treated as "sons of the soil," and given full legitimacy by means of the Shona's long-standing structures of political authority to conduct their guerrilla campaign in the name of the ancestors, whose will they were now understood to embody.

The Zimbabwean case illustrates how easily Bloch's model of ritual's rebounding violence can be transposed onto the anthropological study of revolutions. Due to their concerted association with the ancestors via the spirit mediums, the ZANLA rebels were indeed propelled into a transcendent order. This corresponds to the first stage of violence in Bloch's model, with the vanquishing of the "inner vitality" not only of the spirit mediums, through spirit possession as in Bloch's own Merina case, but also of the rebels themselves, through sexual abstinence and other ritual prohibitions that changed ordinary patterns of consumption, including that of food. But, in contrast to the Merina case, this also spurred the rebels into a second phase of violence, in which the "extremal vitality" of enemies (witches and political adversaries alike) is the target of military attack, very much in line with Bloch's model, although in this case pursuing the overthrow of the existing political order rather than its affirmation as in Bloch's examples. Ritual and revolution, then, blend into a single sequence of action, each building on the power of the other, and precipitating, in this case, the defeat of the colonial regime and the institution of ZANU-PF's state-socialist government, notoriously headed by Robert Mugabe for the best part of the next four decades.

It is hard not to appreciate the more general purchase of Bloch's basic model on the anthropological study of revolutions, even in cases in which the link to overtly ritualized actions such as spirit possession is not as pronounced, or even present. 
The three central ingredients of the model-violence against internal vitality, the propulsion into an alternative political order, and its assertion over the existing order through violence toward external victims-seem to lend themselves to all manner of transposition on real-life revolutions. For example, the idea that revolutions involve an initial commitment to self-sacrifice (a preparedness to put one's very life on the line in the name of a revolutionary ideal) is so common as to appear banal. "Freedom/ emancipation/independence/socialism/ (what-haveyou) or death!" is the standard cry of the revolutionary, and in chapter 3 we shall see how this kind of self-abnegation is often fundamental to the constitution of persons as revolutionaries (Holbraad 2014). Moreover, revolutionary ideals themselves, whatever they might be, are typically similar to Bloch's transcendent orders of a "world beyond" in their lofty and often utopian character. Indeed, we shall see in chapter 5 that the role of ideology, which is so often central to the motivation of revolutionary action, is typically precisely that: to present an alternative to the social realities of the here and now, exactly in line with Bloch's characterization of transcendence. Finally, the second, outward round of violence stipulated by Bloch is nigh on the signature of revolutionary action: the decision to treat the reigning powers as enemies and bring about their downfall through force is often regarded as the very essence of revolution (Humphrey 2019).

By the same token, however, one can query whether the easy fit between Bloch's model and standard ways of thinking about revolutions might, to some extent, be due to certain basic assumptions they both share, not least about the nature of time. It is interesting to note, for example, that even though many of his examples of ritual transformation would conform quite straightforwardly to Gluckman's standard anthropological notion of "cyclical time," Bloch's model has built within it a linear notion of chronological succession-precisely the kind of temporal order Gluckman associated with the modern world, and Koselleck theorized as part of its very constitution. For Bloch, of course, this is quite deliberate. The chronological succession of time moving ineluctably onward-future, present, past-is just a fact of nature, while the role of ritual is to "mystify" this by creating the illusion of an order of permanent structures that appear to transcend ordinary linear time-this being the essentially "ideological" role of ritual as a means of domination (Bloch 1989). The very notion of cyclical time, therefore, is for him just an effect of this kind of mystification, as is any other supposed deviation from the natural fact that time passes, and we are all biological beings who are born, grow, mature, and die. The social order-and the same must be said for the orders revolutions seek to bring into being-may require people to imagine that things could be otherwise, but that does not make it any less illusory. The institution of society is indeed "imaginary," as the Greek-French philosopher Cornelius Castoriadis (1987) would have it, although here "imagination," for Bloch, is to be taken as a synonym of "illusion." 
This raises the question of what might happen if we were to unmoor the anthropological analysis of ritual from the kind of naturalistic conceptions of time in which Bloch founds it. While we shall return to this question of revolutionary time in chapter 6 , for purposes of our present argument about revolution and ritual we wish to explore in particular what the alternative temporal conceptions that rituals so often involve might also be able to tell us about alternative ways of thinking about revolutionary time. If, for example, the anthropological study of ritual leads us to contemplate nonlinear ways of conceiving of time itself, then where might this lead us in thinking about the temporality of revolution? Might the standard assumption that revolutions constitute a momentous break with the past for the sake of bringing about a different kind of future also be anthropologically subverted (cf. Bryant and Knight 2019)? Are habitual modern ways of distinguishing past, present, and future, and of imagining the passage of time as a chronological succession, necessarily at the heart of revolutionary action, and is such action always best conceived of as an "event" (see also Lazar 2014)? In the next section we tackle these questions with reference to critical ethnographic examples.

\section{NONLINEAR REVOLUTIONS}

As we shall see in more detail in chapter 6, arguments showing that linear ideas of time are far from universal are legion in the history of anthropology. ${ }^{3}$ In addition to the classic idea that "nonmodern" peoples often experience and / or conceptualize time as an ever-returning cycle (e.g., Eliade 2018), as we have seen, proposals for indigenous models and experiences of time that do not conform to the modern conception of chronological succession-past, present, future-are standard fare in the discipline (e.g., Geertz 1973a; Strathern 1990). How such nonlinear temporalities might modify our understanding of revolution is the more general question we deal with in chapter 6 , where we examine the relationship between revolution and cosmology more broadly (see also Holbraad and Pedersen 2013; Holbraad et al. 2019). Here we shall limit ourselves to suggesting arguments with specific reference to alternatives to Bloch's linear model of ritual transformation. Since Bloch's model is both highly sophisticated in its own right and embodies the normative assumptions of linear time, it provides a useful point of dialectical contrast for the kinds of arguments we shall be sketching out here.

Lan's account of the role of the ancestors in the Zimbabwean anticolonial struggle provides a good first illustration of what an analysis of revolution that relies on the classic anthropological idea of cyclical time might look like. Unlike

3. For a classic review of these debates, including an account of Bloch's contribution to them, see Gell 1992. For an updated review see Hodges 2008. 
Gluckman, as we have seen, Lan's ethnographic analysis is of a phenomenon that can unproblematically be classed as a "revolution"-indeed, one that had many of the trappings of "modern" revolutions and that was partly inspired by Marxism. Yet it incorporates elements that Gluckman would class as "repetitive," associated most crucially with the agricultural rituals of chiefly succession and the role the mhondoro play within them. In particular, we have here a situation in which ancestors who are deemed (by definition) to have lived in the past make regular reappearances in the present by possessing the bodies of living spirit mediums and speaking through them.

Lan casts this as a shift that can be understood within the temporal coordinates of linear succession. When the Shona peasants started treating the spirit mediums as their political leaders, rather than their "sellout" chiefs, as far as Lan is concerned they were shifting allegiance from the "chiefs of the present" to those "of the past" (1985: 140). Indeed, to the extent that the ZANLA rebels came to represent the order of the ancestral mhondoro, the whole anticolonial revolution could quite naturally be seen as an attempt to return to a past that the colonial regime had sought to obliterate. In that way Lan's study could be interpreted as a confirmation of a point made again and again by political and social theorists and philosophers who write on revolution; namely that, for all their commitment to radical change overthrowing the ancien régime, revolutions are often motivated by a desire to restore an earlier era. Enlisting writings by Franklin, Tocqueville, Paine, and Burke, for example, Hannah Arendt reminds readers of her classic comparative study of the French and American revolutions, On Revolution-in both cases the protagonists, at least initially, saw their aim as revolving "back to an 'early period' when they had been in the possession of rights and liberties of which tyranny and conquest had dispossessed them" (Arendt [1965] 2006: 35). That this somewhat paradoxical notion of a forward-moving return to the past should be prominent in the context of anticolonial struggle is of course hardly surprising.

To treat Lan's example in this way, however, would ignore the whole premise of the Shona's relationship with ancestor spirits, and not least the salience of spirit possession as a way of making them present, treating it all as at most a striking local metaphor for the importance of the past. As Lan's own analysis of the king-making powers of the mhondoro shows, by contrast, the ancestors' capacity periodically to return from the past and make their presence felt in the here and now is far from metaphorical: it is precisely because the spirit mediums are able, literally, practically, and demonstrably, to embody the spirits that they are themselves powerful players in the political scene of the present. But if this is so, then we have here precisely the kind of breakdown of standard assumptions about the linear succession of past, present, and future that one would associate with anthropological arguments about cyclical time. If the mhondoro are both of the past, qua ancestors who lived in a bygone era, and of the present, in which 
they are nevertheless able to manifest themselves, then their peculiar power entails a collapse of that linear temporal distinction. The mhondoro literally embody the alternative temporal possibility that that past, qua past, can recur in the present and, conversely, that the present, qua present, can be infused by recurrences of the past. More than representations of a kind of historical heritage, then, the possessing spirits of the mhondoro can be conceptualized, quite literally, as time travelers. Their translations from the ancestral era to the here and now embody a nonlinear trajectory of time itself.

Such an interpretation of Lan's ethnography yields a substantial departure from the standard temporal coordinates of revolutions. The constitutive role that the mhondoro played in the rebels' struggle against and overthrow of the White government in Rhodesia suggests that this was anything but an attempt to rid Zimbabwe of "the muck of ages and . . f found society anew," to recall the classic adage (Marx and Engels 2001: 94-95). Nor was it merely an example of Arendt's point about the restorative qualities of revolution. Rather, our nonlinear temporal interpretation of Lan's study shows what a nonlinear account of revolution might look like. Revolution, on this account, does not unfold within the linear coordinates of chronological time but rather deliberately interferes with them. With its demotion of chiefs into functionaries, the colonial government sought to dissipate the political power of the ancestors-with power here understood as the manifestation of the past in the present, over which it perforce reigns. The ZANLA forces' revolutionary action, in response, draws precisely that power back into the political field, now via the mediums, with the rebels themselves manifesting the ancestral past in their present as well as future-oriented actions. Revolution, then, as time travel. Not the restoration of the past, but its institution as a constituent of the present: that is what revolution looks like in a situation where ancestral spirits are understood as real political players, as they are for the Shona.

The broader anthropological lesson one can draw from the Shona case is that the varied temporal coordinates that revolutions might involve in any given ethnographic situation have a lot to do with the different cosmological conceptions with which they are so often related. In such a view, the linear conception of revolution Koselleck associates with modernity can itself be seen as having its roots in Judeo-Christian traditions of conceiving of Providential time as a progression from Creation to Judgment Day, punctuated by prophetic moments of rupturethis would chime with our earlier point about the frequent association of revolution with millenarianism (Cohn [1957] 2004). The anticlerical tradition inaugurated by the French Revolution could then be seen as an attempt to empty out that temporal form of its religious content, while keeping its linear character intact, much as natural science was doing around the same time. Perhaps the most vivid evidence of how important the form of time itself was to the advent of revolution as an avatar of modernity was the implementation during the French Revolution of the French Revolutionary Calendar. Inaugurating a New Time in its own 
right, the calendar sought to purge the measurement of time of any religious associations, completing the rationalizing anticlerical agenda of decimalization, but crucially keeping the very notion of linear chronological progression at its heart. Revolutionary movements ever since have sought to reinitialize time in similar ways, paradoxically marking a break with tradition by confirming the power of an essentially messianic act.

The suggestion that even the most avowedly secular of modern revolutions can display deeply Judeo-Christian traits has been made often and well (Billington 1980; Arendt [1965] 2006; Badiou 2003) - a point to which we shall be returning in more detail in chapters 5 and 6 . Of interest to us here is just the way this renders the temporal horizons of revolution contingent, connecting them also to religious practices that may of course differ from place to place. The complex associations between revolutionary politics and different strands of Islam, which have become so prominent in recent decades across the globe, provide perhaps the most-discussed contemporary example. In the burgeoning anthropological literature from the Middle East and North Africa (MENA) on the experience of the so-called Arab Spring and its aftermath, for example, the immanent relationship between revolutionary action and Islamic conceptions and practices of piety has been explored most penetratingly with reference to ideas about predestination. To take just one case, in a monograph tellingly titled Egypt in the Future Tense, Samuli Schielke (2015) explores how grassroots as well as theological debates about the idea that the course of history is always already "written" by God lent a complex temporal inflection to people's involvement in and support for the events of Tahrir Square in January 2011. Future-oriented revolutionary action was cast by some as an exercise of individual freedom underwritten by the will of God. Others, by contrast, deemed it an expression of a divine destiny already decided-an idea, deployed by the Muslim Brotherhood in particular, as a way of casting as the revolution's inevitable outcome their own fusion of divine providence with mundane government (Schielke 2015: 220-23; see also 23-24; cf. Elliot \& Menin 2018). Revolution, then, not as a rupture with the past but as its predetermined realization.

The intricacy and sense of possibility that this kind of temporal diversity introduces into the anthropological study of revolutions is vividly illustrated by another study of the experience of the uprising in Egypt, by Amira Mittermaier (2014; see also 2019). Here the ethnographic focus is not on the events of Tahrir Square but rather on a Sufi khidma held just a few kilometers away, in Cairo's City of the Dead. Khidma, literally "service," are spaces set up by Sufi practitioners to provide refreshment, food, and rest for people who may need or wish it, thus enacting God's grace (barakat) and generosity (Allah karim - "God is generous"as the metal plate at the entrance of the khidma of Mittermaier's study reads). Mittermaier makes virtue of the fact that, during her fieldwork there in 2010-12, daily life in this particular khidma was not related in any direct way to the events of Tahrir Square and their political aftermath in Egypt as a whole. The khidma had 
been run for many years by a lady dedicated to providing food to regular as well as occasional guests, and, while politics in general and the momentous events of the 2011 uprising in particular did naturally feature sometimes in people's conversations, cooking for and generally looking after people was her abiding concern. Nevertheless, Mittermaier suggests, the concerted orientation toward the present that the "ethics of immediacy" of the khidma enacts may be instructive in the context of the debates that erupted, both in Egypt and globally, in the aftermath of Tahrir Square, about "other modalities of being-in this case of the political and the social" (Sabea cited in Mittermaier 2014: 69). As participants in the uprising attest, Tahrir Square itself was a space where people could experiment with modes of "togetherness in the present" - "mutual care, sharing, openness, generosity, and an attunedness to Others" (Mittermaier 2014: 68; see also Sabea 2014, and Porter 2017 on Yemen). For Mittermaier, the ways in which similar dispositions play out in a khidma down the road in Cairo can instigate a "conversation with Tahir-as-utopia [that] resonates with a line of exploration pursued by at least some Egyptian activists" (72).

The resonance set up by Mittermaier has the question of time at its center. In particular, the experience of immediate care in the present in the khidma, which in some ways parallels the ethos of mutual care that developed in Tahrir Square during the weeks of its occupation, is in contrast to the temporal horizon conjured by the demand for social justice that was so widespread in the revolution. While the power of this demand is partly owing to its vagueness, with an array of different constituents subscribing to it (from trade unionists and NGO activists to international backers and commentators, neoliberal reformers, and leaders of the Muslim Brotherhood), its orientation toward effecting change in the future framed the uprising itself as a means to a deferred goal. Such a temporal framing, we may note, conforms to the standard image of revolution as a rupture with the past (the time of social injustice) for the sake of a better future (an era of social justice). Against such a backdrop, the fact that social justice was in no way achieved, and military control of the government eventually returned in 2013, must count as the revolution's failure.

By contrast, an ethnographic focus on the parallel between the sociality of the khidma and of Tahrir Square during the catalytic uprising of January 2011 reveals a revolutionary temporality that is oriented towards the present. In many ways, as Mittermaier notes, this can be understood in the context of the Occupy movement in the United States and Europe, which has placed such emphasis on the experimental spirit of the "prefiguration" of desired futures in the very enactment of one's struggle to bring them about (Juris 2008; Maeckelbergh 2009), or indeed the more immediate and "nonlinear" notion of "figuration" (Krøijer 2015: 27 ), in which the point of political action is to realize itself by enacting in the present its (otherwise) future goals. While a number of the activist commentators in the aftermath of Tahrir Square made similar arguments (e.g., Sande 2013; 
Risager 2016), however, the implications of Mittermaier's study of the khidma take this idea in a different direction. On the one hand, the longevity of the khidma counteracts the assumption that such forms of present-orientation can only be exceptional and temporary-even liminal in the Turnerian sense. On the other, that very longevity of the forms of togetherness of the khidma is owing most crucially to its sacred status as a space for the realization of God's grace and generosity. To the extent that Sufi conceptions of the divine posit God's grace as both immanent and diffuse in the world (Cherstich, forthcoming), the khidma can be seen as a portal of sorts, connecting the "here and now" (to use Bloch's terminology) with the transcendent order of the divine, which could even be imagined as lying beyond time itself (Böwering 1997: 60-61). Inverting Bloch's model point for point, however, this is not a matter of the timeless order of the divine imposing itself on the transience of the here and now. Rather, the very notion of grace here involves asserting the present-the here and now in its most immediate and bodily guise of eating, drinking, and sleeping - at the expense of the kind of linear, future-oriented time Bloch's model is built on (cf. Day et al. 1998), and which standard intuitions about how revolutions work also take for granted.

\section{CONCLUSION}

In relation to our broader attempt in this book to elaborate an anthropological approach to the study of revolutions, one of the collateral benefits of studies such as Mittermaier's lies in the way they broaden ethnographic attention out from the "action" of revolution-the effervescence of uprisings seen as events-and onto spaces and situations that can shed light upon revolution from a different angle. By way of conclusion, then, we may complement our substantive attempt to disrupt the linear narrative of revolutions as rupture-like events with a more methodological point about where the action of revolution is to be found when viewed ethnographically. Once one moves away from the normative expectation that revolutions ought to be understood, by definition, as events of intense and often violent effervescence, one opens oneself up also to the possibility that, seen as ethnographic objects, revolutions might take on quite different kinds of shapes (see also Hirslund 2011; Højer 2018; Krøijer 2019). Of course, being caught up in the action of revolutionary events themselves might provide a crucial vantage on how revolutions operate. But, as Mittermaier's study shows, accounts of situations that are connected to the epicenter of revolutionary events at a remove of one or more steps can also provide valuable insights.

Unhinging the study of revolutions from a narrow focus on events and exploring ethnographically their permutations in different aspects of social life is perhaps a natural consequence of the holistic, all-embracing quality of ethnographic research. This becomes evident, for example, in a collection of short essays that were published hot on the heels of 2011 in Egypt, in which anthropologists 
who found themselves in the country at or around that time were invited to present reflections on what the revolution looked like from the angle of their particular field sites. How was the revolution experienced in a village in the countryside (Abu-Lughod 2012)? How do people whose involvement in the revolution was primarily through watching the events of Tahrir Square unfold on their TV screens make sense of the contrasting claims to justice put forth by the different groups involved in the uprisings (Ghannam 2012)? What new forms of solidarity take shape at the periphery of the events in Cairo, for example through residents in neighborhoods organizing their collective protection from looters as well as from the police (Hamdy 2012)? How is revolution experienced by those who do not have the "privilege" of joining in its action, but have to remain in domestic spaces instead-not least women caring for children and grandparents while the young men are out in the streets protesting (Winegar 2012)?

From an ethnographic point of view, far from being peripheral to the understanding of revolution, lateral standpoints such as these are integral to it. This is not just a matter of providing a more complete or complex image of how revolutions affect and are experienced in the different social domains and constituents they involve-although it is that too. It is also a matter of connecting the study of revolutions to the perspective of the people who are involved in them. For the young man protesting in the streets, the thoughts and feelings of his mother, wife, and children who might be waiting and worrying for him back at home is as basic an element of his experience of revolution as is, say, his fear and loathing of the police. For an anthropologist, understanding these relationships, and how they are embedded in local (and variable) social structures and the forms of sentiment that they involve, is a basic way of gauging the ways in which the shape and significance of revolutionary transformations might differ from one context to another. The often subterranean and nuanced ways in which revolution is formed by (and forms in turn) particular kinship practices, conceptions of gender, local social structures and forms of solidarity, and so on, can lend revolutions contrasting social proportions in different ethnographic settings. The next chapter is devoted to exploring these questions. 


\title{
State and Revolution
}

\author{
Nations, Tribes, and Lineages
}

\begin{abstract}
Within this structure of society based on kinship groups the productivity of labour increasingly develops, and with it private property and exchange, differences of wealth, the possibility of utilizing the labour power of others, and hence the basis of class antagonisms.
\end{abstract}

-FRIEDRICH ENGELS

During the second term of Bolivian president Evo Morales, at a time when the proceso de cambio was amplifying its reach and voting base, an unusual dispute begun to unfold within the Bartolina Sisa National Confederation of Peasant, Indigenous and Native Women of Bolivia (simply known as "Bartolinas"), the largest female organization in the country and a structural component of the proceso de cambio. ${ }^{1}$ During a national assembly of the confederation, members of the associations of coca growers from Bolivia's tropical regions proposed to homogenize the dress of all Bartolinas by replacing the traditional Andean female shawls, meticulously decorated and colored according to the region or even community of provenance, with a standard blue shawl. The blue shawl was an attempt to give the Bartolinas a recognizable national uniform for the vast heterogeneity of their membership, which included women from multiple ethnic groups and different regions of the country. But above all, blue was the color of the ruling party-the

1. Literally the "process of change", the proceso de cambio is officially known as Bolivia's "democratic and cultural revolution" and usually identified with the leadership of President Evo Morales from 2006 to 2019. As per many revolutionary processes, if the idea of the proceso de cambio was initially associated with a series of indigenous and popular organizations taking center stage in the historically exclusive Bolivian politics and society, it has been gradually identified with a project defined from the state and structured around the figure of Evo Morales. While this book was in press Morales was ousted from power, feeding a debate as to whether the proceso de cambio had come to an end. A specific analysis of these last events will not be produced in this text. 
Movement Toward Socialism, MAS-therefore reasserting the Bartolinas' role, affiliation, and prominence in Bolivia's proceso de cambio.

The proposal was received with bemusement by highland Aymara women from the Bolivian plateau. In fact, most of them, in the classic highland style, did not even react or reply to a proposal that sounded purely absurd. For these women, who wear shawls, decorations, and power items sometimes passed down from one generation to another, the "blue shawl" just signaled an ontological confusion about what the "revolution" is and ought to be. To replace the traditional shawls signaling the specific stories and colors ("flags") of their ancestors with a blue shawl identifying the ruling party was to throw the baby out with the bathwater! The party was referred to as an "instrument," not an end in itself, for multiple and articulated groups and communities to gain access to the official political sphere and to bend it to their rules and forms; it was a "son procreated by multiple indigenous associations," a mere "political arm" of their communities and organizations (García Yapur et al. 2014; Arbona et al. 2016). This seems to foreground a notion of "revolution" as not necessarily associated with increasingly unified salaried workers but as a political transition toward the segmented networks and logics of local political organizations. Although this is often represented as a tendency of local groups to get stuck in traditional political logics and the defense of particularistic interests, as opposed to national ones (García Linera 2015b), what seems to emerge here is a notion of articulated and networked indigenous groups that precedes and surpasses the homogeneous notion of party and state. In other words, for Aymara women communal political mobilization was not based on the notion of a symbolic and standardized blue shawl homogenizing and "nationalizing" local indigenous groups but rather on a multicolored fabric of patched localisms "indigenizing" the party, the nation, and the state.

In the political analysis of revolutionary transformations, indigenous tribes, kinships, and lineages are often associated with particular, local forms and counterposed to universal structures of political organization such as the state, the party, and the trade union. As apparent in the title of Lenin's masterwork (Lenin [1917] 2014), the notion of revolution has been inextricably bound to the idea of the state. Words like tribe and clan have been problematically associated with traditional forms of sociopolitical organization that ought to be overcome in order to produce a transition toward modern states or "democratic" political formations. A series of canonical narratives and conceptualizations of revolution have not only identified the party and the state as strategic tools and instruments in the consolidation and coordination of revolutionary transformations but have also conceived them as unitary, wider, universal agents of articulation of localized political cultures in order to develop a truly emancipatory political consciousness.

In this chapter, we aim to open up these assumptions by using the ethnographic realities anthropologists have been researching, with a focus on revolution 
through the sociopolitical framework of indigenous tribes, lineages, and kinship alliances. In other words, we are interested in what happens to the conventional and modern narratives about state and revolution when we place them in contexts where the political is often defined by the intersection of tribes, lineages, and ancestors. Also, we look at the specific concepts and ideas of "revolution" developed from the political logics of local tribes and clans.

Although some anthropologists have discouraged the use of terms such as clan and tribe due to the burden of sociopolitical traditionalism intrinsically attached to them, others have actually emphasized the strategic role of these forms of organization to solve conflicts and organize populations, accomplishing a role similar to that typically accorded to the state and even giving shape to other notions of nation. Throughout this chapter and the entire book, we will maintain the use of the word tribe not so much to emphasize its anchorage in political tradition but rather to highlight its proactive role in outlining specific revolutionary notions and practices.

"WORKERS OF THE WORLD, UNITE!": REVOLUTION AS A UNIVERSALIZING PROJECT

At the inception of the Arab Spring, which appeared to coincide with the mushrooming of a series of unconventional, populist, and anti-establishment movements (Podemos in Spain, Syriza in Greece, Occupy in the United States), an intellectual conflict arose between popular and controversial philosopher Slavoj Žižek and US-based, Iranian intellectual Hamid Dabashi-a skirmish that ended up involving several other postcolonial theorists. Following Marx and the notion that even the most local and particular problems remain embedded in the wider global system, Žižek (2013) affirmed that in the case of the Arab Spring or the anti-establishment movements the particularization of protests and the inability (or unwillingness) to present the protests as a global, universal, and systemic revolution appealed to the defenders of the status quo. Žižek emphasized how the lack of a common coordinating body to guide the multiple political mobilizations tended to present the upheavals in terms of a series of separate local problems that ought to be alleviated rather than of a universal threat against the general order.

In contrast with Žižek, Hamid Dabashi (2012) argued that in order to understand the Arab Spring one has to think outside of the conventional box of the creation of the central representative party and the conscientization of the masses, while placing the left and Žižek's notions of what a revolution ought to be as part of a hegemonic régime du savoir. Not always convincingly, Dabashi depicts the Arab Spring as the retrieval of an Arab political possibility of being outside of the conventional binary oppositions between Islam and the West-a new dimension of 
politics that conventional narratives of revolutionary practices end up obfuscating. A bit too hastily associating the Arab Spring with the end of postcolonialism and its regime of knowledge, Dabashi asserted that in the world beyond Christian dogma people are not born in a state of sin, and as there is no original sin, there is no final forgiveness and therefore no grand illusion, no master narratives of emancipation, no universal authorities and organizations to redress a flawed individual. What Dabashi seems to be saying is that universalistic notions of revolutionary transformation are often embraced in order to discard locality-based understandings of political action without even considering that those universalistic notions are themselves anchored in a specific and localistic political culture (cf. Badiou 2003).

In Europe, a long philosophical tradition has identified unity and universalism as strategic tools of political emancipation and transformation. What we strive to show here is how these currents of thought have come to clash with and even conceal the political relevance of fragmentary forms of political organization such as tribes, clans, and ethnic groups, supposedly unfit for thorough and global processes of radical transformation. Both in Marxism and modern liberalism, for instance, revolution is understood as a universalizing project, moving away from the particular. Local cultures and beliefs may naturalize undemocratic forms of political subjugation, preventing people from perceiving the true nature of their social and economic situation (Marx [1867] 2011), and reproducing and reifying forms of power that curtail individual liberties (Skinner 2008). Liberalism, for example, has been fostering processes of "disembedding" the individual from local particularities - family, kinship, locality-and from the burden of illiberal tradition in order to make the subject a free, agentive, and creative citizen able to freely sell his / her labor on the market (Polanyi 1959; Scheele 2007).

In the internationalist and socialist tradition, there has been a constant emphasis on the union of all workers of the world against the old regime (Marx and Engels [1848] 2005), stressing the necessity both of a certain degree of homogeneity among the fighting masses and of overcoming traditional and fragmentary organizational structures (Marx [1852] 2008; Wolf 1969; cf. Stern 1987). Particularistic and localistic interests may undermine the strength of the workers' movement but also be detrimental to the expression of the universal and general interest (Hegel 1999; García Linera 2015b). Universal structures such as the party, the union, and the state are therefore required to overcome the fragmentation of workers bound up in multiple localities, affiliations (clan, tribe, kinship, family), and beliefs and to integrate a multiplicity of groups while channeling them toward a common emancipatory horizon.

According to this view, peasant masses or indigenous peoples immersed in particularistic beliefs and attached to traditional, localized, and fragmented forms of political organization (from culture to family, from kinship to ethnic 
organizations) were not quite able to generate a new, creative revolutionary vision and program of thorough political liberation (Moore 1966; Wolf 1969; Gluckmann 1963). Peasants and indigenous groups were either the parochial initiators of revolts or simply reacting to changes determined by powerful external forces (Stern 1987: 6), but they were fundamentally unable to imagine a global, systemic transformation.

Despite their prominence in strikes and insurgencies (cf. Wolf 1969), peasant groups, indigenous communities, or Middle Eastern tribes were said to lack political discipline and organization (cf. Chakrabarty 1994; Chatterjee 1993; Guha 1983). Their organization was weak, with the structural conditions, or even local modalities of associations-often based on a ritualized systems of authority or rotational forms of leadership (cf. Ávila Molero 200o)-hindering peasants or indigenous groups from fully grasping the discipline and functioning of trade unions and politics more generally (cf. Chakrabarty 1994: 168). They supposedly lacked a disciplined body of workers subjected to a series of institutional controls, from the rights and obligations of membership to the regular meetings. Therefore, peasants and indigenous groups were considered unable to express themselves ideologically and politically (Zavaleta 2011) and needed to be educated and organized by the avant-garde of the party in order to access and effectively participate in the realm of the political (Chakrabarty 1994: 169).

If we take the example of the French Revolution, the whole revolutionary endeavor is driven by the consolidation of a wider, unitary, and universal organizational structure that could supersede local affiliations. The French Revolution has been conceptualized as bringing about the concept of nation as a new social unit, a whole new political community, disentangled from previous and particularistic cultural anchorages, which was one and indivisible and where sovereignty resided (Sieyès 1989; Ricciardi 2003). Moving away from particularism and toward universalism, the nation was to become a universal entity by replacing the God-like monarch through revolution. The French Revolution not only crystallized a nationalist program but also a new political unit (the nation) to which people felt ultimate loyalty. When Louis XIV convened the General Estates during the financial and political crisis in 1789,140 years after the last time they were convened, the representatives of the Third Estate proclaimed its organization to be a national assembly that was one and indivisible and where the sovereign will resided. Instead of the king-God, the people/nation was now the sovereign entity. Not only would this lead to the revolutionary slogan of "the people as sovereign" but also to the constitution of the nation-state as a universal revolutionary entity. With some exceptions, the state as the embodiment of a national community would become a compulsory stage in the evolution of political formations and in their possibility to aspire to wider and greater political changes (see also Geertz 1973C, 1973d). In the following section 
we explore the role attributed to the state among political theorists in processes of radical political transformation.

\section{THE STATE AS UNIVERSALIST}

\section{AND REVOLUTIONARY AGENT}

The role of the state in revolutionary processes has often been associated with the expression of universal and general interests versus either the chaotic revolutionary masses or the interests of the few. For Hegel (1999) the concept of revolution is characterized by a complex movement or tension which implies, on the one hand, moving the principles of revolution inside the state and, on the other, progressively adapting the relationship between the constitution and the people in order to educate the latter about the changes of spirit (Ricciardi 2003). In other words, once the revolution produces a multiplicity of new rights, these rights ought to be composed within an autonomous political unit that the revolution itself, given its chaos and multiplicity, is not able to generate. Robespierre's frictions and ultimate rupture with the sans-culottes (Robespierre 1989) was a consequence of the latter's understanding of themselves as sovereign, implying that the revolutionary government is a simple agent or representative whose ability to take autonomous decisions can be denied at any moment. In Robespierre's opinion, there is no space for direct democracy-and particularly for the constant movements and oscillations that the sans-culottes imposed on society and politics-since "democracy is a state" (1989: 128) where the sovereign people, guided by laws, operate.

A similar dialectical relationship between state and revolution has been employed to theorize recent revolutionary movements, for instance by the former vice president of the Plurinational State of Bolivia, Álvaro García Linera, in relation to the proceso de cambio. García Linera (2015a, 2017) affirms that revolution is like a magmatic force that explodes, manages to break the Earth's crust and erupts into the world, flattening and reshaping everything it encounters in its path (2017: 15). If in its inception this magmatic force floods the world with indomitable power, it also slowly begins to cool down and solidify, having irreversibly transformed the surface of the Earth-but only until the next eruption. For García Linera, revolution as a magmatic force (living labor) dramatically alters the geological and cosmological coordinates and eventually condenses into a new state (dead labor), literally a new state with a new composition and a new monopoly of coercion and legitimacy. As a pragmatic Marxist, García Linera envisions revolution as a creative multiplicity. If, on the one hand, it constitutes a necessary force to transform the world, it presents, on the other, the risk of undermining itself due to the self-destructive tensions among local interests and the multiplicity of its composition that may jeopardize the functioning of revolutionary politics. 
To avoid the latter risk requires the constitution of an institution (the state) that acquires the role of administering the "general," not the local, and unifying and coordinating local actions.

For Lenin ([1917] 2014), the state was the expression of the interests of a specific class, namely the bourgeoisie in capitalist society, and a machine through which these interests were naturalized so that they appeared to be the interests of the whole nation. Instead of envisioning the state as a means to reconcile the interests of different classes, Lenin affirmed that the state can only be the organ of the rule of a definite class which cannot be reconciled with its opponent. Following Engels, in State and Revolution Lenin proposes two stages in the process of transformation of the bourgeois state. The first stage is the so-called "dictatorship of the proletariat" that follows the socialist revolution and that implies the seizing of state power by the proletariat and turning the means of production into state property. For Lenin, the dictatorship of the proletariat is a temporary solution by which the working class will use the state to rebalance centuries of political injustice and as a tool to "expropriate the expropriators"-the bourgeoisie-of their accumulated politico-economic privileges. In the case of the Soviet Union, for Lenin the idea of the dictatorship of the proletariat constituted a necessary path to fill the gap of the politically backward peasant masses who had been exploited for centuries by landlords and living in a serf-like condition. Lenin referred to the political backwardness of peasants and the necessity of a leading political authority able to show them the path of emancipation. In other words, a state-bound vanguard party would lead the way in the process of political emancipation of the peasants.

In a second stage, once a political equilibrium was achieved or once all class distinctions and antagonisms were abolished, the proletarian state-not the bourgeois-will "wither away" in the same way as any other naturalized political ideologies. If in a class society, the exploiting class would need the state for the maintenance of the conditions of production, when the state becomes the real representative of the whole society, it renders itself unnecessary and can therefore "wither away."

Although in different forms, the conquest and manipulation of state power became a central feature of revolutionary endeavors. The state was a fundamental step, tool, or instrument through which revolutionary societies were shaped. From the Soviet Union to China, or with respect to the guerrilla movements in Cuba and Angola, the state has been positioned as the vantage point from which to radically transform society. In the revolutionary processes of the Soviet Union, China, and Cuba, by taking charge of planning the economy, administering the means of production, housing, and the education and "conscientisation" (Freire 1970) of the masses, the "new" state would become an instrumental tool in the transformation of the previous regimes (Yurchak 2006; Holbraad 2014; Cheng 
2009). An exception to this role of the state in revolutionary processes is constituted by the analyses and proposals of anarchism that, despite being largely outshone by Marxism-Leninism in revolutionary practices, have also inspired radical movements in their transformative endeavors.

\section{"Canonical Exceptions" to the State as the Center of Revolutionary Transformations}

Probably the most profound point of disagreement between Marxism and anarchism was centered on the different conceptions of the state. As we have seen, while for Lenin the state was an instrument for the exploiting class to exert and reproduce its domination, for anarchists the state constituted the structure engendering a class society (Bakunin 1971). Therefore, while Marxists promoted the conquest of the state and the constitution of a workers' state that would progressively wither away, anarchists aimed their revolutionary upheavals at the abolition of the state, as the state was seen as reproducing a layer of bureaucrats and salaried employees and a system of class distinction. For Bakunin, revolution is real while in the hands of the masses, but when it begins to be managed and concentrated in the hands of a few ruling individuals it becomes reaction. While Marxism-Leninism envisioned a transitional stage between capitalism and a mature communist society that included a workers' state in the form of the "dictatorship of proletariat," Bakunin (1971) was adamant in rejecting the establishment of any kind of state, which was to be supplanted by federated communal militias, self-governed institutions, and nonhierarchical free associations in the defense of revolution. For Bakunin, the revolutionary option implied moving immediately, without transition, to a mature communist society that would be distinguished by the absence of the state.

A revolutionary movement that has likely capitalized on some of Bakunin's ideas is Mexican Zapatism. The outbreak of the Zapatista rebellion in 1994 drew the world's attention to the plight of indigenous peoples in the region of Chiapas in the south of Mexico and particularly to the profound social and economic transformations of the region as a consequence of the recent neoliberal restructuring of agriculture (Collier 1994, 1998). The Zapatista Army of National Liberation declared war on the Mexican state and the corporate and military groups operating in the region.

Following the structural adjustment policies implemented by the Mexican state, the genuine process of political radicalization of Chiapas's indigenous peoples was accompanied by pan-indigenous groups and organizations with Liberation Theology leanings (Leyva Solano 1994) as well as by Mexican leftists and progressives with close links to early twentieth-century Zapatist ideology (Earle 1994). The distinctive combination of Mayan political elements and the ability of the movement to elicit global attention by means of a transnational communication strategy (Nash 1997) not only led to a mushrooming of studies and publications 
on the topic but also ended up articulating a "transnational zapatism" that likewise became crucial in the political and ideological definition of the rebellion (Johnston 2003; Keck and Sikkink 1998), articulating the indigenous dimension with alter-globalization and anti-neoliberal movements.

Instead of a hierarchical structure of power with a transcendent state or party coordinating the masses and unifying local action, drawing on supposedly lessstructured indigenous notions of politics the Zapatistas were "led" by a subcommander placing society/community above rather than below the ruler and grounding the idea of the ruler on the notion of "ruling by obeying" (Holloway 2002; Mignolo 2002; cf. Clastres 1977), implementing indigenous notions of democracy founded on local practices and organizations (Mignolo 2002). However, Zapatista communiqués were often skillful in reconciling indigenous notions of politics with more conventional leftist ideologies, swapping the particular narratives of ethnic liberation for the grand narrative of human emancipation-therefore universal and nonparticular-and the fight against neoliberalism. On the one hand, such a strategy was successful in foregrounding the Zapatist rebellion at the center of academic and public political discussions far away from Chiapas. On the other hand, in these same media discussions the nucleus of the Zapatist rebellion appeared more and more focused on the charming and metaphoric reasoning of subcomandante Marcos than on the indigenous issues at the heart of the rebellion.

Instead of building on existing political models and colonial practices, Marcos's ideas about Zapatism placed the movement as articulating a "new" notion of politics and revolution with global valence that was particularly appreciated by both postcolonial scholars and global activists. John Holloway $(1996,2002)$ describes how Zapatistas do not so much aspire to change the world by taking power, but to make the world and politics anew, therefore questioning a traditional attitude of the left that positions the state (and its conquest) at the center of radical transformations. Instead of changing society by becoming powerful, Zapatistas attempt to dissolve relations of power altogether. Citing Marcos and other Zapatista leaders, Holloway explains how Zapatism constitutes a rupture with a serious and rigid revolutionary left whose emphases on dedication, sacrifice, and responsibility have engendered processes of suppression of the self and fragmentation of the person (Holloway 1996; see also Holloway and Pelaez 1998) required by the winning of state power. In so doing, Holloway reconciles Zapatism with the criticism of former student rebels of the 1968 protests, who took an explicit political stance against the coercive powers of the state, the party system, and societal norms that curtailed personal freedoms and processes of social liberation (Fusaro 2012). But it also emphasizes how the Zapatistas do not constitute a conventional revolutionary group but a "community in arms" (cf. Zibechi 2006), dispensing with a series of orthodox notions and models of revolutionary operation. 
Possibly, the Zapatista movement constitutes an attempt to reconcile the specificity of indigenous political notions of revolution with universal/global/ transnational movements and politics, somehow replacing the mandatory conquest of the state with the creation of a transnational organization that attempts to control and paralyze counterrevolutionary global interests and forces. However, it remains to be assessed whether this articulation of the global with the particular constitutes an instrumental appropriation of global forms by Mayan indigenous peoples (cf. Escobar 2008; Mignolo 2002) or an incorporation and assimilation of indigenous politics into mainstream forms, diluting or paralyzing its "revolutionary" potential (see the notion of neo-zapatismo in Leyva Solano 2001).

\section{FRAGMENTARY NOTIONS OF THE STATE}

During debates and interviews for this book with Marxist "revolutionary" intellectuals and politicians, one of the polemical points was the relevance we, as anthropologists, tend to place on the indigenous/local political forms and notions of revolution, instead of reproducing the conventional footprint of revolutionary processes through the conquest of the state. Generally, their point of contention is that revolutionary processes require a centralized power such as the state, able to take quick decisions in order to confront a series of subversive threats to the new revolutionary order.

On the one hand, anthropology may activate a tendency to downplay overarching economic and political dynamics in order to promote a cultural mode that privileges difference, specificity, and identities (cf. Jameson 1998; Santos 2008) and, by doing so, according to socialist intellectuals, reproduces fragmentation rather than generating unity. On the other, anthropology has undertaken particularly significant work in highlighting the consequences of placing the state at the center of the analysis of revolutionary transformations (Lan 1985; Davis 1986; Nugent 1997; Abu-Lughod 2012; Mittermaier 2014; Arbona et al. 2016). Notably, the emphasis on the state may overshadow a series of institutional and political arrangements that may turn out to be instrumental in the definition of the form, purposes, and notions of revolutionary transformation.

Political structures with which anthropologists have traditionally engagedkinship, tribe, lineage-have been associated by revolutionary theorists with the "muck of ages" (Marx and Engels 1976: 53; Shah 2014) that ought to be overthrown by a modern revolution in order to found society anew. The party and the state are supposed to supersede social and political differentiations and the recursive dynamics of exclusion that characterize kinship and tribal relations, often reproduced through a specific anchorage in locality and specific genealogies as mechanisms structuring power, therefore guaranteeing impartiality and democratic integration of all members of society. 
Anthropologists have often signaled the role of tribes, clans, and kinship in shaping political systems "alternative" to the state. For instance, Marcel Mauss (1990) conceived of the gift as a kind of primitive form of social contract generating alliances, forms of reciprocity, networks, and interconnections among groups in nonstate societies. The gift imposed forms of decentralized reciprocity diffused in time that came to work as actual intertribal/interclan bonds replacing the state as a container of centralized power. Highlighting the main differences between the modern notion of state and the Nuer tribal system, Evans Pritchard (1940) emphasized how the Nuer administration of power, with nonspecialist bodies in charge of solving conflicts and administering access to resources and strategies to maintain a political equilibrium through segmentary oppositions, crystallized a kind of "anarchic state" (69). ${ }^{2}$

The same Evans-Pritchard (1954) forecast and even supported a fairly linear inclusion or transition of these nonstate societies into the more modern and effective practices of political operation of the nation-state, replacing some of their traditional forms. Gluckmann's work on rebellion in South-East Africa (1963) also reflected such a linear reading of nonstate societies and particularly the inability of these societies to generate thorough political transformations in the fashion of more advanced states. On the one hand, tribal societies somehow hold a notion of sociopolitical transformation that is not fully mature and that does not fully accomplish processes to liberate one's creative capacities (Wolf 1969). On the other, indigenous and tribal notions of transformation, given their particularity, specificity, and localism, are more prone to be engulfed by global phenomena and regimes of knowledge (Comaroff and Comaroff 2009; Žižek 1997; cf. Holloway 2002).

One of the ideas of this chapter and of this book more generally is to show how that "muck of ages" and traditional political structures have remained central in the shaping of revolutionary transformations and of particular notions of revolutions. This often draws on scholarship that has shown how tribes, for instance, through intertribal alliances and networks of operation, have been instrumental in creating presence, services, and institutionality throughout national territories, shaping "fragmentary" notions of the state and the nation (Khoury and Kostiner 1990; Edgar 2006; Cherstich 2014a; Sneath 2007). But it also draws on anthropological works that have shown how the official and conventional state has been

2. A segmentary system is based on the notion of a society internally differentiated by lineage or tribe and simultaneously held together by a system of shared values. In many anthropological works, the segmentary system is depicted as being characterized by strict rules built around the principle of "me against my brothers, my brothers and me against our cousins; my brothers, cousins and me against the world" (Barfield 1990: 160; see Cherstich 2014a). In other words, the segmentary system remains structured around a series of internal alliances and oppositions between lineages aimed at maintaining a degree of internal equilibrium and even distribution of power, generating a stateless form of "ordered anarchy" (see Abu-Lughod 1989: 281). 
founded on the margins of the social body, often leaving in the hands of tribes, kinship, and lineages a series of political functions, tasks, and services the state was unable to accomplish (Das and Poole 2004; Asad 2004).

In the case of Maoist revolutions, for instance in Peru (Degregori 2012) and particularly in Nepal and India (Shah 2014; Shah and Pettigrew 2018; Pettigrew 2013; Hirslund 2011; Zharkevich 2019), scholars have emphasized a supposedly contradictory articulation between revolution and traditional political forms. Maoist revolutionary practices have been centered on the mobilization of the peasantry and rural groups as the main revolutionary forces, as opposed to the proletariat in the Marxist-Leninist ideology (Mao Zedong 1976). Starting its revolutionary struggle in the countryside, peasant kinship bonds were often instrumental to provide safe houses for recuperation, storage of essentials, and the provision of food. However, if kinship ties are important to sustain the struggle, they are also "politically" dangerous because they depend on the relations of reciprocity, complex dynamics of exchange among clans and lineages, and respect for local chiefs that Maoism is supposed to supersede in the new sociality of the movement. Although Maoism wants to break with village social relations and bring about a new sociality beyond the distinctions of kin, it often remains entangled in the peasant networks and relations that define the countryside and control the territory, producing what Michael Hoffman, in his study of such dynamics in areas of Maoist insurgency in Nepal, calls "partial revolution" (2018).

A similar tension is shown in Alice Wilson's ethnography of Saharawi political life (Wilson 2016). Wilson demonstrates how despite the attempts of the Saharawi Arab Democratic Republic (SADR) to repeatedly displace the tribes and introduce legal and administrative structures supposedly conducive to the consolidation of state sovereignty, the Saharawi experienced a process of retribalization in dynamics of conflict resolution, at times projecting tribal relations as strategic resources in the construction of a revolutionary state power against the Moroccan invasion. As Wilson argues, through the lubricated networks of the tribes, their practices of control of the territory as well as their prelegal dynamics and popular courts, the supposedly fragmentary Saharawi tribes had been able to crystallize a communal revolutionary ethos that prioritized a set of collective interests over factional and divisive intertribal relations. In other words, dynamic, flexible, and less structured forms of political administration as well as a tribal political culture, Wilson suggests, may constitute effective tools motivating individuals and facilitating their participation in revolutionary protests and the fight against an authoritarian regime (see also Caton et al. 2014 on Yemen).

Most of the analyses of revolution have tended to conceal the role of lineage, kinship, and tribe in order to focus on emerging new forms of sociality according to the narratives of salvation, redemption, and emancipation through which 
these events are recounted. In this chapter we not only try to explain the role of local kinship forms and ideas to re-signify revolution according to their logics and forms, but also to signal specific forms of radical political transformation where kinship, tribe, and lineage are not annihilated but on the contrary appear as sources and vehicles of specific revolutionary conceptions.

\section{LINEAGES OF REVOLUTION: THE CASE OF IRAN}

In the following sections, we will attempt to show cases of articulation of different groups and spaces according to nonstate principles, but fundamentally to highlight the role of local political structures such as clans, lineages, and tribes in outlining practices and conceptions of radical transformation derived from their own political logic. In other words, we look at revolution through the framework of tribes and lineages, but we also explore concepts/ideas of revolution developed from the political logics of local tribes and clans. With this objective in mind, we aim to rethink and reconfigure some of the mainstream narratives-liberal, socialist, anarchist-in the conceptualization of revolution and political transformation.

Drawing on anthropological scholarship, in this section we show how the Iranian revolution has been interpreted and reconceptualized through the lens of local political frameworks and rationales that challenge the conventional narratives through which it has been explained. Definitely not as popular among global activists as the Zapatista movement, in that it did not flirt with the modernist tenets of global revolutionary transformation (see Foucault's analysis presented in the next chapter), the main point of contention among leftist and progressive intellectuals around the world was that the Iranian revolution, despite bringing to an end the authoritarian rule of the Shah, also created an Islamic republic based on the principle of velayat-e faqih, the Guardianship of Islamic Jurists. Instead of attempting to free society from all forms of ideology and its apparatuses of domination, since its inception the explicit objective of the Iranian revolution was the creation of a Shía state based on its religious ideology.

In 1953, a British-American-supported coup aimed at the defense of the interests of the Anglo-Iranian Oil Company (later renamed British Petroleum Company) ousted the nationalist prime minister Mossadegh, who was willing to nationalize oil, and reinstated the monarchy of the Shah. Under the auspices of the American government, the Shah proposed modernization and liberalization reforms, disregarding the religious and democratic measures of the Constitution. The reaction of local clerics and of the guilds of shop owners (bazaaris) financing religious celebrations, together with groups of students and Marxist organizations, consolidated a political force and solid opposition to the Shah. Ayatollah Ruhollah Khomeini, the spiritual leader of the resistance, was exiled to 
France from where an active exchange of cassettes and recordings of his sermons steadily fed the resistance. Khomeini returned to Iran acclaimed and received by millions of Iranians. After a brief battle with the forces of the Shah, Iran voted by national referendum to become an Islamic republic and approved a new theocratic-republican constitution whereby Khomeini became the spiritual leader.

Instead of focusing on Islamic principles and notions concerning the new Shi'a state, Mary Elaine Hegland (2014), one of very few foreign anthropologists to have conducted sustained ethnographic fieldwork in Iran across the last four decades, describes how the Iranian revolution of 1979 is conceived among the peasant villagers of Aliabad, a rural area in Fars province in the southwest of the country. Far from framing the revolution in terms of the emergence of a new and universal order, Hegland explains how the political participation of rural villagers in the revolution, their organization, and their political strategies are framed in terms of logics of kinship, descent, and local power disputes. In fact, Hegland explains how the struggle between the Shah and Khomeini is understood and enacted in rural Iran through the framework of the taifeh-keshi, a local understanding of conflict over power and resources among different interest/ descent groups that is transposed from the local to the national scenario. If revolution has been conceived as an event incommensurable with previous forms of organization, Hegland shows how the rules of taifeh-keshi remained not only the sociopolitical principles structuring everyday life but also the framework to comprehend the Iranian revolution and the struggle between the Shah and the revolutionary forces.

The taifeh is a model of political organization that relies on common interests and shared identities, often associated with kinship ties and maintained through forms of help and support to other members of the taifeh. A taifeh can be a kin, but also the clergy or the police. The taifeh-keshi is the process by which the taifeh comes together to take action in a political conflict. The taifeh-keshi is the cultural paradigm and a means that has been regulating political transformations in rural areas for centuries.

In fact, political life in the village revolves around the taifeh-keshi. In every village there is a kin line (taifeh) which, through a system of alliances and due to its ability to maintain political equilibrium, solves conflicts, contributes to wellbeing, and is recognized as the leader of the village. However, the taifeh leadership can be challenged and changed in different circumstances. Hegland describes the pattern of transformation of political leadership in Aliabad in four stages: (1) a kin leader of the village begins to gain wealth and status, mobilizes followers, and creates alliances through marriage, pulling in support; (2) a series of clashes take place between the ascending and the incumbent leaders of the village; (3) the incumbent headman performs an outrageous act seen as detrimental to the political equilibrium and well-being of the village that brings an all-out attack 
and reverts affiliations from the incumbent to the ascending leader; and (4) a final confrontation of forces or struggle takes place where the incumbent is possibly ousted and the unity of the village is re-created under the new leader.

The sequence of events described above has constituted a mechanism of political regulation whereby power and leadership could be repeatedly reconfigured in case of authoritarian acts by the incumbent leader through the intervention and alliance of the other taifehs composing the village. During the years of the Shah, the leading taifeh from Aliabad, the Seyyid, established a bond with the Shah gendarmes interested in enforcing their rule in rural areas. This new alliance ended up impeding Aliabadies from directly intervening in local politics according to the traditional patterns of taifeh alliances that historically had proved able to curtail the authority of the leader and to limit the powers of the kin line, as the Seyyid were now supported by and allied with external forces such as the Shah/ gendarmes. The power of the Seyyid had become unchallengeable.

Politics was no longer conducted at a local level and had instead become a national matter. In the meantime, the youngsters of Aliabad had started studying at the university in Shiraz and local workers commuted to the city by bus. This ended up expanding their networks toward the national level as they associated themselves mostly with supporters of Khomeini and the revolution in opposition to the Shah/gendarmes and the Seyyid family. So while the taifeh of the leader had been forging alliances with external forces such as the gendarmes and the Shah, the other taifeh(s) in Aliabad had become increasingly connected with the revolutionary forces of Khomeini in the region. This expansion of the radius of political operation of the Aliabadies came to reproduce the taifeh-keshi pattern.

The incumbent leader's family (the Seyyid) of Aliabad commits an outrageous act by knifing a local youngster studying in Shiraz and supporting Khomeini. This exercise of excessive force by the leader leads the whole kin and relatives of the youngster's taifeh to mobilize (this time not only locally but also nationally). Villagers are outraged, affiliations are reverted, and a confrontation/war begins, coinciding with the outbreak of the revolution. The taifeh-keshi overlaps with revolution. Once again revolutionary politics is enacted through networking (taifeh-keshi), exchange, and social interactions by maintaining, curtailing, and putting on hold taifeh ties. This is a type of taifeh that has now, however, expanded in scope.

The political conflicts between the Shah and Khomeini and the subsequent transformation are interpreted as the transposition of the taifeh-keshi paradigm from the local to the national level. Instead of Shía symbols and ideologies, or a new model of state government based on the Islamic principle of the Guidance of the Jurist, what motivated villagers' "revolutionary" activities was the kinship culture of taifeh-keshi that produced the local struggle according to strategies and political practices historically anchored locally. The newly emergent set of 
people - the winning taifeh - would then take over political power and everybody would unite under the new leader who has developed forms of affiliation with Ayatollah Khomeini. In other words, despite transposing kinship to a national level, radical political transformation not only is being interpreted but also framed according to the political patterns of kinship outlining an unexpected correspondence and identification between revolution and the paradigm of taifeh-keshi.

\section{STATELESSNESS AND REVOLUTION: UNIVERSALIST PROJECTS AND LOCAL PARTICULARITIES \\ IN THE CASE OF LIBYA}

While in the previous section we explored the understanding of the Iranian Revolution through the kinship framework of taifeh and showed how local notions of kinship may still remain instrumental in the conceptualization of revolutionary transformations, in this section we will look at the central role of tribal mechanisms and conceptions in the definition of Libyan notions of state and of revolution. In fact, with specific reference to the Libyan revolution of 1969, we will explore the possibility and the concept of a "stateless revolution" based on tribal forms of political organization.

Following the Libyan revolution of 2011, scholars and journalists (Lacher 2013; Friedman 2011; Barber 2011) began attributing the failure of the revolution to the lack of national unity and to the lack of understanding of the state by supposedly sectarian tribal herders that weakened the sense of national identity. This stance reproduced both the antithetical relationship between state and nonstate societies we have described earlier, and the notion that the accomplishment of a revolutionary project always requires the state.

In Libya, tribalism does not necessarily constitute a divisive phenomenon limiting national identity (Cherstich 2011, 2014a); on the contrary, it has been instrumental in the constitution of the nation (Evans-Pritchard 1949). During Turkish-Ottoman rule, the dysfunctional policies of the Turkish administration, leading to a high degree of social inequality, drove the tribes to fight against the Ottomans, coalescing by means of intertribal alliances (saff) in order to confront an external threat (Evans-Pritchard 1949). Something similar happened when the Italians occupied Libya at the beginning of the twentieth century and different tribes allied to fight against them, particularly in Eastern Libya (Evans-Pritchard 1949). The same groups that analysts today describe as divisive, always fighting each other, actually unified to create a nation, a Libya free from the invading forces. Indeed, it is fair to say that Libya as a nation, with its current geographical borders, is the result of this tribal anticolonial struggle (Cherstich 2014a; EvansPritchard 1949). In other words, from an historical point of view, in Libya it is the tribes that created the nation. 
Evans-Pritchard-probably our most remote ancestor in the construction of an anthropology of revolution-describes this phenomenon in detail. In particular, he documents a rather counterintuitive overlap in Libya between the Sanusi Muslim fraternity, founded by an illustrious Sufi mystic and scholar of Islamic law and theology, and the nomadic Bedouin tribes in the area of Cyrenaica (Eastern Libya). The decision of the fraternity to operate mostly with rural tribes in marginal areas, providing services to the tribes such as conflict resolution, education, and religious services in exchange for tithes, rent of land, and agricultural/animal products, ended up structuring a theocratic system of fraternity lodges scattered throughout the territory, each corresponding to a tribe or a section of a tribe. This scattered system of lodges reflected the structure of nomadic Bedouin tribes that maintained links with multiple actors and territories, from merchants to colonial officials, providing constantly updated information about what was happening outside of Cyrenaica.

Run by sheiks of the Sanusi order, the lodges accomplished a political and religious function, and they were recognized by tribes as their own lodges and fraternities while simultaneously being articulated to the religious/political center of the Sanusiya in the town of Jaghbub where the Gran Sanusi leader resided. Each lodge was a cult center, but it also was part of a general cult directed through the lodges to the leader of the order, the Gran Sanusi, who in exchange granted his baraka (blessing) to the specific tribe or subsection of a tribe. The lodges, often located in oases and remote areas, also functioned as schools, caravanserais, social centers, law courts, banks, storehouses, poorhouses, and burial grounds.

Even though scholars have problematized some aspects of the analysis of Evans-Pritchard (Ziadeh 1958; Peters 1990), it is fair to say that the Sanusiya with its multiple roles-economic, religious, political-was superimposed upon the tribal system, and it was able, at least to some degree, to unite the different tribes despite their enmities and conflicts, based on a common way of life and a common lineage structure. What ended up maintaining the unity of these structures was a common aspiration to create the conditions for Muslim people to live under their own law, tradition, and government as well as a common hostility to external interferences. The Sanusiya/tribes turned into a proper political force founded on a particular religious-political ethos, able to wage war on foreign invaders and challenge the colonial order but also to materialize a novel form of political organization not necessarily molded to the conventional structure of the state while defying linear narratives of political transformation.

In Libya, tribes have mainly made their living through sheep farming, and their tribal rules have been instrumental in regulating the use of water resources and pastures but also in terms of conflict resolution over access to land and intertribal marriages. Cherstich (2014a: 415) describes how many tribes have a system 
in which each member makes a donation to a common fund on a monthly basis. Such payments constitute a kind of "tax" to create a tribal "social security" fund used to contribute toward the funeral costs of underprivileged members, help those members who have lost their jobs, and / or provide some kind of financial help over a period of time. This role of the tribes in the provision of instrumental, basic services as well as the organization of large territories and resources has positioned them as legitimate sociopolitical actors making up for the failings of the state.

Cherstich (2014a) is adamant in affirming and explaining that these practices of social, political, and juridical intervention by the tribes in everyday matters are not a consequence of their lack of recognition of the legitimacy of the state or of a tribal sovereignty that overrules the state. On the contrary, the intervention of the tribes appears to be a consequence of the inability of the state to operate effectively in certain everyday matters. Somehow, the role, presence, and visibility of the tribe shrink at times when a more solid state is able to accomplish its most basic functions and amplify when the weakness and ineffectiveness of the state becomes palpable and problems, services, and conflicts have to be sorted out the tribal way. In this sense, Cherstich poses tribalism as a system that is not necessarily antithetical to national identity and official state institutions but actually complementary and conducive to them. In such a context, could the tribe or the system of allied tribes provide a platform for the materialization of a specific type of tribal revolution?

With the 1969 revolution, Gaddafi took an ambivalent stance toward tribes. Upon the abolition of the Sanusi monarchy and the affirmation of the revolutionary government of the Free Officers, Gaddafi instituted the so-called Jamahiriya, a type of stateless state. The Jamahiriya system, or "State of the Masses," was an Islamic/Socialist system of popular assemblies that was thought to work without the state, replacing ministries, congress, and representative forms of political decision-making with a set of popular assemblies.

Based on Gaddafi's idea described in the Green Book, the concept of statelessness remained grounded in the conception of political representation as nontransparent and the promotion of "natural" political forms based on the structures and forms of the tribe, kinship ties, and alliances driving practices of direct democracy and participation in everyday politics as opposed to the political specialists and delegates of representative democracies. In other words, the idea of the Jamahiriya, on the one hand, attempts to undermine those universalistic but supposedly artificial and nontransparent political forms such as the party, the ministries, and the government, offering instead the possibility to think about revolution without the intermediate step of the state. On the other hand, the Jamahiriya is presented by Gaddafi himself as another 
type of universalist project, namely the Third Universal Theory of the state-after the capitalist and the communist-which ought to be exported to other countries.

Although the idea of statelessness was instrumentally used by Gaddafi to lead the country according to his will, the concept in itself was highly appealing to Libyans (Davis 1986) - at least in the early years of the revolution. As argued by anthropologist John Davis, the concept of the stateless state is rooted in a form of ideal tribal government from the past, generally referred to by the term alhukuma al 'arabiya-a phrase that can be translated as "Arab government," "people's government," or, better yet, "no government"-an ancestral form of self-rule that predated the creation of nation-states and that plays a fundamental role in the Libyan political imaginary (Davis 1986: 61). If statelessness for people who live in states connotes displacement, Davis (1986) shows how in the case of Libyan tribes, for people who live without conventional forms of government, social order and peace depend on all members of the society knowing well their place in the local political forms. People's sense of status or placement can create a sense of interdependence and solidarity among those tribal members who owe personal loyalty to each other, and Libyans, as argued by Davis, contrasted it with the impersonality of states. Davis describes how Libyans have an image of stateless autonomy in which loyalties are unmistakable and unavoidable. But also such a notion of statelessness remains founded on the tribes' articulation, violent resistance, and revolt against colonial powers. In fact, as we have seen, their territorial control, their alliances, and modalities of occupation of the territory were instrumental in creating a local modality of political administration, operation of justice, and trade.

Gaddafi's ambivalence toward the Libyan tribal system is crystallized in his successive outlawing of tribes that came to be seen as a cause of division and an obstacle to national identity - even though the tribes created the nation (Cherstich 2014a: 409-10). In the nineties, however, Gaddafi appears to change his mind again. He starts praising the importance of tribal leaders - not the tribes-in his political addresses, encouraging the population to follow their decisions and sociopolitical modes of administration. Eventually, Gaddafi creates an assembly of tribal leaders called “The Popular Social Leadership." Gaddafi's praising of the tribal ethos in his speeches is often complemented by a description of the tribes as free peoples who live in tents in the desert and preserve the values and traditions of Libyan society.

On the one hand, from the point of view of official rule, the Jamahiriya is a single tribe that somehow solves the problem of fragmentation and division. On the other hand, after its inception, the Jamahiriya-state is perceived by Libyan tribes as just another tribe (Davis 1986) with which to negotiate, strike alliances, and wage war according to segmentary mechanisms. In this way, tribalism not only survives as a system of law that runs parallel to the state and solves problems 
locally but also incorporates in its own structure and form the notion and apparatuses of revolution as tools to expand, reproduce, and/or strengthen its own logic and system.

Bearing this in mind, it is interesting to note how the tribes played an active role in the revolution of 2011 that brought about the collapse of the Jamahiriya. Though based on the notion of statelessness, in practice Gaddafi's rule ended up generating a "heavy state" that monitored all aspects of the lives of Libyans, mainly through the constant presence of Gaddafi's secret service (Capasso and Cherstich 2014: 384; Capasso 2014). Tribal groups, together with other sections of Libyan society, fought to change this state of affairs. On the one hand, they helped to dethrone Gaddafi not because of an inherent aversion toward the state, but because the Jamahiriya had become a super-state whose tendency to interfere in private matters had to be contained. On the other hand-given that the 2011 revolution did not end up producing an alternative state that could replace the Jamahiriya due to unforeseen complications and foreign interventions - in the post-Gaddafi phase the tribes resumed their role as social agents who help to solve problems locally in the absence of the state (Cherstich 2014a: 418-20).

If, according to Marxism, revolutionary politics ought to be framed in terms of superseding ideologized forms of kinship reciprocity and dangerous tribal hierarchies supposed to reproduce the interests of the leading families, in the case of Libya what begins to be outlined is a typology of revolution as reproducing tribal political structures and mechanisms while rejecting modern colonial notions of political order. What seems at stake in the case of Libya are a set of tribal mechanisms that intervene in everyday life to address the shortcomingsand weaknesses - of official institutions but that also activate a series of tribal alliances and kinship ties in order to overturn an oppressive ruler or an external and communal enemy that is perceived as "just another tribe" centralizing excessive power. It is through these mechanisms and alliances that a tribal notion of revolution is outlined. As we further elaborate in the following section, this leads us to think of and place the revolution in counterintuitive locations other than the usual state-centered framework described earlier.

THE BLUE SHAWL AND THE MULTICOLORED FABRIC:

\section{STATE AND INDIGENOUS ORGANIZATIONS \\ IN THE BOLIVIAN PROCESO DE CAMBIO}

The Bolivian proceso de cambio received unexpected attention from mainstream media and it has mostly been represented by both scholars and journalists through the narrative of the integration of the historically excluded indigenous majority into the nation (Postero 2017; Goodale and Postero 2013; Regalsky 2010; 
García et al. 2014; Soruco et al. 2014; Svampa and Stefanoni 2007; Canessa 2012; Zegada et al. 2011). In general the state, its economic and social policies, and its leadership have been positioned at the center of the analysis of Bolivian revolutionary transformations. While in the previous section we have explored notions of nation anchored in segmentary systems as well as ideas and practices of revolution crystallized by the mechanisms and notions of tribal political organizations, what we outline in this section is a series of political loci, strategies, and spaces of popular sovereignty challenging the notion and role of the state and the party as the centralizing and leading agents of revolutionary transformations.

During the upheavals that marked the beginning of the proceso de cambio, political observers were faced with rather unusual dynamics. The leaders of local unions and neighborhoods committees accustomed to negotiating with official institutions and party vanguards were pushed aside and replaced in political and military decision-making by hundreds of articulated popular assemblies and associations (Mamani 2010; Zibechi 2006). Grouping together a few families, these assemblies were involved in the daily local administration of popular markets, the issuing of sales licenses, and the control, safety, and security of marginal neighborhoods, replacing the state in the exercise of its most basic day-to-day functions and the provision of basic services.

The idea of a popular/indigenous political form made up of articulated but nonintegrated associations, each maintaining a degree of autonomy and political decision-making and spanning multiple territories, had long been an aspiration and practice of the indigenous sectors of Bolivia. Clearly differentiated from the idea of a political party, in the 1990s indigenous and popular sectors created the so-called "political instrument," a strategic political organization conceived as a "bird born of multiple eggs" (cf. Arguedas [1966] 2009), a "son / daughter" (García Yapur et al. 2014: 92) of the multiple articulated peasant and indigenous associations, with the intention to avoid both the delegation of authority to a specialist political elite and the consolidation of the vertical structure of a political party. Often perceived by external observers as lacking discipline and organization (Lazarte 1991), the political instrument's absence of secretariats (Anria 2009) and bureaucracy guaranteed forms of direct political access to a multiplicity of local organizations, often maintaining different political stances and aspirations without having to renounce their local political forms and logics and adopt those imposed by the supposedly universal rules of the official political system.

Both the popular assemblies as a system of articulated microgovernments (Mamani 2010; Zibechi 2006) playing a strategic role in El Alto's upheavals and the "political instrument" as a network of indigenous, peasant, and popular organizations begin to outline another type of sociopolitical space and logic of organization. Scholars (Arbona et al. 2016) have referred to this specific modality 
of organization in terms of a "fabric" of "interlaced" groups, articulated but not integrated, a set of differentiated and autonomous segments that are nevertheless thought to be complementary parts of a functioning political body (cf. Bastien 1985, see also García Yapur et al. 2014).

In their description of the Feria 16 de Julio in El Alto, the largest popular market in Bolivia and one of the most important of the region, Arbona et al. (2016) are impressed by the lack of a union committee or a governing body in charge of settling internal conflicts, dealing with formal institutions, or negotiating with external partners willing to invest in this booming commercial area. The Feria 16 de Julio functions by means of the articulation of hundreds of associations of popular traders, producers, and neighbors that have been expanding their radius of operation and reproducing their organizational forms and practices well beyond the urban boundaries. Within each association you find several "secretaries of relations" (secretarios de relaciones) who are in charge of weaving or consolidating relations both with the other associations constituting the Feria and with a number of external groups, from suppliers to institutional actors. This system constantly strives to avoid the concentration of power in one of the segments / associations; internal mechanisms are activated to split a segment in two if its growth and power begin to challenge the political equilibrium. This "fabric" of articulated segments avoids the delegation of power and sovereignty to a transcendent power holder and the exercise of forms of external authority. The fabric remains coterminous with the community, allowing each family to play an active role in the local decision-making processes while maintaining a constant rootedness in local realities. According to Arbona et al., the dynamics of the fabric not only enable them to overcome the hierarchical and sectorial structure of the party or union, with their narrative of increasing unification of salaried labor, but also to outline strategic modalities of decision-making, organization, and control of territory tangential to the conventional ones defined by the state.

If for some left-leaning intellectuals and politicians of the Morales administration the proceso de cambio could be identified with the consolidation of a stronger and more inclusive state capable of consolidating a firmer grip on the national economy and the territory, for the indigenous and popular sectors the radical transformation lays in the possibility of affirming and expanding a fabric of diverse and articulated segments. Such a fabric has always been there, often camouflaged beneath semblances of more familiar political formations, from the trade union to the cooperative (García Linera 2008). However, its symbolic emergence, its capacity to articulate groups across territories, has brought to the forefront a counterintuitive political terrain molded on the segmentary principles of Andean political formations that have been able to reproduce themselves beyond the circumscribed and parochial territory traditionally assigned to kinship lineages and ethnic groups. While the state appears to be characterized by a centripetal force defining the political mechanisms and their articulation with the territory through 
a vertical structure of regional governments, provinces, and municipalities, the fabric outlines a tendency to penetrate a multiplicity of territories simultaneously and a capacity to generate processes of connection of different groups and spaces but no integration. While the state constitutes a transcendent structure representing the nation, the fabric remains coterminous with local organizations. If the canonical notion of revolution has connoted an emancipation from traditional and indigenous political forms, the proceso de cambio can be perceived from the point of view of Aymara indigenous and popular sectors as the transpositionand expansion (see chapter 6) - of a series of "own" political principles and logics toward the core field of politics.

Despite the rhetoric of the revolutionary government in Bolivia describing itself as a government of social movements, the political projects of the revolutionary state and those of the indigenous sectors have been slowly but clearly diverging (Postero 2017). The revolutionary state has been increasingly building its identity as a powerful and paternalistic figure that redistributes the substantial revenues from the exploitation of hydrocarbons to underprivileged indigenous communities while attempting to co-opt them into the proper political path. Scholars have highlighted the consolidation of a controlling and overarching state capable of bending social and indigenous movements to its will (Zegada et al. 2011) but also the emergence of unexpected dynamics of negotiation, articulation, and overlap between the state and local political formations (Soruco et al. 2014; Arbona et al. 2016). If in some cases state narratives and co-option attempts have been successful, indigenous popular sectors have been appropriating state revenues and policies to strengthen their own rules, political spaces, and decision-making capacities (Arbona et al. 2016). At the inception of Evo Morales's government in 2006, the member of an association of female fishmongers from an Aymara community on the shore of Lake Titicaca settled in El Alto commented:

Look, Evo is like the husband marrying us all, marrying Bolivia the day of the elections. He has got his task, we have got ours. He ought not to meddle with us, he ought not to tell us what to do. We have already learned what we have to do. $\mathrm{He}$ ought to be there making sure the foreigners and the qaras [white Bolivians] don't disturb. For all the rest, we are taking charge of it. (Gutierrez 2015: 40; our translation)

Although framed in terms of a marital relation, the relationship of the fishmongers with Evo/the state is not at all identifiable with a type of romantic, unconditional love. Marriage among Aymara popular sectors is never a romantic confluence of forces and destinies, but rather the tense and sometimes conflictive encounter of two autonomous and articulated elements. This process entails a reciprocal and gradual leveling of differences in order to create a state of equilibrium between the two and a horizontal relationship with no delegation of decision-making and constant leveling of excesses. 
From the point of view of indigenous and popular sectors, what "revolution" brings about is not only (or not so much) the conquest of the state-or the withering away of the state-but the emergence and crystallizing of a fabric of articulated but different groups, associations, and lineages with a degree of autonomy, another political terrain constantly attempting to appropriate and level the state, to limit its power, and its tendency to disregard or engulf the fabric. Such a fabric is not vertically and hierarchically connected to the state or inserted in the latter's political logic - as in the case of the relationship between the state and the trade union. "Revolution" not only brings about a "new," sovereign, and segmentary political structure but actually inserts the state into a new political horizon and segmentary logic where it is constantly "appropriated" and "leveled," as per the forms of operation of the segmentary system. In other words, revolution does not imply here the turning toward a "new" luminous political horizon embodied by the conquest of the state but rather the turning "back" toward the segmentary forms of Andean polities activating, potentiating, and expanding them not in order to integrate them into the state but to place them in a horizontal relation of force with it.

\section{CONCLUSION}

In this chapter, we have looked at what happens to the conventional notions of politics and the state when revolution is seen through the logics of kinship, tribalism, and lineage. We have also attempted to outline what kinds of surprises from the standard European notion of revolution we are faced with when thinking of revolution through segmentary logics and ideas. In the first place, we have attempted to locate a tension or identify differences between the notion of the state as a unitary, universal political institution and the fragmentary political notions of tribal / kinship / indigenous polities. On the one hand, the state presupposes the monopoly and concentration of power, legitimacy, and coercion exercised by bodies separated from society and specialized in the administration of justice, law, and education. On the other hand, in the examples drawn from Iran, Libya, and Bolivia we have experimented with notions of power as distributed and dispersed through the social body and coextensive with the community, where the universal and unitary notion of the state comes to be inserted in the fragmentary and particularistic local logics. These fragmentary logics of the state remain grounded in the articulation but not integration of multiple political structures and in the attempt to constantly curtail and level power to avoid an excess of concentration.

These ideas and divergences between state and nonstate are in direct correspondence with a notion of revolution that is conventionally interpreted as based on the overcoming of local particularities, the emergence of new social units, and the centralization and hierarchization of power in order to channel the old society 
toward a transcendent new political horizon disentangled from the immanence of present, quotidian life. In this chapter we have addressed processes and ideas of revolutionary transformation centered on the visibilization, recognition, and reproduction of local political forms or on the transposition of particularistic notions of the political from the local to the national level. While in the case of Libya we have foregrounded a kind of revolution (1969) attempting to do away with the state from the very beginning on the political basis of tribalism, in Bolivia we have outlined a revolutionary process connoted by a deepening of a fabric of associations and relations while avoiding freezing them into forms of transcendent domination (i.e., a state). In general, this has enabled us to showcase a set of revolutionary, political transformations as operating step by step, coterminously with society, without an ultimate political project or transcendent horizon defined a priori to aspire to. 


\title{
The Revolutionary Person
}

\author{
Penitence, Sacrifice, and the New Man
}

\begin{abstract}
Man will make it his purpose to master his own feelings, to raise his instincts to the heights of consciousness, to make them transparent, to extend the wires of his will into hidden recesses, and thereby to raise himself to a new plane, to create a higher social biologic type, or, if you please, a superman.

- LEON TROTSKY
\end{abstract}

This epigraph is taken from Literature and Revolution, Trotsky's famous account of how, in the classless society he thought the proletarian revolution in Russia would bring about, the arts would contribute to new forms of "self-government" in which "social construction and psycho-physical self-education will become two aspects of one and the same process" ([1924] 2005: 207). In this chapter we examine this idea-namely, that revolutionary transformations involve concerted and deliberate attempts to correlate changes at broader political and social levels (i.e., the kinds of transformations we explored in the previous chapter) with changes that go deep into the most intimate aspects of people's lives. In different ways and in different senses, we suggest, revolutions can be as much projects of radical personal transformation as they are projects for sociopolitical upheaval. Indeed, more than that, we shall see that one of the abiding characteristics of revolutions is that they connect those two scales, making political change a function of changes in people's personal comportment (and very much vice versa). The characteristics of revolution as a mode of collective political action, then, must be understood in the light of its qualities as a profoundly moral project that makes personal demands on people, operating in the most intimate ambits of their lives, indeed, in some cases, on their very souls. With revolution, as the old feminist adage had it, the personal is-deliberately, abidingly, and often in a marked and recognized way-political.

This is captured most emblematically by the programmatic way in which so many revolutionary movements and states have proclaimed as a prime goal the 
creation of, if not necessarily Trotsky's "superman," then certainly a "New Man." With deep roots in Enlightenment ideas about the malleability of human beings through education, the idea that revolutions must transform the very fabric-both moral and physical — of the people whose lives they seek so radically to transform is one that appears again and again since the time of Robespierre, who himself, according to some accounts, conceived of the Revolution as a "school," in which "knowledge would always be augmented by morality" (Schama, cited in Cheng 2009: 11). Under the influence of Marx, the "great revolutions" of the twentieth century laid much store in casting off the yoke of oppression in order also to overcome the personal forms of "alienation" that exploitation produces. Revolutionary societies would produce "New Men," as Lenin's program would have it (e.g., Lenin [1902] 2008), not only through education of the masses, but also through the example set by the revolutionary vanguard embodied by the Party, as well as new techniques and technologies of labor, structural principles of economic and urban planning, and so on. Conceived as projects of total societal transformation, revolutions have characteristically set themselves the goal of producing new kinds of citizens-people who would take the goals of revolutionary transformation to heart, subsume themselves to its collective ends, self-sacrificially as well as selfcritically shedding selfish and material motives in favor of the moral incentives of altruism and the collective good. The good of the self, then, as the good of the revolution, and vice versa.

The deeply Christian sonorities of the concept of the New Man are as telling as they are paradoxical, considering the militantly anticlerical character of so many of the revolutions with which it has been associated. To be sure, we saw in chapter 1 the frequent connection between revolutions and ritual phenomena of various kinds, noting the significance of ideas and practices or personal transformation in such contexts (e.g., in Bloch's model of transcendent orders consuming the "inner vitality" of ritual participants and thus preparing them for revolutionary action, as in Lan's account of the Zimbabwean freedom fighters). Indeed, focusing on the demands revolutions place on people puts the relationship between revolution and religious phenomena center stage, since the latter so often constitute par excellence arenas for the conformation and transformation of people's personal comportment. Morality, altruism, asceticism, self-sacrifice, even piety and zealotry are all central to forms of life that are in different contexts considered "religious" (cf. Asad 1993), while, as we shall see in the detailed examples of this chapter, they are also deeply at stake in processes of revolutionary transformation. In that sense revolution is rather like religion, with both of them reaching deep into people's personal lives, though each with its own demands and with potentially very different-and of course sometimes radically antithetical-results. In some cases, revolutions come to replace in important respects the religious phenomena against which they are pitted, taking on in their stead the task of forming people 
in particular ways. To take a striking example, while systematically eradicating the influence of the Russian Orthodox Church, as we shall be seeing, the Bolshevik revolution famously took on some of the most basic practices of Russian Orthodox devotion. For example, as will be discussed in more detail in chapter 6 , the images of Lenin and Stalin that proliferated in both public and domestic spaces after 1917 were positioned and treated in a manner similar to consecrated Orthodox icons. Conversely, as illustrated by the raging debates about the role of Islam in the revolutionary uprisings in the Middle East and North Africa region in the early 2010s, religion and revolution can often come together, or even merge, in the claims they make upon people. Being a good revolutionary may in certain contexts become an element or expression for being, say, a good Muslim.

In this chapter we use the link between revolution and religion as a heuristic device for exploring the ways in which revolutionary transformations operate on, and at, the scale of the person. To be clear: our aim is not to chart out the complexities of the relationship between revolution and religion for their own sake. This is a theme that we shall be encountering again and again throughout this book, as in this chapter, and which we shall be treating most explicitly in chapter 6 as part of a broader anthropological argument about the cosmological variability of revolutions, as well as their cosmogonic qualities. In the present chapter, however, we are interested in the relationship between revolution and religion for what it tells us about the way revolutions constitute people. The rationale for this is simple. If religious phenomena are preeminently about the formation of particular kinds of "subjects," as some of the recent literature refers to people in this context (see also Laidlaw et al. 2018), then the complex and varied ways in which revolutions relate with religious practices in different ethnographic settings can tell us a great deal about how the formation of persons is also at stake for revolutions. The contested correlations between revolution and religious practices in particular settings, in other words, brings revolutions' claims to and on processes of personal transformation to the surface, making them ethnographically visible and analytically legible.

Locating our anthropological approach in relation to the broader literature on revolutions, we note that questions about the formation and transformation of "revolutionary subjectivity" have received close attention by political theorists and philosophers in particular, often in ways that resonate with revolutionary protagonists' own concerns over how people capable of carrying the torch of revolutionary struggle are to be formed. Louis Althusser's influential "structuralMarxist" analysis of ideology (2001), for example, had at its heart the question of how such institutions as family, school, and church make deeply ideological conceptions about what people are and how they ought to behave seem natural. For Althusser, this happens through processes of "interpellation"-the manners in which these institutions turn concrete individuals into ideologically freighted 
"subjects" by "hailing" them, as when one might turn, for example, in response to a policeman calling out, "hey, you there!," and in doing so take for granted one's own subjection to his state-sanctioned authority. Revolution, for Althusser, could only be successful if it replaced these subject-forming "Ideological State Apparatuses," as he called them, with radically new ones, capable of sustaining a truly proletarian class consciousness-a task with which, as Althusser laments for the Soviet case, Lenin was deeply concerned but did not live long enough to carry out (2001: 91-92).

In later chapters we shall encounter other ways in which philosophers of revolution have dealt with the question of "the subject." In more recent debates in the European radical Left, as we shall see, Alain Badiou has suggested that events, including revolutions above all (see also chapter 1 ), are able to constitute the very subjects who show "fidelity" toward them (Badiou 2001) — an idea that Badiou sources back, tellingly, to the narrative of St. Paul's conversion (2003; see also Robbins 2010). Rather than reviewing this whole body of literature, however, for the purposes of this chapter we shall limit ourselves to examining the thinker who has had the strongest influence on anthropologists' writings in this fieldnamely, Michel Foucault. Foucault's influence on anthropologists' thinking about how people are constituted in different ethnographic contexts-how particular political, economic, or other institutional practices and arrangements have different "subject effects," as the Foucauldian terminology has it-goes well beyond the study of revolution. Running in some ways parallel to Althusser's argument about ideological interpellation (see also Montag 1995), Foucault's basic concern with the constitution of subjects as a contingent historical process has been taken up eagerly by anthropology, melded with the discipline's long-standing interest in localized ideas of "personhood" and the practices in which they emerge. What is so interesting about Foucault's engagement with revolutionary subjectivity in particular, however, is that it marks a shift in his own thinking about how subjects are "effected." While in his "early" works the constitution of subjects is seen as primarily an effect of different arrangements of power (as seen in such classic studies as Madness and Civilization [1988c], on confinement in mental institutions, and Discipline and Punish [1995], on prisons and surveillance), in his "late" period subjects are constituted through ethical practices of self-care, which, in his famous lectures at the College de France at the turn of the 1980s, Foucault called "technologies of the self" (1988b).

That this idea of self-formation should resonate so strongly with revolutionary practices is no accident. For, as we shall see, this shift in Foucault's thinking coincided with his much-discussed sojourn in Iran, where he witnessed firsthand the revolution that brought Ayatollah Khomeini to power in 1979. The peculiar blend of the revolution's political aims with Shi'a forms of religious asceticism, which so fascinated Foucault, brings to the surface precisely the kinds of questions of 
revolutionary self-formation we focus on in this chapter. Starting with Foucault's account of them, therefore, allows us to place our anthropological approach to revolutionary personhood in the context of the broader questions of self-formation raised by Foucault's work. But it also provides an opportunity to explore ways in which the comparative perspective of anthropology can forge alternatives to Foucauldian analyses, which, as others have also remarked (cf. Boyer 2003; Stedman Jones 1996), sometimes tend to take the oxygen out of debate, albeit owing, no doubt, to the brilliance of Foucault's insights.

\section{FOUCAULT IN THE IRANIAN REVOLUTION}

Foucault's writings on the Iranian Revolution, and particularly those he wrote in 1978 in Tehran as a self-styled "philosophical correspondent" for the Italian daily Corriere della Sera, have been nothing if not controversial. Foucault's exuberant enthusiasm about the "political spirituality" of a revolutionary uprising that, as we saw in the previous chapter, conjoined leftist, anticolonial impulses with Shía spirituality and ritual in a manner that to him seemed entirely original, was met with suspicion in Europe and, as the revolutionary "Islamic Republic" soon descended into dark years of terror, with real opprobrium (see also Carrette 2000). A whole furor erupted at that time about whether Foucault, in his apparent endorsement of the events unfolding in Iran, had acted as an apologist for what turned out to be an abhorrently brutal machinery of power, with tendencies toward "archaic fascism," as one critic of Foucault put it at the time (Rodinson 1981: 233). More recently, in a highly charged critique of Foucault's Iran-inspired oeuvre, Janet Afary and Kevin Anderson (2005) have posed what they see as Foucault's relativist validation of Khomeini as an example of a broader failure by the European Left to subject the rise of Islamism to rigorous critique-an intellectual appeasement that, according to Afary and Anderson, opened the way for "postmodern" intellectuals' indulgent reactions to $9 / 11$ and its aftermath.

In a landmark study of Foucault's writings on Iran, framed as a response to Afary and Anderson's attack, Iranian sociologist Behrooz Ghamari-Tabrizi (2016) argues forcefully that these critiques not only get Foucault wrong but also misrepresent the Iranian Revolution (in which Ghamari-Tabrizi himself participated as a militant Marxist-Leninist student at the time). Foucault's enthusiasm for what was happening in Iran in the late 1970s, argues Ghamari-Tabrizi, was not born of a romantic fascination with premodern alternatives to Western liberal modernity, as Afary and Anderson suggest, nor was it part of an argument from or for moral relativism. Rather, in the momentous manner in which the Iranian Revolution put Shi'a conceptions and practices at the heart of the uprising against the Shah and his Western backers, Foucault saw an attempt to redefine the very conception of revolution and its transformative potentials. Seen against the background of the 
post-1968 disillusionment of the European Left with revolutionary politics, argues Ghamari-Tabrizi, Foucault's Iran-inspired writings sought above all to explore alternatives to linear, developmentalist conceptions of History (including the Marxist), which posits revolution as a teleological project "firmly rooted in a past orientation and a future projection" (Ghamari-Tabrizi 2016: 59). Instead, in Iran Foucault saw the possibility of revolution understood as "a moment when historical subjects refuse to subject themselves to History" (59). Foucault puts the point forcefully in his final piece on Iran, published in May 1979 in Le Monde, partly in response to commentators who ridiculed his support for a revolution aimed at establishing an Islamic state:

Uprisings belong to history, but in a certain way, they escape it. The movement through which a lone man, a group, a minority, or an entire people say, "I will no longer obey," and are willing to risk their lives in the face of a power that they believe to be unjust, seems to me to be irreducible. (Foucault, quoted in Ghamari-Tabrizi 2016: 70)

Central to Foucault's conception of the Iranian Revolution as a nonteleological, essentially irreducible phenomenon is the role he saw Shi' ism play within it, and it is in this connection that the question of personal transformation arises so importantly for him. The political spirituality that Foucault saw on the streets of Tehran involved infusing the political aim of overthrowing the Shah with the ascetic ethics of martyrdom and penitence that lie at the heart of Shi'ism. Indeed, among the most striking features of the Iranian revolution was its overtly Shi'ite symbolism and practice-public self-flagellation, demonstrations of men and women wearing black shirts and veils, displaying photos of dead "martyrs," and so on. While for many commentators this was all evidence of a frighteningly conservative traditionalism at the heart of Khomeini's movement, for Foucault they bespoke a more open horizon of revolutionary transformation. Crucially this opening was at base a matter of personal transformation-a concern Foucault saw at the heart of Shi'a rituals of penitence and martyrdom. His explanation of this point, given to the Iran correspondents of Libération in March 1979, merits long quotation:

In rising up, the Iranians said to themselves-and perhaps this is the soul of the uprising: "Of course, we have to change this regime and get rid of this man, we have to change the corrupt administration, we have to change the whole country, the political organization, the economic system, the foreign policy. But, above all, we have to change ourselves. Our way of being, our relationship with others, with things, with eternity, with God, etc., must be completely changed, and there will only be a true revolution if this radical change in our experience takes place." I believe that it is here that Islam played a role. It may be that one or other of its obligations, one or other of its codes exerted a certain fascination. But, above all, in relation to the way of life that was theirs, religion for them was like a promise and guarantee of finding something that would radically change their subjectivity. Shi'ism is precisely a form 
of Islam that, with its teaching and esoteric content, distinguished between what is mere external obedience to the code and what is the profound spiritual life; when I say they were looking to Islam for a change in their subjectivity, this is quite compatible with the fact that traditional Islamic practice was already there and already gave them their identity; in this way they had of living the Islamic religion as a revolutionary force, there was something other than the desire to obey the law more faithfully, there was the desire to renew their existence by going back to a spiritual experience that they thought they could find with Shi'ite Islam. (Foucault, quoted in GhamariTabrizi 2016: 65-66)

This ear-on-the-ground commentary on Iran, in its rudiments, is a statement of the essence of Foucault's "late" argument about "technologies of the self." Subjects are not only constituted by the arrangements of power that conduct their conduct (this being the core idea of "early" Foucault), but also through the "care" that they are able to direct at and for themselves in ways that have the potential to "radically change their subjectivity," as Foucault puts it in the above quote on Iran. Indeed, one of Ghamari-Tabrizi's central concerns is to show how Foucault's interest in the correlation of political and personal transformation in the Iranian Revolution marked the turning point in his broader thinking about subjectivity and power, setting in motion the analysis of the self and its care that he developed, famously, in relation to ancient Greek and early Christian forms of ascesis (Foucault 1986). For our purposes here, we focus more narrowly on what is in many ways an anthropological tenor in Foucault's writings on Iran, and what this may contribute to an anthropological understanding of revolutionary personhood.

To be sure, there is a basic confluence between Foucault's attempt to find in the Iranian Revolution an alternative to the scripted "progressivist" notions of revolution that he expected his European readers to take for granted, and our anthropological attempt in this book to multiply conceptions of revolution by attending to its different ethnographic manifestations. Indeed, his argument to an extent adopts the critical stance that is characteristic of anthropology. The contingency of the Iranian case is deployed as a vantage point from which to dislodge the certainties of "the age of revolutions," as he calls it, which for the past two centuries has constituted "a gigantic effort to acclimate uprisings within a rational and controllable history" (Foucault and Bernauer 1981: 5). Shi'ism is at the heart of this argument because it serves to relativize the standard image of revolution in two crucial ways, both of which have to do with the forms of personhood it cultivates.

The first relates to the association of the uprising with the public rituals of penitence with which Shi'ites commemorate the death of Hussain-the grandson of the prophet Muhammad who is central to Shi'a devotion-at the battle of Karbala. ${ }^{1}$ According to Foucault, the ethic of self-sacrificial martyrdom that these

1. The battle was fought in $680 \mathrm{CE}$ between the army of the second Ummayad Caliph Yazid I and a small army led by Hussain. In the Shía tradition Hussain is seen as a martyr who stood up against 
public reenactments of the trauma of Hussain's death at Karbala perform adds a deeper spiritual dimension to the overtly "political" aims of revolutionary violence (e.g., in the Iranian case, the deposition of the shah and takeover of the state machinery). While people's preparedness to die for the cause is necessary for the revolution to be effective, its expression as (re)enactment of Shi'a martyrdom turns this into an act of personal religious devotion (see also Ansari, forthcoming). The sacrifice, precisely, of the "self" takes to its very limit the religious injunction to "change ourselves," as Foucault had it, and renders it coterminous with the revolutionary struggle - a continuity of meaning that is encapsulated in all of its complexity in the Muslim notion of jihad (Heck 2004). Furthermore, secondly, the character of "spirituality" that Foucault finds in Shi'ism in particular allows him to posit the "irreducibility" of the revolution, as he sees it, as an essentially exploratory, open-ended act that defies the teleologies of History. Behind its adherence to religious codes and the identitarian politics that they furnish-though also, as we saw in the quote above, because of them-Shi' ism opens up a horizon of "existential renewal." And, once again, the correlation of the personal and the political that is achieved in the Shi'a conception of martyrdom renders the possibility of subjective change and the injunction to search for it a project of political exploration, too-a collective act of renewal that renders history "uncontrollable" and, in that irreducible sense for Foucault, revolutionary.

Yet there is also a basic sense in which Foucault's approach is significantly different from the anthropological tack our book develops, and this has to do with the strongly normative streak in his conception of the technologies of the self-a normativity that rubs off onto his conception of revolution, too. While, as Ghamari-Tabrizi argues against Foucault's critics, Foucault's account of what was happening on the streets of Tehran was certainly more thoughtful than just an endorsement of Khomeini and his politics, his effusiveness is nevertheless significant: for Foucault Iran provided an exemplar not just of what revolution "could" be, but of what it ought to be. Indeed, the desire to make an argument for a particular kind of revolution, in the context of what developed also into an argument for a particular kind of ethics in his subsequent work, is evident in the unabashedly motivated, even partial manner in which he treats the Shi'a dimension of the uprising he witnessed. While his philosophical point about the irreducibility of revolution to history is profound-and we shall return to this idea in later chapters-from an anthropological point of view, Foucault's appeal to Iran to make his point is problematic.

a tyrannical and unjust ruler. According to Hamid Dabashi $(1993,2011)$ the notion that injustice should be always fought against, as exemplified in the battle of Karbala, is at the heart of Shi'a Islam, so that Shi'ism is best understood as a religion of protest marked by inherently revolutionary tendencies. For an analysis of the role played by the battle of Karbala in contemporary Shi'a contexts, see Pinault 1999 and Deeb 2009. 
On the one hand, while, as we saw, Foucault points to the specificity of Shi' ism as a "form of Islam that ... distinguishe[s] between mere external obedience to the code and what is the profound spiritual life," he rather quickly presses his point about Iran to the service of a broader argument about the political spirituality of revolution. This glosses over a whole series of questions about the varying manifestations of political spirituality (if such they are) in different religious traditions (e.g., particular forms of Islam compared to each other, or to particular forms of Christianity) at different times and places and in different political circumstances. Considering the significance that Foucault's own genealogical method attaches to understanding practices as they are enacted in particular times and placesthe kind of attention to specificity that is amply evident in his genealogical presentation of ancient Greek and early Christian forms of ascesis in works that, as Ghamari-Tabrizi suggests, his experiences in Iran partly inspired-it is surprising that Shi'a concepts and practices of penitence and martyrdom should be treated in such a generic way. For example, what might the implications be of the differences, both ritual and theological, between, say, the Shi'ite rituals of penitence during the celebrations of Muharram and the early Christian tradition of exomologesis (which Foucault discusses in detail in subsequent writings-Foucault 1979), for the enactment of subjective transformation in different political circumstances? How, furthermore, might the distinction between "external obedience to the code" and a more inwardly transformative "spiritual life" be modulated by these differences, and what difference might this make for the potentials of political transformation in each case (see also Ghannam 2015)?

On the other hand, Foucault's desire to generalize from the Shi'a dimensions of the Iranian Revolution also tends to render his reading of the Iranian case itself rather selective. For example, alongside the emphasis on penitence and martyrdom, a more rounded analysis of the Shi'a dimensions of the Iranian Revolution would chart out the varied ways in which what Foucault calls the "obedience to the code" of religious dicta may have also played important roles. As anthropologist Roxanne Varzi (2006: 33-43) has shown, for instance, Khomeini's charismatic leadership, which allowed him to command such obedient devotion among his followers during and after the revolution, was constituted partly by the way he cultivated his status as an imam. In the Twelver tradition of Shi' ism that is the official religion of Iran, this term is reserved for the spiritual successors of the prophet Muhammed, who were assassinated one after the other by rival groups over the centuries, until $874 \mathrm{CE}$, when the Twelfth Imam went into occultation (ghayba), with a promise to return at the end of the world as the Mahdi (a redeemer who will bring justice and peace, as per Islamic eschatology). As Varzi shows, Khomeini's claim to having an unmediated connection to the divine was central to his role at the apex of the Islamic Republic after the revolution, and integral to the doctrine of Governance of the Jurist (velayat-e faqih), which he instituted as the prime 
principle of his theocratic government, as we also saw in the previous chapter. The image we are left with, then, is one that is rather more complex and contradictory than the one Foucault presented. Even as Shi'a esotericism may support the opening of subjective horizons Foucault celebrated, it also bolsters particular forms of leadership and political control that underpin the authoritarian character of the Islamic Republic Khomeini and his supporters instituted, which became so evident after Khomeini took power.

The enormous impulse that Foucault's late work on the self has given to anthropology at large since the 1990s - and not least to the anthropology of Islam (Asad 1993; Mahmood 2005; Hirschkind 2006) — can be understood partly as an attempt to add ethnographic depth and comparative rigor to his insights about the transformational potentials of the self. For example, stimulated by the Foucauldian agenda set for the anthropological study of Islam by Talal Asad in particular (1993, 2003), Saba Mahmood (2005) has offered a widely influential-and much debated (e.g., Marsden 2005; Schielke 2010; Elliot 2016) - account of the political potentials of women's piety movements in Cairo, seeing them as particular ways of configuring human agency and freedom in relation to God. While the study predates the Egyptian uprisings of 2011, it provides a penetrating analysis of the ethical underpinnings of radical mosque movements that formed part of the emergence and appeal of the Muslim Brotherhood. In particular, it shows how these movements sought to present an alternative not only to Western-style conceptions of a "liberal self" but also to some Sunni clerical discourses that framed the practice of Islam more in relation to national aspirations than as a matter of personal transformation. Alas, Mahmood, who died in 2018, was not able to trace the consequences of her analysis for an understanding of the revolutionary dynamics of Tahrir Square and its tumultuous political aftermath. We may note here, however, both resonances and contrasts between her ethically oriented argument and Amira Mittermaier's analysis (2014) of the relationship between the ethos of Tahrir Square and Sufi-inspired sociability of sharing in the khidma, discussed in chapter 1.

Perhaps the most systematic Foucauldian study of the constitution of revolutionary subjectivity, however, is provided in Oleg Kharchordin's magisterial account (1999) of the relationship between the collective and the individual in Soviet Russia. Framing his work as a counterpart to Foucault's archaeology of individuation in Western Europe, Kharkhordin unearths the genealogy of Bolshevik conceptions of the individual in the Russian Orthodox tradition, and particularly the public rituals of penitence that were much more central to its development than they were in Catholicism and the Reformation. ${ }^{2}$ Central to this

2. Caroline Humphrey offers an alternative account of the genealogical entwinement of religion and revolution in Russia based on a study (2014) of the excommunicated communities of Old Believers of Trans-Baikalia during the Soviet and post-Soviet periods. 
genealogy is the concept of oblichenie, translated as both "to accuse" and "to reveal the self." The concept goes back to the very beginning of the Russian Orthodox Church, and has its roots in exomologesis - the early Christian rites of public penance (the very rites that Foucault too, as we saw, connects back to in his account of Shi'a rites of martyrdom in Iran). Through the centuries, Kharkhordin shows, oblichenie denoted both practices through which the sins of the powerful and the heretics were exposed ("accusation") and rites of penitence through which a believer's own saintly self was revealed by rigorously rejecting sinful behavior ("self-revelation").

In the nineteenth century, however, at a time when its practice by the church had begun to wane, oblichenie occupied an increasingly central place in the discourse in the revolutionary movements that presaged the rise of Bolshevism, referring particularly to the revolutionaries' task of revealing the misdeeds and injustices of the Tsar and his government. By 1902, in What Is to Be Done?, Lenin himself adopts the term to describe the Bolsheviks' mass commitment to revealing injustices and other issues to be rectified by the revolution. Following the revolution of 1917 and the ensuing civil war, however, oblichenie begins to refer also to the acts of criticism and, importantly, self-criticism through which the faults of errant Party members and, later, ordinary citizens at large were exposed. In a way that bore striking resemblance to the workings of the ecclesiastical courts, Kharkhordin shows, the collective tribunals that were held not only by Party structures but also, as the 1920 s progressed, in all collective milieus of Soviet life (schools, offices, factories, etc.) turned most crucially on these acts of public selfexposure. And as the most chilling part of Kharkhordin's genealogy shows, by the 1930s oblichenie had become the central means through which the terror of Stalin's "purges" was conducted.

These modalities of public self-revelation are central to Kharkhordin's account of Soviet understandings of the "individual" (lichnost'). Just as, for Foucault, practices of penance were a prime arena of individuation in the history of Christianity, so the Bolsheviks' adaptation of such rites for revolutionary purposes contributed to the particular conceptions of the individual that developed in Soviet Russia. Kharkhordin makes the significance of this parallel clear:

The Russian Revolution may have effected a change similar to the Protestant Reformation, which also intensified an early Christian practice to reinvigorate the ailing religiosity. Luther made Augustine's solitary confession into the central practice of what became Protestant culture . . . . In doing so, he received credit for helping develop the individualism of Western culture. The Bolsheviks similarly radicalized those ecclesiastical practices that were available to them in their culture, based on Eastern Christianity and the centrality of public penance. Instead of using the aristocratic models of individualization copied from Western models of confessional practices and solitary self-reflection, they turned the Orthodox practice of oblichenie, nearly defunct in the official Russian Church, into the predominant mechanism 
of bearing witness to one's achievement of lay sainthood and "assurance of grace." The radical reformation of ecclesiastical practices in this case also yielded an individual, but of a specific kind. If the Western individual was born as a confessing animal, its Soviet counterpart came to be a penitent beast. (1999: 228)

This trajectory relates also to the particular inflection given in this context to the revolutionary conception of the New Soviet Man-the "superman" of our epigraph from Trotsky. First put forward as the ideal for revolutionary activists in Nikolai Chernyshevsky's bestselling novel of 1863, What Is to Be Done?, the idea that the revolution's success depended on changing "the very nature of man . . . to conform to the requirements of [the] new order" (Alt and Alt 1964: 23) was central to Lenin's own revolutionary manifesto of the same title, published in 1902 (2008). For Lenin this was above all a matter of cultivating among the workers a new kind of soznatelnost'-a word commonly translated as "consciousness," but which Kharkhordin argues is better translated as "Conscience", to reflect the ethical as well as spiritual dimensions of its usage (1999: 57-59). Fostering such a Conscience, not only among a select few New Men, but, on that model, among all Bolsheviks and ultimately all citizens, became a prime task of the revolution and the wholesale transformation of Russian society it sought to precipitate. The Ninth Party Conference of 1920, for example, proclaimed that the only legitimate grounds for differentiating between Party members would be "on the basis of the degree of their soznatelnost, dedication, endurance, political maturity, and readiness to sacrifice themselves" (cited in Kharkhordin 1999: 59-60) - the hallmarks, in other words, of the New Soviet Man. It was precisely the possession of these characteristics that, then, the public fora of Bolshevik oblichenie were designed to test-at first by revealing the deeds (revolutionary or otherwise) of the individual under scrutiny, following the pattern of the Orthodox rites, and then, with Stalin's rise to power, delving deeper and deeper into the hidden recesses of people's "selves" (sebia), passing judgment on their whole personality, and, at the height of the Great Terror of the late 1930s, rendering even their intentions potentially culpable (ibid., 180-81).

Tracing a line from religious rites of penitence not to "political spirituality" but to the horror of Stalin's purges, Kharkhordin's analysis demonstrates beautifully how the normative character of Foucault's approach to revolutionary transformation can indeed be sidestepped, deploying Foucault's core insights on the subjective effects of self-care to provide nuanced accounts of the ambiguities of real-life revolutionary situations. Still, there may also be something limiting about framing the question of revolutionary personhood in Foucauldian terms alone. The framework-indeed the language-that Foucault's body of work provides has become so dominant in the anthropology of political subjectivity in recent decades that it can end up being somewhat domineering, acting a little like a technology of the (anthropological) self in its own right. Productive as it can be, the core image of "individuals [effecting] by their own means or with the help of 
others a certain number of operations on their own bodies and souls, thoughts, conduct and way of being, so as to transform themselves in order to attain a certain state of happiness, purity, wisdom, perfection, or immortality" (Foucault 1988b: 18), as Foucault's famous definition would have it, can seem unduly narrow to anthropologists accustomed to thinking of the constitution of the person in terms of a much more varied set of social contexts-including, most classically, entirely mundane activities related to kinship (e.g., Carsten 1997), say, or exchange (Mauss 1990; Strathern 1988). Certainly, to develop a comparative framework for thinking about revolutionary personhood, one must be able also to think beyond the ascetic forms of spirituality that Foucault's genealogy traces back to Greece and early Christianity.

Our proposal in this regard is, if you like, to "demote" Foucault's framework, as but one possible realization of what we shall call the "anthropologies of revolution." Here we mean the term "anthropologies" not as a tag for the disciplinary approach this book seeks to promote, but rather, to help make that argument, drawing on the term's theological meaning: anthropology as the study of humans in relation to God and the providential universe of divine creation (e.g., see Cortez and Jensen 2017). For purposes of the study of revolutionary personhood, of course, this theological understanding of anthropology can only be metaphorical. Yet the analogy on which the metaphor relies is not loose and, in view of our foregoing comments on the relationship between revolution and religion, can also be revealing. Theological anthropology asks questions about how to conceive of the relationship between humans and a transcendent God who created them, as well as the world in which they live, including the demands that this relationship places on people's personal comportment "in God." In a move reminiscent of relevant debates in "political theology" (e.g., Scott and Cavanaugh 2008), we seek basically to adopt this set of questions by replacing "God" with "revolution." Whether they are understood as events, projects, or values and ideals, revolutions too can be conceived as transcendent (in whatever sense) in relation to the people they involve. Moreover, as we shall be showing more and more concertedly in chapters to come, they characteristically have a godlike capacity, if not to create a world ex nihilo, then certainly to change drastically the coordinates of the worlds that people inhabit-this being what, in the Conclusion, we shall call the "cosmogonic" character of revolution. But before we get to that, we are already well underway to seeing how revolutions make demands on people-again, like a divine entity might do-placing limits on and opening new prospects for their personal comportment as subjects. So, the different ways in which the relationship between revolutions and the people they involve is constituted and shaped, how this refigures ways in which people see themselves and their relations to other people as well as to the processes and institutions of the revolutionary project, and what forms of personal transformation this may precipitate in different 
contexts-these are the kinds of questions our focus on "revolutionary anthropologies" asks.

Foucauldian questions about technologies of the self, with their accompanying discussions about agency and freedom as well as piety and spirituality (Laidlaw 2014), certainly form part of such an "anthropological" framework. Foucault himself seems to indicate as much when, in the passage cited above, he imagines Iranians verbalizing their revolutionary fervor as a matter of completely changing "our way of being, our relationship with others, with things, with eternity, with God, etc." - that is as good a list of "anthropological" questions as any, albeit cast in the key of Shi'a self-care. Taking this broader approach, in fact, would allow us to include in the study of revolutionary personhood questions that arise also from the topics we have already broached up to this point in this book. Varying kinds of ritual, as mentioned already, both presuppose and precipitate different forms of personhood. For example, one could contrast the Shi'a asceticism that was Foucault's focus with the rituals of spirit possession Lan describes in his study of Zimbabwe, to explore how this contrast plays out in the constitution of revolutionary subjectivity in each case. In view of the long-standing social anthropological contention that people are constituted according to their position with different kinship formations and other local structures of social organization (e.g., Fortes 1983), one could similarly explore the consequences for the question of personhood of many of the issues discussed in chapter 2. For example, how does the universalizing image of the revolutionary "citizen" that revolutions often promote articulate with ideals of personhood that take form in more localized and variegated social structures, including, for instance, gendered values of duty, honor, or courage. Indeed, gender is particularly important in this context, and much empirical work in this field has called into question the androcentric - indeed patriarchalassumptions that undergird not only the discourse of revolutionary protagonists themselves but also that of its analysts (Davis 1983; Molyneux 1985; Tétreault 1994; West 2000; Babb 2001; Härkönen 2016; Wilson 2016). ${ }^{3}$ How, if you like, are images of the New Man modified and modulated in relation to these more localized ideals of humanity, and should that not also be New Woman? - questions that could also be examined in relation to conceptions of leadership and charisma that will be the topic of our next chapter.

Rather than go over this ground here, for the remainder of this chapter we shall use two examples to illustrate some of the questions that arise from the study of revolutionary personhood. Adopting their relationship to religious practices and concepts as a heuristic prism, as suggested above, our aim is to chart in each case

3. A more thorough discussion of this point is offered by Alice Wilson in her entry for the Cambridge Encyclopedia of Anthropology, from which we have sourced some of the references adduced here (Wilson 2019). 
the coordinates that give different revolutionary "anthropologies" their shape in each context. We begin with a study of the formation of personhood in the Chinese Communist Revolution, focusing on Maoist conceptions in particular as a prime point of reference for the very idea that revolutions turn crucially on their capacity to produce "new people."

\section{MAO'S MODELS OF THE NEW MAN}

Looked at from the middle distance, the role given to the cultivation of revolutionary subjects in Mao Zedong's revolutionary China is strikingly similar to what we saw in relation to Kharkhordin's discussion of the Bolshevik revolution in Russia. All the same ingredients are there: the idea of a New Man, the emphasis on altruism and self-sacrifice, a battery of techniques of personal surveillance and control involving public criticisms and denunciations, together with demands for selfcriticism and other acute forms of self-revelation. Indeed, as Chinese-American historian Yinghong Cheng (2009) shows in a detailed discussion of the development of these practices in China (on which our account here is mainly based), Mao and the Marxist-Leninist Party structure he founded in the 1920 s in many ways modeled China's path to revolution on Russia's, while also diverging from it critically and sometimes pushing it in more radical directions. When it comes to the systematic and psychologically violent ways in which revolutionary personhood was molded after Mao's ascent to power in 1949-forms of "thought reform" that are often described in the literature as Orwellian (cf. Quo 1988)—comparison between China and Soviet Russia bears out Martin Malia's contention that "each revolution learns from the experience of its predecessor, and so escalates . . e each time to a more intense level of radicalism" (2006: 5).

This may appear surprising in light of Kharkhordin's genealogical argument about the specifically Russian Orthodox background of Soviet conceptions and practices of revolutionary personhood, and the same could be said of the prominence given in China to the very idea of a "New Man," with its strongly Pauline sonorities. To be sure, the question of how revolutionary practices are able to travel as self-purported "universals" and take root in diverse sociocultural environments, and how to think about this anthropologically, is one to which we shall be returning repeatedly in later chapters. Here, however, we dig a little deeper into the Chinese case to reveal some of the distinctive features of the Maoist approach to revolutionary transformations of the person, founded on the notion that a revolutionary reconstruction of Chinese society must involve, as Mao put it as early as 1917, "reforming philosophy, reforming ethics, and fundamentally changing people's thought" (cited in Cheng 2009: 52). In particular, we focus on two distinguishing features. First, the question of "permanent revolution" in Maoist China, which, according to Cheng, involved also a relentless intensification of techniques 
of "thought control." Second, the emphasis placed throughout this process on the emulation of exemplary figures who personified the (in some ways shifting) ideals of the New Man. Recalling Kharkhordin's analysis of the Russian Orthodox roots of Soviet practices of self-revelation, our emphasis here will be on certain underlying Confucian dimensions of these forms of revolutionary action in Mao's China.

Mao's conception of the need for the revolution to be pursued as a permanently ongoing project of transformation has been much discussed by historians and political scientists (e.g., Schram 1971; Starr 2015), not least in comparison to Trotsky's earlier writings on prospects for a "permanent revolution" (e.g., Dunayevskaya 2003: 128-87), with which Mao himself compared his own (Schram 1963). A point often made is that the particular socioeconomic circumstances the Chinese Revolution had to confront, and particularly the predominantly agrarian character of the country's vast population, made Mao's doctrine of permanent revolution historically necessary. As Cheng also reiterates, for Mao's revolutionary program to be effective it had to take the shape of successive waves of ever-deepening and drastic sociopolitical transformation: from the initial uprising and ensuing civil war, through the sweeping social reforms of the 1950s, to the disastrous Great Leap Forward of 1958 after China's break with the Soviet Union, and then the violent human iconoclasm of the Cultural Revolution of the late 1960 s and 1970s. What makes Cheng's account relevant to our purposes here, however, is that he tells this story also as one of ever more penetrating attempts by the revolutionary process to reformat individuals, molding them into "new people" (xin min), in the idealized image of Mao himself as well as other selected models of revolutionary citizens.

In addition to the Soviet influences, Mao's program of thought reform had roots in his early involvement in the New Culture Movement of the 1910s. This comprised an urban intelligentsia who argued that for China to overcome the humiliation of defeat in wars with European powers as well as Japan, the population would have to overcome the docility of Confucian ethics and forge a "spiritual revolution," led by youth who could break the shackles of tradition and embrace the modern spirit of self-realization (with Friedrich Nietzsche's writings on the "superman" providing much of the inspiration). Combining the heroic tone of these influences with an idiosyncratic cosmology based on the notion of a "cosmic truth," the young Mao divided people into three categories-saints, sages, and the unwashed-according to how close they were to grasping this truth. Saints and sages were tasked with the education and enlightenment of the unwashed, creating the conditions for a new society to emerge. In 1918 Mao cofounded the New People's Study Society, in which a group of young intellectuals subjected themselves to a strict regime of study and Spartan physical hardship, with the aim of sharing the fruits of the collective program of enlightenment with uneducated peasants and workers through intensive educational campaigns. As the 1920 s 
progressed, Mao injected into these essentially ascetic structures a militantly Marxist-Leninist political content, and in the context of the newly founded Communist Party began to experiment with methods for bringing the program of thought reform to the masses.

The central planks of this momentous program of personal reform were put in place during the revolutionary struggle of the 1930s and 1940s, when Mao and his forces were based in Yan'an, a mountainous and isolated province of northwestern China. With a view to consolidating Mao's power and turning into effective revolutionaries the plethora of young recruits who poured into Yan'an to take part in the revolutionary campaign, the Yan'an encampments were systematically organized as "closed communities of discourse" (Cheng 2009: 60). The ideological doctrines of "Mao Zedong's thought," as Mao's adaptations of Marxism were branded, formed the curriculum of theoretical and practical instruction with which cadres-in-the-making were bombarded on a daily basis. It was in this context that one of the most pronounced-and in some important ways distinctive-features of Maoist "thought reform" was systematized; namely, its abiding emphasis on the emulation of model individuals who embodied the values of the revolution. Casting himself as "teacher" (rather than, say, leader) in a way that echoed the time-honored Confucian structure of moral guidance, Mao gave many of his most studied teachings the form of fable-like morality tales in which a central character - a worker, a soldier, a farmer, a cadre-acted out the virtues of the steadfast revolutionary. From Yan'an onward, through the successive waves of postrevolutionary convulsion that culminated in the Cultural Revolution, these tales became the centerpiece of the population's moral-cum-political education, with schoolchildren, workers, and soldiers, as well as Party cadres, learning to recite them by rote in morning assemblies that, as Cheng has it, resembled "a religious community's morning prayer" (63).

There is, of course, nothing exceptional about Mao's use of model individuals to bolster the appeal of his revolutionary project. In one way or other all political projects have their heroes, and Mao's technique of consecrating ordinary individuals as revolutionary exemplars was itself borrowed from the USSR, where tales of model workers, students, soldiers, scientists, mothers, and so on were standard fare for the masses' ideological formation as early as the 1920s (Cheng 2009: 33-37; Kotkin 1997; cf. Boym 1995). Nevertheless, as Cheng argues, in the Chinese context the appeal to model individuals as objects of moral emulation has deep roots in Confucianism, lending Mao's political project an unmistakably moral dimension in the eyes of a population long acquainted with Confucian ethical practice. Imitation, for Confucius, was a prime mode through which ordinary people could learn from their rulers, so it was the latter's duty to conduct themselves virtuously so that "the people are aroused to virtue" (Confucius, cited in Cheng 2009: 49; see also Hershock and Ames 2006). Indeed, to the extent that Confucianism runs together politics, government, and ethics as aspects of a single project of virtuous 
conduct (Yan 2016), Mao's manner of pursuing his revolutionary path to communism had an unmistakably Confucian hue to it-this being a paradox, of course, since the content of Confucianism had from the start been set up as an enemy of the revolution.

In an article focused mainly on Buddhist-informed ethical practices in Mongolia, Caroline Humphrey (1997) elaborates anthropologically a distinction between code-based ethical frameworks, in which subjects follow rules, and self-cultivating ethical practices based on the imitation of moral "exemplars"-individuals who are deemed to be morally exalted in one way or other, and therefore worthy of emulation (see also Needham 1992; Robbins 2018). The model individuals of Maoism, Humphrey acknowledges, can be understood as exemplars in this sense. However, their continuity with Confucian (or, in Chinese Inner Mongolia, Buddhist) ethical practices also invites unfavorable assessments on the part of the very people they are meant to inspire. For Humphrey, a compelling characteristic of exemplars is their inherent tendency toward richness and complexity, as subjects are called upon to reflect on the depth of varied exemplars' flesh-and-blood biographies, and actively consider which aspects of which exemplars (which may be potentially conflicting) to follow and cultivate for themselves. When Mao's government machinery "attempted to hijack exemplary precedents to their own ends" (Humphrey 1997: 25), seeking to "blot out all previous models [and] take over the moral landscape" (40), ordinary Mongols saw through it. "[E]veryone resented the brainless simplicity of these models," and, by the 2000 s when Humphrey was writing, "Mao's models have more or less zero currency" (41) (see also Liu 2002; Steinmüller 2011). If one can say that, in a deliberately unacknowledged way, Maoism treated Confucian (model-based) ethics as its model, what it produced was mainly bad imitations.

Still, as Cheng argues, there is more to Maoism's Confucian roots, particularly when one considers also its emphasis on self-reform, subjecting people to ever more forceful forms of collective criticism and self-criticism. Liu Shaoqi, Mao's influential deputy, explained the premise of this practice in his popular pamphlet How to Be a Good Communist, written during the Yanan period. After discussing the many ways in which self-avowed "communists" fall short of the ideal, Liu concludes:

Therefore people should realize the necessity of self-reform and see themselves as reformable. They should not assume themselves as unchangeable, perfect, saintlike, and thus needing no more reform. This is not meant to insult them but to recognise the inevitability of the progress of nature and society. Otherwise people could not achieve progress. (Liu Shaoqi, cited in Cheng 2009: 57)

As Cheng points out, it is significant that, to illustrate that even the most virtuous of men are subject to self-reform, Liu adduces the examples of Confucius and Mencius as models of purposeful and constant self-cultivation. Indeed, the notion 
that human beings are endlessly malleable and perfectible is a feature that distinguishes the Confucian tradition from the classical liberal conviction that humans are inherently both good and bad (cf. Cheng 2009: 59), or, as we might add, the Christian conception of sin that underlies the penitential traditions with which Foucault and Kharkhordin connect revolutionary self-revelation in Iran and the USSR respectively. And it is just this idea of self-reform as a permanent pursuit that underlies the regime of thought reform in Mao's China. Cheng illustrates:

Wang Yangming, a prominent neo-Confucian of the Song dynasty, was an example of . . . self-perfection. Before he died, he felt that, after a lifelong struggle against all undesirable thoughts, his mind and soul were so pure that, "There is nothing left in my mind but a holy emptiness." Many centuries later, in the Yan'an Rectification, Xie Juezai, a senior communist leader with a sound Confucian education, recounted this story in association with his experience of constant self-reform.

(Cheng 2009: 50)

Of course, "holy emptiness" is only one way of describing the effects of thought reform in China, which reached unprecedented heights of physical and psychological violence in the campaigns of the Cultural Revolution. While Cheng does not make this argument himself, it may be plausible to go as far as linking this violence to the basic notion of human malleability that he traces back to Confucianism. To the extent that techniques of thought reform were premised on the idea that "moral improvement has no fixed limit" (Cheng 2009: 59), aspects of an individual's character or thought that remained unamenable to reform were not just erroneous but, in a sense, abominable, and therefore the legitimate target of ever more aggressive methods of psychological eradication.

Going a step further, seen from the vantage of revolutionary "anthropology" we outlined earlier, the significance of this kind of malleable personhood in Maoist China illustrates also how basic understandings about the nature of the person can help to shape the way that revolution itself is conceived. As already mentioned, the concept of a "permanent revolution"-revolution as an ineluctable process of ever-shifting coordinates and ever-deepening transformative effects, pressing its own "progress" forward in new ways, under changing historical circumstanceswas central not just to Mao's thinking, but also to the course of history in Maoist China and its devastating trajectory of death and suffering. To be sure, as the vast literature on the topic shows (e.g., Starr 2015), Mao's theory of permanent revolution had a lot to do with the particular historical circumstances of the Chinese Revolution. Interestingly also, in relation to the argument about the subterranean links between Maoism and Confucianism, it has been asserted that Mao's concept of revolution in permanent flux was presaged by his early flirtations with Daoism and its cosmology of becoming (Schram 1971: 224-25). However, if, as Cheng's account shows, the transformation of people was a prime arena in which revolutionary transformation itself was registered, then one could also suggest that the 
permanence of Mao's revolution was, at least in part, a function of the permanence of the project of human perfectibility that it set in motion (see also Liu 2009: 185; Smith 2017). If revolution, as a political form, is about releasing the full potentials of human malleability, and that malleability has "no fixed limit," then the revolution also must be imagined as having no fixed limit either. A revolutionary anthropology, then, that posits transformation as a permanent state.

To illustrate further the subtlety as well as the complexity that a focus on revolutionary anthropologies can bring to the study of personhood in revolution, we now turn to a second case study, which draws on Holbraad's own research in Cuba (2004, 2012, 2014, 2017a, 2017b, as well as ethnographic material collected more recently). As we shall see, in many ways the anthropology promoted by Fidel Castro, Ernesto "Che" Guevara, and their fellow combatants after their rise to power in 1959 is a variation on the state-socialist conceptions developed in the Soviet Union and China, based on ideas about the concerted production of a New Man and his revolutionary potentials. However, focusing on the ideal of self-sacrifice that, much as in the USSR and China, lay in the heart of these conceptions, we go on to broaden the scope of the argument ethnographically, to consider how practitioners of Afro-Cuban religions that are active in Cuba today relate to these conceptions. Based on a different set of ideas about the significance of sacrifice - in this case animal sacrifice - in processes of self-transformation, participants in these popular religious practices also, at times, have seen themselves as contributors to the project of revolution in Cuba. The case, we argue, illustrates how a focus on the constitution of the person can take the analysis of revolutionary transformation beyond the rather hackneyed study of the divergence between ideology on the one hand and practice on the other, and reveal the nuanced and complex imbrications between the two (see also Yurchak 2006).

\section{TWO ANTHROPOLOGIES OF REVOLUTION IN CUBA}

From the first years of its inception, the Cuban Revolution has presented itself as a radical attempt to refigure the relationship between individual persons and the putatively transcendent state structures that govern them. In that sense, and as with other revolutionary processes we have discussed already in this chapter, the project of revolution in Cuba has been an "anthropological" one, too. In his emblematic text Socialism and Man in Cuba (in Guevara and Castro 2009), for example, Guevara addresses the "common argument from the mouths of capitalist spokesmen ... that socialism, or the period of building socialism into which we [in Cuba] have entered, is characterised by the abolition of the individual for the sake of the state" (7). To the contrary, Guevara argues polemically, the "fundamental task" of the revolution is to "build communism, [for which it is necessary] to build the new man (el hombre nuevo)" (13), who must "strive every day so that 
[his] love for living humanity is transformed into actual deeds, into acts that serve as example, as a moving force" (25). Far from being "abolished," for Guevara the individual in revolutionary Cuba is "freer" (26), fashioned into a subject who not only embodies the ethos of the revolution but enacts the very condition that the socialist state is charged with bringing about-an early example of political "prefiguration," as more recent debates on societal transformation would have it (Juris 2008; Krøijer 2015; Briceño 2018).

It is important to note here that while Guevara's notion of the New Man is but a version of the kinds of ideas we have already seen from previous state-socialist contexts, there are also aspects of his proposal that are distinctive, in ways that are relevant to our argument about revolutionary anthropology. For Guevara, as well as for Castro himself in those early years, before Guevara's death in 1967, the Cuban Revolution presented an alternative to Marxist "scholasticism," and particularly theories of "pure transition," according to which communism is supposed to result from objective conditions emanating from the class dynamics of late capitalism and, following revolution, the dictatorship of the proletariat (Guevara and Castro 2009: 16-19). On the contrary, argued Guevara, Cuba represented the possibility of speeding up this transition by supplementing the objective conditions for socialism-only partially met in the historical contingencies of revolutionary Cuba-with an irreducibly subjective component, namely forging the New Man. A matter of inculcating new forms of consciousness (conciencia) through intensive and all-embracing changes in political mobilization, labor arrangements, the arts and, above all, education, this focus on subjectivity (over and above objective conditions) was a crucial aspect of the Guevarist ambition for the "simultaneous creation of socialism and communism" (Bengelsdorf 1994: 91; cf. Badiou 2009: 25).

The "sped up" image of revolutionary transformation has interesting implications for the question of revolutionary anthropologies, and particularly the Cuban Revolution's project of reconfiguring the relationship between the (revolutionary) state and the (equally revolutionary) person. What is most deeply at stake in the Guevarist program of political-cum-subjective change, then, is not just a clash between two ways of organizing the relationship between a state and a people (liberal, say, versus totalitarian), but rather two alternative ontological positions on what might count as "state" and "people" in the first place. Where liberal assumptions premise the two sides of this political equation as (to a degree) mutually independent variables - sovereigns and subjects who retain their respective scopes for autonomy, with different degrees of relativity-Guevara seeks to articulate revolutionary politics in Cuba as a concerted attempt to render them mutually dependent: a "society in formation," as he writes, "that will permit a complete identification between the government and the community in its entirety" (Guevara and Castro 2009: 16, emphasis added). Expressed in the quasi-theological terms 
of "anthropologies," the revolutionary project in Cuba in those early years was one of mitigating the sense of transcendence that is typically taken to be an inherent characteristic of state structures, and rather orchestrate into existence a situation where the person and the state are effectively one and the same thing. A statesocialist revolution in which (new) people's individual deeds serve as a "moving force," and, in turn, a new man who in his (and the macho masculinism of the terminology is noteworthy!) constitution enacts the goals of the revolution.

Elsewhere, Holbraad (2014) has explored how this ideological notion of revolution as a fusion of state and person has remained practically operative in Cuba after the initial idealism of Guevara subsided into the realities and compromises of later periods of the revolutionary process on the island, including the so-called Special Period of the post-Soviet years of the 1990s and 200os. While, much as Humphrey describes for Inner Mongolia, Guevara's exalted notion of the New Man has for decades been considered hopelessly idealistic and outdated, one of its major premises has in a way persisted-its central commitment to self-sacrifice. During his fieldwork in Havana since the late 1990s, and even today, Holbraad found that at a discursive level ordinary people may take a range of stances toward what official discourse still calls "the revolutionary process" (el proceso revolucionario), including daily litanies of complaint about its many failings. Tellingly, however, in situations where their commitment to the revolution was challenged in one way or other, many of those same people would revert indignantly to an embattled language of self-sacrificial violence, affirming their own continued preparedness to fight for a political project they still saw, with self-conscious heroism, as "theirs" (see also Rosendhal 1997; Weinreb 2009; Gold 2015).

Holbraad's argument (2014) was that insofar as the association of revolutionary commitment with self-sacrificial violence runs deep even in contemporary Cuba, it continues to underwrite a conception of revolution as a fusion of state and person. As the ultimate expression and most basic premise of the ascetic ethos of the New Man, the commitment to self-sacrifice gives subjects a particular form, making them coterminous with the revolution which in turn is understood, as Castro put it in a famous speech in 1961, to contain "everything within" it (Castro, from García Luis 2008: 116-17; cf. Arendt [1965] 2006: 11-58; Kwon 2013; Atran 2016). Or, as Guevara himself proclaimed in 1965, two years before his own iconically self-sacrificial death, "there is no life outside the Revolution" (Guevara, cited in Pérez Jr. 2005: 349). In a way that may run as deep as biblical debates about Abraham and Isaac (Putnam 2008; cf. Miller 2014), then, the basic revolutionary demand for self-sacrifice configures a revolutionary "anthropology" that is just as powerful. Namely, one that orchestrates a political universe in which state structures and the people they co-opt stand not in a relationship of transcendence but rather one of mutual constitution, where state and subject may be said, following Lévy-Bruhl (1926; cf. Sahlins 2013; Goldman 2019), to "participate” in each other. 
This mention of Lévy-Bruhl, whose notion of participation was put forward as a feature of what he took to be the "mystical" premises of "primitive mentalities," suggests that our treatment of revolutionary anthropologies can be pushed further, to include also constituents whose involvement in the Cuban Revolution diverges from the Abrahamic logic of self-sacrifice promoted by the revolutionary authorities themselves. We have in mind here the practitioners of Afro-Cuban religious traditions, which were brought to Cuba from Africa during the slave trade, and which were severely restricted by the revolutionary authorities after 1959, only to resurface with vigor from the 1990 s onward, when government restrictions were relaxed in the difficult years of the Special Period (Holbraad 2004). To be sure, practitioners of Afro-Cuban religions in recent years have been just as liable as anyone else in Cuba to complain about the government and express their disappointment in a revolution that in its initial phases did so much to improve the lives of the working class and non-White segment of the population, among which these practices have traditionally been most popular (Ayorinde 2004). ${ }^{4}$ As with other ordinary people in this period, however, Holbraad found that in other contexts, and particularly when challenged or provoked, many of them would profess their loyalty to the revolutionary project, on occasion revealing that current of underlying violence which gives form to the self-sacrificial logic of revolution. For example, in the article making this argument about violence and the machismo of self-sacrifice, Holbraad recounts an occasion when a middle-aged man expelled from his home a drunken visitor who had mocked the images of Fidel Castro, Che Guevara, and Camilo Cienfuegos hung on the living-room walls, lurching at his visitor with a machete and shouting in paroxysm, "Get the fuck out! In this house we are revolutionaries, fuuuuck!" (Holbraad 2014: 368). What Holbraad did not mention in the context of that discussion, however, is that both men were longstanding initiates of Ifá, a prestigious, male-only Afro-Cuban tradition of divination. The machete that the host was able to dig out of his wardrobe for the attack was kept there (also) for ritual purposes, in fact, related to the animal sacrifices that are a central feature of Afro-Cuban religious practice.

One might conclude from this kind of ethnography that practitioners of AfroCuban religions are as thoroughly subject to the violent logic of revolutionary selfsacrifice as anyone else in Cuba, and that would be correct. However, for purposes of our present argument about revolutionary anthropologies, it is interesting to note also an altogether different framework of ideas and assumptions these practitioners are able to bring to bear on the political circumstances of the revolution. This springs from a more general logic of action that underpins all Afro-Cuban

4. For a study dedicated to understanding the dynamics of disappointment in a postrevolutionary society, based on ethnography in Serbia following the overthrow of Milosevic in 20oo, see Greenberg 2014. 
religious practice; namely, that the events that make up people's lives are always and in principle under the influence of divinities and other spiritual forces whose actions and dispositions influence the course of worldly events. As Holbraad $(2012,2019)$ explains with reference to the divinatory tradition of Ifá in particular, this subjection of life to divine forces follows a "mythopractical" logic, according to which all worldly affairs are traced back to their mythical origins. These are accounts or "stories" (historias) of their "birth" under the reigning influence of particular creator divinities, who are themselves expressions of an all-pervasive principle of creation and transformation, called aché. Managing one's affairs in this world, then, involves developing and regulating one's relationships with these divinities and forces through ritual actions. Animal sacrifice is particularly salient in this respect, "feeding" the divine entities with blood and other ritual substances to enhance their force and efficacy, that is, their aché.

These practices are appealing to practitioners since they allow them to influence personal affairs, and initiation into an array of different Afro-Cuba traditions is as popular in Cuba today as it ever was, allowing initiates to wield these powers for their own good and that of their clients and ritual protégés. However, broader social circumstances, including political affairs, are also understood to be subject to these divine forces. This is the case, for example, with the so-called letra del año-an annual divination that initiates of Ifá perform collectively at the beginning of every year, laying out the overall fortunes of practitioners for the year (Watson 2010: 160-211). Increasingly in recent years, this has included perceptibly political dimensions, with diviners pronouncing, albeit in the cryptic terms characteristic of this form of divination, on matters of national economy, prospects for migration, or the fortunes of particular political personalities (Routon 2009). Indeed, the manner in which practitioners subject Cuban politics to the mythopractical logic of their ritual practices was brought home to Holbraad in a conversation in 2002 with a prominent initiate of Ifá, who was expressing his indignation at the government's periodical attempts to co-opt the religions in more official structures. In the macho tonalities that are often characteristic of Ifá practitioners' discourse, he explained:

What they don't say is that were it not for us [the initiates of Ifá] this thing would have fallen long ago. We've got the Yankees to the North and everyone is against us. How many attempts have they not made against him [Fidel Castro]? But we feed this land (esta tierra), we give it the power it needs to resist, after all these years and all that we have gone through. Animals, animals, and more animals, for every initiation, every ritual. That's our work, the work we do for this.

"This" or "this thing," as Holbraad has discussed elsewhere (2017a), is a way Cuban people have in ordinary discourse of referring diffusely to the political circumstance that the "project of revolution" of official discourse had created. What we have here, then, is an altogether different framework for understanding the 
anthropology of the Cuban Revolution-one that turns the relationship between the state-driven project of revolution and its putative "subjects" (in this case the initiates of Ifá) on its head. Rather than the revolution co-opting and reformatting people through the demand of self-sacrifice, here we have people (initiates) sustaining the revolution by injecting it with the powers animal sacrifices provide. In this way revolution is itself co-opted by the power of the divinities, becoming a worldly expression of an all-encompassing logic of mythical-cum-divine origination. Initiates, who in the Levy-Bruhlian sense "participate" in (i.e., become a constitutive element of) this process of mythopractical transformation, effectively become the guarantors of the revolutionary process and its development against all historical odds. If, according to the official, Abrahamic-style revolutionary anthropology, the revolution "contains" people by rendering them ontologically coterminous with its own process through the ascetic demand of self-sacrifice, here we have an inversion. The revolution itself is "contained" by the sustaining life force of aché, which the initiates are able to wield and underwrite through the ritual actions of animal sacrifice.

\section{CONCLUSION}

The Cuban case illustrates our most basic point in this chapter-one that is obvious to any anthropologist-namely, that understanding how revolutions come to constitute persons, and how persons come to shape them in turn, must involve also studying local ideas and practices of personhood. In each of our examplesIran, Russia, China, and Cuba - the political project of transforming people into revolutionary subjects has been in one way or other aligned with local ideas about what people are, how they are constituted, and how they relate to others, including transcendent powers and divine entities. Indeed, questions about the shape such alignments might take are as live for the people involved in them as they are for the anthropologists who study them. For example, we have seen that in both Russia and China the revolutionary impulse was very much against the ecclesiastical and Confucian "traditions," which the project of creating a New Man was meant explicitly to eclipse. Nevertheless, as we saw, deep structural elements associated with these traditions were transposed into the revolutionary project itself, while also being significantly transformed by it. In Iran, at the other end of the spectrum, we have a revolutionary movement that draws much of its strength from local religious conceptions and practices, giving them a constitutive-indeed exaltedrole in the development of the revolutionary project. Far from seeking to replace Shi'ism, the Iranian Revolution becomes its prime avatar. Hence, for participants in the revolution, and subsequently for the subjects of the Islamic Republic it instituted, being a good Muslim and being a good revolutionary subject become demands that are inextricably linked, making the alignment of the two a prime 
reference point for ordinary people as much as for the state authorities charged with policing their comportment. And finally, contemporary Cuba provides an intermediary example, between the two extremes of mutual exclusion on the one hand and mutual constitution on the other. After years of Soviet- and China-like persecution (which was never nearly as violent in Cuba, however), since the $1990 \mathrm{os}$ Afro-Cuban conceptions and practices began to flourish within the country's everrevolutionary environment. In doing so, as we saw, they have been able to provide an alternative framework for understanding the relationship between revolution and person-one that, in its own terms, can be said to encompass the "anthropological" alignments that the revolution itself prescribes.

Rather than further proliferate the examples of revolutionary anthropologies, we end this chapter by placing our analysis of revolutionary personhoodindeed of "revolutionary anthropologies" - in the context of developments in the anthropology of personhood more broadly. In particular, our central question about how revolutionary conceptions of the New Man relate with diverse local ideas and practices of personhood resonates with a central theoretical question in the anthropology of personhood more broadly; namely, how far the conception of the person as an "individual," upon which much social theory is based, is useful for charting this ethnographic diversity. Revolutions the world over, as we have seen, have had to align a basically Eurocentric (not to mention Pauline and thus emblematically Judeo-Christian) idea of the person-the New Man and all of the assumptions associated with it-with local conceptions, often grounded in divergent religious and ritual traditions. Similarly, anthropologists must deal with the divergence between basic Eurocentric assumptions about individuality, autonomy, agency, and so on (many of them enshrined in the liberal tradition of the French Revolution, and carried through also to revolutionary conceptions of the New Man), and alternative conceptions that in many ethnographic contexts cut against these assumptions, rendering them quite unsuitable for anthropological description and analysis.

In anthropology at large, the limitations of models of personhood based on the idea of the individual have motivated a radical critique of "humanist" assumptions in anthropological analysis, giving rise to what is often referred to as a "post-humanist" stance (cf. Laidlaw et al. 2018). The tendency, broadly, has been to move away from ideas about individual freedom, agency, and autonomy as distinctly human characteristics, and toward more "processual" approaches that emphasize the relational constitution of persons and efface principled distinctions between humans and nonhumans (e.g., Braidotti 2013). Human beings, according to this view, are better understood not as entities in their own right but rather as emergent effects of complex and ethnographically contingent relational processes-be they, for example, shifting configurations of power and knowledge, as in early Foucault (1995), networks of human and nonhuman "actants," as Bruno 
Latour has suggested from the perspective of Science and Technology Studies (1993), or "dividuals" distributed across each other through relationships of kinship and exchange, as Marilyn Strathern has argued on the basis of Melanesian ethnography (1988).

As Humphrey has suggested in an influential article, tellingly titled "Reassembling Individual Subjects" (2008), however, these attempts to radically downplay individuality as a starting point for understanding personhood also come at a cost. Dissolving the individual in this way, she argues, tends to inhibit anthropologists' interest in people not just as "persons" but also as particular personalities. That is to say, alongside our interest in the varying processes through which the category of the person is constituted locally, as anthropologists we are also interested in the "singularity, or the originality of . . . particular person[s] as . . actor [s] in a given cultural situation and specific historical circumstances" (2008: 358). What is called for, therefore, are analytical frameworks that allow us to understand how "a singular human being might put him or herself together as a distinctive subject by adding to, or subtracting from, the possibilities given by culture as it has been up to that point" (358). Inspired partly by Badiou's theory of the event (2001, 2009), Humphrey develops such a framework by positing "decision-events" as moments at which people constitute themselves as individuals by "'plumping for' a specific way of being a person, if only temporarily, and by prioritizing, the keeping at hand of divergent multiplicities in an emotionally cogent, internally shuffle-able array of possibilities" (Humphrey 2008: 363, emphasis omitted).

It is telling that many of Humphrey's examples of this constitution of persons as individuals in the moment of decision are taken from contexts of revolutionary action, illustrating her model of decision-events, for example, with reference to the political trajectory of Bayar, a young activist who sought to instigate revolution in the Urad West Banner of Inner Mongolia in the 1920s (362-63). Going beyond her specific model of individuality, however, Humphrey's argument is significant here for the way in which it sets up the overall challenge an anthropology of revolutionary personhood must confront. We have seen throughout this chapter the many ways in which people's singularity as historically placed individuals with the capacity to act-and not least to change themselves, often in incredibly potent ways-is often at issue in revolutionary contexts. The very idea of a New Man is but an incarnation of this idea, but so is the broader demand for personal transformation and self-discipline that revolutions characteristically invoke and, to a degree (often a radical degree), enact. Revolutions, one might say, are rarely "post-human" in character-indeed, most often they are in one way or other carriers of the very forms of humanism much contemporary anthropological (and broader cultural and social) theory is pitted against. The challenge for a comparative anthropology of revolutionary personhood, then, is how to take this into account without sidelining the myriad ways in which local cultural and social inflections of revolution 
put these forms of "humanism" under pressure, often in a decidedly post-human direction, as we saw with reference to Cuba, for instance. For the anthropology of revolution, we might say, there is no choosing between "humanism" and "posthumanism" as alternative theoretical options. Rather, the relationship between the two becomes an ethnographic conundrum in its own right, amenable to a manifold of expressions in different historical, social, cultural, and indeed religious and ritual settings. 


\section{4 \\ The Revolutionary Leader \\ Charisma, Authority, and Exception}

In the midst of the popular tempest, we must be the invisible pilots guiding the revolution, not by any kind of overt power but by the collective dictatorship of all our allies, a dictatorship without tricks, without official titles, without official rights, and therefore all the most powerful as it does not carry the trappings of power.

-MIKHAIL BAKUNIN

"A specter is haunting Europe," Marx and Engels famously announced at the beginning of their manifesto, "the specter of Communism" and "all the powers of old Europe have entered into a holy alliance to exorcise this specter" (Marx and Engels [1848] 2005: 5). An iconic opening, and a metaphor for the opposition encountered by communist doctrine on the old continent but also, perhaps, a hint about a specific quality of revolutions: a certain "spectral" contradiction that characterizes them. On the one hand, revolution is often described, by Marx and elsewhere, as an inevitable event ([1848] 2005: 19; Arendt [1965] 2006: 51), as if an irresistible force with an agency of its own, whether collective impulse for change or the very course of history, takes hold of the revolutionaries, acting through them and compelling them to subvert an old world that is no longer sustainable. This is a process akin to mediumship, the experience of being possessed by an unrestrainable "spirit of revolt" (Kropotkin 1975: 3). On the other hand, as much as it stirs people, revolution needs to be ignited by someone. Like a specter it needs

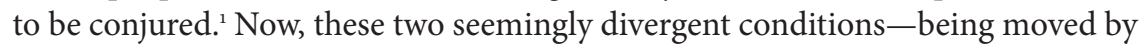

1. Marx's views on the inevitability of revolution should not be exaggerated. Compare, for instance, Marx's "specter" with Hegel's notion of "spirit," understood as perfect self-awareness that gradually manifests itself in world history: an idea that Marx came to reject as he distanced himself from Hegelianism. One might argue that whereas Hegel's spirit acts through human beings, Marx's specter is ultimately summoned by them-it requires agency and human initiative-for "it is flesh and phenom- 
revolution and being the agent who sets revolution into motion-are reconciled, at times, in a specific figure, one who is usually found addressing the crowds with a firm voice, or caringly reassuring fellow insurgents in times of crisis. It is the revolutionary head: an individual led only by revolutionary ideals and, therefore, fit to lead the revolution and one who is capable of conjuring the specter precisely because he is possessed by it.

Such a view of leadership as a mixture of active and passive traits particularly marks the relationship between the head and his supporters. For in many revolutionary narratives the leader is portrayed not only as someone with authority over his people, but also as subject to theirs. Consider, for instance, the liberal episteme as it developed in the context of the American and French revolutions, and, later, with the Spring of Nations, the wave of democratic upheavals that took place in Europe in 1848. Eager to demolish ancient views of power as a privilege assigned to the king by God-a prerogative to rule the masses deep-seated in the supernatural order of things - these discourses articulated leadership as a quality rooted in a different, earthly source of sovereignty: popular will. Headship thus came to be understood not only as the ability to guide citizens but also as the faculty to execute their decisions (Baker 1990: 284), a twofold capacity to lead the community while ultimately being led by it. This concept has been interpreted, particularly by early liberal thinkers, with a stress on the need to shepherd the uneducated multitudes to make sure they exercise their authority in an orderly and effective manner (Foucault 1988a: 72; Sa'adah 1990: 153-60; Dawson 1972: 26), but, in revolutionary forms, whether inspired by liberal tenets or otherwise, this notion has often carried an emphasis on the unrestricted leading role of the people. Thus, the head of the revolution is not simply someone who strives to fulfill the wants of his fellows; rather, he appears to be completely subject to such wants, and motivated, even possessed, by them. ${ }^{2}$ A vessel filled, in theory at least, with the wishes of others.

It is this view of the leader as a conduit for popular will that informed Robespierre when he notoriously declared, "I am the people" (McPhee 2012: 125). While it is true that many revolutionary discourses have dismissed similar statements as a dangerous gateway to tyranny, it is also true that the idea that one can channel

enality that give to the spirit its spectral apparition" (Derrida 2012: 5 ). Incidentally, Marx also uses a spectral analogy with reference to capitalism, whose uncontrolled growth resembles "the sorcerer who is no longer able to control the powers of the underworld that he has called up by his spells" (Marx and Engels [1848] 2005: 12).

2. Michael Taussig has successfully shown that the dynamic of possession, which involves an invasion of one's body perpetrated by a spiritual other, "is a movement parallel to the circulation of the ghostly magic of the Nation State through the 'body' of the society" (1997: 139), so that, one might argue, often the leader's claim to be possessed by the people is part of a broader process where the people are, in turn, possessed by the state. 
the desires of other human beings is often found in these discourses. Marxist revolutionaries of the past century, for instance, maintained that without a vanguard party leading the way to revolution, "the energy of the masses would dissipate like steam not enclosed in a piston-box" (Trotsky 2008: xvi), but they also clarified that, in the final analysis, "what moves things is not the piston or the box, but the steam" (xvi). They therefore promoted a view of leadership as a dispositif that is, at the same time, operated by the energy of the people and necessary for this energy to be made operative: a mechanism that will cease to function when the conditions are right for communist society to be established and for people to rule themselves. Conversely, anarchist thinkers stressed that the masses are fully able to achieve liberation without the help of vanguards (Malatesta 2015: 176). Among them, however, some held that one can enable this autonomous process of emancipation by relating to the people as the "midwife of their spontaneous emancipation" (Bakunin 1992: 20), whereby the yearnings of the exploited can be made more explicit without being directed from above: a facilitator whose only function is to "illuminate those hopes and aspirations which exist in the great majority in vague forms" (Kropotkin 1971: 47).

Notwithstanding their differences, these traditions thus share a fundamental outlook on the dynamics of revolt: the idea that paving the way for revolution is an occupation founded on the capability to be inhabited and moved by the longings of other human beings. This notion continues to be debated within these discourses, and today is even closer to their core than in the past, as intellectuals assessing these traditions have realized, or further confirmed, that vanguardist strategies inevitably diminish the role of the people, and should therefore be abandoned in favor of more participative tactics of resistance (Ward 2004: 90-98; Amster et al. 2009; Carter 2011; Hardt and Negri 2017: 3-22; cf. Marusek 2018). Bearing this in mind, in this chapter we encounter different takes on what it means to lead. In particular, we see how, at times, revolutionary heads have manipulated the epistemes we have briefly outlined and, while presenting their actions as expressions of the will of the people, have in fact created a gulf between themselves and the masses, cultivating the idea that, while revolution might have certain rules, those rules do not apply to those who lead. At other times, as we will discover, these epistemes have been combined with local political and religious categories, so that, contrary to typical post-French Revolution articulations of authority, revolutionary leaders are perceived not only as individuals who are able to amplify the will of other humans but also as liaisons between different planes of existence: intermediaries who can channel spiritual forces and divine beings, lending their bodies to such supernatural entities so that they may take an active role in revolution. By unpacking these othering forms of leadership we shed light on the role played by power not only during revolutionary outbreaks but also in their aftermath. This, in turn, 
allows us to comment more broadly on how notions of leading and following are discussed and put to practice in different ethnographic settings.

\section{THE ORDINARY AND THE EXTRAORDINARY}

Before we consider unconventional forms of headship, we need to unpack familiar ones further, exploring how leadership features not only in revolutionary theories but also in well-known analyses by scholars who have observed revolutionary phenomena: an operation that requires some preliminary clarifications. Leaders, as we have seen, are supposed to be vectors of popular will, to be in tune with it, as in a description of Fidel Castro by Ernesto Guevara in which el Che portrays the interaction between the leader and the Cubans as a "dialogue of two tuning forks" ([1967] 2009: 17): a process whereby Fidel and the masses reach communion with each other and "vibrate in a dialogue" (17), so that the leader appears to be one with the people. Often, however, the revolutionary head is also expected to be one of the people, a principle that, at times, has pushed those who are at the forefront of the revolution to disguise their identities in order to remark that their individuality is not particularly relevant, as they are just ordinary workers who happen to work for the general good. This is the case, for instance, with Mikhail Bakunin's famous notion of "invisible dictatorship," a strategy of revolt criticized by other anarchist thinkers but one which, in Bakunin's view, would allow revolution to be led by clandestine cells that are "recognized by none, imposed by none" (Bakunin in Confino 1974: 259); due to their anonymous character, these cells would be completely exempt from self-interest, egotism, and ambition. A more current example is provided by Subcomandante Marcos-until recently the most visible figure of the Zapatista movement-whose masked persona stood as an undifferentiated symbol for all the underprivileged of the world, meaning that Marcos was, at the same time, "a black person in South Africa, an Asian person in Europe, a Chicano in San Isidro, an anarchist in Spain, a Palestinian in Israel” (1995: 310-11).

Given this stress on the "ordinariness" of leadership, it comes somewhat as a surprise that, when European sociological inquiry has set out to analyze the status of revolutionary leaders, it has often done so by focusing only on the unique characteristics of these figures, paying attention to traits that supposedly set them apart from commoners. The seminal work of Max Weber comes to mind, particularly his analysis of the notion of charisma, defined as a feature that allows certain individuals to come across as "endowed with supernatural, superhuman, or at least specifically exceptional powers or qualities" (1968: 48): attributes ascribed "to prophets, to people with a reputation for therapeutic or legal wisdom, to leaders in the hunt, and heroes in war" (48). Charisma implies a sense of vocation, the feeling that one has been called to do what others cannot, a characteristic that, according 
to Weber, is more important for the success of the charismatic head than public recognition (49). Charismatic leadership, thus, inevitably contrasts with other forms of headship that are based on inherited privileges, formal procedures, and traditional rules $(24,51)$, as the charismatic head often feels that his role is to upset these habitual practices and to bring about unexpected revelations, innovations, or completion. Consequently, charisma stands out, in the Weberian framework at least, as "the greatest revolutionary force" (53), a power capable of swiping away norms and routines that are perceived as too static $(52,63)$.

Together with this radical potential, however, Weber recognizes another defining trait of charismatic authority, one that might, in a sense, bridge the gap between the emphasis on the ordinary nature of leadership as found in many revolutionary discourses and the Weberian focus on the extraordinary abilities of the leader: the notion that charismatic leadership cannot be enduring, as it always gives way to other, more conventional forms of authority. With reference to this point, Weber identifies a trajectory in the development of charisma. Whereas an exceptional individual justifies his status through his sense of vocation, his successors, who often lack his supposedly unique talents, articulate their legitimacy by demonstrating a link with him. This dynamic generates, for Weber, the need to formalize charisma, to turn it into a quality whose transmission is regulated by norms; thus, while charisma was once the opposite of routine, it becomes a routine in itself, particularly after the leader's death: a matter of holding an office rather than an exhibition of exceptionality (54-59). This routinization can be observed, according to Weber, not only with dynamics of succession among leaders, both revolutionary and otherwise, but also, specifically, in revolutionary praxis (64). It is for this reason that, for example, the professional army was disbanded and replaced with a voluntary, one might say charismatic, army of the people during the French Revolution, only to be formalized again under Napoleon when he portrayed himself as heir to the revolution (36).

Undoubtedly, Weber's model has been subjected to criticism, particularly his idea that the routinization of charisma is linked, especially in the modern age, to an increasingly disenchanted view of the world, one where authority tends to be expressed through rational and bureaucratic procedures rather than in terms of supernatural gifts. This latter notion has been debunked by current sociological research, as scholars have shown that the divine still has a role to play in some modern articulations of leadership (Landy and Saler 2009): a dynamic that becomes apparent later in the chapter. Besides, whereas Weber believed that routinization might bring about less-authoritarian articulations of power, as the leader's successors might seek legitimacy through the consensus of the people rather than by claiming exceptional traits (Weber 1968: 29, 61), more recent analyses have focused on the despotic sides of routine. In particular, these studies have shown that often bureaucratized expressions of power rely on a specific tendency-found in some individuals' psychological makeup-to follow authoritarian figures that 
present themselves as protectors of rules and conventions (Adorno et al. 1993). Yet the relation between exceptionality and routine continues to attract scholarly attention and, rather than dismissing these concepts, contemporary inquiries have highlighted how, contrary to what was implied by Weber, the two are inherently interdependent, particularly when it comes to revolutionary leadership: a dynamic that is elucidated by philosopher Giorgio Agamben. ${ }^{3}$

Agamben argues that even when authority finds its justification in routine and norms, often those in power feel they have to break such rules, temporarily and paradoxically, in order to preserve a sense of law. They have to create exceptionality to sustain the routine. To illuminate this paradox Agamben explains how, in exceptional cases like war or other states of emergency, legal codes are habitually suspended, as such intense and unpredictable circumstances cannot be faced using conventional, fixed legal instruments. An exception is therefore made: Actions that might be considered unlawful, such as the exercise of violence, become, at least to some extent, legitimate (Agamben 2005a: 14, 29). This temporary suspension of rules, however, is not necessarily equivalent to a complete absence of norms. This is not only because such states of exception are frequently envisioned within legal codes but also, on a deeper level, because the exceptional fact, whether war or something else, becomes, in a sense, a law unto itself that dictates what needs to be done until conditions are safe for conventional laws to be reestablished (2005a: 14, 29). Naturally, as Agamben shows, this return to routine never happens smoothly because, whereas under normal circumstances law is used to regulate facts, in states of exception, as we have seen, law and fact fade into each other (2005a: 14, 29), so that it becomes impossible to distinguish fully between transgression and execution of the law (1998: 57). Consequently, an ambiguous situation is created, one that, Agamben argues, might offer fertile terrain for new and revolutionary articulations of authority.

More specifically, Agamben shows how the state of exception can be seized or prompted by a revolutionary group or leader that might declare the de facto annulment of a legal code seen as unjust and, therefore, in contradiction with the very idea of law (2005a: 28-29). In Agamben's view the truly revolutionary potential of this process of opposing the law in the name of a higher, more just law lies in the fact that, at least in theory, a perpetual state of exception can be established. In this scenario, justice never becomes fully crystallized into laws and routines that are, by definition, coercive and, therefore, potentially authoritarian $(62,88)$, a view also supported by other philosophers (Benjamin 2002: 236-52). Agamben,

3. Agamben's work also presents a profound critique of the Weberian notion of modern disenchantment, as the philosopher shows how modern thought, particularly when it comes to understanding the notion of power, continues to deploy theological categories, so that one could argue that modernity brings theology to completion (Agamben 2011: 287). On the subject see also Schmitt 2005: 36 . 
however, contends that a perpetual state of exception can also have the opposite result. Whether it is an established form of authority or a revolutionary one that seeks to establish a new order, power can declare a constant state of emergency in order to strengthen its grip. In other words, those with authority can continuously act outside the law with the excuse of doing so to retain the true spirit of the law (Agamben 1998: 50), violating the rights of their subjects to protect the notion of right (88), which might entail, for example, killing dissidents without it being considered homicide (83), thereby holding absolute power. ${ }^{4}$ In this sense, the exception becomes, truly and dangerously, the rule. By portraying leadership as the capacity both to protect the order of things and to break such order, the leader occupies a position that is unbound by restrictions, both extraordinary and ordinary, both internal and external to the norm. The unpredictability of revolution becomes, therefore, indiscernible from the predictability of routine: a condition that can be observed in some expressions of revolutionary headship.

\section{EXTERNAL MASTERS AND VOLATILE HEADS}

In his study of late socialism in the USSR, Alexei Yurchak captures the scenario described by Agamben, documenting, historically and ethnographically, a case exhibiting a perpetual state of exception. Yurchak shows that, following the first effervescent years of the Bolshevik Revolution, the Soviet Union entered into a routinized phase. This is not only because Joseph Stalin replaced magnetic leader Vladimir Lenin as the guide of the state-thus acting, as Weber would argue, as a routinized version of Lenin's charismatic authority-but also because, in time, Soviet revolutionary practices had started to appear somewhat predictable. The slogans of the leading party had acquired a formal character devoid of substance, and were performed mechanically and wearisomely without paying attention to their meaning, almost as ritual formulas framed in an archaic and incomprehensible idiom (Marcuse 1969: 87-89). ${ }^{5}$ Furthermore, whereas the early stages of the Soviet Revolution were characterized by an attempt to experiment with language and art in order to create new and revolutionary forms of communication, even under Lenin, although more visibly under Stalin, the Soviet Union became marked by a constant friction between the party vanguard and the artistic avant-

4. Agamben argues that nowadays such deviation of the state of exception is increasingly becoming a standard form of governance (1998: 20-38).

5. According to Herbert Marcuse, this ritualization had the purpose of preserving the original purity of the Soviet message in the face of contradictions, presenting it as "a truth that must be believed and enacted against all evidence to the contrary" (1969: 89). This reflected, in Marcuse's view, the fundamental paradox that characterized the Soviet Union: a context that had succeeded in bringing about Marx's promises of emancipation, but that, at the same time, prevented these promises from turning into a reality by making use of authoritarian means (89, see also Bauman 1985). 
garde, and by the enforcement of extremely standardized forms of aesthetics that left no room for innovation (Yurchak 2006: 38; see also Stites 1989; Buck-Morss 2000: 42-89). The Soviet context, therefore, appeared to be entrenched in static, unmovable routine. Such a stagnant state of affairs, however, was only possible, as Yurchak demonstrates, because Stalin craftily fashioned himself as an "external master" (Yurchak 2006: 39), a leader who defines the routine by being outside of it, as a constant exception to the rigid codes and norms he is supposed to enforce.

To convey this point, Yurchak points out that Stalin would comment on the correctness of scientific publications dealing with philosophy, linguistics, genetics, agriculture, chemistry, and physics $(2006: 43,45)$, fields in which he had no certified expertise but that were nevertheless placed under his scrutiny for approval. Similarly, the leader would judge the aesthetic value of films, literary texts, and works of art, discerning whether such discourses were compatible with the Soviet revolutionary orthodoxy, even to the point of assessing whether musical compositions were harmonious enough to be compatible with the physiology of human hearing, and therefore suitable for listeners within the Soviet project (2006: 46; see also Groys 1992; Paperny 1993; Todorov 1995). However, rather than evaluating these matters against a publicly available Leninist-Marxist canon-a set of principles and texts that could be commented upon by everyone-he would appraise them against an "external canon" (Yurchak 2006: 41) to which he had exclusive access, applying regulations that supposedly only he could grasp. Thus, whereas Stalin was allowed to assess virtually every aspect of reality, none could judge whether his actions were compatible with the Marxist tradition, because he presented himself as defining such tradition from an objective, external position unreachable by others. Under the surface of the dull routine of Soviet life there was thus a permanent state of nonroutine wherein the leader was exempted from scrutiny.

Yurchak further shows how this process continued after Stalin died and was succeeded as head of state by Nikita Khrushchev. With the passing of the external master, there was no guarantor who could certify the correctness of things; it therefore became increasingly difficult to discern rules from exceptions, as any statement or behavior could potentially be considered a deviation from the canon (Yurchak 2006: 47). In consequence, the general tendency was to replicate whatever was perceived as orthodox praxis under Stalin, because with none to define the norms from a position external to them everyone tended to stay safely within the rules. Even Khrushchev, who had publicly denounced Stalin's cult of personality as an obstacle to the communist project and urged for a return to Lenin's original message, behaved as if the ghost of Stalin were closely monitoring him, always being careful not to step outside accepted discourses in his speeches $(48,74)$. Such caution produced even more rigid and often empty discourses: texts written in a plain form so that their accuracy could not be questioned. In the words 
of one of Yurchak's informants, after Stalin any communiqué by Soviet leadership could be read "top to bottom and bottom to top with similar results" (50). Any new debate over this peculiar state of affairs only justified it, a situation exemplified by the idea, formulated by some Soviet linguists at the time, that such monotonous use of language correctly represented the single Marxist-Leninist reality that, in the Stalinist interpretation, had to pervade all aspects of life (50).

Similar dynamics could be observed in Libya under the rule of Colonel Muammar Gaddafi, another context heavily characterized by the enduring effects of a state of exception becoming a routine. Having seized power in a revolutionary coup in 1969, Gaddafi eradicated the Libyan monarchy and, as part of his revolutionary project, devised, as we have seen in chapter 2, a specific form of governance, the Jamahiriya, the "State of the Masses" or "Peopledom" (Anderson 1986: 264). Blending his own understanding of socialism and Sunni Islam together with elements of the Libyan tribal ethos (as previously explained), Gaddafi created a system of governance based on interconnected popular assemblies: congresses where Libyans would regularly meet and discuss both internal and external policies, governing themselves, at least in theory, directly and without the aid of a state apparatus in a form of "supervision of the people by the people" (Gaddafi [1975-81] 2005: 18). During his forty years in power, Gaddafi seemed to have succeeded in establishing the absolute primacy of the masses, thus fulfilling what has been, as discussed above, the aim of many a revolutionary project. In actual fact, however, the colonel retained absolute control over Libya. Although he had no official leading role, presenting himself simply with the honorary title of Qaid al Thawra, the "Guide of the Revolution," Gaddafi often altered or ignored decisions made by the popular assemblies (Cherstich forthcoming). More importantly, the colonel never participated in the system he had created; even though, according to the rules established by Gaddafi's revolutionary scheme, it was compulsory for every adult healthy Libyan to take part in the assemblies, he himself never did so (ibid.). Therefore, much like Stalin, Gaddafi acted as an external master of sorts, a leader excluded from obligations who, from this advantageous position, imposed such obligations on others.

With reference to this point, it is also important to clarify that Gaddafi cultivated a constant sense of exception by making sure that his status could never be pinpointed. While it is true that the enemies of his revolutionary endeavor fueled propaganda aimed at representing him as a dangerously unpredictable and unstable "mad dog" (Reagan in Hagger 2009: 115), it is also true that Gaddafi actively presented himself as a constantly mutable being that escaped definitions. For example, he continuously changed his appearance, resorting to paraphernalia and even to plastic surgery (Cherstich 2014b: 98-101). More importantly, he constantly altered his programs, allying himself with other national governments and then unexpectedly declaring them to be adversaries of his revolution, or remarking 
that Libyans were free subjects who should not have to pay any form of taxation, yet occasionally asking them to pay for gas, electricity, or other services. His ruling thus appeared to be characterized only by exceptions (98-101), and Libyans often felt that they could not keep up with the ever-changing decisions of their leader. As explained by a taxi driver interviewed by Igor Cherstich in the city of Tripoli, the center of Gaddafi's power, the capricious head of Libya might literally "wake up tomorrow and decide to ban smoking, and then we will all have to quit cigarettes" (102). In the following chapter, we will analyze how this volatile condition came to an end, and how Libyans finally codified Gaddafi's status, choosing to frame his shifty figure within a precise interpretation of his nature. For now, however, it suffices to say that the most dramatic consequences of Gaddafi's a-normative style of governance was the perception that no one was ever safe. As in the Soviet case, Libyans often practiced circumspection, because in the confusing absence of parameters, any action could be considered an expression of dissidence and be harshly punished by Gaddafi's police or by his notorious secret service (Cherstich 2014b).

\section{TRICKSTERS AND VECTORS OF THE DIVINE}

When confronted with such erratic forms of leadership, commentators have often analyzed the persistent propensity to foster exceptionality and unpredictability as a strategy of domination. As with an examination of the Bolshevik Revolution provided by Marcel Mauss in one of the earliest attempts at an anthropology of revolutionary phenomena, where the sociologist, a socialist himself (Graeber 2004: 17), criticizes the Bolsheviks as a "socialist sect" (Thomassen 2012: 685; see also Kalb 2018 for a trenchant critique). Although willing to recognize the Russian Revolution as an unprecedented attempt to implement communist principles (Thomassen 2012: 686), Mauss describes the Bolshevik leaders as "murky elements [using] the opportunity to accumulate disorders and follies" (Mauss in Thomassen 2012: 695), swindlers who manipulate the instability characterizing the revolutionary process to keep the people confused and subjugated: "Pure adventurers" who "exploit the Russian Revolution" (695). More recently, similar considerations have pushed anthropologist Bjørn Thomassen to draw a parallel between revolutionary leaders and the trickster (695-97), a figure found in a number of ethnographic accounts where the term is used to describe seemingly analogous supernatural beings featuring in different mythological narratives (Hyde 1995). Much like the Bolshevik leaders in Mauss's analysis, or Gaddafi's ever-changing way of ruling, the trickster is a mischievous entity, a God, hero, or spirit who has affinity with liminal situations where norms are shaken and become blurry (Hyde 1995): an embodiment of the state of exception that transcends precise categorizations. In some tales the trickster helps to solve a conflict by being external to 
it, that is, by avoiding taking sides or assuming definitive positions. More often, however, the trickster's real agenda is to perpetuate instability (Hyde 1995), so that this character operates as an outsider with "no existential commitments" (Thomassen 2012: 695): a deceiver who retains no allegiance with the parties involved in a quarrel and that has no interest in resolutions. ${ }^{6}$

Incidentally, Thomassen's proposition calls to mind the tenets of some controversial European revolutionary theories. His suggestion that revolutionary heads could be metaphorically seen as tricksters reminds us, for instance, of the theories of French anarcho-syndicalist Georges Sorel, who, much to the disdain of other anarchist philosophers, advocated the tactical necessity to frame revolutionary actions in mythological and epic terms in order to appeal to the supposedly irrational masses (Sorel 2009; Graeber 2004: 18). Attracted by legendary and ancestral narratives, the crowds will be led, in Sorel's theory, by a revolutionary elite who reinforce the myth by engaging in unpredictable, symbolic, conspiratorial acts of violence, constituting figurative tricksters of sorts (Sorel 2009). More importantly, however, Thomassen's reference to the trickster might allow us to better situate the external masters we have encountered in the previous section. On the one hand, through their revolutionary ventures, leaders like Gaddafi or Stalin appear to be focused on upsetting an old, pre-revolutionary order and creating a new one, as creation, newness, and, in a sense, revolution are often listed as defining features of the trickster. On the other hand, these figures remain, like the mythological outsider, forever external to things and deeply uncommitted. Uninterested even in their own projects of change, they are concerned only with maintaining a state of uncertainty that favors their authority, as "the defining feature of terror regimes is not order, system and repression-it is ambivalence" (Thomassen 2012: 696). The metaphor thus helps us to shed light on some styles of revolutionary command, although it also prevents us from grasping the way in which leadership is expressed in other contexts.

To fully assess Thomassen's use of the allegory of the trickster one has to remember that in some settings the relationship between authority, revolution, and divinity unfolds in a way that is neither allegoric nor necessarily tricksterish. Take, for instance, the case of Liberation Theology, a synthesis of Christian doctrine and Marxist principles that plays an important role in a number of Latin American revolutionary movements. In such discourse the supernatural facets of revolutionary authority are not understood in metaphorical terms, but as actual reality, as affiliates of this branch of theology share with other mainstream Christian thinkers the idea that, following the death and resurrection of Christ and the coming of

6. Thomassen notices that in the case of the Nazi and Fascist uprisings, Hitler and Mussolini were "indeed 'outsiders' or marginal figures driven by resentment" (2012: 696). Far from being charismatic and gifted leaders à la Weber, these leaders were "rather genuine human failures and outcasts who in highly liminal moments somehow captured power" (696). 
the Holy Spirit as recounted in the Gospels, the authority of Jesus is truly "present in the entire church, the body of Christ" (Boff 1985: 40). Unlike other theologians, however, these thinkers have often stressed the need to downplay the more hierarchical aspects of the church, putting great emphasis on the Christian notion that the poor are privileged recipients of God's grace. Their work has therefore focused on empowering those who are at the margins both of society and of the church; an attempt, one might say, to unleash the inner leadership that is truly present in the deprived through the works of the Holy Spirit, so that they can lead their own liberation. What is more, in sharp contrast with the eternally uncommitted trickster, these theologians have often shown great commitment to helping grassroots organizations to emancipate themselves in an unconditional pursuit of social and political justice: an aspect that has led some critics-both within and outside Christian churches-to accuse Liberation theologians of being willing to resort to armed insurgency, thus bypassing Jesus's command to unreservedly love one's enemies (Berryman 1987: 75, 195).

In light of these reflections one realizes that, rather than following a specific model-be it that of the trickster or others - revolutionary leadership takes multiple forms and is informed by specific cultural, political, and religious traditions. It is also important to clarify that, as much as it might be illuminating for some cases, the figure of the trickster is not the only trope from the anthropological repertoire to be found in analyses of the rapport between the divine and revolutionary heads, as anthropologists have often preferred to use other well-known themes from the ethnographic literature in their investigations. A case in point is Lucia Michelutti's study of the Bolivarian Revolution, a socialist process that began in Venezuela in 1999, and a context in which leadership is best understood, in Michelutti's view, through the anthropological notion of "divine kinship" (2017). The concept, which is used by ethnographers to describe kin ties between humans and supernatural figures, has often been applied in the study of the "divine kingship" claimed by royal families who trace their lineage back to divine ancestors (Frazer [1890] 1993; Hocart 1970; Sahlins 2017; Graeber 2017). ${ }^{7}$

Michelutti, however, employs the notion to examine the role taken by President Hugo Chávez, who, despite his death in 2013, "continues to shape Venezuelan revolutionary selves" (2017: 233). ${ }^{8}$ Such persistent influence has, according

7. In some ethnographic contexts divine kings are seen as "stranger-kings": leaders whose ancestry is foreign to the land they rule, and who are often viewed as individuals who remain somewhat outside of conventional society (Sahlins 2017). Bearing in mind that the style of ruling of this particular type of king is often described as being unbound by moral rules and categories, these kings share a certain similarity with the trickster. For an analysis of how such similarity stands at the heart not only of divine kingship but also the very notion of sovereignty, see Agamben 2005: 65-73; Graeber 2017.

8. On the role of divine kinship in contemporary democratic politics, see Michelutti 2014; Forbess and Michelutti 2013. 
to Michelutti, largely to do with the way in which the leader framed his authority during his career. In particular, Michelutti shows how Chávez gained popular consensus by stressing his descent from both African slaves and indigenous Venezuelans, translating the tricksterish capacity of the revolutionary leader to avoid definitions into self-portrayal as one of the people rather than an exception from them: an embodiment of the diversified, mestizo culture of the country (239). Chávez, however, traced a relation of descent not only with the different ethnic components of Venezuela but also with its various religious traditions, thus effectively articulating his lineage in semi-divine terms.

As Michelutti explains, Chávez presented himself as the heir of Simon Bolívar, a Venezuelan hero who fought to establish the independence of various Latin American countries, and after whom Chávez named his own revolutionary project. Now Bolívar, as Michelutti demonstrates, plays an important role in local Venezuelan Afro-Indian cults, where the hero is prayed to as a spirit pertaining to the corte libertadora (court of the liberators), one of many courts of spirits that include not only precolonial and African gods, but also deified figures of Venezuelan history and famous revolutionary leaders, both local and from other Latin American countries (236-37). Bearing this in mind, one can appreciate how Chávez presented his leadership as inherited through a pedigree that was, at the same time, divine and revolutionary. Michelutti also elucidates how in his lifetime Chávez-now seen by many as a spirit himself (236-37) — revitalized Venezuelan popular religion as part of his project to de-marginalize the popular classes (238), thus indirectly supporting such claims of divine investiture. Furthermore, the leader often described his revolutionary mission using messianic themes from local Evangelical traditions, thus hinting at another spiritual lineage that linked him back to Christ, whom he described as the first socialist (238): a genealogy visually expressed by juxtaposing photographs of Chávez with those of saintly figures and the Virgin Mary (244).

Michelutti demonstrates how, despite articulating his leadership in genealogical terms and emphasizing his role as successor to previous spiritual and revolutionary leaders-practices that, as we have previously seen, Weber posited as part of routinized authority-Chávez acted as a classic charismatic head. Local Venezuelan politicians often imitated his rhetoric, mannerisms, and style, organizing their public appearances in the same format as those of popular national television programs where the leader regularly appeared to speak to his people, behaving therefore as routinized versions of the original head, as "mini-Chávezs" of sorts (Michelutti 2017: 241-45). Such routinization was particularly evident, in Michelutti’s opinion, in Chávez's successor Nicolás Maduro. Despite claiming on various occasions to have spoken with the spirit of Chávez-thus receiving supernatural validation from his predecessor and confirmation of his status as new head of the Venezuelan revolutionary project-Maduro needed constant democratic 
elections for his authority to be justified, whereas Chávez's charisma largely stood by itself (241-45). As a result, many Venezuelans felt free to criticize Maduro and other politicians for some of the shortcomings of the Bolivarian Revolution, but not necessarily Chávez (241-45), thereby emphasizing the leader's exceptional capacity to merge with his people: a direct charismatic relationship that required no mediators and that persisted after the death of the head. ${ }^{9}$

\section{THE AFTERLIFE OF LEADERSHIP}

The case of Chávez stands out as an instance where the revolutionary leader has highlighted the supernatural dimension of his authority to such an extent thatdespite never explicitly claiming to be more than a human being-his semi-divine presence pervades people's memory. It is important to stress, however, that in other contexts similar processes of postmortem deification take place even if the leader has not cultivated a relationship with the divine when alive. In fact, at times, the figure of the deceased might be reinterpreted through religious categories that, unlike with Chávez, are completely antithetical to his agenda, and not necessarily with the aim of glorifying him. In such cases the leader's transfiguration into spiritual being might serve the purpose of fashioning an explanation for the misdeeds he committed when he was alive: a way to frame a critique of the head's revolutionary project that makes sense in light of local understandings of laws regulating the relation between gods and humans. This phenomenon is exemplified in Caroline Humphrey's (2003) analysis of popular perceptions of Stalin among the Buryat people-a Mongol subgroup forming a minority in Russia-whose Buddhist practices were violently persecuted under the Stalinist regime. As described by Humphrey, the Buryat saw Stalin as the reincarnation of a mythical blue elephant that features in a well-known Buddhist narrative, an interpretation that, in Humphrey's view, allowed them to contextualize the oppression they suffered within a familiar supernatural logic.

According to the story, the blue elephant belonged to a rich patron who decided to build a great temple-pagoda. The animal helped with the construction, and was so fatigued by the endeavor that his inner organs became visible through his skin, although, as a result of his holy commitment, the elephant reached enlightenment (2003: 188). However, when the pagoda was completed and a lama came to bless all those who helped in building it, the priest forgot to laud the elephant. Enraged, the animal renounced his enlightened status, decided to avenge the offense, and swore to destroy Buddhism three times in his next incarnations (188), a curse that,

9. The level of Maduro's popular support, however, should not be underestimated. This is a necessary clarification given the recent events taking place in Venezuela and current interference by the American government in the politics of the country. 
according to the Buryat, had tremendous consequences for the Buddhist faith. Humphrey recounts that the Buryat were unsure about the first reincarnation of the elephant, but identify the second in Langdarma, a ninth-century Tibetan king who persecuted Buddhism, and the third in Stalin. Such exegesis, Humphrey argues, carried an element of reassurance, as the Soviet leader embodied the third and last threat posed by the elephant, so that after his death Buddhists could finally be safe from the animal's curse (189). At a deeper level, however, the narrative also helped the Buryat to make sense of various aspects of Stalin's life as expressions of the ineluctable laws of karma. The leader, according to the Buryat, was able to succeed as a revolutionary head because he had achieved great merit when he helped build the temple in the form of the elephant. Yet, by the same logic, Stalin inherited the terrible vow made by the animal, and he was therefore forced by destiny to persecute Buddhism. In theory, as per the rules of karma, Stalin could have compensated for the misdeeds of his previous lives by means of good deeds, but in his case, as the Buryat told Humphrey, the doom generated by the oath of the elephant was so strong that none could have possibly overturned it, not "even the Buddha and the deities" (189).

Interestingly, Humphrey demonstrates that, because of this reading of the figure of Stalin, the Buryat regarded him with a degree of empathy, as a man partially exculpated of personal blame: a character forced by spiritual dynamics greater than himself to perpetrate terrible deeds (182). Yet this view also allowed the Buryat to have compassion for themselves, and to excuse the fact they were forced to be complicit with the leader's crimes. To elucidate this particular point, Humphrey explains that the Buryat minority inhabited an area that was perceived to be at the borders of the state, a place close to other neighboring powers and therefore, from the perspective of the Soviet leadership, prone to infiltration by enemy spies (178). The Buryat's status as a suspect people was further enhanced by the fact that the Soviet regime saw them as a community so attached to reactionary supernatural beliefs as to be unfit for the revolution. As a consequence, special restrictions were enforced on them and their fidelity to the state was continually questioned and required constant confirmation. It is therefore plausible that, although the order to repress Buddhism came from Soviet leaders, some Buryat persecuted their own lamas to protect themselves from accusations of being traitors (197). When Humphrey was told that during the anti-Buddhist purges "they took the lamas behind the hill and shot them" (197), her interlocutors possibly used "they" to mean a mixture of "us" and "them." By articulating Stalin's wrongdoings as an inevitable consequence of the cycle of rebirths, the Buryat thus portrayed both the revolutionary leader and themselves as perpetrators who were also, at the same time, victims: tragic figures who were obliged to commit evil against the dictates of their better selves. ${ }^{10}$

10. Humphrey draws a parallel with psychoanalytic theory, and particularly with the notion of paranoia, understood as "displacement onto external people and events of internally generated, 
This ethnographic case is particularly intriguing as it offers an understanding of the identification between a leader and his people that contrasts with familiar views of the mechanics of revolution. In some canonical revolutionary traditions, as we have explained, the will of the people is canalized through the head-and made one with him-so that it can operate as a force that can change society and the course of history. In Buryat perceptions, however, a stress is placed on the limitations of human willingness in the sense that those who lead and those who are led can only partially affect events, as both have to endure the cosmic consequences of the actions of others. Incidentally, this view also carries an alternative conceptualization of the inevitability of revolution, a notion that, as briefly mentioned at the beginning of the chapter, characterizes Marx's revolutionary approach as well as others. Whereas in the Marxist episteme revolution features as the unavoidable consequence of historical factors-a concept that will be tackled in greater depth in the next chapter-among the Buryat we encounter the idea that the success of a revolutionary endeavor, and indeed of every endeavor, is the result of an inexorable destiny of which human history is but a consequence. The life, death, and exploits of Stalin are therefore reinterpreted by this community who lived at the margins of his political project, and inscribed within an assessment of history that differs from that which, theoretically, inspired the Soviet venture. This is one way for those at the periphery to make sense of power: by viewing it through the lens of their own categories. It is important to clarify, however, that far from being a peculiarity of the viewpoint of those who live at the outskirts, radical rearticulations of the figure of the leader can often be found at the epicenter of revolutionary projects. This can be clearly seen when assessing other facets of the Soviet context, and particularly if we examine the vicissitudes that characterized the death — and, in a sense, the afterlife- of Vladimir Lenin.

As demonstrated by Alexei Yurchak, after his passing Lenin was the object of a strategic reinterpretation carried out by his successors (2015). To elucidate this process Yurchak recounts how the Bolshevik leader was embalmed, his remains displayed in a mausoleum right at the symbolic center of the Soviet Union, Moscow's Red Square, and presented as a relic of the revolution. Over the years, Soviet scientists deployed different means to prevent the body from decomposing. Yet, as Yurchak shows, such operations were aimed at maintaining Lenin's appearance, including minor details like the original pigmentation around the armpits, rather than preserving his flesh (2015: 117). Various parts of Lenin's body were in fact replaced by nonorganic material so that, although standing as a faithful simulacrum of the leader, eventually the mummy only contained a small percentage of the original organs and tissues (117). According to Yurchak, this transfiguration into a "form without substance" was part of a broader maneuver aimed at transforming the revolutionary leader into a static vestige that had little to do with

unconscious quandaries" (2003: 29), a tendency to trace the cause of one's internal turmoil to the faults of others or to destiny, understood as an otherly force par excellence. 
the real Lenin: a process that had already begun during the leader's final years. When Lenin's health deteriorated, his peers had started to fight with each other over supremacy, and Lenin was marginalized in order to limit his capacity to designate a successor: a marginalization that, paradoxically, took the shape of consecration. By promoting the notion that "Leninism as a teaching was bigger than the flesh-and-blood person called Lenin" (122), prominent figures of the Russian Revolution encouraged the collection of the writings of their leader, texts that were deemed so fundamental to the preservation of revolutionary orthodoxy as to be considered almost holy: items that not even Lenin could edit or comment upon (122). Such a deification of sorts-which contrasted with Lenin's attempt to discourage people from constructing a personality cult around him-allowed his successors to keep him at bay and to exercise power without being bound by his influence. By consecrating Lenin his peers thus turned him into a symbol stripped of agency.

Yurchak further elucidates how, quite ironically, by transforming Lenin into a still image, his successors made it possible for Leninism never to be a fixed doctrine. Although ensuing Soviet leaders all described Lenin's revolutionary thought as the fundamental and unchangeable basis of their politics, each of them-from Stalin to Gorbachev-produced drastically new interpretations of Leninist theories in order to justify their own style of leadership. This constituted Lenin as an icon "behind which they could hide" (123), an image that allowed those in power to present themselves as nominal heirs of the great leader and, at the same time, implement ideas that were not condoned by him. Such a state of affairs, according to Yurchak, was reflected in the techniques used to maintain Lenin's mummy, which involved a "dynamic method of preservation that required regular reembalming, submerging the body in baths in special solutions for long periods of time, filling it with new liquids and substances" (127), so that Lenin's body was "continuously examined, fixed, resculpted, and reembalmed" (117) as a way of keeping it eternally the same by constantly altering it. The mummy thus appeared as a "living sculpture" (128), not only in the sense of being a "sculpture of the body that is constructed out of the body itself" (128) but also, more profoundly, because the relic was an entity whose features appeared immutable, but whose inner fabric constantly changed. As such, according to Yurchak, Lenin's simulacrum epitomized the Soviet party which, despite being represented by different leaders, was destined, in the Soviet narrative at least, always to remain the same: the eternal detainer of power, whose existence transcended that of individual heads and whose authority endured, notwithstanding its radically different incarnations. ${ }^{11}$

11. Yurchak draws a parallel with the bodies of royals. As famously elucidated by Kantorowitz (2016), in medieval legal theories the body of the monarch was seen as double, in that it encompassed both the actual body of the king and the immortal body of kingship which survived after the king's death. In funerary rites the effigy of the king-which reproduced his features and often contained his 


\section{CONCLUSION}

Bearing in mind the complex mixture of permanence and alteration that characterized Lenin's afterlife-and, more broadly, the Soviet context-we can move our attention toward a particularly intriguing facet of revolutionary leadership, a specific trait that is found in many of the cases we have touched upon, and that we can now briefly unpack by way of conclusion. The aspect in question is the degree of fluidity that seems to mark the instances of headship we have examined. Doubtless, there are recognizable and recurrent characteristics of leadership, not least the fact that in many of the contexts we have analyzed, leaders tend to be prevalently male: an aspect that testifies to dynamics of exclusion on the basis of gender that appear to be ingrained in some revolutionary projects. Nonetheless, leaders are also characterized by variation and flexibility: a tendency to escape monolithic categorizations and definitions.

This propensity for undefinedness can be observed, for instance, in the case of the tricksterish "external masters": heads who constantly change their policies and stances, presenting themselves, as we have seen, as permanent exceptions to norms and rules, purposely keeping their revolutionary enterprises unclear, mutable, and open-ended in order to stay in power. A similar tendency, however, can be found even in the context of leaders who embrace extremely codified revolutionary agendas-at times with very specific references to distinct canons like the Marxist tradition, as in the case of Lenin-as these figures too elude classifications, and are constantly reinterpreted and expanded upon. In the light of these dynamics one can detect a certain element of "unfinishedness" that typifies at least some expressions of revolutionary authority, an openness to conceptual reorganization that demonstrates that even when considerable effort is put into presenting the leaders' personas and their ventures in a specific fashion, the actions of those who lead may still be radically rearticulated by those who are led.

Should one be inclined to support the notion of a leaderless revolution-as in the case of the anarchist episteme elucidated at the beginning of the chapter-this propensity for malleability and reinterpretation might reveal an inherent partiality, incompleteness, and defectiveness in the very practice of leadership, as revolutionary processes seem to be structurally prone to multivocality, differentiation,

\footnotetext{
hair or other parts of his body-stood in opposition to the corpse of the king, making the imperishable essence of kingship visible (Yurchak 2015: 130). Similarly, Lenin's mummy, an effigy of sorts, represented the "immortal, infallible, perpetually renewed body of the sovereign party" (2015: 147) that persisted even after the death of individual leaders. Somewhat in a similar vein, Rafael Sánchez shows how in Venezuela, power holders "monumentalize themselves" (2016: 4), cultivating a statuesque demeanor in order to, supposedly, embody the changeless will of the people: a maneuver that allowed them to artificially homogenize Venezuela's ethnically heterogeneous population and to reinforce their authority. On the relation between the bodies of deceased leaders, statues, and monuments in postsocialist contexts, see Verdery 1999.
} 
and openness: the result of people putting forward their own different interpretations of the world and of what might be wrong with it, rather than merely relying on a leader's giving voice to their different emancipatory aspirations. Conversely, if one was to embrace some recent Marxist analyses (Laclau 2005), the indefiniteness of leadership might not necessarily appear to be detrimental to revolutionary policies, as "unfinished" leaders, precisely because of their capacity to avoid being fully defined by detailed revolutionary programs, might be able to represent a range of different groups whose demands for change are not met, thus turning the existence of particularisms into an occasion for cohesion among the exploited. This might give rise to the tracing of a clearer differentiation between those who have power and those who, despite their differences, are subjugated by it, so that revolutionary action against the former can take place (ibid.).

Regardless of whether the fluidity of leadership might be the ultimate proof of its ineffectiveness, or the expression of its radical potential, the fact that revolutionary heads inevitably appear to be multifaceted and prismatic figures who are constantly shaped by the gaze and the perception of other human beings speaks, in the end, to a particular idiosyncrasy of revolutions, and that is the unavoidable prominence of the people-in whatever way such notion is understood-in the unfolding of upheaval and revolts. Doubtless, one cannot read all revolutionary phenomena through the lens of the canonical view of leadership as a mere function of the will of other human beings. Nonetheless, a certain primacy of the "others," even when revolutionary endeavors seem to revolve around a particular "self," appear to feature both in familiar and unfamiliar expressions of revolutionary authority. 


\title{
Revolution and Ideology
}

\author{
Truth, Lies, and Mediation
}

\begin{abstract}
Morality, religion, metaphysics, all the rest of ideology and their corresponding forms of consciousness, thus no longer retain the semblance of independence. They have no history, no development; but men, developing their material production and their material intercourse, alter, along with this their real existence, their thinking and the products of their thinking.

-KARL MARX
\end{abstract}

Consider how poet Octavio Paz describes the Mexican Revolution: "A search for our own selves ... a releasing of many ferocious, tender and noble feelings that had been hidden by our fear of being" (Paz [1950] 2005: 149). ${ }^{1}$ In Paz's words the revolution features as an instance of unprecedented authenticity, one finally offering Mexicans the opportunity to express their real emotions, aspirations, and desires. An "explosion of reality" (149), Paz calls it. Such words resonate with many other descriptions of the revolutionary moment. Take, for instance, Franz Fanon's famous account of the Algerian anticolonial revolution of the 1950s. "After centuries of unreality, after having wallowed in the most outlandish phantoms, at long last the native, gun in hand, stands face to face with the only forces which contend for his life-the forces of colonialism" (Fanon [1961] 2007: 58). Revolution, in these descriptions, is understood not only as the beginning of a new state of affairs, ushering in the New Man of chapter 3, but also as the end of "unreality." This is the moment in which illusions and phantoms come to an end, and the reality of self and things can at last emerge; a time when, in the words of Chairman Mao, one can "grasp the essence of the thing" (Tse Tung [1930] 2014: 119), meet the truth face to face, and distinguish, gun in hand, between friends and foes, verity and lies, real and unreal.

1. The Mexican Revolution, also referred to as the Mexican Civil War, represents a lengthy process of political change that began a century after the Hidalgo insurrection discussed in chapter 1. 
Revolutions, it seems, bring about disclosure. Reality, once hidden, is made manifest. To describe this process, both theoreticians and practitioners of revolution have often made use of a specific concept, a notion that has featured in the speeches and writings of countless agitators, radicals, and rebels: ideology. This loaded term appears in a variety of discourses, at times simply indicating systems of ideas that are shared by a group of people, often with reference to political creeds, but also, more broadly, to interpretations of the way society works and explanations of what it means to be human. Ideologies, in this understanding, are descriptions of reality that help us make sense of the world (Geertz 1973b: 220; Therborn 1999: 2). Further, even though this use of the term does not prevent judgments on which ideologies describe the real accurately and which do not, here the concept itself holds a neutral connotation (Mannheim [1936] 2000: 59-83; Abercrombie et al. [1980] 2014: 188). There might be good and bad ideologies but, ultimately, the term "ideology" simply designates a worldview. There is, however, another use of the word, one that requires us to take a much stronger stance in assessing the way reality is described, and it is this second, more intense meaning of the concept that historically has proved more influential in revolutionary discourses.

One can detect traces of this stronger connotation even when "ideology" is used in a nonevaluative manner. Even when one deploys the concept simply to mean "the way in which a group sees reality," the term always has certain implications. Ideologies are culturally specific in that they always interpret reality through the lenses of social, political, or religious views; consequently, they are not impartial (Therborn 1999: 3). Indeed, they are emotive, tending to describe the world as one would like it to be, rather than as it is (Geertz 1973b: 205). Ideologies, therefore, are usually seen as discourses that differ, whether in style or content, from supposedly objective descriptions of the real produced in disciplines such as economics or the natural sciences, although it is understood that these too might entail ideological views (Abercrombie et al. [1980] 2014: 173-74). ${ }^{2}$ Indeed, this notion of ideology as subjective discourse can be found even when philosophers use the concept to claim that the world begins to exist only when we describe it, and that, therefore, there is no such thing as an objective reality devoid of ideological connotations. In this case too there is an implication that our descriptions of the world inevitably carry with them our prejudices and preferences (Jameson 1984: viii; Anderson 1998: 24).

Now, this view of ideology as partial and ultimately tendentious description of the real has a precise genealogy. It is with Marx that the concept first acquires

2. "Where science is the diagnostic, the critical, dimension of culture, ideology is the justificatory, the apologetic one" (Geertz 1973b: 231). "Not all ideology is or can operate as science, art, philosophy, or law, but all these emerge out of ideological configurations and may function as ideologies" (Therborn 1999: 2). 
the meaning of a biased, not completely truthful interpretation of things, and it is due to him that the term has become forever part of the revolutionary vocabulary (Therborn 1999: 4). Ideology, in the Marxist framework, indicates false beliefs that in time have become a habitual component of the way we interpret the world. These sedimented lies, for Marx, can be challenged and uprooted by revolutionary effort, and it is often in this sense that the revolution is understood as an event that reveals reality. Revolution puts an end to ideology and, when this happens, Marx tells us, false descriptions of reality are replaced with new, more reliable interpretations that are closer to the actual truth of life and society. These views-and the opposition between ideology and reality that they imply-have been developed by various Marxist philosophers, and in this chapter we briefly present some of the main theories produced in this context by these thinkers. However, we also juxtapose these reflections with the way notions of truthfulness and falseness are articulated, thought about, and put into practice in concrete revolutionary contexts.

As we will see, in places like Iran and Libya, revolution has certainly been understood as an event that establishes a more truthful existence. Some of these revolutionary discourses have also been influenced in various degrees by Marxist views. Nevertheless, we will see that these contexts have produced their own understandings of what counts as real and what counts as ideological, and these notions have often been articulated in ways that are different from those of the European revolutionary tradition. Exploring these local takes on the relationship between reality and ideology gives us a chance to tackle a number of questions. If ideologies are false representations of the real, then why do people believe them to be true; furthermore, do they actually believe in them at all? Is it possible, as Marx thought, to end ideology? Is revolution necessarily about extinguishing anything that stands between us and reality? Proponents of Marxist lore have provided insightful answers to some of these queries, but so have Iranian ayatollahs and Bolivian social movements. Let us therefore see how these answers resemble or differ from each other, mapping how different revolutionaries have positioned themselves vis-à-vis the complex relationship that exists between reality and the way we describe it.

\section{THE WORLD UPSIDE DOWN}

To better compare Marxist thought with other revolutionary discourses we first need to explain how, according to Marx, ideology is false. To this end it is useful to clarify that before Marx, in the aftermath of the French Revolution, liberal philosopher Antoine Destutt de Tracy had already used the term ideology, and Marx knew it. In the context of the celebration of reason that marked the Enlightenment, Tracy had proposed the creation of a new science of ideas, a discipline that would study mental processes using the means of natural sciences (Rich- 
ards 1993: 103). Tracy called this discipline "ideology," and claimed that his new science could objectively assess which of the ideas put forward by the French Revolution were sound and which were not. This was, for Tracy, a way to purify the revolution of its irrational and utopic components, which he located in the demands for redistribution of wealth and direct democracy that had been made by revolutionary groups close to the sans-culottes (Rehmann 2013: 18). In opposing these requests Tracy enlisted ideas whose reliability was supposedly proven by the science of ideology, namely the need for people to be governed by representatives, and the individual's right to do as he pleases with his property (Tracy [1818] 1973: 47).

Interestingly, Marx too believed that ideology provided a justification for these ideas, although he understood this dynamic in a completely different way. Tracy had attempted to prove that liberal values were scientifically truthful, rational, and rooted in human nature (Tracy [1818] 1973: 23). Marx, on the contrary, did not see these values as objectively true, but rather as the product of Tracy's subjective way of seeing the world: an expression of his background and of the social class to which he belonged. In particular, according to Marx, Tracy's defense of private property had mainly to do with the fact that, apart from being a philosopher, Tracy was a wealthy landowner and "a fish-blooded bourgeois doctrinaire" (Marx [1867] 2011: 711), and, as such, he was inclined to protect his property against the demands of the unprivileged. Tracy's ideology was thus a convenient subjective truth presented as the truth, and the same applied, in Marx's view, to other ideas in the domain of politics, law, and morality. In all that "men say, imagine, conceive" (Marx and Engels 2001: 47), Marx thought, there is ideology: ideas that are presented as natural and good for all, while in fact they serve the interests of the few. ${ }^{3}$

Thus, for Marx ideology has a dangerous capacity for deceit, particularly in the context of capitalism. Ideological discourses justify the divide between those who own the property, capital, and means to produce and sell, and those who, in order to survive, are forced to work for and buy from the former. Ideology deceives by hiding the exploitative character of this divide, and, therefore, by representing reality in a completely twisted manner. In ideology "men and their circumstances appear upside down" (Marx and Engels 2001: 47), and this distorting quality, Marx argued, is so powerful that it infects the very consciousness of people. Religion, for Marx, played an important role in this process. By confining the realization of justice to the afterlife, religious discourses justify exploitation in this life, contributing to the creation of a "false consciousness" in the oppressed (Engels 1942a: 511): an

3. Napoleon was the first to use ideology in a pejorative sense. Tracy's followers were known as idéologues, a term that came to indicate thinkers influenced by the Enlightenment. Napoleon accused them of undermining his authority, dismissed their science, and declared, "we must lay the blame for the ills that our fair France has suffered on ideology" (Rehmann 2013: 19). 
illusionary image of the self based on the idea that it is natural for the poor to live a life of sacrifice working for a master without enjoying the fruits of their own labor because such is God's will (Marx 2007: 72).

In Marxist thought there is, therefore, a clear-cut division between ideology and reality. On the one hand, there is the real, the tangible actuality of exploitation; on the other, there is the unreal, "the chimeras, the ideas, dogmas" (Marx and Engels 2001: 37), the ephemeral falsities of ideology. In this differentiation, for Marx, lies the key to instigating revolutionary change. By looking at the concrete inequality that exists in society, one discovers that what appears good in ideology is bad in reality, thus uncovering the contradictions of ideology "in a purely empirical way" (42). This realization brings about another. Although ideology affects people's lives, it is not, strictly speaking, a real thing that exists in itself. Ideology only exists in our heads; it is made of inconsistent concepts and thoughts that are there only to justify the reality of exploitation. ${ }^{4}$ As such, ideology will vanish as soon as exploitative conditions come to an end (47). When revolution establishes fairer material conditions - a better reality for all-humans will abandon false consciousness, and embrace their real selves, the "essence of men" (37), which, for Marx, entails the capacity to satisfy one's needs by creatively expressing oneself through work. ${ }^{5}$

Marx's revolutionary project had a universal vocation. The emancipation of the oppressed, in his view, would bring about the emancipation of all humans: the end of the tyranny of lies and a return to reality and truth for all mankind (Marx 1970: 140-41). This appealing promise attracted the interest of many, with Marx's premises offering themselves to a variety of readings. Marx himself elaborated some of his views during his lifetime and left much unsaid, leaving space for different interpretations of whether ideology could be considered to be completely false (Eagleton 1991: 87). This allowed Marxist philosophers to interrogate Marx's sharp differentiation between reality and ideology, and to theorize the possibility that there might be points of contact between the two. In particular, these intellectuals became interested in the gray area that might exist between the real and the unreal, and in the possibility that the unreal lies of ideology might paradoxically prove useful in establishing the reality of revolution. Therefore, before we look at how these issues have been dealt with in other revolutionary contexts, it is worth examining how Marxist thinkers have tried to stay within the parameters of Marxism

4. According to the majority of commentators, Marx thought that while it is true that ideology is generated by material conditions, it is also true that in turn it influences these conditions. This position is clearly stated by Engels (1942b: 475).

5. On the one hand, Marx thought that specific material conditions create specific ideological stances on what it means to be human (Marx and Engels 2001: 47). On the other hand, Marx believed that the ability to freely and consciously transform the world through work is an inherently human characteristic, our "species being" (Marx 1974: 329; Wartenberg 1982: 79-80; Patterson 2009: 39-57). 
and, at the same time, go beyond it. Many have debated these matters, but here we consider only a few examples of theoreticians who have examined the degree to which the unreal can be real.

\section{THE REALITY OF IDEOLOGY}

One of the first to embark on such an endeavor was Italian intellectual Antonio Gramsci, whose influential ideas can help us chart the different approaches to ideology that developed after Marx. Gramsci brought about a fundamental innovation in Marxism, introducing the idea that for ideology to work as a tool of power the oppressed must give their consent to it. To elucidate this point, Gramsci identified a specific component of ideology that he called "hegemony": false beliefs that are not imposed on the exploited-whether through false consciousness or coercion-but consciously accepted by them (Gramsci 1992b: 201, 219). According to Gramsci, hegemony is freely assented to because doing so proves advantageous; it allows a person to behave according to the parameters of dominant ideology, and, therefore, to do as the majority does, to fit into society. Hegemony is thus experienced by the oppressed as the best course of action, an expression of "common sense" (Gramsci 1992a: 173): indeed it informs one's practices, giving meaning to life in a concrete way and offering guidance on how to behave with good sense at home or at work. Hence we have, with Gramsci, a variation on the original Marxist premises. Hegemony, is not, as in Marx's ideology, something we think, but something we do: a practice that, although not based on truth, is not, strictly speaking, false because it resonates with one's real experiences (Eagleton 1991: 118).

Humans, for Gramsci, always navigate the world according to interpretations of reality that make sense to them in light of their experiences: descriptions of the real-ideologies - that make them conscious of themselves as subjects who act in the world. And while it is true that the dominant ideology is based on false premises, it is also true that some ideologies might have an emancipatory quality, an inherent capacity to provide awareness that one is a subject capable of action. In Gramsci's view, therefore, the difference between good and bad ideologies does not reside, as Marx has it, in how truthfully they represent reality, but in how good they are at situating us in the world (Gramsci 1992b: 175). Based on experience, the dominant ideology contains both elements of conformity ("in my experience doing as others do proved good for me") and potential resistance ("that one time I did not do as others do it was good for me") (Eagleton 1991: 118). Consequently, it produces a sense of being in the world that is marked by contradictions. Bearing this in mind, Gramsci believed that revolution should not try, as Marx argued, to end ideology; rather, it should establish a better ideology that accounts for our experiences in a coherent, noncontradictory manner (Williams 1977: 111).

Gramsci's thought expresses the inevitability of ideology. In his analysis there is the sense that humans never see reality as it is, but always through the medium of 
ideological interpretations, a notion that we find in the majority of modern Marxist investigations, and particularly in the work of leading Hungarian philosopher Georg Lukács. Much like Gramsci, Lukács argued that it is impossible for us to perceive the real without ideology; however, he took this notion in a slightly different direction. He believed that even though we cannot see reality fully, we can still grasp parts of it-glimpses of the truth, so to speak-and this, for Lukács, is precisely the problem with ideology. For Lukács, ideological narratives interpret the world on the basis of partial understandings (1971: 204), so that, rather than lies, they are better described as partial truths. ${ }^{6}$ Like Gramsci, however, Lukács did not believe that all ideologies are equal. While all offer an incomplete understanding of reality, some are more incomplete than others (Eagleton 1991: 98). That is the case, in Lukács's view, with the ideology of the dominant classes, which certainly has something to say about who is supposed to dominate and to be dominated in society, but fails to elaborate-indeed, is practically silent-on the underlying reasons that might determine the exploitative relationship between the two.

Other ideologies, Lukács argues, offer a more detailed interpretation of the world, and if Marxism itself might be considered an ideology, Lukács believes that it belongs to this second type: it searches for deep connections between things; it tries to put together a bigger picture that accounts for complexity (Eagleton 1991: 96). In short, it is a partial truth that is less partial than others. Such considerations have brought Marxist thinkers to argue that the opposite of ideology, or at least of bad ideologies, is neither truth nor reality, but complexity. Ideology does not so much misrepresent the real but selects certain aspects of reality, which may even be true, and presents them as the whole: a reflection that has pushed a number of Marxists to draw a parallel with psychoanalysis. As famously argued by Sigmund Freud, our relationship with the unconscious is one of selection. Our mind selects our memories and perceptions, and it represses the more complex and disturbing-often, perhaps, the truer ones-by relegating them to the unconscious, so that our conscious identity is, in actual fact, a simplified version of ourselves. Similarly, ideology removes complexity from the world and from the self, producing a reductive, sanitized, simplistic sense of identity and reality. ${ }^{7}$

Among those who tried to complement Marx's theories with Freud's insights, German theorist Theodor Adorno deserves special mention. Adorno argued that,

6. Lukács explains this partiality by arguing that thought is a component of any process of change (1971). The moment an oppressed group thinks about its conditions, the concrete possibility of resisting oppression appears: thought immediately becomes part of a change in reality. According to Lukács, therefore, we never know reality fully because the very act of knowing - of thinking about realitychanges it (Eagleton 1991: 94). For a Marxist critique of Lukács see Poulantzas 1987.

7. Some Marxists have preferred an analogy with language. Jürgen Habermas, for instance, sees ideology as a form of communication that has been distorted to such a degree that it has lost both the criteria according to which it can be judged to be distorted and the linguistic tools that allow us to describe it as such (1984: 39 ). 
as ideology abhors complexity, it creates anxiety about anything that is difficult to grasp because it is different from us (Adorno 1973: 161; Eagleton 1991: 126), encouraging an obsession with sameness (Jameson 1981: 114-15) and the formation of a self that knows no other. The role of revolution, for Adorno, is therefore that of rediscovering otherness and heterogeneity in order to "open the road to the multiplicity of different things" (Adorno 1973: 6) that exist outside of ourselves and that are not accounted for by ideology. ${ }^{8}$ In a unexpected twist, Marxists like Lukács and Adorno thus turned Marx's interest for "reality as it actually is" on its head by showing that ideology focuses precisely on the way a given thing is, and hides the links that connect things with each other: the fact that "what is, is more than it is" (Adorno 1973: 161). If Gramsci endorsed the creation of a coherent way to look at the world, with Adorno we almost see a suspicion of anything that is too coherent, because any easy-to-grasp, one-dimensional view of the world bears, potentially, the mark of oversimplification and ideology (Marcuse 1991: 13).

Some Marxists took this approach to its logical extreme. French philosopher Louis Althusser, for instance, argued that the very idea of a coherent self-the sense of identity that allows us to say "I"-is the product of ideology. If it is true, as psychoanalysis holds, that for the conscious self to emerge, the most complex aspects of the self have to be repressed in the unconscious, then, Althusser argued, the "I" is the result of ideological simplification: a product of the repression of our own multiplicity (Althusser 2001: 109). As we have explained in chapter 3 , this operation is achieved through what Althusser calls "interpellation." The moment that someone, particularly someone in authority like a teacher, parent or policemen, addresses us as "you," our ideological "I" is born, and we immediately interiorize the place of subordination that the dominant ideology has assigned to us in society, such as that of a student, child, or citizen (109). ${ }^{9}$ In proposing these arguments Althusser was influenced by Jacques Lacan, a psychoanalyst whose ideas have permeated the most recent discussions of ideology, particularly the work of Slavoj Žižek, a Slovenian philosopher whose thought measures how far Marxist thinkers of today have moved away from Marx's original formulation of ideology as unreal lie.

Žižek borrows from Lacan the idea that one should differentiate between the Real — the truth of the world and of our selves—and Reality — the truth as we experience it and try to make sense of it (Žižek 1995: 14). Using this differentiation,

8. Adorno also warns us against the opposite extreme. Focusing merely on difference is also an ideological move, because to identify what is singular one has first to assume a sameness against which the singular can be defined as such. For Adorno, therefore, "singularity is itself an abstraction, the waste-product of identity thinking" (Dews 1994: 57).

9. Althusser also believed that ideology becomes so interiorized by the subject that it mainly works at the level of the unconscious (Eagleton 1991:115). For a Marxist critique of his approach see Hall 1985; Eagleton 1991: 144; Thompson 1995. 
Žižek argues that we never see the Real because facing it would overwhelm us to the point of psychosis. Rather, we always try to render it comprehensible by using our interpretations, our ideologies. Even though ideology is a fiction, a discourse that never faithfully represents the Real, without it we could not have a livable reality (Žižek 1994, 2008: 45). Contrary to Marx, Žižek thus maintains that the Real, or actual truth, has to stay hidden behind ideology for reality, our truth, to emerge. Žižek clarifies, however, that in our lives we always have experiences that contradict ideological explanations of the world, phenomena that remind us that ideology cannot account for the whole of the Real. ${ }^{10}$ For revolution to happen, Žižek holds, we should not try to create more coherent or more complex ideologies that account for these contradictions, as per Gramsci and Lukács; rather, we should capitalize on this very capacity of the Real to resist being encompassed by ideology, as it can help to subvert dominant discourses. ${ }^{11}$ Yet in doing so, we should also always remember that, ultimately, revolution, like every human endeavor, is an ideological construction. Given that for our reality to exist we necessarily need to act as if ideology is the truth, revolution too should be pursued by believing it is the truth. Then, should the revolution succeed, we should retroactively treat it as a "real truth" that has been such all along (Žižek 2009: 460).

\section{BELIEVING AND PRETENDING}

These intellectuals have proposed different approaches to ideology. In broad terms, however, one can identify three main issues that seem to be at stake in the Marxist analysis: the fact that people experience and believe in ideology as the truth; the role of ideology as the medium through which we see reality; and the question of whether revolution can establish a better ideology, a less partial, more comprehensive worldview. Let us therefore shift the discussion and consider how these three issues play out in actual revolutionary contexts, first briefly elaborating on Žižek's analysis, particularly in relation to how power-holders disseminate propaganda-false ideological information-for political purposes. Expounding on his idea that truth needs to be hidden by ideology for reality to take place, Žižek argues that, deep inside, citizens know the truth about propaganda; they know it is false (2008: 74-75). However, they behave as if they do not, because the truth, the fact that power-holders lie to them, is destabilizing. Therefore, they repress their knowledge of the truth, so that their everyday reality can persist; they ignore the

10. In the early work of Lacan, the Real indicates primordial pre-language experiences we feel in our body and mind, but later on Lacan uses the term to indicate the fact that language and ideology always fail to make sense of everything we experience. In this sense, the Real is not an actual thing but the very limitation of culture and language: a gap (Žižek 2008: 191-95).

11. For an explanation of how the Real's resistance toward Ideology can also sustain Ideology, see Žižek 2008: 140-43. 
fact that they have been given a false interpretation of things so that they can go on with their work, lives, and routines. Žižek argues that people begin by pretending propaganda is true, and then this becomes such an important part of their world that they end up believing that it is (74-75), a consideration that can help us tackle the first of our three issues, people's belief in ideology.

Ethnographic accounts have problematized Žižek's analysis. Take, for instance, Yael Navaro-Yashin's analysis of Turkey, a country whose political discourses have been marked by the so-called Atatürk Dervimleri, a series of revolutionary reforms introduced by Mustapha Kemal Atatürk, the founder of the modern Turkish state. In the 1920s Atatürk introduced radical changes in the country, dismantling various state practices rooted in Islamic discourses that had operated during the Ottoman Empire, thus supposedly turning Turkey into a secular state. NavaroYashin shows that the Turkish state still relies on motifs from Atatürk's revolution to create propaganda aimed at legitimizing itself. ${ }^{12}$ In analyzing this state of affairs, she explains that often Turkish citizens pretend to believe in state ideology. More specifically, she shows that, while it is true, as argued by Žižek, that sometimes, by pretending, these subjects start to believe, it is also true that often they simply pretend in order not to be bothered by the Turkish government (Navaro-Yashin 2002: 1-16, 162-71, 179). Such considerations help us detect an aspect of ideology that seems to have escaped the gaze of Marxist intellectuals-namely, that while it is true that ideology can permeate our identity and our world, it is also true that when it comes to the lies of power, there is space for pretense. Publicly portraying oneself as a believer in an ideology while privately remaining skeptical of it remains an option, a phenomenon that has also been documented in other ethnographic contexts where resistance has been shown to take place "offstage" through implicit and subtle strategies (Scott 1985: 241-89, 1990; Weeden 1999: 67-86).

It is also important to stress that, at times, tracing a clear-cut difference between pretense and actual belief in ideology-a distinction that seems to be implied in the theories of the Marxist philosophers we have mentioned-proves a difficult task. Although Žižek proposed that the former always paves the way for the latter, often the two seem to coexist. This was the case, for instance, in Libya, before the popular revolution of 2011-aided by a controversial military intervention by the international community-put the socialist rule of Colonel Muammar Gaddafi to an end. As part of his propaganda machine, Gaddafi had filled Libya with giant photographs of himself on billboards that portrayed him not only as a symbol of the nation, as per his motto "Gaddafi is Libya, and Libya is Gaddafi", but also as an undefeatable fighter and prophetic guide: a being with supernatural status not achievable by commoners (Khatib 2013: 185). When the anti-Gaddafi revolution

12. Navaro-Yashin (2002) problematizes the difference between secular and religious, showing how in Turkey they are both expressions of the same culture of statism. 
took place, however, Libyans reversed this ideological project (187). They drew mocking caricatures of Gaddafi on walls and buildings, transforming the leader from a semi-divine being into an object of derision: a transmutation that culminated in the colonel's brutal death (197). ${ }^{13}$ When the revolutionaries captured Gaddafi, they ridiculed him and killed him, thus marking the end of a process in which Libyans had seemingly gone from believing in propaganda to rebelling against it. A closer look, however, discloses that, under Gaddafi, people's attitude toward his ideology was not one of full acceptance, as one might expect following both Marx and Žižek, but an indistinguishable blend of sincere credence and genuine skepticism.

Undoubtedly, Libyans were not immune to Gaddafi's ideology, and at times they even embraced it by putting up portraits of the superhuman leader in their workplaces. However, they also referred to Gaddafi in extremely human terms. Often they called him "Muammar," using his first name, so that in the event of being questioned by Gaddafi's police over negative comments, they could say they were talking about a different Muammar, quite a common name in the country (Cherstich 2014b: 102). This was certainly a precautionary measure, but it was also a way to stress the mere humanity of the leader, a trait that was underlined by using fleshly insults when referring to Gaddafi, swearwords that were commonly deployed in everyday life: kelb (dog), tes (goat), zamil (effeminate homosexual) (102). Libyans thus pretended to believe in the ideological framing of Gaddafi as superhuman while in fact they knew he was just a man. ${ }^{14}$ What is interesting to notice, however, is that the same people who described Gaddafi as a cunning politician who fooled his people through propaganda also admitted that there was something uncanny about him, as demonstrated by the fact that he had remained in power despite numerous assassination attempts (102).

Although Libyans did not buy into the propagandistic view of Colonel Gaddafi as a supernatural benign force, they did accept the possibility that their leader might have some magical traits, describing him as a scary, eerie entity. Often they alternated between calling him some colorful swearword and referring to him as "Shaytan" (Satan). For some, Gaddafi was a sorcerer, an expert in manipulating genies that would tell him in advance of any threat or plot against him (Cherstich 2014b: 103). For others, Gaddafi had mastered the dark arts to such a degree that he had been able to transcend the limits of human nature; often people even questioned whether the leader was mortal at all (104). One might therefore assume

13. On the role of aesthetics and representation in recent revolutionary contexts see Werbner et al. 2014, and Winegar 2016.

14. Arguably the only one who fully believed in Gaddafi's propaganda was Gaddafi himself. According to Abercrombie et al. ([1980] 2014: 2), dominant ideologies ultimately succeed in establishing certain views of the world because they are passionately believed in by the dominant rather than by the dominated. 
that Libyans were entangled between pretense and belief, although the element of belief played out differently than Gaddafi had expected. The views of Gaddafi as human and superhuman thus coexisted, and it was only with the revolution of 2011 that Libyans were able to actualize one of the two possibilities. In producing caricatures of their leader, images that, by exaggerating his facial traits, stressed his corporality, Libyans were finally able to establish Gaddafi's humanness, a trait established once and for all with his killing (94).

This brings to mind the notions discussed above, particularly Gramsci's understanding of ideology as discourse marked by contradictions-in this case the contradictory view of Gaddafi as both mortal man and magical entity-as well as the view of revolution as an occasion to embrace a noncontradictory view of the world, demonstrated by Libyans who choose to see their leader as merely a man. It is important to remember, however, that often people do not seek to solve the contradictions of ideology, nor they do feel forced to choose between pretense and belief. Rather, at times, ideology does not demand belief to begin with. A similar dynamic is documented in Alexei Yurchak's analysis of the USSR between the 1950 s and the 1980s. In unpacking this scenario Yurchak argues that in late socialism, state ideology was much more concerned with form, with people behaving in ways that formally reinforced the ideology, than with content, that is, sincere belief in the socialist doctrine (Yurchak 2006: 25). In local elections, for instance, Soviet citizens would vote without bothering to discover the implications of their vote, and the state had no interest in cultivating a more committed attitude toward these political duties (25).

Significantly, Yurchak explains that people did not perform these acts because they feared repercussions from the government. Rather they did so because late Soviet ideology was performative and flexible in nature (27-28). Ideological discourses allowed people to attach their own meanings to the performance of their duties as Soviet citizens, which, although often dissimilar from those of official state ideology, were not perceived by the government as a form of resistance, nor did they prevent subjects from feeling a genuine affinity toward socialism (27-28). Yurchak's study, therefore, invites us to unpack the difference between belief and pretense, putting forward the notion that ideology may have more to do with behavior, performativity, and personal reinterpretations than with static belief or codified experiences.

This is a consideration that, incidentally, resonates with the findings of the vast anthropological debate on the notion of belief (e.g., Needham 1972; Asad 1983; Latour 2010), and with the works of anthropologists and sociologists who have shown that individuals do not necessarily perceive the contradictory aspects of ideological narratives as incongruous (e.g., Asad 1979; Hall 1980; Ortner 2006; Schielke 2009). Interestingly, however, Yurchak's study also presents ideology as that which stands between people and their reality. Though fluid and prone to 
different interpretations, Soviet state discourse was a medium that allowed subjects to make sense of their actions, a point which leads us to assess the second major issue we identified in the debate on ideology: the way in which ideological discourses mediate people's relations with the world and with themselves.

\section{THE GREAT MEDIATOR}

As we have seen, thinkers like Gramsci and Lukács concede that human beings always see the world through the lens of their ideological interpretations. According to these philosophers, therefore, our experience of things is never immediate; rather, it is necessarily mediated by ideology. Nonetheless, as we have also seen, Marxist theorists, with the noticeable exception of Žižek, also articulate revolution as offering the possibility to lessen the mediating capacity of ideology to such a degree that the complexity of reality - the real as it is-becomes more visible. Marxism thus seems to imply, at least in some of its incarnations, not so much an attempt to completely do away with that which mediates between ourselves and reality but, rather, the desire to reduce it to the minimum necessary: a theme that can be seen in many aspects of Marxist praxis. Take, for instance, Lenin's understanding of the "withering away of the state" mentioned in chapter 2. This notion encapsulates the idea that, although under communism people are supposed to rule themselves without a state, they cannot do so straight away. The role of the state as mediator between the masses and the exercise of power is still deemed necessary in the first phases of revolution. While eventually the state must disappear, this process is seen as one of slowly fading away, a reduction to the minimum necessary: a view that differentiates Marxism from other revolutionary epistemes like anarchism which, as we have seen, advocate either the instant eradication of all mediators (be it the state or other institutions) (Chomsky 2008: 94-95; Lenin [1917] 2014: 97), or the immediate creation of spaces that operate autonomously from these mediators (Graeber 2002: 68).

It is important to stress, however, that not all revolutionary discourses are concerned with reducing the mediation of ideology and unveiling reality as much as possible. In fact, some revolutionary theories aim at doing the very opposite: augmenting the degree of mediation. Consider the case of Iran. Even though different sections of Iranian society, including Marxist associations and religious groups, contributed to deposing the Shah, eventually, as we have seen in chapter 3, senior cleric Ruhollah Khomeini prevailed as leader of the revolution. Doubtless, Ayatollah Khomeini appropriated bits of Marxist language, mainly in matters of popular mobilization, and, like Marx, understood revolution as enabling people to access the true reality of things (Varzi 2006: 36-37). However, the leader also acted as an intermediary between Iranians and divine will: the interpreter of those pieces of Islamic jurisprudence that, in his view, justified his revolutionary actions and poli- 
cies. Indeed, Khomeini's mediating power was so effective that his public speeches would come to have binding legal value as soon as they were spoken (36-37). In sharp contrast with the Marxist approach, the Iranian leader thus presented himself as a necessary medium through which the truth could be shown to the masses: a notion that Khomeini articulated in complex spiritual terms.

Using themes from Iranian Sufi mysticism and drawing on esoteric interpretations of Shi'a cosmology, Khomeini referred in his speeches to the Sufi distinction between baten (the inner, true nature of reality) and zaher (the outer, external, and superficial facet of the real: a "veil" that covers up the truth) (Mottahedeh 2000; Varzi 2006: 5, 19). In Iranian mystical doctrines, one can never completely uncover the inner reality and directly face it, as this dimension is too intricate and deep to be grasped. Rather, the truth can only be understood through the medium of the outer, that is, through allegories, symbols, and veiled poetic descriptions that reveal some aspects of the truth and, at the same time, conceal others (Varzi 2006: 4). Now, Khomeini presented himself as the one who could guide Iranians through this complex maze of metaphors and indirect references. Furthermore, he articulated his very persona as a metaphor. Even though he emphasized that people should exercise power in a direct and unmediated fashion-an approach that led him, among other things, to launch a referendum that allowed Iranians to choose between the Shah and his own rule-he aimed at presenting his image as the key allegory through which one could understand the revolutionary process and participate in it.

To this end, photographs of Khomeini were mass-produced and used as the lens through which one could contemplate the spiritual aspects of the revolution (Varzi 2006: 6, 27). The pictures were pinned to the uniforms of Iranian soldiers and even, in some cases, to the graves of the dead, meaning that Khomeini was present on the battlefields, at mourning ceremonies, everywhere; seeing Khomeini's likeness people could identify with him and interiorize his teachings $(6,27)$. This practice resonated with Iranian Sufi doctrines according to which religious images are useful tools that can help one contemplate divine truth: media that allow the Sufi to slowly grasp the mystical reality that lies beyond the image and ultimately within oneself (28-30). Such use of spiritual motifs illuminates the deeper aspects of Khomeini's thought, and helps us to shed light on the difference between the Marxist view of revolution as an occasion to lessen ideological mediation and the Iranian one as an amplification of it. Nonetheless, there is an important clarification to be made. Since the Iranian Islamic state sprang out of a Shi'a setting, where clerics often act as intermediaries between people and divine will, one might conclude that it is precisely because of Shi'a cosmology that Khomeini emphasized the concept of mediation, whereas Marxists, being adverse to religion, tend to reduce it. This, however, would be a great simplification of the revolutionary dynamics that are at stake here. 
Doubtless, some Shi'a discourses put great emphasis on the notion that truth needs to be mediated: an aspect that particularly stands out if one compares, for instance, Shi'a Islam with Sunni Islamic traditions where mediation, though present, has less prominence. ${ }^{15}$ Nonetheless, the situation is more complex, and mediation cannot be seen as the inherent trademark of Shi'ism-as opposed to Sunnism - as shown by a brief comparison with Gaddafi's case. In his writings, the Libyan leader often combined Sunni discourses, socialist doctrine, and antiShi'a criticism to stress that people should exercise power without mediators, a recurrent theme in Gaddafi's revolutionary theory used in order to portray himself as a champion of Sunni orthodoxy (Gaddafi [1975-81] 2005). However, as we have seen both in this chapter and in the previous one, Gaddafi, too, acted as a mediator. Like Khomeini, he also used imagery aimed at presenting himself as an embodiment of the nation: not so much a representative of the Libyans but rather a medium standing between them and the realm of politics. These considerations give us the chance to clarify an important point: although Khomeini's and Gaddafi's revolutions were cosmological events (an aspect that will be explored in greater detail in the following chapter), they were not static expressions of local cosmologies. Rather they were projects that emphasized some aspects of the Shi'a and the Sunni repertoires and downplayed others. It is by looking at the tendency to select aspects of established religious traditions that we can better compare these revolutionary instances with the Marxist episteme.

Even though, as we have seen, Marxist philosophers like Lukács identified in ideology a tendency to select some parts and present them as the whole, this very propensity can be found in the Marxist tradition as well. While such a realization does not prevent us from answering the Marxist invitation to identify the selective descriptions of reality that power puts forward for its murky ends, one cannot help but notice that Marxism, too, has taken up some aspects of religious discourses and omitted others. While Marx excluded God from his worldview, he kept, one might say, a spiritual sensibility. In describing the dehumanizing nature of capitalist society, he spoke of a system that is de-sanctified (Berman 2010: 115), a sad condition where "all that is holy is profaned" (Marx and Engels [1848] 2005: 10). One can also detect a similar attitude in contemporary Marxist works, some of which will be further explored in the concluding chapter of the book, where themes of the Christian tradition are reinterpreted and used as metaphors that help to elucidate new interpretations of Marxist doctrine (Badiou 1997; Žižek 2003). At times these analyses even defend what they see as the positive aspects of religion against the attacks of liberal atheists (Eagleton 2009), an approach rooted in Marx's view

15. These, of course, are not static features of the two main Islamic traditions. Arguably the fact that religious scholars have lost their authority in the Sunni world is mainly a modern phenomenon (Eickelman and Piscatori 1996: 46-68). 
that, although religion is a lie, it is often also the "sigh of the oppressed creature" (Marx 1970: 131), a way to voice the heartfelt laments of the poor against the injustices of this world. ${ }^{16}$

These reflections help us identify two important dynamics: first, while it is true that religious revolutionaries borrowed from Marx-from Gaddafi to many other blends of socialism and Islam that have developed in the twentieth century-it is also true that the Marxist tradition borrowed from religion. ${ }^{17} \mathrm{Sec}-$ ondly, leaving aside old-fashioned and simplistic discussions of whether Marxism is better understood as a secular religion, a position held by many detractors of Marxist philosophy, one cannot help but notice an unequivocal resemblance between Marx and the monotheistic traditions. This is a likeness that has long been observed by scholars (Löwith 1949: 33-51) and at times even acknowledged by Marxists themselves, to the point that some have identified an inherently theological kernel within Marxism (Benjamin 2002: 288-91, 2007: 253; Weil 2004: 162). ${ }^{18}$ This is particularly true of the Marxist notion that one day, when revolution takes place, ideology will lessen its grip on reality. The Marxist take on ideology implies a Judeo-Christian temporality, a sense of time centered around expectations of things to come (see chapter 1 ), in that it offers the promise of a future earthly kingdom of heaven: a new order of things where there will be very little room for the lies of power, and truth will become more visible than it is today. Bearing this theme in mind, we move on to unpack the last of our three issues: the capacity of revolution to bring about a better ideology, a more truthful way to account for reality.

\section{BECOME WHO YOU ARE}

In order to tackle this final issue, we first need further clarification. The Marxist idea of revolution as the advent of a better ideology should be contextualized

16. Such attitude can be found also in Gramsci, who thought that the oppressed have real spiritual needs, and that Marxism, being a coherent system, could fulfill these needs better than religion (Fulton 1987: 202; Crehan 2002: 118).

17. Although it is often forgotten in public debates, the first modern instances of Islamic revolutions looked at socialism, rather than at a literal interpretation of Islamic scriptures, as a source of inspiration: an attitude inaugurated by Egyptian revolutionary leader Gamal Abd-el Nasser (Nasser 1958). The situation is very different nowadays, and according to some, it is precisely because of the disappearance of a radical left in Islamic countries that Islamism has spread (Žižek 2012: 73-74). It should also be noted that Nasser and Gaddafi, as well as influential Arabic socialist thinkers such as Michel Aflaq (1969), had a complex relationship with orthodox Marxism and disagreed with some of its core tenets.

18. Controversial anarcho-syndicalist Georges Sorel saw the Marxist account of revolution as a myth (2009: 42). Some entirely disagree with this approach, and see the argument that Marxism has a religious genealogy as an attempt to undermine the achievements of modern thought by reducing them to mere secularized versions of religious themes (Blumenberg 1985). 
within a broader Marxist tendency to articulate the present through the lens of the forthcoming. To grasp this inclination one can consider, among other things, the way Marxism sees the capitalist system. For Marx, exploitation will disappear with the advent of revolution; thus, capitalism is a source of suffering that will one day pass. Interestingly, however, capitalism is also a suffering that, once contextualized with an eye to the future, has a redemptive side. Since, as we have seen, capitalism entails a contradiction-its reality disproves its ideology-Marx sees in it an occasion to acknowledge the wrongs of today and to take the first step toward the establishment of a better tomorrow, so that revolution appears to be, in a sense, the historical, inevitable product of the contradictions of capitalism (Berman 2010: 104). Capitalism is therefore, to some extent, a necessary evil, reminding us of the "felix culpa," or "happy fault," of the Christian tradition, the idea that even the original sin committed by Adam has a redemptive side since it is precisely because of it that Christ came to redeem the world. The lies of capitalism, like the lies of the serpent in the Garden of Eden, thus have a role to play in the trajectory that leads to the establishment of the truth, a perspective that has generated descriptions of Marxism as a secular "theodicy," a "justification of God," an apologetic discourse typical of Christian theology's search to decipher the part played by evil in the process of mankind's salvation (Eagleton 2010: 136). ${ }^{19}$

Marxism's promise of a better ideology is, therefore, founded on the idea that, in the words of Marxist thinker Ernst Bloch, "the world without future-laden properties does not deserve a glance" (1995: 223): the notion that "our best days have yet to be lived," to quote Turkish communist poet Nâzım Hikmet (2002: 86). Interestingly, such need to make sense of the present only in light of the future has been documented also in a number of non-Marxist revolutionary contexts. Take, for example, Samuli Schielke's account of the 2011 Egyptian revolution. Schielke argues that this uprising was an impulsive event without a specific agenda. Nevertheless, he also shows how Egyptian revolutionaries chose to interpret it as a process of change: a precise moment in a specific trajectory leading to a different and better future (Schielke 2015: 215). ${ }^{20}$ By reading the uprising in such manner, Schielke argues, revolutionaries developed an "ethos of futurity" (215), a sense that life should be lived through a constant search for the new and better (see also

19. Marx's certitude in the advent of revolution is instilled with a sense of providence, a trait that he inherited from his chief philosophical inspirer, Hegel. Marx's faith is such that he welcomes the full flourishing of capitalism as the necessary prelude to revolution (Carandini 2005: 3). For an anthropological—and socialist—critique of this view see Robinson 2019.

20. Such notion that revolutionary discourses can be radically altered in the course of revolutionary action is found in a number of analyses of the Arab Spring. For instance, Kjetil Fosshagen (2014) has argued that the popular revolutionary spirit of the recent uprisings that have occurred in North Africa has been hijacked by the local liberal upper-middle classes. Fosshagen draws a parallel with the Spring of Nations - the wave of upheavals that took place in Europe in 1848-where a similar dynamic took place. The parallel has been proposed also by Alain Badiou (2012). 
Mittermaier 2019: 155-78). As we have explained in the introduction, in Schielke's view, this "ethos of futurity" was rooted in two discourses: capitalism, with its insatiable search for new ways to achieve profit; and literalist Islam, with its focus on the rewards that the faithful will one day enjoy in the afterlife (Schielke 2015: 105, 122). However, bearing in mind what we have said, and notwithstanding Schielke's shrewd insights, one wonders whether the Egyptian case actually echoes, at least in some ways, the Marxist model. Certainly, it bears a similarity that, to be properly assessed, demands a brief critical examination of Schielke's analysis, particularly in relation to the way in which, according to Schielke, Egyptian revolutionaries articulate the present.

Schielke (2015) documents the dissatisfaction with the "now" attendant on the future-oriented ethos of Egyptian revolutionaries, an attitude that, in his view, mirrors capitalism's tendency to dismiss the present in favor of novelty and Islamism's demands for religious perfection that are often met with failure and imperfection in the "here" and "now," but that will propel the faithful toward a better future in heaven. However, like the Egyptians, Marx too was frustrated with the present, likewise seeing it as a time that "gives no satisfaction" (Marx 1993: 426). Although he detected an obsession with newness in capitalism, a tendency for things to "become obsolete before they can ossify" (Marx and Engels [1848] 2005: 10), he, too, could not help but include the present in a future trajectory. Therefore, there is a difference between Marxism and the Egyptian revolutionary ethos on one side, and Islamism and capitalism on the other, and this difference does not lie in their orientation - which in both cases points toward the future-but in how they conceptualize this future. Capitalism and Islamism look at the forthcoming with a sense of permanence. The tomorrow they promise relies on the idea that the free market, or the literal interpretation of Islam, will stay unchanged for all eternity, and that future newness will take place only within these unchangeable premises (Graeber 2011: 32). Conversely, Marx, and arguably the Egyptian revolutionaries, see the future as impermanent; they conceive of the possibility of a completely new, radically different point of view on things awaiting us in the future: a fundamental change in ideology, to use the Marxist language.

Perhaps this similarity between the Marxist model and the Egyptian case (their shared understanding of the future) becomes more visible when one compares them with revolutionary instances that are not based on the notion of a future horizon of change (e.g., see Haugbolle and Bandak 2017). Take, for instance, Ross Porter's study of the Yemeni revolution of 2011. ${ }^{21}$ Porter shows how Yemeni revolutionaries, although concerned with changing the dictatorial policies of President Ali Abdullah Saleh, did not articulate such change in terms of future developments that would one day replace the current state of affairs. On the contrary, they saw change as some-

21. On previous revolutionary insurgencies in Yemen, see Vom Bruck 2005, 2019. 
thing to be experienced in the moment: the realization, made in day-to-day life, that one can be immune to the oppressive ways of thinking and behaving pervasive under Saleh (Porter 2016: 64, 2017). According to Porter, the Yemeni revolution was therefore not so much focused on expectations of a better tomorrow where things would be clearer, truer, or better; rather, it involved a sense of hope in the now-the need to experience a better future already in the present-to the point that, in a way, for revolutionaries present and future ceased to be two distinct moments in a chronological trajectory (Porter 2016: 65). In the concluding chapter of the book, we again encounter this idea that revolution might erase the difference between the current and the forthcoming, but for now it suffices to say that the Yemeni case clearly illustrates that some revolutions do not entail the classical Marxist notion that one day, after revolution has succeeded, we will see the world differently.

An even clearer example in this sense is the Bolivian proceso de cambiostrongly influenced, as previously explained, by indigenous practices (Tassi 2017: 1) - in which revolution features not as an ideology-changing operation but as an occasion for Bolivians to free themselves from the need to change, a chance to see the world as they currently see it. While this revolutionary process did not entail a supposedly pure indigenous essence, it did involve an Aymara "subsoil," a substratum of practices and beliefs with inherent continuities and change, cultivated by the Aymara but ignored by Bolivia's white ruling class (Tassi forthcoming, 2016: 1-33). In its inception, the proceso ${ }^{22}$ was framed by indigenous and popular sectors as an instrument helping to bring this subsoil to the surface and taking center stage in the sociopolitical life of the country. This dynamic mirrored the indigenous notion of Pachakuti, or "World Reversal" (Gutiérrez 2014), an important concept in Aymara cosmology that entails the presence of a powerful but hidden underworld where Andean indigenous forms and practices are followed by all, which will one day emerge and prevail, so that even the white will live like "indios." The proceso was therefore a tool for Andeans to crystallize the possibility to be themselves. While the theme of a "return to the true self" is found in many revolutionary discourses - including, as we have seen, Marxism, with its idea that revolution instantiates the true "essence of men"-in Bolivia this notion was articulated without the Marxist stress on the future as a time of radical change. ${ }^{23}$

22. As mentioned earlier, the political project of the state and of indigenous movements have been slowly diverging (see Postero 2017) to the point that the expression "proceso de cambio" is being increasingly associated with the political project of the state.

23. In Iran, for instance, socialist revolutionary thinkers made reference to the notions of "Gharbzadegi" (Westoxification) - the venomous influences of the Colonial West; as a critique against this phenomenon they called on Iranians to return to themselves and to their roots (Al E-Ahmad 1984; Shariati 2015). A similar theme is found in the writings of Mexican poet Octavio Paz, mentioned at the beginning of the chapter, where the capacity of revolution to instantiate a more truthful reality is articulated more in terms of "being who you truly are"-as in, discover who you are already—than in relation to classical Marxist notions of radical change. 
Whereas Marxism carries the monotheistic idea that the truth increasingly reveals itself in history in a redemptive process that reaches its climax when the revolution ameliorates interpretations of reality, the proceso foregrounds the indigenous cosmological theme of the emergence of something that, while neglected, is already present. Although parallels can be drawn here with the Marxist invitation to unveil the reality that lies behind ideology, there is a fundamental difference: with the Aymara there is neither redemption to be sought nor a horizon to be chased. Rather the horizon is already here, and it demands cultivation, not change. Using a familiar Western philosophical language, one might argue that the Bolivian case stands out as one marked by "immanence," as opposed to Marxism which, despite its focus on material conditions, implies "transcendence": the need to transcend the current in expectation of what lies ahead, but also the conviction that, ultimately, reality transcends ideology. Indeed, this is a characteristic of Marxism that, despite numerous re-elaborations, has remained the same since its inception and that marks the difference between the Marxist understanding of revolution and other revolutionary epistemes: the notion that truth lies beyond our descriptions of it and that one must labor to get close to it, with full faith that in the future the distance will shorten.

\section{CONCLUSION}

The different contexts we have cited help us recognize a habit that often features in how ideology is approached by scholars and observers of revolutionary phenomena: a tendency, eloquently documented by Yurchak, to analyze ideology through the lens of static binary oppositions (Yurchak 2006: 5). In this chapter we have problematized some of these dichotomies, namely: the notion that you either believe in ideology or merely pretend to; the distinction between ideological mediation and lack of it; and the idea that the way we see the world now differs from how we will see it in the future. In addition to these three, many further simplistic pairings are implied in those we have considered, which often characterize political commentary, such as the difference between compliance and resistance (5). Our overview shows the limitation of this binary way of thinking; however, one wonders whether the dissolution of dichotomies is the only end result here. Ultimately, rather than simply problematizing the Marxist differentiation between reality and ideology — the greatest binary of all — we have unpacked the way Marxist thinkers themselves have problematized this dichotomy. In short, we have sought to deal with Marxism's complexity, not with its simplicity, and although it is difficult to read all the cases we have mentioned using Marx's conceptual tools, one has to recognize sophistication in the Marxist understanding of the relation between the real and the ideological.

It is also important to stress that, even though dichotomies collapse as soon as we move from one context to another, one detects a common preoccupation in 
all the revolutionary discourses we have analyzed: a concern for what counts as reality and what does not. Doubtless, this preoccupation is not at the heart of all revolutionary experiences, and often the differentiation between real and unreal that marks some revolutionary projects is not as sharp as one might expect; nevertheless, the preoccupation is still there. Therefore one cannot help but notice that revolutions bring with them specific economies of reality and unreality, flexible systems that assign a place to each. There is a distinct way of seeing the world here, although one that is declined in different ways according to different cosmological understandings of what constitutes the real. With this in mind we move to the next chapter, wherein the way in which cosmology informs revolution is further explored. By way of conclusion, however, it is important to clarify that, while unpacking dichotomies can be a way to do justice to some of the cases we have explored, often the most interesting results can be achieved by taking dichotomies seriously: by examining what revolutionary agents understand to be true or false, and how this understanding shapes the world they want to build or preserve, whether it is one marked by the future liberation of the oppressed, or by the emergence of what is already here. Then, should a proposition seem convincing, one might even decide that simplistic binaries do not necessarily prevent us from doing what many revolutionary critiques demand: picking a side. 


\title{
6 \\ Revolutionary Cosmologies
}

\author{
Spirits, Myths, Worlds
}

\begin{abstract}
Since everything is coming to an end like this, you should be living holy and saintly lives while you wait and long for the Day of God to come, when the sky will dissolve in flames and the elements melt in the heat. What we are waiting for is what He promised: the new heavens and new earth, the place where righteousness will be at home.
\end{abstract}

-2 PETER 3:11-13

As we saw in chapter 3, in 1979 the Iranian Revolution replaced a pro-Western, semi-absolute monarchy with a theocracy based on the concept of the "Guardianship of the Jurist" (velayat-e faqih), a Shi'a notion according to which Islamic Jurists should guide the people during the time of the occultation of the Hidden Iman, and conduct the government according to the law and principles of the Quran. At the end of a decade that in Europe and America had been associated with the political emancipation of the masses, and that had emphasized creativity and agency to counteract the inertia of society and tradition (Scheele 2007), the Iranian Revolution dealt a serious blow to progressive intellectuals. In fact, it crystallized a political movement identifying liberation with Islamic government and with "the mysterious current that flowed between an old man who had been exiled for fifteen years [Ruhollah Khomeini] and his people" (Foucault, in Afary and Anderson 2005: 205). By advancing a narrative of returning to Islam as it was in the time of the Prophet, the Iranian Revolution overturned the comforting storyline of a linear transition toward a future horizon of liberation from power formations and grand narratives.

In a famous article suggestively titled "What Are the Iranians Dreaming About?," Michel Foucault gives the following description of the Iranian revolutionary movement and the aspiration of an Islamic government:

It is first and foremost about a movement that aims to give a permanent role in political life to the traditional structures of Islamic society. An Islamic government is what 
will allow the continuing activity of the thousands of political centers that have been spawned in mosques and religious communities in order to resist the Shah's regime. I was given an example. Ten years ago, an earthquake hit Ferdows. The entire city had to be reconstructed, but since the plan that had been selected was not to the satisfaction of most of the peasants and the small artisans, they seceded. Under the guidance of a religious leader, they went on to found their city a little further away. They had collected funds in the entire region. They had collectively chosen places to settle, arranged a water supply, and organized cooperatives. They had called their city Islamiyeh. The earthquake had been an opportunity to use religious structures not only as centers of resistance, but also as sources for political creation. This is what one dreams about [songe] when one speaks of Islamic government. (Foucault, in Afary and Anderson 2005: 207)

In Iran, the idea of the mass protests and revolutionary upheavals in which thousands of youngsters expressing a common allegiance to Islam confronted the rifles of the gendarmes was explicitly associated with religious notions of annihilation of the self (bi-khodi). This was the same response as produced in the crowd of a pilgrimage and shahid, the sacred martyrdom / sacrifice capable of bringing about a world that has been denied (Al E-Ahmad 1985; Shariati 2010). In this sense, a multiplicity of elements-from revolution to pilgrimage (Hajj) to the historical reenactment of the martyrdom of Hussain, the grandson of the Prophet and prominent figure of Shi'a Islam killed in Kerbala, as explained in chapter 3-are bound together in a common fight against racial, colonial policies and the rule of the Shah.

Seen from the point of view of the kind of progressive and emancipatory politics that was dominant in Euro-American life in the 1980s, Khomeini-with his turban, robe, beard, and defiantly theocratic rhetoric-was an expression of the "wrong" kind of change; indeed, he was an uncomfortable expression of a failure to purify the "new dawn" / present of a "dark past" imbued with nonmodern forms and beliefs (Latour 1993; Keane 2007; Maurer 2005). To modern secularist sensibilities, such an overlap between religion and political transformation in modern times seemed to constitute the heart of darkness of our comprehension of time and change, one that still lurks at the center of our interpretations of political events.

During the so-called "Arab Spring" of the early 2010s, scholars and journalists rushed to congratulate the millions of protesters across the Muslim world willing to overthrow some of the authoritarian regimes of the region. Soon enough, however, when it became apparent that the political transformations in question did not reflect the liberal and modern expectations of these illustrious observers, the "failed hopes" of the Arab Spring began to crystallize into what was branded an "Islamist Winter" (Bradley 2012; Israeli 2017). The assumption in this way of framing the events in the Middle East and North Africa was that this could only be a transition toward illiberal and ultimately antidemocratic politics, which came as 
a natural consequence of religion overshadowing the true intentions of the Middle Eastern upheavals.

As we have seen in an array of different contexts in previous chapters, among political scientists and philosophers the concept of revolution has been positioned as one of the constitutive ideas of political modernity. This entails the production of a new linear and secular time brought about by the emancipation from, or the destruction of, traditional and illiberal social structures, and the nullification of the validity of particularistic beliefs and truths (Malia 2006; Koselleck 1985). In the socialist tradition in particular, the notion of revolution has been often conceived as a universal, secular model of sociopolitical action and transformation that can be equally applied to a variety of cultural contexts from the Soviet Union to Cuba, from Iran to Mozambique.

In this chapter we explore how conventional conceptions of revolution remain embedded in nonsecular beliefs and religious practices. First, we produce a critical analysis of "standard" European ideas of revolution showing how, despite their association with a universal and secular political framework, they remain firmly and predominantly anchored in Christian notions of time, sacrifice, and salvation. Secondly, we demonstrate that standard ideas of revolution may be appropriated, re-signified by, or framed in terms of local cosmologies, showing how different cosmological contexts have been able to produce specific notions and practices of revolutionary transformation. What can we make of revolution when examined through the prism of indigenous, non-Christian cosmologies? What happens when we place modern ideas of revolution in a temporal and spatial order that in different ways goes beyond the coordinates of modernity? What are the cosmological implications and transformations or forms of being that revolution brings about?

\section{THE NEW TIME OF REVOLUTION}

The Iranian Revolution described earlier is in tension with the timeline and horizon of standard European notions of revolution often built on the emancipation from God, tradition, and the models of the past. Throughout this section we explore the effort of revolutionary theorists to secularize and purify revolution from the past, tradition, and spiritual forms. Such a position not only crystallizes a clash with the classic domains of interest of anthropology but also ends up outlining a specific ideological-and one could say, cosmological-notion of time and transformation. As we shall see, this effort of "purification" is paralleled by a recursive resurfacing of the past, tradition, and religion into revolutionary practices and forms outlining a set of specifically Christian cosmological principles onto which the Euro-American notions of revolution remain anchored.

Let us return briefly to the question of time mentioned in chapter 1 . Time is a prime aspect, or function, of cosmology and a considerable body of anthropological 
literature has addressed how different cultures and groups have developed different horizons, logics, and understandings of time. Likewise, revolutions and revolutionaries have also shown an obsession with time and its alteration, traditionally being concerned with transforming time to signal the sense of epochal transformation brought about by the revolution and the irreversible twist in the direction of an epoch. The new "fascist era," for instance, was instituted with the intention of starting to count time with Roman numerals from the "March on Rome" of 1922 that signaled the inception of the Fascist regime. So, for instance, the year 1925 would be identified as year "III" of the new era. Similarly, in the case of socialist revolutions, we witness practices of reconfiguration of time and space on the basis of the revolutionary mythology, the institutionalization of a Soviet revolutionary calendar, or, in the case of Cuba, a form of counting chronological time from the beginning of the 1959 revolution. Thus, the year 2019 would be identified as year 60 of the glorious revolution in all government publications and media sources (Hirschfeld 2007). It is interesting to observe at this stage that these new revolutionary forms of counting time, despite intentions of signaling an era starting afresh and a rupture with previous ideas, religions, and societies, appear to reproduce the same mechanisms of counting time as the most established of religious traditions, all of which assign the year "o" to that of the birth of the Messiah or the Prophet.

As we have seen in chapter 1 , the association of revolutions with attempts to reorient time toward the future, to separate the present from the past and engender new, linear ideas of time, is, however, relatively recent. Among medieval and Renaissance astronomers, for instance, a revolution connoted a circular movement of return to an original point. In her work On Revolution, Hannah Arendt framed it as a metaphor of "an eternal, irresistible, ever-recurring motion to the haphazard movements, the ups and downs of human destiny, which have been likened to the rising and setting of sun, moon, and stars" ([1965] 2006: 33), therefore somehow removed from the influence of human power. Such movements did not interrupt the course of history, which was conceived of as recursively falling back into a different stage of its cycle prescribing a course that was preordained.

Medieval historian Jacques Le Goff explains how, during the late medieval period, with the empowerment of guilds and the consequent withdrawal of the Church to an increasingly transcendent, nonmundane function, the clock of the city council (often managed by trade guilds) came to replace the Church clock in defining urban rhythms and dynamics. Le Goff (1980, 1982: 132-33) contrasts the guilds' need to measure time and regulate urban life with the Church's lax attitude in this domain; time had been conceived of as a prerogative of God, as shown by the Church's calendric system based on mobile festivities without fixed references. A process of secularization in the forms of counting and understanding time signaled not only a break with the circular, medieval notion of time but also a shift in the control and definition of time into human hands. 
Historians of revolution (Koselleck 1985; Malia 2006; Arendt [1965] 2006) trace how eighteenth- and nineteenth-century scholars reversed the medieval connotation of revolution, beginning to employ the term to refer to processes of human liberation that no longer implied a sense of return but rather an idea of overturn (Arendt [1965] 2006). Revolution began to be defined as a process of emancipation, or a liberating transition to the rule of law and representative government by overthrowing divine monarchy-in any case under pressure due to its inefficiency, criticism of intellectuals, and defection of elites (Malia 2006: 303).

Liberal understandings of revolutionary processes implied a transition toward increasing freedom both from the tyranny of political systems and from tradition (the Church, the lineage, the family) seen as curtailing the liberties and limiting the rights of the individual (Dworetz 1990). The destruction of, or liberation from, traditional institutions demanded forms of education that could teach the layperson to make meaningful, rational, and emancipating choices, and impart skills in the specialist management of power and liberal principles by electorally responsible politicians and legalistically inclined judges. In fact, the institutions (the school, the democratic government) and the interests of the emancipated bourgeoisie were projected as the natural tools and conditions of both liberation from the natural instincts of untaught humanity and the shaping of the modern, individual citizen. Old lifestyles and sociopolitical conditions learned or inherited from the past began to be considered unsuitable to modern circumstances, fueling political action with goals of reorienting and transforming, destroying, and experimenting with new forms of life more appropriate to the new conditions.

Marxist notions of revolution shared with these liberal understandings the sense that medieval circularity and ideas of return had been replaced by a linear and universalizable path propelling humanity from slaveholding to feudal to bourgeois and ultimately to socialist society through ontologically different stages of development (Marx [1852] 2008). Marx, however, not only outlined a common and universalizable path of dialectical development but also placed an emphasis on contradictions and violent ruptures with the old world and society.

\section{"The Spirits of the Past" and "the Poetry from the Future"}

It is worth repeating here the beautiful and metaphoric parallel between language and revolution Marx draws in the Eighteenth Brumaire of Louis Bonaparte:

The beginner who has learned a new language always translates it back into his mother tongue but he assimilates the spirit of the new language and expresses himself freely in it only when he moves in it without recalling the old and when he forgets his native tongue. ([1852] 2008: 15-16)

A new stage of politico-economic development and/ or a new political language brought about by revolution could only truly come to life through a more or less proactive act of forgetfulness of the ancestral era and severance from the old world. 
In the case of the Soviet Union, Alexei Yurchak (2006) provides an insightful analysis of the approaches to revolutionary language in the Soviet Union and particularly to the conception of "unlearning" the old language in order to experiment with new forms of thinking more suitable to the new socialist condition. ${ }^{1}$ Lenin, for instance, associated the people's revolution with a moment of popular uprising marked by popular demands and efforts on the part of the people to build a new society in their own way, one opposed to the old society that needed to be destroyed (Lenin [1917] 2014). The new history, the new society, the new thinking that revolution brings about are thought to outline radically different notions of time, thought, and the world, which are incommensurable with the past; in fact, the past with its burden and its models can be an obstacle to the full development of revolution.

Framed this way, revolution implied the founding of society anew and, in trying to create that future in the present, an attempt to eradicate the "muck of ages" or, as Shah (2014) says, the muck of the past. Instead of conjuring up the spirits of the past and drawing "its poetry from the past," Marx conceived of social revolution as drawing its poetry "only from the future" as "[i]t cannot begin with itself until it has stripped itself of all its superstitions concerning the past" (West and Raman 2009: 1; Fanon [1961] 2007).

Certainly Marx was an attentive researcher of past revolutionary endeavors with the intention of both learning from past mistakes and identifying and comprehending the elements, historical circumstances, and strategies that might lead to a successful revolutionary outcome in the future. However, with some noticeable exceptions (Benjamin 2007; Polanyi 1959) and many nuances of course (e.g., Marx [1852] 2008), modern, liberal, and Marxist interpretations of revolutionary processes implied the formation of a new political system and society that were incommensurable with a previous order. Concepts such as "creativity" and "newness" became tools to define a new revolutionary time or horizon, one in radical discontinuity with preexisting moral and social conditions, structures, and ideologies that reoriented expectations toward the future (Donham 1999).

The conception of revolution as a sudden cut with the past, a rupture with the bonds, and the inheritance of the old society, with habitus and repetition, necessarily instigates a tension with religious forms and "phantoms"; these may result in structural obstacles and continued conservative forces both at the outbreak of revolution and in the construction of a revolutionary society. For Marx,

Religious suffering is, at one and the same time, the expression of real suffering and a protest against real suffering. Religion is the sigh of the oppressed creature, the heart of a heartless world, and the soul of soulless conditions. It is the opium of the people. (Marx 1970: 175)

1. For an argument on the power of language as a force of revolutionary transformation, based on a study of nationalist revolutions in Indonesia, see Siegel 1997. 
Religion is envisioned here as a stupefaction of the working class that distorts the reality of its exploitation, the veil camouflaging the suffering of the oppressed, as something God-given that prevents the subaltern from rebelling against his / her condition.

As we have seen, in the Wretched of the Earth, Franz Fanon ([1961] 2007) associates revolution and the struggles for independence of colonized countries with liberation from the "phantoms" of the past:

And the youth of a colonised country growing up in the atmosphere of shot and fire, may well make a mock of, and does not hesitate to pour scorn upon the zombies of his ancestors, the horses with two heads, the dead who rise again and the djinns who rush into your body while you yawn. The native discovers reality and transforms it into the patterns of his customs, into the practice of violence and into his plan for freedom. (20-21)

The modern concept of revolution is inextricably bound up with the notion that the course of history suddenly begins anew, that an entirely new society, new story, a story never known and told before, is about to unfold, a story that is often a woman- or man-made story, not shaped by Providence. The revolutionary gaze and action is repeatedly formulated in terms of a future horizon. As per Orin Starn's example about Shining Path discussed in the Introduction, the revolutionary theorist seems to say: Do not look back at the past, tradition, and religion if you want to understand-and produce-a truly radical transformation (see also Starn and La Serna 2019). But such an auratic future of salvation, truth, and poetry seems to outline, as we shall see, a distinctively religious, cosmological horizon for standard European notions of revolution. As we show in the next section, despite the secularized and purified-from-the-past script of political theorists, a set of screened-out religious motifs and traditions repeatedly reemerge at the heart of modern revolutionary formations. In fact, leaders, intellectuals, and the "people" often end up drawing from the local religious stock and tradition for the consolidation of revolutionary processes or the configuration of "new" revolutionary orders and models.

\section{THE CHRISTIAN ROOTS OF REVOLUTION}

In the aftermath of the Russian Revolution, Lenin was adamant that the role of the cult of personality of charismatic leaders was a prejudicial practice, misleading the masses and reproducing forms of power not authorized by the sovereign proletariat. Yet Lenin himself ended up promoting monument-building to revolutionaries of the past and fighters for socialism as a strategy to magnify the heritage and grandeur of the socialist project. Interestingly, Lenin aimed at shaping an international heritage by building monuments to great socialist thinkers and fighters as opposed to the nationalist heritage of nation-states, although, eventually, 
even he drew the aura and the "poetry from the past" in the construction of a Soviet revolutionary process and its identity. The consolidation of a revolution driven by a future horizon of transformation and doing away with old models, hierarchies, and traditions was eventually building on the aura of past and eminent revolutionaries and politicians.

As we mentioned in chapter 4, after his death, an intense debate unfolded in the Politburo over what to do with Lenin's body (Yurchak 2015). The decision to preserve it, embalming it and displaying it for posterity, drew on notions of the canonization, cult status, and immortality entrenched in religious practices, in the cults of saint and relics, ultimately clashing with the basic tenets of MarxismLeninism. In fact, the personality cult of the Soviet leader appeared to be built on conventional religious and spiritual beliefs. The linear and secularized time carefully and meticulously introduced by the Russian Revolution appears to revert with the embalming of Lenin's body, which mummifies the Soviet leader-or Soviet ideology (Yurchak 2015) - thereby breaking with modernity and its time.

Buck-Morss (2000) brilliantly shows how in Russian households the so-called "red corner," traditionally reserved for Orthodox icons, had been transformed into "Lenin's corner" with the image of Lenin replacing the religious paintings. This kind of dynamics, rather than severing the Soviet revolution from the past or destroying the phantoms and spirits of old for the sake of a new society, outlines a notion of revolution as building on those same "spirits." One of the most spectacular projects of Soviet political engineering was to tear down and attempt to replace the Orthodox Cathedral of Christ the Savior in Moscow with the Palace of the Soviets, although construction of the latter was never accomplished due to the Nazi invasion. Something similar had happened during the French Revolution when Notre Dame was transformed into the Temple of Reason, generating a new type of civic religion with a specific rituality and calendric system (Dawson 1972).

The so-called theory of God-building found fertile ground among some Marxists of Bolshevik Russia and the Soviet Union (Boer 2014). Maxim Gorki was probably the most prominent intellectual to adhere to such a movement, often portraying the masses as gods, creators of miracles and immortals during the Russian Revolution. Partially based on the French Revolution's "cult of reason," the theory of God-building proposed a meta-religious context in which religion was viewed primarily in terms of the psychological and social powers of ritual, myth, and symbolism; the goal was to exploit this religious force for revolutionary purposes.

Buck-Morss (2000) observes a similar process among Soviet revolutionary artists who sought to interrupt the continuity of perception and estrange the familiar, severing historical tradition through the force of their fantasy. The idea was to step out of the frame of the existing order either through transcending space and advancing toward the "eternal" (the case of the painter Malevich and his nonobjective, abstract art) or through primitive art, turning to the symbols and myths of deep Russia and de-articulating the present from its necessary future. These 
practices not only begin to question the notion of a newness ex nihilo in relation to modern revolutionary processes but also start to unearth a series of cosmological forms and instruments that appear to be playing a strategic role in revolutionary processes.

We have seen how the figure of Che Guevara as a Jesus-like modern savior and ascetic political visionary (Scheele 2007) conceptualized a messianic notion of the New Man, morally improved and spiritually redeemed, fashioned on the model of Saint Paul's "New Man" shaped in the semblances of the resurrected Christ and "which is renewed in knowledge after the image of him that created him" (Colossians 3:10). In the Nicaraguan revolution of 1979 (Montoya 2012), large portions of the Catholic Church supported Sandinista revolutionary operations against the dictator Somoza in clear tension with the Vatican. Drawing on a combination of Christian theology and Marxist socioeconomic analysis, the Nicaraguan Church and Liberation theologians not only took a clear stance that favored the poor and the liberation of the oppressed but also became a strategic source of organization for peasant groups through their grassroots religious activities and associations (see also Cooper 2018).

As we discuss in detail in the Conclusion, Walter Benjamin (2007) outlines a similar idea of revolution as retrieving and redeeming an oppressed past/ tradition from the spatialized, neutralized jaws of history and unstitching it from its inevitable homogeneous future. In his essay "Theses on the Philosophy of History" (1940), Benjamin locates the revolutionary task in the rescuing of "tradition" from a "conformism" that threatens to overwhelm it. The task is to set alight the sparks of hope in the past (Robinson 2013). In contrast with the notion of modernization as progress that reduces revolution to the salvation of future generations, producing a corrosive conformity in the present, Benjamin's revolution avenges past generations and actualizes the drive of a messianic past. Although conventionally identifying revolution with a rupture in the Orthodox time frame and in the continuity of history, for Benjamin the rupture consists of the interruption of the homogeneous "empty time" imposed by capitalism as a disciplining instance, in order to embark on a new messianic time redeemed from the past and entering and imploding the time of capitalism.

In his interpretative study of Benjamin, which focuses on his "revolutionary criticism," Terry Eagleton (1981) beautifully summarizes Benjamin's notion of socialist revolution as a mobilization of past memories, spirits, and ancestors in the attempt to shatter the homogenizing force of modern history:

If we were able to recollect our ancestors, then in a moment of shock we might trigger the unpalatable memory trace at a ripe time, blast through the continuum of history and create the empty space in which the forces of tradition might congregate to shatter the present. That moment of shock is socialist revolution. (Eagleton 1981: 78) 
If socialist revolutions have conventionally been theorized as producing an incommensurability with tradition and religion, in the previous paragraphs we have begun to observe how revolutionary processes attempting to throw religion and tradition out of the window often experienced a return of religion and the past through the back door. In the case of the French and Russian revolutions, as we have seen, religion was instrumentally used by the political avant-garde as a powerful symbolic mechanism that could enable to spread and deepen a new, secular revolutionary ethos. However, a number of socialist political thinkers have even more radically tackled the notion of religion in revolutionary thinking outlining the explicitly religious foundations of the standard European ideas of revolution. Generally, the work of Alain Badiou is a prime point of reference for this kind of endeavor. However, a number of lesser-known predecessors have more or less intentionally addressed the issue.

In his most famous political work, suggestively titled "The Revolutionary Catechism," Russian anarchist Sergei Nechayev ([1869] 2014) outlines the precepts, duties, and attitudes required of the modern revolutionary in the constitution of a new subject and a new world. Nechayev's manifesto opens with this exemplary sentence: "The revolutionary is a doomed man. He has no personal interests, no business affairs, no emotions, no attachments, no property, and no name. Everything in him is wholly absorbed in the single thought and the single passion for revolution" (par. 1). What follows is the recommendation for a series of ascetic practices of renunciation, sacrifice, and immolation explicitly inspired by the tradition of Christianity and designed to allow the revolutionary to overcome attachments to family, love, and friendship and eventually to renounce his / her own life for the sake of a grander political objective.

Partly breaking with previous Marxist tradition, the influential work of Alain Badiou, Saint Paul: The Foundation of Universalism (2003), has explicitly juxtaposed the event of Christ's resurrection and revolution in direct relation and symmetry. Badiou frames the event of Christ's resurrection in typical revolutionary language and rationale as capable of bringing about a new type of subjectivity and a new political language, but also of bringing to light a series of elements and forces that were hidden or invisible in the previous order of things. In Badiou's work the articulation between revolution and Christianity becomes ever more explicit through the analysis of the figure of Saint Paul. The sinful life of Saint Paul is redefined by the encounter with the resurrected Christ not in the sense of a simple shift in terms of belief and thinking but actually in terms of salvation. Saint Paul's conversion is described by Badiou in terms of a thunderbolt, a caesura from his previous life and from the past that literally instantiates a new man, a new order of things, a new form of living as "the old self has been crucified with God."

Badiou's language and work become particularly useful in identifying correspondences and elective affinities between revolutionary jargon and some of the 
TABLE 1. Correspondences between Christianity and Revolution

\begin{tabular}{|c|c|}
\hline Christianity & Revolution \\
\hline $\begin{array}{l}\text { New Man redeemed from } \\
\text { original sin (Saint Paul) }\end{array}$ & $\begin{array}{l}\text { New Man redeemed from ideology and ethically improved } \\
\text { (Trotsky; Che Guevara) }\end{array}$ \\
\hline Priestly guidance & Vanguard/Leadership \\
\hline Lies/Sin & Ideology \\
\hline Asceticism & $\begin{array}{l}\text { Renunciation of the family and cherished familial bonds for the } \\
\text { sake of a higher calling (revolutionary action/socialism) }\end{array}$ \\
\hline Suffering / Sacrifice & $\begin{array}{l}\text { Selfless renunciation of one's well-being or life in the present to } \\
\text { achieve heroic status in the future }\end{array}$ \\
\hline Salvation & $\begin{array}{l}\text { A new transcendent horizon in the future giving shape and } \\
\text { direction to human action }\end{array}$ \\
\hline Eternity & $\begin{array}{l}\text { A timeless world liberated from subjugation and ideology where } \\
\text { everyone is equal }\end{array}$ \\
\hline
\end{tabular}

principal Christian concepts (see Table 1; see also Arendt [1965] 2006: 16). In other words, Badiou seems to be asserting that the language of revolution is drawn from a religious Christian framework. So, for instance, the Christian and sinful notion of "lie" appears to be equated in the revolutionary language with that of "ideology" as a dangerous distortion from a "God-given" truth. The notion of priestly guidance of the "flock" resonates with that of the revolutionary vanguard leading the masses toward a horizon of salvation and emancipation. ${ }^{2}$ Nechayev's ascetic practices and renunciation of cherished attachments-self, family, tribe-explicitly follow Christian ascetic renunciation of worldly matters for the sake of a higher calling: a type of sacrifice in the present that aspires to the materialization of a better world in the future or even to secure one's eternal salvation or liberation. ${ }^{3}$

Unearthing the resonances between Christianity and the canonical notions of revolution gives rise to a number of questions. What would revolution look like in contexts where the religious and cosmological coordinates are different? What

2. Revolutionary thinkers themselves have noticed this resemblance. For instance, Gramsci criticized vanguardist approaches to revolution as they involve a "priestly type of leadership" (1992b: 56). Incidentally, Gramsci proposed a different revolutionary strategy, one that relies on intellectuals as figures who might influence public discourses and persuade other individuals to join the revolutionary cause. Significantly, Gramsci differentiated between "traditional intellectuals" (literati, clergymen, priests, and artists who see themselves as proponents of eternal truths that apply to all) and "organic intellectuals" (who are organically embedded within one specific social class and work to benefit this class) (King 1978: 25-28). In Gramsci's view, the latter have a role to play in emancipating the subaltern classes. Gramsci is not the only Marxist who distanced himself from the notion of the vanguard. The most vocal and radical critics of the priestly nature of vanguardism, however, have been the anarchist thinkers (Gouldner 1982: 861).

3. Significantly, Bakunin criticized Nechayev's approach to revolution for being too mystical and ascetic, dismissing Nechayev as a "monk of the revolution" and a "fanatic" who is "nearer to the Jesuits than to us" (Confino 1974: 244). 
kind of revolution may spring from a set of Islamic principles? Or, in a context such as Islam where there is no notion of original sin and therefore no redemption through a "conscious" guide, what notion of redeemed, revolutionary "new man" can take shape?

With these questions in mind, in the following sections we analyze a range of ethnographic examples to highlight how conventional notions and models of revolution are reinterpreted and re-signified in different and specific cosmological contexts; how localized and particularistic myths and rituals may produce revolutions; and how specific cosmologies generate unique ideas of revolutionary transformation.

\section{RE-SIGNIFYING REVOLUTION TO LOCAL CATEGORIES}

In the previous sections we have explored the narratives of secularization and purification of the standard European notions of revolution that make them universalizable and applicable as a universal model to a multiplicity of contexts and realities across the world. Eventually, we ended up addressing its religious undertones and cosmological foundations that are often concealed by most political theorists. In the following paragraphs we focus on what happens when we transpose these standard ideas and notions of revolution to different ethnographic settings with different histories, cosmologies, notions of time, and transformation.

During the rebellions against colonial powers in sub-Saharan Africa, local conceptions and languages of power-from cults of the ancestors to spirit possession, from witchcraft to sorcery-became instrumental political frameworks often interacting with conventional ideas of revolution. Harry West (2005) describes how Mozambique achieved independence from Portugal in 1975 as a result of the armed struggle by FRELIMO (Mozambique Liberation Front). Trained in neighboring Tanzania, FRELIMO fighters' liberation of the country started from the most remote rural areas, following a Maoist guerrilla strategy based on proselytization among the peasantry and hit-and-run ambushes (cf. Degregori 2012). Describing the clash between FRELIMO fighters and the Muedans of the Mozambican plateau, West shows that in order to comprehend the encounter and its reciprocal misunderstandings we must look to Muedans' languages of power as shaped and conceptualized in their religion, sorcery practices, and traditional beliefs. Discussing the religious notions and dynamics of sorcery (uwawi) among the Muedans, West outlines the specificities of their ideas and how these interacted with the socialist conceptions and notions of FRELIMO fighters. In uwawi, according to the Muedans, power finds its beneficent manifestation in the work of responsible sorcerers who possess the ability to enter into the invisible realm, undoing the work of maleficent sorcerers and elaborating and actualizing transformations in the world. 
The Muedans' conception of power is synonymous with these maneuvers of repeated and continuous acts aimed at making and unmaking transformations, referred to as kupilikula, in the realm of the invisible. Therefore, from Catholic missionaries to the revolutionary guerrillas of FRELIMO, all these speakers of an unfamiliar language of power have been conceptualized by Muedans on the basis of the uwawi power framework as "sorcerers," with access to the invisible realm, attempting to transform the world and proclaiming transformative visions. Thus, ironically, while both the Christian missionaries and the revolutionaries have attempted to prohibit practices of traditional religion and sorcery as inappropriate to modern forms, belief, and politics, the Muedans have repeatedly conceptualized missionaries and revolutionaries in terms of their own language of power as powerful sorcerers attempting to reverse and undo previous transformations while bringing about a new reality and world.

In other words, the attempts by FRELIMO fighters to counteract local forms of sorcery and their vocal assertions of the falseness of Muedans' traditional practices were understood by the Muedans as a kind of revolutionary uwawi sorcery aiming to neutralize other forms of power. Although both missionaries and revolutionaries thought of themselves as bringing about an ultimate truth in political termsa truth nullifying the validity of Muedan beliefs and practices-their discourse continued to be conceptualized by locals according to Muedan cosmology, sorcery, and power: inescapably framed in terms of a fight between competing forces. Ultimately, these modern foreign languages, which often disparaged the backwardness of local religious practices, beliefs, and ideas, reproduce local/ traditional cultural categories that appear more resilient than expected in relation to progressive, advanced, and modern notions of revolution and transformation.

West (2005) emphasizes that the process of revolution, decolonization, and democratization in Africa does not depend on the application of Western models of power to African realities (see Fanon [1961] 2007), but rather on the cultivation of local languages of power present in people's everyday lives that might express an emergent political ethics. For West, the "political" problem is that in Africa both policy makers and revolutionaries have been speaking and imposing foreign political languages and notions of power.

In the case of the Muedans of Mozambique, we witness a process of reinterpretation and re-signification of the standard European ideas of revolution that consistently reframes them in terms of local notions of power rooted in the practices of uwawi, highlighting a reciprocal misunderstanding between locals and foreign revolutionary fighters. If we turn to the operation of Maoism in India (Shah 2014; see also Shah and Pettigrew 2018), we observe how the conventional conception of revolution and its revolutionary ethos are being reconfigured and altered by means of Hindu religious and political categories.

Alpa Shah (2014) describes how in the last decade, as part of an international strategy, an underground Maoist guerrilla movement in West Bengal has 
revitalized a decade-long struggle to seize power from the Indian state and develop communism. The Maoists consider their movement to be the armed struggled of exploited peasants and workers aiming at the attainment of a fairer, classless society, while, according to Shah, the Indian state envisions them as the main internal security threat. Shah draws a parallel between Maoist cadres committed to radical equality and transformation and the figure of the Hindu renouncer seeking liberation from the endless cycles of suffering and rebirth. Aiming for radical equality beyond caste, challenging taboos and hierarchies, the Hindu renouncer opts out of society and its conventions in order to create a parallel society. Shah draws attention to the ideological significance of the figure of the renouncer in the making of dedicated communist revolutionaries in contemporary India, demonstrating that the underground movement has shown surprising persistence due to its parallelism and subversion of the figure. Differing from the case of Mozambique, where the divergence in understandings of power among revolutionaries and Muedans leads to an ironical and enduring misunderstanding, Shah shows how local religious categories, ascetic practices, and cycles of rebirth become structuring elements in the putatively universal, Indian Maoist definition of revolution.

\section{LOCAL TRADITION AS A REVOLUTIONARY TOOL}

In the example of Indian Maoism we have begun to explore how conventional practices of revolution defined by the standard Maoist framework are reframed on the basis of Hindu notions of worldly liberation that become strategic principles in the materialization and definition of a specific revolutionary ethos, practice, and scope. Along these lines, in this section we investigate a set of ethnographic examples where local languages of power and indigenous religious practices are explicitly incorporated into a platform of political liberation. This enables us not only to experiment with other horizons of transformation but also to visualize revolutionary forms and practices that may call into question the universal model described earlier.

David Lan's work on guerrillas and spirit mediums during the struggle for the liberation of Zimbabwe, already discussed in chapter 1 in relation to notions of ritual and time, shows how Dande practices of spirit mediumship, linked to the cult of the ancestors, became part of the structural dynamics of revolutionary activities. Although the ideology of ZANLA guerrilla leaders clashed with these forms of traditional religion and most of them came into Dande with the task of politicizing the peasants, as we saw, it soon became clear that any form of political legitimacy among the Shona would only succeed with the endorsement of a set of cosmological notions and practices concerning the ancestors and the reproduction of the cosmos. During forms of spirit possession, the spirits of past chiefs (mhondoro) provided the force and energy of rain-making that enabled the reproduction of kin and families and also reasserted the political power of the lineages 
over the land. ZANLA participation in ritual practices was therefore instrumental both in gaining political power from the spirits of the chiefs and in order to claim to be autochthonous "owners of the land" in opposition to white "conquering" Rhodesians.

Instead of a straightforward incorporation into the practices of militarily trained and politically advanced ZANLA fighters, the interactions and practices of the locals provide an insight into the role played by local ritual practices, clans, and lineages in the revolutionary movement. This altered the narrative and discourse of the guerrillas, which needed to integrate references to the ancestors and rely on the spirit mediums as political referents for any political action and decision. In fact, the ancestors provided the revolutionary movement with a new ideological basis and heritage with which to rethink the idea of nation, allowing them to reframe the new Zimbabwe in terms of an ancient polity over which the ancestors had ruled long ago.

Lan presents an interesting dimension of the role of local religious forms in a context of revolutionary war and transformation, pointing out that Shona cosmological ideas and practices enabled the guerrillas to recreate and reproduce the connection with the ancestors. More importantly, those ideas were institutionalized within the guerrilla groups, becoming structuring practices in the lives of combatants who were placed under the protection of the ancestors but also socially normed according to the rules thrust on them by spirit mediums. So, for instance, combatants were prohibited from killing wild animals in the forest, eating certain foods, and having sexual intercourse, as respect for these embargos would allow them to become invisible during warfare and to acquire powers from the ancestors. The local cosmology became an instrumental dimension in the construction of a revolutionary anticolonial platform as well as a modern nation-state.

Another example of a revolutionary movement being born out of cosmological practices is the case of Haiti, the first and uniquely successful slave uprising that produced the independent republic. Trinidadian socialist historian, writer, and intellectual C.L.R. James described the Haitian revolution in his book Black Jacobins (1963) and, despite his scant references to voodoo-to be expected of a socialist-the work still manages to convey the strategic role played by religious and spiritual practices in the uprising (see also Geggus 1992; cf. Jean-Marie 2019). Voodoo became the medium of the revolution because the slaves traveled miles to sing and dance and practice their rites, creating the conditions for scattered peasants to generate spaces of congregation and resistance in which to question the rules and forms of slavery. Consequently, voodoo ritual structures became the tools of organization for revolutionary action, and it is not surprising that the first leader of the Haitian revolution, Boukman, was a papaloi or high priest.

C.L.R. James describes how revolutionary action was planned in the middle of voodoo rituals and preceded by voodoo incantations and the sucking of the blood 
of a stuck pig by groups of the rebel slaves. Papaloi Boukman frames the revolution in a creole-language prayer in terms of revenge of our wrongs, as "ordered by our god," a god that will also "direct our arms" in the revolt against the whites. In preparation for the war against the French army, the slaves carried out preliminary maneuvers in dead silence while the papaloi-priests chanted the spells and the women and children danced to the point of frenzy. When all these activities had reached the necessary height of excitement the fighters attacked.

Local cosmology, religions, and practices of spirit possession provided the foundation not only for rebellion but also for shaping a new political order. In Haiti, voodoo rituals became the terrain where revolution was instantiated while spirits guided the bodies of the rebels during military actions, literally turning revolution into a form of spirit possession. While we have addressed in chapter 1 the revolutionary potential of rituals, in this section we have shown the cosmological properties of revolution and how the notion of revolution springs not only from the social forms of black slaves and indigenous groups but also from specific notions of power and modalities of articulation with spiritual forces.

\section{INDIGENOUS NOTIONS \\ OF REVOLUTIONARY TRANSFORMATION}

As illustrated by the case of Mozambique, from the point of view of peasants and indigenous groups, revolution has traditionally been seen in terms of an external geopolitical event invading or even threatening a locality. However, as in the case of Haiti, indigenous rituals, myths, and organizational forms may become the platforms from which to develop forms and notions of revolution that draw on local concepts and histories. Building on these examples, in this section we explore the scope, meaning, and possibilities of an indigenous conception of revolution.

In the case of the proceso de cambio in Bolivia, scholars have repeatedly signaled the resonance between the revolutionary process and the indigenous myth and notion of Pachakuti (Hylton and Thompson 2005; Gutiérrez 2014; Arbona et al. 2016), literally "the return of time/space" in Aymara. The myth of Pachakuti, which began to take shape across the Andes and among different groups during the colonial era, can be summarized as follows: After the quartering and burying of the limbs of the dismembered body of the Inca emperor (Atahualpa) - or of the Aymara chief Tupak Katari-in different locations across the Andes, it was said that the body of the emperor-or of the Aymara warrior-would grow back together underground, causing another world to develop (Arguedas and Roel Pineda 1973; Castro-Klarén 1993). Through what is called a Pachakuti-a reconfiguration of time and space-this underground world would surface, reestablishing the rule of the indigenous world over the current rulers while also giving rise to a time of health and justice where the whites would work like indios. 
During the colonial war of independence from the Spanish Crown at the beginning of the nineteenth century, Aymara people had already experimented with the instantiation of the myth during indigenous revolts supporting liberation from the colonial yoke. In 1804 the provisional formation of an indigenous republic in the town of Oruro did not lead to the killing or expulsion of whites and mestizos but rather to their being obliged to wear ponchos and sandals (abarcas) and chew coca leaves (Thompson 2002), all actions specifically associated with the indigenous peasantry. Pachakuti not only changes the rhythms and directions of time-as signaled by the Congress clock running counterclockwise-but also brings about an immanent space or cosmos. In practice, it takes the semblance of a cosmological transformation, an emergence in all its intensity of an indigenous world that has previously been rendered invisible and relegated to the social and political margins. In such a process, indigenous cosmological forces such as the Andean Mother Earth, Pachamama-nurturing in her womb the limbs of Atahualpa / Katari-and traditional indigenous textiles, or even the everyday cultural practice of chewing coca leaves, are framed as essential tools to antagonize an external power and also as revolutionary instruments that in their daily and quotidian operation persistently and methodically shape and potentiate an indigenous cosmos that will counteract and possibly reverse white domination.

Throughout the proceso de cambio this indigenous concept of renewal has been symbolically mobilized and strategically appropriated by the Morales administration to point at the specificity and indigenous twist of the Bolivian "revolution" and even to masquerade some of its most liberal and less revolutionary politics (see Goodale 2019; Salazar 2015). Beside, the prebendal relations between the apparatuses of the revolutionary state and the indigenous organizations has led scholars to deemphasize the "cosmic" character of the revolution (see Reinaga [1970] 2010) in order to pragmatically foreground convenience and corruption (Zegada and Komadina 2017). We still retain that some of the local categories, political expectations, and notions of transformation of the popular and indigenous sectors remain critical to understand the scope and character of this phenomenon.

Scholars, for instance, have discussed how at the inception of the upheavals of the proceso de cambio in the 4,00o-meter-high city of El Alto, alteños discussed in their assemblies the option of flooding the city with indios by having eight to twelve children, like their grandparents, thus causing the gradual disappearance of the whites (Zibechi 2010; Mamani 2010). The language used to describe the insurrectionary movement was dotted with expressions such as "waves," "flooding," "spilling over," and "ant-like" (como hormigas) to depict the protesters pouring down from the plateau. Nestled at the bottom of a mountain canyon and encircled by indigenous settlements, the white and mestizo inhabitants of La Paz have historically lived in fear of being besieged by the indios. Not only did the local communities and assemblies "flood" the survival capability of the government and 
depose a president speaking Spanish with a heavily American accent, they also "spilled over" and "poured down" from the plateau to the steep canyon where La Paz stands, inundating the seat of government. Instead of the conventional idea of revolution as a sudden rupture with the preexisting political order, Aymara sectors resorted to the liquid metaphor and to their own cosmological categories.

The ant, for instance, is the being par excellence that embodies a specific pattern of small repetitions inducing a sense of multiplication and cosmological reproduction. Repeated sequences of ants jammed in honey are used by traders in their offering to cosmological forces to attract customers "like ants" and for their business to reproduce and multiply. In the lavish dance parades for the celebration of local saints, the line of repeated, heavily costumed dancers (like ants) are thought to make the saint "reverberate" (retumbar) in every street corner of the city, reproducing and overflowing its reach and power across the landscape (Tassi 2010, 2013). Rather than seeing revolution as transcending the worldly space and aspiring toward a transcendent horizon, Aymara "revolution" is framed through their own cosmological categories of "reproduction," along with their rules, practices, and political forms, flooding and overturning the rest. Instead of a sudden separation of the past from the present and a reorienting of expectations toward the future, it appears as if the barycenter, the axis of the cosmos, has shifted, redefining a set of sociopolitical coordinates: what was submerged and marginalized has now moved toward the surface and the center.

Tassi (forthcoming; cf. Arbona et al. 2016) describes how Martín, one of his informants, founder of the most renown religious brotherhood in La Paz and head of a traditional family of Aymara origin, would often boast that in his family all female members had to wear a pollera-the traditional Andean attire of multiple skirts. This implied that some of his daughters-in-law, when joining the family, had to abandon conventional Western clothes (hacerse de pollera). Subtly, Martín's boasts did not merely reference the proud "return" of the past encouraged by some indigenous intellectuals (Yampara 1992; Yampara et al. 2007; Untoja 2001), but also a process whereby the pollera is taking center stage in urban social dynamics and even in the expression of status. As per the narrative and notion of Pacha$k u t i$, clothing items such as the pollera and the bowler hat have been socially and symbolically reconfigured from marginal and discriminated-against objects and symbols to definitory instances of a "new" social and cosmological reality.

Arbona et al. (2016) mention that, in a neighborhood of El Alto, people voted en masse in the 2011 elections for the Magistrates' Council for a middle-aged woman named Cristina Mamani. Cristina was an alteño woman in her forties whom nobody in the neighborhood knew personally; they had merely seen her picture on the ballot paper. Her image-dressed in the bowler hat and the pollerawas a convincing element to the locals who disregarded a number of candidates with higher academic qualifications and neater, more modern, more appropriate 
appearance for the position. Being a pollera woman was taken as the expression of an affinity with the interests and aspirations of the popular sectors but also of an association with self-determination and firsthand knowledge of the practical possibilities and limitations of the country, unlike local intellectual/political circles and even formal institutions.

Eusebio, a young student from El Alto, was encouraged to run as a candidate in an alteño constituency because of his Aymara looks and humble physical appearance, his measured but direct way of speaking, and his firsthand and practical-rather than specialist-knowledge of local problems. Paradoxically, instead of a disposition for political leadership or personal management and negotiation skills, Eusebio was nominated for not being a politician, at least not in the conventional sense. What can be observed here is how attire and practices racially associated by the whites with the lumpen proletariat, filth, and amoral sexuality (see Weismantel 2001 regarding the pollera) are publicly framed from the Aymara point of view as constitutive components of a world with a certain moral, cultural, and intellectual hegemony over conventional ruling sectors. This is nothing new; although concealed or made invisible, these elements have always been there. However, they are now being amplified, "reverberated" to the point of bringing to the surface dynamics that, despite operating under the radar of mainstream and official institutions, have remained central to structuring local reality. Methodical insistence on culturally specific practices, items of clothing, and beliefs dismissed by both modernity and official institutions have become a strategy of both reproduction and amplification of a marginal world now aspiring to become the hegemonic center of life.

In the case of the Aymara and of urban popular sectors, instead of constituting an incommensurable rupture, "revolution" takes the form of a process of potentiation, surfacing, and overflow of a cosmos that has been growing underground, at the margins of the official political institutions; an intensified expression of the everyday organic life of communities and associations routinely participating in meetings, demonstrations, civic parades, and other collective responsibilities (cf. Albro 2006). Instead of conforming to conventional revolutionary ideals of transformation, such a notion of revolution promotes the possibility of "being who we are" in a context where a set of national and international agents have continually worked toward precluding this possibility. ${ }^{4}$

4. The economic ascendance of some indigenous and popular sectors in Bolivia in the last decades has brought scholars (Shakow 2014; Pellegrini 2016; CIS 2018) to emphasize dynamics of indigenous participation in the orthodox processes of modernity, from practices of consumption to patterns of social differentiation, from the use of technology to the access to private schools for their offspring. Some scholars have even paralleled these economic transformations with a destructuring of indigenous values and forms of organization (Urioste 2017). It is worth mentioning that the cosmological shift we have been describing that feeds a repositioning of the margins toward the center does not imply an 
In this sense, the ethnographic materials described end up emphasizing specifically Aymara notions and "horizons" of radical transformation. Instead of a transcendent horizon of freedom, salvation, and undifferentiated equality, revolution appears to be driven by an immanent cosmological reconfiguration that repositions the social margins of society right at the center. Such a reconfiguration is not created by a sudden rupture with tradition and with religion but rather through a potentiation of a set of objects, practices, and cosmological elements that activate such "revolution." In other words, religion and myth are neither the veils of the oppression nor the opium of the people. On the contrary, religion and myth become the decisive forms, forces, and domains of revolution. Through their potentiation and intensification revolution is ultimately instantiated.

\section{CONCLUSION}

In the tradition of political science's-and, to a degree, anthropology's-study of revolution the peasant, the indigenous, and the slave have been conceived as structurally incapable of producing revolutionary transformations (Wolf 1969; Stern 1987). They were the parochial initiators of revolts but eventually the ball had to be handed over to more sophisticated groups: intellectuals and vanguard parties capable of harnessing peasant energies, but for ends never dreamed of by these subaltern groups, thereby transubstantiating unsophisticated effort or brute force into refined revolutionary strategies or political projects with their own teleology. What we have seen throughout this chapter, however, is that rituals, myths, and religious forms may become tools of teleological transformation. The political projects of peasants and indigenous groups, formulated and instantiated by indigenous peasants themselves, may not require sophisticated political elites to translate the dissatisfaction of the people into "genuine" political projects.

This enables us, first, to provincialize European ideas of revolution often used as universal models or forms for revolutionary action throughout the world. To be sure, supposedly universal European notions of revolutionary action (see the discussion of universalism in the Conclusion) continue to be appropriated and employed locally (see Donham 1999). However, if we persist in measuring revolution/ political transformation according to standardized horizons, canons of

indigenous rejection of or contrast with modernity but rather a possibility of being both modern and indigenous. In fact, the notion of "being who we are," as expressed by one of Tassi's informants, also clashes with the two main narratives describing indigenous possibilities of being: either integrating and adjusting indigenous practices to the forms and demeanors of hegemonic modernity, or returning to the community and to marginal, rural ways of living, conserving native traditions and impersonating a timeless alternative to capitalism and modernity. The combination of "being who we are" and their reconfiguration described earlier introduces a new possibility of being indigenous and hegemonic, Aymara and modern, at one and the same time. 
sacrifice and consciousness, in terms of lack, divergence, and immaturity in relation to a universal model, we run the risk of reproducing our own categories and hierarchies of knowledge while missing practices and concepts of revolution framed in terms of indigenous principles.

Secondly, this establishes the foundations of an anthropology of revolution, one able to highlight unexpected interpretations, re-significations, practices, and concepts and break the dichotomic tension between the canon and "alternative" local conceptions, thereby multiplying the possibilities of what revolution could be by emphasizing its multiple understandings as social and cultural practice. 


\title{
Conclusion
}

\author{
Worlds in Revolution
}

Throughout this book we have addressed different formations of revolutionwhat we may call "shapes of revolution"-from the most established examples of modern secular revolution to less well-documented, though no less powerful, forms of upheaval. In particular, in the previous chapter we have seen how these different revolutionary endeavors are informed by distinct understandings of the way the universe operates, lending revolutions different cosmological coordinates in each case. At times such understandings are articulated locally, that is, by relying on indigenous cosmological assumptions, while at others, as we have also seen, revolution is perceived as a language of liberation coming from outside: an external impulse. Often related to European revolutionary traditions, it is, nevertheless, contextually reinterpreted, and therefore involves a complex dialogue between different cosmological frameworks and concerns. Either way, our central contention thus far has been that attempts by revolutions to transform the sociopolitical conditions of human beings must be understood in light of the varying assumptions, discourses, and practices concerning the nature of the world, its capacities for change, and the role of people in bringing it about. The politics of revolution, we might say, must be understood with reference to the cosmological terrain in which it is enacted.

In this concluding chapter, however, we add a further twist to this thought, namely, that revolutions can be understood not only with reference to the cosmological coordinates that "frame" them (cf. Abramson and Holbraad 2014) but also, and perhaps most crucially, as cosmological projects in their own right. Revolutions, we suggest, are projects that set out to alter in unanticipated ways the manner in which people experience and conceptualize the universe and their place within it. In that sense revolutions have an inherently cosmogonic dimension: they are events that seek to generate and regenerate worlds-changing their coordinates, altering their spatiotemporal foundations, reconfiguring the position of human beings within them, reconstituting the very conditions of their existence. To be sure, when viewed from an anthropological standpoint, most political forms can be said to have cosmological and even cosmogonic dimensions of this kind. We know this from classic studies not only of putatively "nonmodern" political 
contexts-from the studies of African kingship we have already reviewed, to famous analyses of the cosmogonic character of the "theatre state" in Bali (Geertz 1980) or the Mandala-like "galactic polities" of Southeast Asia (Tambiah 1977) - but also of emblematically "modern" political formations, such as nationalism (Anderson 2006), state socialism (Collier 2011), and colonialism (Taussig 1986; Mitchell 1991). Still, while we do not claim that revolutions are exceptional in this respect, we do suggest that they are distinctive, if only in degree, and in three main ways.

First, as have seen throughout the book (and the point is so obvious that to some it has appeared as essential to the very definition of revolutions-e.g., Brinton [1938] 1965), revolutions are characteristically invested in the question of change, though admittedly in widely varying ways. That is to say, unlike many other political forms in which cosmological dynamics may be at stake, in revolutionary projects the act of bringing about or otherwise radically reconfiguring worlds takes the form of a cosmological transformation. It is for this reason that we are tempted to conceptualize revolutions as "cosmogonic" ventures: bringing about or otherwise radically reconfiguring worlds is one of their deepest stakes. Secondly, and again unlike other political ventures in which cosmological reconfigurations of various kinds might come about as largely unintended consequences, in revolutions such transformations are pursued explicitly and deliberately. ${ }^{1}$ Revolutions do not just change the world; their point is to do so. Cosmogony is not so much their consequence as their reason. Indeed, thirdly, the temptation to consider such changes in "cosmic" terms is owed partly to their deliberately wholesale, as well as radical, character. Where tamer programs for political transformation may involve piecemeal reforms limited to specific aspects of life (e.g., a reform in the scope of suffrage, which then altered conceptions of "the people" as political actors), revolutions characteristically take on an allembracing quality. To recall Marcel Mauss's term (1990), revolutions typically set themselves up as "total" social phenomena: political change is realized in and through projects of radical social transformation that go deep into local social forms, as well as the very constitutions of persons, space, time, power, and divinity, as we have seen in detail in previous chapters. ${ }^{2}$

1. One example of unintended consequences would be Benedict Anderson's argument that nationalism emerged in late eighteenth-century Europe as a "spontaneous distillation of a complex 'crossing" of discrete historical forces" (2006: 4).

2 Such totality should be understood in light of our argument that revolutions explicitly set out to change the world. Unlike revolutions, other holistic sociopolitical projects might not overtly acknowledge their own capacity to affect all facets of life. Consider, for instance, forms of global capitalism and neoliberalism that-despite presenting themselves as ventures aimed at freeing the subject, thus furnishing human beings with an agency and a degree of independence that were denied by the totalitarian experiments of the nineteenth and twentieth centuries-impose, in the end, a total reorganization of the world and of those who inhabit it. 
It is precisely this concertedly holistic quality of revolutions, as we have suggested throughout this book, that makes anthropology-the holistic science par excellence (Malinowski 1922; Otto and Bubandt 2010) - a royal road toward gaining a proper handle on them. This, after all, is our main complaint about the way revolutions tend to be treated by other disciplines: by focusing exclusively on political dynamics over everything else, they have missed the inherently holistic character of revolutions. Treating revolutions as events of cosmogonic proportions, by contrast, makes a virtue of their "total" quality, and places their political significance in relation to all of the topics we have opened up for anthropological scrutiny in the preceding chapters.

To be sure, the notion that revolutions are cosmogonic acts is not, strictly speaking, an anthropological discovery of our own. Descriptions of revolutions as Big Bang-like events that spawn new worlds have been recurrent since the French Revolution. The rage of the underprivileged, for example, has been described as a subterranean force breaking the earth's crust and irremediably changing the features of the cosmos. Revolutions, like volcanoes, spread a purifying fire over nations, burning to ashes the old world while simultaneously fertilizing the soil they are meant to destroy, thus creating the conditions for a new, generative rebirth (Ashburn Miller 2011: 154-55). Writing about the European uprisings of the early nineteenth century, for instance, Karl Marx describes these insurrections as phenomena akin to oceans of lava ready to blast away the surface of rock, and in envisioning his own revolutionary project, he often claimed to hear the continent shake and the crater of revolution rumble, voicing his hope for an eruption in his epistolary exchanges with Engels (Gandy 1979). Similarly, as explained in chapter 2, in more recent years Marxist Latin-American intellectual Álvaro García Linera has described revolution as a volcanic magma that violently erupts, and then slowly cools, solidifying into new political institutions that remain meaningful until the next eruption occurs, when, now old, they are burned to ashes, giving way to more just replacements (García Linera 2017). Revolutions thus feature in these accounts as truly cosmogonic events: outbreaks that destroy old worlds and generate new ones, inaugurating a novel era-a new time and space-and carrying human beings along a linear route of progress and refinement. Indeed, this is so prevalent that the point made in previous chapters regarding the linear understanding of the cosmos as found both in many modern revolutionary discourses and in monotheistic traditions could be reiterated here.

The notion that the muck of the ages is overcome in order to bring a better world into existence recapitulates two central ideas of the Abrahamic faiths: first, as Arendt points out ([1965] 2006: 16-18), the notion of a singular event-be it the storming of the Bastille or the advent of Christ-precipitating a qualitatively New Time, a gearshift of the rectilinear cosmology of history and, by that token, a cosmogonic moment; and, second, the idea-implicit in the association between 
revolutions and eruptions - that the past is nullified and erased by the advent of radical newness. The latter is a concept that has a diffuse resonance with the idea of Creation as an act of Will (divine in monotheistic accounts, human in familiar modern takes on revolution), bringing about something out of nothing, as in the creation of the world ex nihilo recounted in the book of Genesis (cf. Rubenstein 2012).

Below we expand on the apparent similarity between modern articulations of revolution and Abrahamic cosmology. However, for now it is important to clarify that, as much as it might be relevant to the understanding of revolutionary projects, a view of cosmogony as a process that necessarily unfolds in a linear manner does not fully help us to grasp some of the phenomena we have unpacked in the book. As we have shown throughout the chapters, the cosmological coordinates of revolution can be multiplied and diversified in different ethnographic contexts, and the same can be said of its cosmogonic narratives. Upheavals come in different shapes and sizes and so do the worlds they aim to create. As we have seen, for example, in some cases the change brought about by revolutions is not understood as the establishment of a completely new order of things that nullifies the past but rather as a new rediscovery of an old one. Besides, cosmogonies can fail, or alter their course. Often they are not articulated as the outcome of a trajectory that follows a linear development and eventually comes to realization. Rather, they might involve a continuous and endless process of adjustment, a cosmology constantly in the making (cf. Barth 1990). When we speak of revolution as a cosmogonic project, then, we mean it in a capacious sense: in revolutions the generation of the world is always and deeply at issue, but what "generation" and indeed "world" might mean are questions that we must leave resolutely open to interrogation in each case.

Naturally, this approach can hardly dismiss revolutionary projects that appear to rely on linear cosmogony, not least the long tradition of writings (and doings) inspired by Marx. Throughout this book we have sought to establish a dialogue between such powerful, enduringly relevant—and, as we have also seen, globally influential-epistemes and alternative conceptions that ethnographies of revolution in different parts of the world can help to articulate. Our intention in setting up this dialogue has been neither to dismiss the European traditions of debate nor forcibly exoticize the concept of revolution. Rather, by adopting the broader vantage of anthropological comparison, we have sought to uncover the deeper stakes of revolutions as "total" phenomena, encompassing more than just the standard narratives about radical political upheaval. Having made this case, however, we are now in a position to track two reciprocal moves in our dialogue with more established theories of revolution. First, we want to show how certain strands of Marxist writings have dealt with themes that are pertinent to our argument that revolutionary cosmogony does not necessarily imply linearity and creation out of 
nothing. Secondly, we want tackle a question that has informed theoretical writing on revolution, particularly, as we saw in our discussion of the role of ideology in chapter 5, those pertaining to Marxist philosophy, namely the question of universality. If revolutions characteristically set themselves up as total, and therefore, in a sense, universalizing projects-consider such emblematic revolutionary pronouncements as "declaration of the rights of man," "workers of the world unite," "bread, justice, and freedom" - then how might this tally with our proposal to consider them acts of cosmogony? Where, we may ask, does the variability that the notion of cosmogony introduces leave the idea that revolutions aim to transcend the particular in favor of the universal?

\section{BEYOND THE LINEAR: BENJAMIN AND BADIOU}

Marxist philosophers themselves have at times attempted to go beyond established understandings of revolution, thus hinting at the existence of nonlinear revolutionary cosmogonies. In his famous "Theses on the Philosophy of History" (2007: 253-64), for instance, the legendary and often cryptic Marxist thinker Walter Benjamin takes us through the potentials of revolutionary transformation in relation to the constitution of time, thus framing the question of revolution in explicitly cosmogonic terms. In particular, drawing inspiration from Jewish traditions of esoteric thought-a topic that intrigued Benjamin throughout his career-the thinker attempted to connect the Marxian concern with revolutionary transformation to mystical interpretations of the idea that the Messiah promised by the scriptures will return to establish a new world and a new sense of time. Interestingly, as we shall see, the upshot is a nonlinear account of revolutionary temporality, one that, although faithful to Marxist premises, is quite different from Marx's own.

Benjamin's analysis proceeds from the Jewish mystical idea that the Messiah's arrival can occur at any time, and the faithful must be constantly alert and ready for it. From this perspective, time is always marked by a sense of expectation, and, consequently, the present is never experienced merely as a "now." Rather, in a sense, the present is always already projected toward-and, therefore, pervaded by - the future, so the two cannot be distinguished in a clear way (2007: 263-64). This continuity between present and future sheds light on the true significance of the coming of the Messiah. In the words of Jewish theologian Gershom Scholem, one of Benjamin's prime interlocutors, such coming involves "transcendence breaking in upon history, an intrusion in which history itself perishes" (1971: 10). The Messiah, in other words, will bring about a form of newness so radical that, rather than simply abolishing the old world and generating a new one in a linear cosmogony of sorts, it will operate beyond the categories of "old" and "new" as they are conventionally understood. The power of the Messiah, therefore, will be 
so great as to be unrestricted by such categories, and indeed by time itself. Crucially, in this way he will be able to redeem, simultaneously, all the wrongs of the past, as well as those of the present and the future.

Benjamin saw a similar, though unexpressed, redeeming capacity in Marxist thought (Derrida 2012: 211), and by emphasizing this potential he devised a messianic formulation of the cosmogonic powers of revolution. His account was founded on a core intuition: the idea that a redemption beyond time as found in Jewish mysticism was compatible with the Marxist critique of capitalism. Further, it could prove more effective in the fight against capitalism than the usual tendency of Marxists to see revolution as the coming of a better world as, after all, capitalism also claims to carry humanity along a route of advancement (Benjamin 2007: 257-58; see also Berman 2010). To elucidate his point, Benjamin argued that a true revolution is such only if it is able to make sense of the fact that in the past many have tried to rise against the wrongs of the world, even though they may have failed. Marx's position toward these failures was essentially to learn from them, incorporating them into his dialectical model of history in order to set the conditions for revolutionary success in the future (Marx [1852] 2008: 15). Benjamin, on the other hand, thought that a successful revolution ought to connect with these aborted attempts at a deeper level, that it could succeed in their name, thus operating a retroactive redemption, a fulfillment in the present of all the unrealized potentialities of the past (2007: 260). Benjamin's conception of revolution was cosmogonic, then, insofar as he thought of revolution as an event that has the potential to precipitate a new kind of world or "era," one in which all wrongs could be redeemed. In his account, however, such a cosmogonic dimension is not articulated with a stress on the need to nullify the past or to leave it behind, as in standard Marxian conceptions, but rather, as with the Messiah, through a redemptive and in that sense affirmative relation with it.

Benjamin, we might say, wanted to free Marxism from a view of history as a trajectory of progress that, in his view, limited its liberating potential (Eagleton 1981: 78, 2010: 38). His attempt to do so, to be sure, has exerted a strong influence on subsequent attempts to modify and renew conceptions of revolutionary change by an array of neo- or indeed post-Marxist thinkers (e.g., Žižek 2008: 59), and not least with the renewed interest in "messianic time" in European political philosophy (e.g., Agamben 2005b). Bypassing, qualifying, or otherwise rethinking linear conceptions of time and history has been a central concern of these writings, particularly in the work of Alain Badiou, which has featured so prominently in recent debates. Indeed, Badiou's work is relevant to our purposes here, and deserves to be explored in some detail since cosmogonic concerns, which are in many ways analogous to Benjamin's, lie very much at its surface. Though an atheist himself, Badiou too, like Benjamin, draws inspiration from a spiritual tradition, namely, in his case, the letters of Saint Paul. While it is true that Badiou is 
one of many leftist thinkers to take an interest in Paul (Lyotard and Gruber 1999: 15; Žižek 2003; Preve 2006; Caputo and Alcoff 2009; Milbank et al. 2010; Baker 2013; Pasolini 2014), his treatment is distinguished by its markedly cosmogonic tenor, particularly in the parallel he draws between revolution and the resurrection of Christ: a parallel that pushes him to define a revolutionary cosmogony that, as with Benjamin, is not fully linear, at least when compared with more canonic Marxist articulations.

When Paul describes the resurrection, according to Badiou, he portrays it as a breaking point. The resurrection is such a constitutively "new" event that it cannot be apprehended from within the scope of categories of thought that were in use before its advent, such as Greek philosophy and Jewish law: the two main sets of discourses in Paul's time (2003: 42). The resurrection thus reveals the limitations of these prior ways of looking at the world. To illustrate this point, Badiou draws attention to the fact that both Greek philosophy and Jewish law put the stress on their mutual differences, as seen, for example, in the Jewish commitment to circumcision and the Greek rejection of it. This is in stark contrast with the idea of a risen Christ who saves all humans regardless of their background because in the eyes of God there is "neither Jew nor Greek," as Paul says (42). The event of the resurrection, then, brings forth an altogether new situation, in which the basic constituents of the world as people experienced it at the time (e.g., the distinction between Jews and Greeks) are superseded by new ones (e.g., humanity taken as a whole).

Badiou's Pauline analysis does have a strong emphasis on newness as the overcoming of an old order, and it would not be incorrect to say that for him events such as the resurrection effectively act to reorder the very constituents of reality. However, it is important to be quite precise about this point, since it goes to the heart of the difference between Badiou and Marx on the one hand, and the affinity between Badiou and Benjamin on the other. The novel situation in which all humans are united into a whole, according to Badiou, does not feature in Paul's writings as something that emerges as an altogether "new reality" or "world" out of the event of resurrection. Rather, it is something that was real even before Christ's rising, with the difference that at that time it could not be articulated, since the discourses that were then available were so focused on distinguishing Jews from Greeks that they precluded a more unified sense of humanity. So here cosmogony must be understood not as a matter of creating worlds out of nothing but rather as one of revealing realities that were already present in the past, although neither seen nor computed.

In a sense, then, Badiou's views resemble classical Marxist positions more than Benjamin's, particularly in the idea, encountered in chapter 5, that revolution makes reality visible by helping subjects to abandon the ideology that once hid it from view. Badiou, however, proposes an understanding of this process that is 
significantly different from that of more orthodox forms of Marxism. In particular, he argues that in Paul's account the disclosure of reality that the resurrection brings about does not require Greeks and Jews to abandon their traditions, and, in that sense, to annihilate the past. Rather, it asks them to become witnesses to an event that cannot be understood through such traditions, so that, although rooted in their customary commitments, Greeks and Jews can nevertheless become open to new aspects of the world (Badiou 2003: 43). While Paul confines this dynamic to the spiritual realm-particularly to the possibility of a "spiritual revolution" (Ephesians 4:23), Badiou extends it to any revolutionary event. Hence, in Badiou's view, revolution adds new dimensions to the world not by seeking to abolish prerevolutionary discourses - as with classical Marxism - but by relying on the way in which subjects, who are positioned within different and otherwise localized traditions, respond to the novelty of the event of revolution as that which exceeds those traditions without necessarily obliterating them.

In light of these considerations, both Badiou and Benjamin stand out as important predecessors in our anthropological approach to revolutionary cosmogonies. Furthermore, their analyses allow us to clarify that even though, as we have often said in the book, the Judeo-Christian tradition is in important ways characterized by a linear view of time, linearity is far from being its only component. This is as true for the Jewish messianic themes that inspired Benjamin as it is for Pauline Christianity, whose cosmology does not rely only on a temporality that points toward the future (the second coming of Christ) but also on the idea that Christ has already come, so that humanity does not simply proceed linearly toward the "end of time" but rather lives in the "time of the end" - a special time, carved within linear time, where it is imperative spiritually to meet Christ in the present (Agamben 2005b: 67-69, see also Lancaster 1988: xviii). The work of Benjamin and Badiou, then, shows that ultimately the idea of a purely linear cosmogony belongs more to classical Marxism and other attempts to secularize the Judeo-Christian paradigm of salvation than to this paradigm itself (Scholem 1971: 10).

Yet it is also important to stress that, ultimately, neither Badiou's nor Benjamin's approach fully coincides with ours, at least when it comes to documenting the ways in which revolutions are understood in different contexts. Although both these thinkers challenge standard cosmogonic assumptions, they nevertheless base their analyses on what is essentially a modern and secular view of the cosmos: one where the reconfiguration of the world operated by revolution is carried out by human beings as the sole actors of history. Admittedly, scholars have long debated whether Benjamin's approach is better understood as secular or theological (Dickinson and Symons 2016), whereas Badiou's approach is explicitly rooted in a humanist stance (Badiou 2003: 1-3). Regardless of their differences, however, these philosophers stand out as distinctively secular when one compares their work with the much more radically varied revolutionary epistemes we have encountered in previous chapters. For instance, while Benjamin believed that the 
notion of the messianic was particularly suited to describe revolution, he very much excluded the possibility of the Messiah truly manifesting himself (Rabinbach 1992: xviii). By contrast, as we have seen, the Iranian Revolution has relied heavily on the idea that the messianic figure of the Hidden Imam will return to establish justice on earth. Similarly, if Badiou saw in the resurrection a powerful paradigm of the revolutionary event, in the Liberation Theology movements underpinning revolutionary action in parts of Latin America and elsewhere, the prospect of revolution is based on the unabashedly nonsecular principle that Christ's resurrection is not merely a theoretical model for other events but a real event in its own right.

When juxtaposed with these discourses, Benjamin's and Badiou's writings come across, as they readily acknowledge themselves, not as alternative Christian or Jewish revolutionary cosmogonies but rather as Marxist articulations of Judeo-Christian themes: a feature that, as we have seen, characterizes even more orthodox Marxist analyses, although not with the same degree of experimentation. Even though both intellectuals show an awareness of the risks one encounters when assessing a religious cosmology through the lens of a secular one (Badiou 2001: 24; Benjamin 2007: 25), their approaches do not help us fully to make sense of the role played by gods, spirits, and other nonhuman agents in local revolutionary cosmogonies. While Benjamin and Badiou certainly enact the possibility of putting canonical revolutionary epistemes in dialogue with other traditions, as we have attempted to do in the book, their formulations remain an attempt to provide a general framework of revolutionary cosmogony within which indigenous ideas of revolution can only (and at best) be subsumed. Although this might be considered a legitimate move, should one be inclined to embrace the tenets of secular revolutionary projects, we are interested in the conceptual possibility of reversing such an approach, documenting the ways in which indigenous notions of world-making generate their own, specific, and in their own ways all-encompassing paradigms of politics and cosmogony. Ours is an effort to multiply the possibilities of revolution conceptually. In so doing, we do not aim to show that such possibilities are all equally desirable from a political point of view-a stance that, incidentally, would contrast with the demand, made by many revolutionary projects of their practitioners, to embrace one specific political and cosmological stance. Rather, we seek to show that, in setting out to reconstitute the world, each particular revolutionary project articulates its own understanding of the universal potential of this process.

\section{REVOLUTIONARY UNIVERSALISM MULTIPLIED}

We saw in earlier chapters how Koselleck's contention that revolution is the modern political form par excellence is borne out by the central role revolutions so often accord to universal goals and ideals-universalism itself being a 
prime avatar of Enlightenment thought. The very image, after all, of historical development as a march away from the particular and toward the universal, precipitated by increasingly radical revolutionary upheavals, has deep roots in the Enlightenment-it is as much an emblem of modern political thinking as revolutions are themselves. As Luis Dumont (1994) argued so forcefully in his masterful comparison between French and German images of individualism in the eighteenth and nineteenth centuries, the most central contention of the French Revolution itself was the idea that its aims were universal. Liberty, equality, and fraternity, alongside such cardinal values as laicism or the right to private property, are to be furthered as goals worthy of humanity as a whole, of which the project of "civilization" that the French Revolution embodies is merely an expression. That the revolution should be "French," in that sense, is only an historical accident. ${ }^{3}$ The revolution abolishes culture, as it were, such that French culture is really just universal culture. Dumont sums the idea up with reference to an imaginary figure conjured by his comparative argument:

[F] or the Frenchman, the existence of boundaries, of different languages, of conflicts of interest between nations, is negligible in relation to man's essence as expressed in his watchword: Liberty, Equality, Fraternity. The basic or global French ideology is as powerful as it is simple, and devoid of concrete elements. At bottom, it consists of a single principle: the human subject as universal. The creed has come down to us from the Enlightenment, of course, through the dispensation of the great Revolution that fondly marks the beginning of the establishment of truth on earth. (1994: 201)

For Dumont himself, however, such a claim to universality can only ever be understood as a particular system of value, to be compared anthropologically with alternatives that can be found elsewhere-for example, that of the Vedic caste system in India, in which the individual, far from universal, is subordinated hierarchically to the values of the system taken as a whole (1981), or the case of post-Reformation Germany, in which the individual is valued not as a social unit alongside others but rather in their deeply personal relationship to God (1994; see also Pedersen

3. Indeed, for Dumont, the "artificialism" of such a conception of human emancipation-the fact that it posits itself as an expression of universal humanity, transcending its contingently local realizations - can also be detected in Lenin's leadership of the Bolshevik Revolution. That Lenin should imagine, contrary to prevalent Marxist conceptions at the time (not least in Russia), that his country could skip directly from czarism to proletarian socialism in one fell revolutionary swoop, is, to be sure, partly an expression of the deeply Russian character of his understanding of the power of the Russian people, asserted as against "Western" principles of universal individualism. At the same time, the conviction that this autochthonous power could be deployed artificially to overcome itself-that it to say, to overcome its own contingency in favor of a universal revolutionary principles-is profoundly "modern." This ability of modern universalism to be "acculturated" in varying circumstances and mixed with elements that are quite contrary to it explains, for Dumont, why "Lenin's artificialism [could be] adopted later on by communist parties the world over" (1994: 12). 
2019). Treating universalism as an ethnographic variable in this way is certainly confluent with Benjamin's and Badiou's philosophical attempts to root the universalistic tenor of revolutions in particular spiritual traditions. As we saw, they allow Jewish messianism and Pauline Christianity, respectively, to alter the Marxist formulation of universalism. It is by carrying this maneuver that they manage to offer alternative notions of universality: one where novelty surpasses all localities without destroying them (as with Badiou) or where the redemption operated by revolution extends to the whole of human history (as per Benjamin).

However, Dumont's move to "demote" the French Revolution's claim to universality, as it were, also illustrates how anthropological comparison can amplify the critical potential of such an approach. Both Benjamin's and Badiou's temperings of universalism are attempts to recuperate the temporal complexity of the JudeoChristian traditions from which, as we have seen, modern ideas about revolution have emerged, in order to reinfuse them into contemporary proposals for revolution. Although an anthropological analysis of these projects should take their claims seriously, including claims of universality, we also suggest here the possibility to go beyond these trajectories in order to ethnographically document other prospects for revolutionary universality. By way of closing, then, let us illustrate this with reference to the ethnographic torsions of the idea of the universal in our own respective field sites, namely Libya, Bolivia, and Cuba.

Taking the case of Libya first, we may note that, as we have explained, Colonel Gaddafi's revolutionary project aimed at abolishing the nation-state, which Gaddafi considered an artificial colonial construction, as opposed to more natural forms of organization found in Libya, including kinship-based tribal groups. In particular, as we also saw, Gaddafi maintained that the structures of the state against which his revolution was pitted should be replaced by the "State of the Masses": a system in which citizens gather in popular assemblies and address political issues among themselves without the mediation of state bodies. Importantly, Gaddafi presented this formula as a universal model that could be applied outside of Libya, and indeed, during the early phases of his leadership, he put considerable effort into trying to export his political model to other countries. In fashioning his universal theory, however, Gaddafi adopted a distinctive Libyan perspective. Gaddafi thought that, once the artifice of the state was removed, society would be kept together by more authentic forms of solidarity: those founded on religion and on kinship. In Libyan tribal discourses these are meant to tie individuals together through blood relationships and religious obligations, allowing them to solve potential conflicts without the help of the state (Davis 1986: 49, 212). Similarly to the case of the French Revolution unpacked by Dumont, therefore, Gaddafi's universalism relied on the assumption that, in this case, Libyan culture was, in a sense, universal. Unlike the French case, however, Gaddafi articulated this assumption in an historical perspective as he believed that forms of 
universalism such as those produced by the West-forms that relied on secularism and the inevitability of the nation-state-had run their course and proved ineffective. Based on these premises, Gaddafi argued that his revolutionary venture had precipitated a new historical phase of human history, one that could finally allow Libyans, as well as other neglected localities of the world - which he often described with the collective term "black man" (Gaddafi [1975-81] 2005: 97) -to propose and establish their own, not necessarily secular or state-based, understandings of universalism. ${ }^{4}$

Rather than simply assuming that Libyan idiosyncrasies had a universal vocation, Gaddafi thus argued that such idiosyncrasies encapsulated those of all other neglected particularities, and that, in turn, such particularities could offer a new, refreshing perspective to the rest of the world. In a sense, Gaddafi's take on universalism resembles that of Marx, as the Marxist project stemmed from a similar, compelling premise: the notion that, throughout history, the universal tenets expressed by the French Revolution had ultimately benefited only a specific particularity-bourgeois particularity-so that a new understanding of the universal was needed, one that had to be formulated from the specific point of view of the exploited (Marx [1852] 2008). It is important to stress, however, that whereas Gaddafi, or Marx, saw the emancipation of one particularity as the necessary condition for universal emancipation, other discourses we have encountered in the book feature a radically different view of the universal dynamics of revolution.

The context of the Bolivian proceso de cambio is a case in point, as it sheds light on an understanding of universalism that differs from Gaddafi's in that, rather than presupposing the necessary primacy of a particularity, it fosters the coexistence of different specificities. In particular-as we have seen in chapter 2-in the Bolivian context, and more specifically among the Aymara, we find the idea that the reproduction of the cosmos relies on a fertile connection carried out by diverse and often antagonistic groups, cosmological forces, and territories: for example, mountainous / masculine highland and humid/feminine lowland. This cosmological outlook is reflected in practices aimed at activating processes of economic, political, and religious articulation across different and autonomous groups and territories, all of which are seen as necessary to sustain the universe. Such practices-which resonate with ancient forms of political administration of multiple groups and territories as found in the Inca Empire (Harris et al. 1987) shed light on a distinct Andean articulation of universalism, one which is founded on the idea that different entities can be connected with each other through generative networks, meanwhile maintaining their own particular traits.

4. Notice, however, that Gaddafi also stated that his model was inspired by ancient Greek notions of democracy (Davis 1986: 50), thus showing how local forms of universalism often entail complex combinations of various cultural repertoires. 
Incidentally, appreciating such a distinctively Andean articulation of universality helps us to problematize the notion-implicit in any attempt to forcefully incorporate different localities into Western universal forms, whether revolutionary or otherwise-that indigenous groups are ill equipped to produce a view of the universe and of revolution that goes beyond their circumscribed particularity: a notion that has left its unfortunate mark on Bolivian politics. So Bolivian progressive intellectuals have taken on the task of projecting to the universal level a series of local particularities. By drawing on local indigenous structures such as the community (or the ayllu, an Andean administrative unit), such intellectuals have reframed the ayllu as the basis of the collective production and appropriation that constitutes socialism. In other words, the "universal ayllu," once bridged by socialism instituting a transitional epoch of increasing socialization of decision-making promoted by a centralized state, will activate a gradual replacement of the capitalist civilization (García Linera 2015). Much as we have seen with Benjamin and Badiou, Bolivian intellectuals thus incorporated specific localities into a more canonical revolutionary narrative: a move that, in this particular case, was aimed at presenting the proceso as a recognizable revolutionary project in the eyes of potential external allies of the Bolivian revolution. This move, which demonstrates that, ultimately, Bolivian intellectuals have persisted in seeing indigenous people as incapable of universalism, irremediably reconfigured the proceso. The Aymara notion of a rather decentralized political body articulated by generative arteries dispersed across multiple territories was replaced by the canonical idea of a centralized state where, supposedly, the different groups were represented (Postero 2017; García Linera 2015).

As a final example, we can mention the case of Cuba where, unlike Bolivia, we do not have two different understandings of universalism that eventually clash with each other, but rather an official, state-sponsored version of it that coexists with other, more grassroots conceptions that do not necessarily contradict each other. As we saw in chapter 4, notwithstanding years of persecution, practitioners of Afro-Cuban religious traditions are able to conceive of themselves as participants in Cuba's revolutionary project by refracting it through the terms of Afro-Cuban cosmology. While in chapter 4 we referred to these conceptions in relation to revolutionary personhood, here we may note their cosmogonic, as well as universal, character, paying particular attention to the idea, found among practitioners of Afro-Cuban religion, that the Cuban Revolution has been able to sustain itself, against all odds, because of the life force (aché) with which continual animal sacrifices infuse it. This is, above all, a statement about cosmic production and reproduction. Much like mana, the famed Oceanian concept-cum-substance (Holbraad 2007), aché is conceived as a "power" or "capacity" that permeates everything that exists since the time of its very "birth," that is, the times of origin to which much of Afro-Cuban mythology is devoted. Everything has aché to some 
degree-divinities, animals, plants, objects, people, words, situations-and each thing can gain it or lose it depending on circumstances, animal sacrifice being a prime means for "charging" (cargar) particular entities with its force. Aché, then, is universal in the sense that it is all-encompassing, though manifest in different degrees, depending both on the will of divinities, who wield it, and on the actions of people who, by virtue of their own aché-charged initiation, can invoke their powers.

Crucially, the official revolutionary discourse in Cuba, for its part, also sets itself up as a universalizing project, though in a more "modern" sense. Notwithstanding its more particular concerns with "Cubanness" (Ayorinde 2004), the vocabulary of universal emancipation, cast in terms of social justice and equality, has been at the heart of the Cuban revolutionary project from its very beginning. We may seem, therefore, to be confronting here a conflict of universals: an Afro-American cosmogony of life forces, divinities, and sacrificial rituals pitted against a collective state-socialist-indeed, internationalist-endeavor promoting universal human emancipation. However, this is not necessarily how practitioners of Afro-Cuban religions see the matter themselves. To the extent that everything that exists manifests aché in one way or other, and things that are felt to be powerful reveal their particular charge of aché, the endurance of the revolution in Cuba is yet another proof of its confluence with the cosmogonic principles of Afro-Cuban ritual practices. What we have here, then, are two encompassing forms of universalism. On the one hand, the Cuban Revolution "contains" within its all-embracing reach the practitioners of Afro-Cuban religion who, from its point of view, are citizens with rights to practice their rituals and religion-one that has become increasingly prominent under the auspices of state-sponsored institutions that support it as part of the national culture. On the other hand, we have the cosmogonic logic of Afro-Cuban spirituality, according to which the revolution, with all its claim to be creating a new world, is itself an entity that manifests the power of the all-embracing cosmogonic principle of aché. Each side, then, sees the other as a "particular" instance of a universal principle-be that revolutionary emancipation and respect for religious freedom or the power of aché as an all-encompassing living force. Thus, these two claims to universality do not vie for position in some all-or-nothing contest of mutual antipathy but rather fold into each other, as each renders its counterpart a manifestation of its own cosmogonic powers.

This brief presentation of alternative, not necessarily modern understandings of universality-Gaddafi's idea that Libyan culture had the potential to reflect the universal aspirations of the neglected; the Aymara notion of a generative coexistence between distinct particularities; and the different mutually encompassing forms of universalism found in Cuba-serves to spell out the consequences of our argument about the cosmogonic stakes of revolution for the question of its claims to universality. Approaching these different "particular universalities" 
as cosmogonic processes, one might consider the etymology of the two words"universality" and "cosmogony." Universe and cosmos are of course synonyms. Notice, however, that there is also a difference. At its root, "universe" builds a notion of singularity into the conception of the world. By contrast, "cosmogony" (as well as "cosmology") has no such connotations. Quite the opposite: studying cosmogonies has a distinct methodological advantage, as it allows us to unpack the different ways in which a cosmos might be generated, reproduced, and transformed, grasping the entities, relations, and dynamics it might involve, and how, crucially, it might align itself in relation to other cosmoi. Placing revolutions' claims to universality within, rather than beyond, the scope of such contingent variations allows us not only to further problematize the more chauvinistic versions of modern Western thought-as discussed amply, for example, by postcolonial critiques at large (Latour 1993; Chakrabarty 2000; Viveiros de Castro 2014) - but also, more specifically, to grasp the different political prospects enacted by revolutionary endeavors.

Our argument in this regard, we may note, brings us into close proximity with recent calls to rescind cardinal modern distinctions between cosmos and polis, nature and culture, fact and value, science and politics, in order to embrace instead a "cosmopolitical" stance that treats these putative dualities symmetrically, exploring the many ways in which the political and the cosmological come together in all sorts of partial and contingent configurations (e.g., Stengers 2010; Latour 2002). Indeed, as we have sought to show, revolutions are cosmopolitical by their very nature. Such a realization, we believe, allows us not only to address a wider and more varied array of revolutionary configurations as revolutions per se, each with its own understanding of the way the cosmos comes about-thus avoiding the temptation to measure them against an external framework-but also to multiply the possibilities of and for political commitment. If anthropology is "revolutionary" in that it shares with revolution an impulse to shake up certainties and explore alternatives, then perhaps it can also furnish a certain bridge from thought to action. By its very nature, the anthropology of revolution can act as a boost to, as well as a critical check on, projects of revolutionary transformation, opening them up to the influence of as yet unthought-of possibilities deriving from sundry "elsewheres" that could, perhaps, inspire radical visions of lives and worlds "otherwise" (Povinelli 2012), and even, maybe, mark out paths toward them. 



\section{References}

Abercrombie, Nicholas, Bryan Turner, and Stephen Hill. [1980] 2014. The Dominant Ideology Thesis. London: Routledge.

Abrams, Benjamin, and John Dunn. 2017. "Modern Revolutions and Beyond: An Interview with John Dunn." Contention: The Multidisciplinary Journal of Social Protest 5(2): 114-31.

Abramson, Allen, and Martin Holbraad, eds. 2014. Framing Cosmologies: The Anthropology of Worlds. Manchester: Manchester University Press.

Abu-Lughod, Lila. 1989. "Zones of Theory in the Anthropology of the Arab World." Annual Review of Anthropology 18: 267-306.

- 2012. "Living the 'Revolution' in an Egyptian Village: Moral Action in a National Space." American Ethnologist 39(1): 21-25.

Abu-Lughod, Lila, Ali Agrama Hussein, Farha Ghannam, Sherine Hafez, Sherine F. Hamdy, Charles Hirschkind, Saba Mahmood, Reem Saad, and Jessica Winegar. 2012. "Forum: Egypt's 2011 Revolt." American Ethnologist 39(1): 21-70.

Adorno, Theodor. 1973. Negative Dialectics. New York: Seabury Press.

Adorno, Theodor, Else Frenkel-Brunswik, Daniel Levinson, and Nevitt Sanford. 1993. The Authoritarian Personality. London: Norton.

Afary, Janet, and Kevin B. Anderson. 2005. Foucault and the Iranian Revolution: Gender and the Seductions of Islamism. Chicago: University of Chicago Press.

Aflaq, Michel. 1969. "Michel Aflaq on Ishtirakiyya, 1946." In Arab Socialism: A Documentary Survey, edited by Sami A. Hanna and George H. Gardner, 297-304. Leiden: Brill.

Agamben, Giorgio. 1998. Homo Sacer: Sovereign Power and Bare Life. Stanford, CA: Stanford: University Press.

- 2005a. The State of Exception. Chicago: University of Chicago Press.

- 2005b. The Time That Remains: A Commentary on the Letter to the Romans. Stanford, CA: Stanford University Press.

- 2011. The Kingdom and the Glory: For a Theological Genealogy of Economy and Government. Stanford, CA: Stanford University Press.

Albro, Robert. 2006. "The Culture of Democracy and Bolivia's Indigenous Movements." Critique of Anthropology 26(4): 387-410.

Al E-Ahmad, Jalal. 1984. Occidentosis: A Plague from the West. Berkeley: Mizan Press.

- 1985. Lost in the Crowd. Washington, DC: Three Continents Press.

Alt, Herschel, and Edith Alt. 1964. The New Soviet Man: His Upbringing and Character Development. New York: Bookman Associates.

de Althaus, Jaime. 2007. La Revolucion Capitalista en el Perú. Lima: Fondo de Cultura Económica. 
Althusser, Louis. 2001. "Ideology and Ideological State Apparatuses." In Lenin and Philosophy and Other Essays, 85-126. New York: Monthly Review Press.

Álvarez, Sonia, Evelyn Dagnino, and Arturo Escobar, eds. 1998. Culture of Politics / Politics of Culture: Revisioning Latin American Social Movements. Boulder, CO: Westview Press.

Amster, Randall, Abraham DeLeon, Luis A. Fernandez, Anthony J. Nocella, and Shannon Deric, eds. 2009. Contemporary Anarchist Studies: An Introductory Anthology of Anarchy in the Academy. London: Routledge.

Anderson, Benedict. 2006. Imagined Communities: Reflections on the Origins and Spread of Nationalism. London: Verso.

Anderson, Lisa. 1986. The State and Social Transformation in Tunisia and Libya, 1830-1980. Princeton, NJ: Princeton University Press.

Anderson, Perry. 1998. The Origins of Postmodernity. London: Verso.

Anria, Santiago. 2009. Informal Institutions and Party Organization: A Case Study of the MAS-IPSP in Urban Areas of La Paz and El Alto. MA thesis, Simon Frazer University.

Arbona, Juan Manuel, María Elena Canedo, Carmen Medeiros, and Nico Tassi. 2016. El Proceso de Cambio Popular: Un Tejido Político con Anclaje País. La Paz: CIS.

Arendt, Hanna. [1965] 2006. On Revolution. London: Penguin.

Arguedas, José María. 1975. Formación de una Cultura Nacional Indoamericana. Mexico, Espana, Argentina: Siglo XXI Editores.

- [1966] 2009. Dioses y hombres de Huarochirí: Narración quechua recogida por Francisco de Ávila. Lima: Universidad Antonio Ruiz de Montoya.

Arguedas, José María, and Josafat Roel Pineda. 1973. “Tres Versiones del Mito de Inkarrí.” In Ideología Mesiánica del Mundo Andino, edited by J. Ossio, 219-25. Lima: Ignacio Prado Pastor.

Armbrust, Walter. 2019. Martyrs and Tricksters: An Ethnography of the Egyptian Revolution. Princeton, NJ: Princeton University Press.

Asad, Talal. 1979. "Anthropology and the Analysis of Ideology." Man, New Series 14(4): $607-27$.

-1983. "Anthropological Conceptions of Religion: Reflections on Geertz." Man, New Series 18(2): 237-59.

-1993. Genealogies of Religion: Discipline and Reasons of Power in Christianity and Islam. Baltimore: Johns Hopkins University Press.

- 2003. Formations of the Secular: Christianity, Islam, Modernity. Stanford, CA: Stanford University Press.

- 2004. "Where Are the Margins of the State?" In Anthropology in the Margins of the State, edited by Veena Das and Deborah Poole, 279-88. Santa Fe, NM: SAR Press.

Ashburn Miller, Mary. 2011. A Natural History of Revolution: Violence and Nature in the French Revolutionary Imagination, 1789-1794. Ithaca, NY: Cornell University Press.

Atran, Scott. 2016. "The Devoted Actor: Unconditional Commitment and Intractable Conflict across Cultures." Current Anthropology 57(S13): S192-203.

Ávila Molero, Javier. 200o. "Los dilemas del desarrollo: Antropología y promoción en el Perú." In No hay país más diverso, edited by C.I. Degregori, 413-42. Lima: PUCP, UP, IEP.

Ayorinde, Christine. 2004. Afro-Cuban Religiosity, Revolution, and National Identity. Gainesville: University Press of Florida. 
Babb, Florence E. 2001. After Revolution: Mapping Gender and Cultural Politics in Neoliberal Nicaragua. Austin: University of Texas Press.

Badiou, Alain. 2001. Ethics: An Essay on the Understanding of Evil. London: Verso.

- 2003. Saint Paul: The Foundation of Universalism. Stanford, CA: Stanford University Press.

. 2006. "The Cultural Revolution: The Last Revolution?” In Polemics, 290-321. New York: Verso.

-2007. Being and Event. London: Continuum.

- 2009. Logics of Worlds: Being and Event II. New York: Continuum.

- 2012. The Rebirth of History: Times of Riots and Uprisings. London: Verso.

Baker, Gideon. 2013. "The Revolution Is Dissent: Reconciling Agamben and Badiou on Paul." Political Theory 41(2): 312-35.

Baker, Keith M. 1990. Inventing the French Revolution: Essays on French Political Culture in the Eighteenth Century. Cambridge: Cambridge University Press.

Bakunin, Mikhail. 1971. On Anarchy. Edited by Sam Dolgoff. New York: Vintage Books. 1973. Selected Writings Part 1. Edited by Arthur Lehning. London: Jonathan Cape. . 1992. The Basic Bakunin: Writings 1869-1871. New York: Prometheus.

Barber, Benjamin. 2011. "Yes, Saif Is a Qadhdhafi, but There Is Still a Real Reformer Inside." The Guardian, April 13.

Barfield, Thomas. 1990. "Tribe and State Relations: The Inner Asian Perspective." In Tribe and State Formation in the Middle East, edited by P. Khoury and J. Kostiner, 153-84. Berkeley: University of California Press.

Barrett, Michèle. 1994. "Ideology, Politics, Hegemony: From Gramsci to Laclau and Mouffe." In Mapping Ideology, edited by Slavoj Žižek, 235-64. London: Verso.

Barth, Fredrik. 1990. Cosmologies in the Making: A Generative Approach to Cultural Variation in Inner New Guinea. Cambridge: Cambridge University Press.

Bastien, Joseph. 1985. Mountain of the Condor: Metaphor and Ritual in an Andean Ayllu. Long Grove, IL: Waveland Press.

Bauman, Zygmunt. 1985. Stalin and the Peasant Revolution: a Case Study in the Dialectics of Master and Slave. Leeds: University of Leeds, Occasional Papers in Sociology.

- 1994. "A Revolution in the Theory of Revolutions?" International Political Science Review 15(1): 15-24.

Bellin, Eva. 2012. "Reconsidering the Robustness of Authoritarianism in the Middle East: Lessons from the Arab Spring." Comparative Politics 44(2): 127-49.

Bengelsdorf, Carollee. 1994. The Problem of Democracy in Cuba: Between Vision and Reality. New York: Oxford University Press.

Benjamin, Walter. 2002. Selected Writings-Volume 1, 1913-1926. Edited by M. Bullock and M. W. Jennings. London: Harvard University Press.

- 2007. Illuminations. New York: Schocken Books.

Berger, Peter. 1986. The Capitalist Revolution: Fifty Propositions about Prosperity, Equality, and Liberty. New York: Basic Books.

Berman, Marshall. 2010. All That Is Solid Melts into Air. London: Verso.

Berryman, Philip. 1987. Liberation Theology: Essential Facts about the Revolutionary Movement in Latin America and Beyond. Philadelphia: Temple University Press.

Billington, James H. 1980. Fire in the Minds of Men: Origins of Revolutionary Faith. New York: Basic Books. 
Bloch, Ernst. 1995. The Principle of Hope, Volume 3. Cambridge, MA: MIT Press.

Bloch, Maurice. 1974. "Symbols, Song, Dance and Features of Articulation: Is Religion an Extreme Form of Traditional Authority?" Archives Europeen de Sociologie 15(1): 55-84.

-1986. From Blessing to Violence: History and Ideology in the Circumcision Ritual of the Merina. Cambridge: Cambridge University Press

1989. "From Cognition to Ideology." In Ritual, History and Power: Selected Papers in Anthropology, 106-36. London: Athlone Press.

- 1992. Prey into Hunter: The Politics of Religious Experience. Cambridge: Cambridge University Press.

- 2013. Marxism and Anthropology: The History of a Relationship. Oxford: Clarendon Press.

Blumenberg, Hans. 1985. The Legitimacy of the Modern Age. Cambridge, MA: MIT Press.

Boer, Roland. 2014. "Religion and Socialism, A. V. Lunacharsky and the God Builders." Political Theology 15: 188-209.

Boff, Leonardo. 1985. Church, Charisma and Power: Liberation Theology and the Institutional Church. Eugene: Wipf \& Stock.

Bosteels, Bruno. 2005. "Post-Maoism: Badiou and Politics." Positions: East Asia Cultures Critique 13(3): 575-634.

Bourgois, Philippe. 1981. "Class, Ethnicity, and the State among the Miskitu Amerindians of Northeastern Nicaragua." In Latin American Perspectives 8(2): 22-39.

- 1982. "What US Foreign Policy Faces in Rural El Salvador: An Eyewitness Account." Monthly Review, May.

Böwering, Gerhard. 1997. “The Concept of Time in Islam.” In Proceedings of the American Philosophical Society 141(1): 55-66.

Boyer, Dominic. 2003. "The Medium of Foucault in Anthropology." Minnesota Review 5860: $265-72$.

Boym, Svetlana. 1995. Common Places: Mythologies of Everyday Life in Russia. Cambridge, MA: Harvard University Press.

Bradley, John. 2012. After the Arab Spring: How Islamists Hijacked the Middle East Revolts. New York: Palgrave Macmillan.

Braidotti, Rosi. 2013. The Posthuman. Cambridge: Polity Press

Briceño, Pablo Agustin. 2018. Waiting for Power: Affection, Ethics and Politics in the Everyday Life of Popular Chile. Doctoral thesis submitted to University of Edinburgh.

Brinton, Crane. [1938] 1965. The Anatomy of Revolution. New York: Vintage Books.

Bryant, Rebecca, and Daniel M. Knight. 2019. The Anthropology of the Future. Cambridge: Cambridge University Press.

Bubandt, Nills, and Ton Otto, eds. 2010. Experiments in Holism: Theory and Practice in Contemporary Anthropology. Malden, MA: Blackwell.

Buck-Morss, Susan. 200o. Dreamworld and Catastrophe. London: MIT Press.

-2009. Hegel, Haiti, and Universal History. Pittsburgh: University of Pittsburgh Press.

Canessa, Andrew. 2012. "New Indigenous Citizenship in Bolivia: Challenging the Liberal Model of the State and Its Subjects." Latin American and Caribbean Ethnic Studies 7(2): 201-21.

Cannell, Fanella, ed. 2006. The Anthropology of Christianity. Durham, NC: Duke University Press. 
Capasso, Matteo. 2014. “The Libyan Drawers: 'Stateless Society', 'Humanitarian Intervention,' 'Logic of Exception' and 'Traversing the Phantasy"' Special issue, "The Multiple Narratives of the Libyan Revolution," edited by Matteo Capasso and Igor Cherstich. Middle East Critique 23(4): 387-404.

Capasso, Matteo, and Igor Cherstich. 2014. "Editors' Note: The Libyan Event and the Part for the Whole." Special issue, "The Multiple Narratives of the Libyan Revolution," edited by Matteo Capasso and Igor Cherstich. Middle East Critique 23(4): 379-85.

Caputo, John D., and Linda Alcoff, eds. 2009. St. Paul among the Philosophers. Bloomington: Indiana University Press.

Carandini, Guido. 2005. Un'Altro Marx: Lo Scienziato Liberato dall'Utopia. Rome: Laterza.

Carrette, Jeremy R. 200o. Foucault and Religion: Spiritual Corporality and Political Spirituality. London: Routledge.

Carsten, Janet. 1997. The Heat of the Hearth: The Process of Kinship in a Malay Fishing Community. Oxford: Clarendon Press.

Carter, Alan. 2011. "Anarchism, Some Theoretical Foundations." Journal of Political Ideologies 16(3): 245-64.

Castoriadis, Cornelius. 1987. The Imaginary Institution of Society. Cambridge, MA: MIT Press.

Castro-Klarén, Sara. 1993. "Dancing and the Sacred in the Andes: From Taqui Oncoy to Rasu-Ñiti." In New World Encounters, edited by Stephen Greenblatt, 159-76. Berkeley: University of California Press.

Caton, Steven, Hazim Al-Eryani, and Rayman Aryani. 2014. "Poetry of Protest: Tribes in Yemen's Change Revolution." In The Political Aesthetics of Global Protest, edited by Pnina Werbner, Martin Webb, and Kathryn Spellman-Poots, 121-44. Edinburgh: Edinburgh University Press.

Chakrabarty, Dipesh. 1994. "Trade Unions in a Hierarchical Culture: The Jute Workers of Calcutta 1920-1950.” In Subaltern Studies III: Writings on South Asian History and Society, edited by Ranajit Guha, 116-52. Delhi: Oxford University Press.

- 2000. Provincializing Europe: Postcolonial Thought and Historical Difference. Princeton, NJ: Princeton University Press.

Chatterjee, Partha. 1993. The Nations and Its Fragments: Colonial and Postcolonial Histories. Princeton, NJ: Princeton University Press.

Cheng, Yinghong. 2009. Creating the "New Man": From Enlightenment Ideals to Socialist Realities. Honolulu: University of Hawai'i Press.

Cherstich, Igor. 2011. Libya's Revolution: Tribe, Nation, Politics. Accessed 23rd March 2020. www.opendemocracy.net/en/author/igor-cherstich/

- 2014a. "When Tribesmen Do Not Act Tribal: Libyan Tribalism as Ideology (Not as Schizophrenia)." Special issue, "The Multiple Narratives of the Libyan Revolution," edited by Matteo Capasso and Igor Cherstich. Middle East Critique 23(4): 405-21.

- 2014b. "The Body of the Colonel: Caricature and Incarnation in the Libyan Revolution.” In The Political Aesthetics of Global Protest, edited by Pnina Werbner, Martin Webb, and Kathryn Spellman-Poots, 93-120. Edinburgh: Edinburgh University Press.

- Forthcoming. Seventy-Thousand Secrets: Sufism, Revolution and Concealment in Libya. 
Chomsky, Noam. 2008. "Notes on Anarchism." In The Essential Noam Chomsky, edited by Anthony Arnove, 92-104. London: Bodley Head.

Chua, Liana, and Nayanika Mathur, eds. 2018. Who Are "We"? Reimagining Alterity and Affinity in Anthropology. Oxford: Berghahn Books.

CIS. 2018. Movilidad socioeconómica y consumo: Patrones de consumos en sectores emergentes. La Paz: Centro de Investigaciones Sociales de la Vicepresidencia del Estado Plurinacional de Bolivia.

Clastres, Pierre. 1977. Society against the State. New York: Urizen Books.

Cohn, Norman. [1957] 2004. The Pursuit of the Millenium: Revolutionary Millenarians and Mystical Anarchists of the Middle Ages. London: Pimlico.

Collier, George A. 1998. "Differentiation, Radicalization, and the Emergence of the Zapatista Rebellion in Chiapas." PoLAR: Political and Legal Anthropology Review 21: 111-22.

Collier, George A., and Elizabeth Lowery Quaratiello. 1994. Basta! Land and the Zapatista Rebellion in Chiapas. Oakland, CA: Food First Books.

Collier, Stephen J. 2011. Post-Soviet Social: Neoliberalism, Social Modernity, Biopolitics. Princeton, NJ: Princeton University Press.

Comaroff, Jean, and John L. Comaroff. 1991. Of Revelation and Revolution, Volume 1: Christianity, Colonialism, and Consciousness in South Africa. Chicago: University of Chicago Press.

- 1997. Of Revelation and Revolution, Volume 2: The Dialectics of Modernity on a South African Frontier. Chicago: University of Chicago Press.

-2009. Ethnicity, Inc. Chicago: University of Chicago Press.

Confino, Michael. 1974. Daughter of a Revolutionary: Natalie Herzen and the BakuninNechayev Circle. London: Alcove Press.

Cook, Joanna, Nicholas J. Long, and Henrietta L. Moore, eds. 2016. The State We're In: Reflecting on Democracy's Troubles. Oxford: Berghahn Books.

Cooper, David. 2018. "Grounding Rights: Populist and Peasant Conceptions of Entitlement in Rural Nicaragua." Social Analysis 62(3): 128-48.

Cortez, Marc, and Michael P. Jensen, eds. 2017. T\&T Clark Reader in Theological Anthropology. London: Bloomsbury T\&T Clark.

Crehan, Kate. 2002. Gramsci, Culture and Anthropology. London: Pluto Press.

Dabashi, Hamid. 1993. Theology of Discontent: The Ideological Foundation of the Islamic Revolution in Iran. New York: New York University Press.

. 2011. Shi' ism: A Religion of Protest. London: Harvard University Press.

. 2012. The Arab Spring: The End of Postcolonialism. London: Zed Books.

Dahrendorf, Ralf. 1997. After 1989: Morals, Revolution, and Civil Society. Oxford: St Martin's Press.

Das, Veena, and Deborah Poole, eds. 2004. Anthropology in the Margins of the State. Santa Fe, NM: SAR Press.

Davis, Angela. 1983. Women, Race and Class. New York: Vintage Books / Random House.

Davis, John. 1986. Libyan Politics: Tribe and Revolution-An Account of the Zuwaya and Their Government. London: IB Tauris.

Dawson, Christopher. 1972. The Gods of Revolution. Washington, DC: Catholic University of America Press.

Day, Sophie, Akis Papataxiarchis, and Michael Stewart, eds. 1998. Lilies of the Field: Marginal People Who Live for the Moment. Boulder, CO: Westview Press. 
Deeb, Lara. 2009. "Emulating and / or Embodying the Ideal: The Gendering of Temporal Frameworks and Islamic Role Models in Shi'i Lebanon." American Ethnologist 36(2): 242-57.

Degregori, Carlos. 2012. How Difficult It Is to Be God: Shining Path's Politics of War in Peru, 1980-1999. Madison: University of Wisconsin Press.

Derrida, Jacques. 2012. Spectres of Marx: The State of the Debt, the Work of Mourning and the New International. Routledge: New York.

Dews, Peter. 1994. “Adorno, Post-Structuralism and the Critique of Identity." In Mapping Ideology, edited by Slavoj Žižek, 46-65. London: Verso.

Dickinson, Colby, and Stéphane Symons. 2016. "Introduction." In Walter Benjamin and Theology, edited by Colby Dickinson and Stéphane Symons, 1-18. New York: Fordham University Press.

Donham, Donald D. 1999. Marxist Modern: An Ethnographic History of the Ethiopian Revolution. Berkeley: University of California Press.

Dumont, Louis. 1981. Homo Hierarchicus: The Caste System and Its Implications. Chicago: University of Chicago Press.

-1994. German Ideology: From France to Germany and Back. Chicago: University of Chicago Press.

Dunayevskaya, Raya. 2003. Philosophy and Revolution: From Hegel to Sartre and from Marx to Mao. New York: Columbia University Press.

Dunn, John. 1972. Modern Revolutions: An Introduction to the Analysis of a Political Phenomenon. Cambridge: Cambridge University Press.

Dworetz, Stephen M. 1990. The Unvarnished Doctrine: Locke, Liberalism, and the American Revolution. Durham, NC: Duke University Press.

Eagleton, Terry. 1981. Walter Benjamin: Towards a Revolutionary Criticism. London: Verso.

- 1991. Ideology: An Introduction. London: Verso.

- 2009. Reason, Faith \& Revolution. New Haven, CT: Yale University Press.

- 2010. On Evil. London: Yale University Press.

Earle, Duncan. 1994. "Indigenous Identity at the Margin: Zapatismo and Nationalism." Cultural Survival Quarterly 18(1): 26-29.

Edgar, Adrienne Lynn. 2006. Tribal Nation: The Making of Soviet Turkmenistan. Princeton, NJ: Princeton University Press.

Eickelman, Dale F., and James Piscatori. 1996. Muslim Politics. Princeton, NJ: Princeton University Press.

Eliade, Mircea. 2018. The Myth of the Eternal Return: Cosmos and History. Princeton, NJ: Princeton University Press.

Elliot, Alice. 2016. "The Makeup of Destiny: Predestination and the Labor of Hope in a Moroccan Emigrant Town.” American Ethnologist 43(3): 488-99.

- 2017. "Permanent Revolution and the Body of Politics in Tunisia." Paper presented at the workshop Permanence: Anthropologies of What Stays. School of Arts, University of Bristol.

- 2020. "Mediterranean Distinctions: Forced Migration, Forceful Hope, and the Analytics of Desperation." In Refuge in a Moving World, edited by Elena Fiddian-Qasmiyeh. London: UCL Press.

Elliot, Alice, and Laura Menin, eds. 2018. "Anthropologies of Destiny: Action, Temporality, Freedom." Special issue, Hau: Journal of Ethnographic Theory 8(1-2): 292-346. 
Elyachar, Julia, and Jessica Winegar, eds. 2012. "Revolution and Counter-Revolution in Egypt a Year after January 25th." Hot Spots. Cultural Anthropology. Accessed 3 January 2019. https://culanth.org/fieldsights/208-revolution-and-counter-revolution-in-egypt-ayear-after-january-25th.

Engels, Friedrich. 1942a. "London, July 14, 1893." In Karl Marx and Friedrich Engels: Selected Correspondence, 1846-1895. New York: International.

—. 1942b. "Letter 213, 21 September 1890." In Karl Marx and Friedrich Engels: Selected Correspondence, 1846-1895. New York: International.

Englund, Harri, and James Leach. 2000. "Ethnography and the Meta-Narratives of Modernity." Current Anthropology 41(2): 225-48.

Escobar, Arturo. 2008. Territories of Difference: Place, Movements, Life, Redes. Durham, NC: Duke University Press.

Evans-Pritchard, Edward E. 1940. “The Nuer of Southern Sudan.” In African Political Systems, edited by Meyer Fortes and Edward E. Evans-Pritchard, 69-79. Oxford: Oxford University Press.

. 1949. The Sanusi of Cyrenaica. Oxford: Clarendon Press.

Evens, Terence M.S., and Don Handelman, eds. 2006. The Manchester School: Practice and Ethnographic Praxis in Anthropology. Oxford: Berghahn Books.

Fanon, Frantz. [1961] 2007. The Wretched of the Earth. New York: Grove Press.

Federici, Silvia. 2012. Revolution at Point Zero: Housework, Reproduction and Feminist Struggle. Oakland, CA: PM Press.

Foran, John, ed. 1997. Theorizing Revolutions. London: Routledge.

Forbess, Alice, and Lucia Michelutti. 2013. "Divine Kinship and Politics." Focaal: Journal of Global and Historical Anthropology 67: 3-18.

Fortes, Meyer. 1945. The Dynamics of Clanship among the Tallensi. Oxford: Oxford University Press.

- 1983. Oedipus and Job in West African Religion. Cambridge: Cambridge University Press.

Fosshagen, Kjetil. 2014. “The Arab Spring: Revolution or 1848 Reaction?" In Arab Spring: Uprisings, Powers, Interventions, edited by Kjetil Fosshagen, 1-20. Oxford: Berghahn Books.

Foucault, Michel. 1979. The History of Sexuality, vol. 1, An Introduction. London: Allen Lane.

- 1986. The History of Sexuality, vol. 3, The Care of the Self. New York: Vintage Books.

- 1988a. "Politics and Reason." In Michel Foucault: Interviews and Other Writings 19771984, edited by Lawrence D. Kritzman, 57-85. London: Routledge.

-1988b. Technologies of the Self: A Seminar with Michel Foucault. Edited by Luther A. Martin, Huck Gutman, and Patrick H. Hutton. London: Tavistock.

- 1988c. Madness and Civilization: A History of Insanity in the Age of Reason. New York: Vintage Books.

- 1994. "Interview with Michel Foucault." In Michel Foucault: Essential Works of Foucault, 1954-1984, vol. 3, Power, edited by James D. Faubion, 239-97. London: Penguin Books.

- 1995. Discipline and Punish: The Birth of the Prison. New York: Vintage Books. 
Foucault, Michel, and James Bernauer. 1981. "Is it Useless to Revolt?” Philosophy and Social Criticism 8(1): 2-4.

Friedman, Thomas. 2011. “Tribes with Flags.” New York Times, March 22.

Freire, Paulo. 1970. Pedagogía del Oprimido. Buenos Aires: Ed. Tierra Nueva y Siglo XXI Argentina Editores.

Fulton, John. 1987. "Religion and Politics in Gramsci: An Introduction." In Sociological Analysis 48(3): 197-216.

Fusaro, Diego. 2012. Minima Mercatalia: Filosofia e Capitalismo. Milano: Bompiani.

Frazer, James. [1890] 1993. The Golden Bough: A Study in Magic and Religion. Ware, Harts: Wordsworth Editions.

Gaddafi Al, Muammar. [1975-81] 2005. The Green Book. Tripoli: World Center for the Study and Research of the Green Book.

Gandy, Ross D. 1979. Marx and History: From Primitive Society to the Communist Future. Austin: University of Texas Press.

García Linera, Álvaro. 2008. La potencia plebeya: Acción colectiva e identidades indígenas, obreras y populares en Bolivia. Buenos Aires: Clacso.

—. 2015a. ¿Qué es una revolución? De la Revolución Rusa de 1917 a la revolución en nuestros tiempos. La Paz: Vicepresidencia del Estado Plurinacional de Bolivia.

_ 2015b. "Estado y Proceso Revolucionario." In Democracias en revolución \& revoluciones en democracia, Á. García Linera, G. Rivadendeira, E. Sader, and R. Torres, 11-45. La Paz: Vicepresidencia del Estado and CIS.

- 2017. ¿Qué es una revolución? De la revolución rusa a la revolución de nuestros tiempos. La Paz: Vicepresidencia del Estado Plurinacional de Bolivia.

García Luis, Julio, ed. 2008. Cuban Revolution Reader: A Documentary History of Fidel Castro's Revolution. Melbourne: Ocean Press

García Yapur, F., Alberto García, and M. Soliz. 2014. MAS legalmente, IPSP legítimamemente: Ciudanía y Devenir Estado de los Campesinos Indígenas en Bolivia. La Paz: PIEB.

Geertz, Clifford. 1973a. "Person, Time and Conduct in Bali." In The Interpretation of Cultures, 360-411. New York: Basic Books

- 1973b. "Ideology as a Cultural System." In The Interpretation of Cultures, 193-233. New York: Basic Books.

- 1973c. "After the Revolution: The Fate of Nationalism in the New States." In The Interpretation of Cultures, 234-54. New York: Basic Books.

-1973d. "The Integrative Revolution: Primordial Sentiments and Civil Politics in the New States." In The Interpretation of Cultures, 255-310. New York: Basic Books.

1980. Negara: The Theatre State in Nineteenth-Century Bali. Princeton, NJ: Princeton University Press.

Geggus, David. 1992. "Marronage, Voodoo, and the Saint Domingue Slave Revolt of 1791." Proceedings of the Meeting of the French Colonial Historical Society 15: 22-35.

Gell, Alfred. 1992. The Anthropology of Time: Cultural Constructions of Temporal Maps and Images. London: Berg

Ghamari-Tabrizi, Behrooz. 2016. Foucault in Iran: Islamic Revolution after the Enlightenment. Minneapolis: University of Minnesota Press.

Ghannam, Farha. 2012. "Meanings and Feelings: Local Interpretations of the Use of Violence in the Egyptian Revolution." American Ethnologist 39(1): 32-36. 
- 2015. "Technologies of Immortality, 'Good Endings', and Martyrdom in Urban Egypt." Ethnos 80(5): 630-48.

Gibson, Thomas. 1994. "Ritual and Revolution: Contesting the State in Central Indonesia." Social Analysis 35: 61-83.

Gluckman, Max. 1963. "Rituals of Rebellion in South-East Africa." In Order and Rebellion in Tribal Africa, 110-36. London: Cohen and West.

Gold, Marina. 2015. People and State in Socialist Cuba: Ideas and Practices of Revolution. New York: Palgrave Macmillan.

Goldman, Marcio. 2019. "Blood, Initiation, and Participation: What Is Given and What Is Made in Afro-Brazilian Religions." In The Culture of Invention in the Americas, edited by Pedro Pitarch and José Antonio Kelly, 31-52. Canon Pyon, Herefordshire: Sean Kingston.

Goldstone, Jack A. 2001. “Toward a Fourth Generation of Revolutionary Theory." Annual Review of Political Science 4: 139-87.

Golte, Jürgen, and Norma Adam. 1990. Los Caballos de Troya de los Invasores: Estrategias Campesinas en la Conquista de la Gran Lima. Lima: IEP.

Goodale, Mark. 2019. A Revolution in Fragments: Traversing Scales of Justice, Ideology, and Practice in Bolivia. Durham, NC: Duke University Press.

Goodale, Mark, and Nancy Postero, eds. 2013. Neoliberalism Interrupted: Social Changes and Governance in Contemporary Latin America. Stanford, CA: Stanford University Press.

Gouldner, Alvin W. 1982. "Marx’s Last Battle: Bakunin and the First International." Theory and Society 11(6): 853-84.

Graeber, David. 2002. “The New Anarchists." New Left Review 13: 61-73.

- 2004. Fragments of an Anarchist Anthropology. Chicago: Prickly Paradigm Press.

. 2009. Direct Action: An Ethnography. Oakland, CA: AK Press.

- 2011. Revolutions in Reverse: Essays on Politics, Violence, Art and Imagination. Oakland, CA: AK Press.

- 2017. "Notes on the Politics of Divine Kingship: Or, Elements for an Archaeology of Sovereignty." In On Kings, Marshall Sahlins and David Graeber, 377-464. Chicago: Hau Books.

Gramsci, Antonio. 1992a. Prison Notebooks, Vol. 1. Edited by Joseph Buttigieg. New York: Columbia University Press.

—. 1992b. Prison Notebooks, Vol. 2. Edited by Joseph Buttigieg. New York: Columbia University Press.

- 1994. "Notes on the Russian Revolution." In Gramsci: Pre-prison Writings, edited by Richard Bellamy, 31-34. Cambridge: Cambridge University Press.

Greenberg, Jessica. 2014. After the Revolution: Youth, Democracy, and the Politics of Disappointment in Serbia. Redwood City, CA: Stanford University Press.

Groys, Boris. 1992. The Total Art of Stalinism: Avant-Garde, Aesthetic Dictatorship, and Beyond. Princeton, NJ: Princeton University Press.

Guevara, Ernesto Che. [1967] 2009. Man and Socialism in Cuba. Havana: Guairas.

Guha, Ranajit. 1983. Elementary Aspects of Peasant Insurgency in Colonial India. Oxford: Oxford University Press.

Gutiérrez, Raquel. 2014. Rhythms of the Pachakuti: Indigenous Uprising and State Power in Bolivia. Durham, NC: Duke University Press. 
2015. Horizonte Comunario-Popular: Antagonismo y Producción de lo Común en América Latina. La Paz: Autodeterminación.

Habermas, Jürgen. 1984. The Theory of Communicative Action, vol. 2, Lifeworld and System: A Critique of Functionalist Reason. Boston: Beacon Press.

Hage, Ghassan. 2012. "Critical Anthropological Thought and the Radical Political Imaginary Today." Critique of Anthropology 32(3): 285-308.

Hagger, Nicholas. 2009. The Libyan Revolution, Its Origins and Legacy: A Memoir and Assessment. Ropley: O Books.

Hall, Stuart. 1980. "Encoding/ Decoding." In Culture, Media, Language, edited by Stuart Hall, Dorothy Hobson, Andrew Lowe, and Paul Willis, 107-116. London: Routledge.

- 1985. "Signification, Representation, Ideology: Althusser and the Post-Structuralist Debates." Critical Studies in Mass Communication 2(2): 91-114.

- 2018. "Gramsci's Relevance for Race and Ethnicity." In Stuart Hall: Essential Essays, vol. 2, Identity and Diaspora, edited by David Morley, 21-54. Durham, NC: Duke University Press.

Hallward, Peter. 1998. “Generic Sovereignty the Philosophy of Alain Badiou.” In Angelaki: Journal of the Theoretical Humanities 3(3): 87-111.

Hamdy, Sherine F. 2012. "Strength and Vulnerability after Egypt's Arab Spring Uprisings." American Ethnologist 39(1): 43-48.

Hann, Chris, ed. 2002. Postsocialism: Ideals, Ideologies and Practices in Eurasia. London: Routledge.

Hardt, Michael, and Antonio Negri. 2017. Assembly. Oxford: Oxford University Press.

Härkönen, Heidi. 2016. Kinship, Love and Life Cycle in Contemporary Havana, Cuba: To Not Die Alone. New York: Palgrave Macmillan.

Harris, Olivia, Brooke Larson, and Enrique Tandeter, eds. 1987. La participación indígena en los mercados surandinos: Estrategias y reproducción social-Siglos XVII a XX. La Paz: Ceres.

Haugbolle, Sune, and Andreas Bandak. 2017. "The Ends of Revolution: Rethinking Ideology and Time in the Arab Uprisings." Middle East Critique 26(3): 191-204.

Heck, Paul L. 2004. “Jihad Revisited." Journal of Religious Ethics 32(1): 95-128.

Hegel, G. W. F.1999. Political Writings. Cambridge: Cambridge University Press.

Hegland, Mary Elaine. 2014. Days of Revolution: Political Unrest in an Iranian Village. Stanford, CA: Stanford University Press.

Henare, Amiria, Martin Holbraad, and Sari Wastell, eds. 2007. Thinking through Things: Theorising Artefacts Ethnographically. London: Routledge.

Hershock, Peter D., and Roger T. Ames, eds. 2006. Confucian Cultures of Authority. New York: State University of New York Press.

Hikmet, Nâzım. 2002. Beyond the Walls: Selected Poems. London: Anvil Press Poetry.

Hirschfeld, Katherine. 2007. Health, Politics, and Revolution in Cuba since 1898. Abingdon: Routledge.

Hirschkind, Charles. 2006. The Ethical Soundscape: Cassette Sermons and Islamic Counterpublics. New York: Columbia University Press.

Hirslund, Dan. 2011. "Revolutionary Waiting: YCL Cadres in Nepal's Transition." Studies in Nepali History and Society 16(2): 229-69. 
Hitler, Adolf. 1925. Mein Kampf. People's Edition. Munich: Eher-Verlag.

Hobsbawm, Eric J. 1959. Primitive Rebels. Manchester: Manchester University Press.

- 1986. "Revolution." In Revolutions in History, edited by Roy Porter and Mikulas Teich, 5-46. Cambridge: Cambridge University Press.

Hocart, Arthur. 1970. Kings and Councillors: An Essay in the Comparative Anatomy of Human Society. Chicago: University of Chicago Press.

Hodges, Matthew. 2008. "Rethinking Time's Arrow: Bergson, Deleuze and the Anthropology of Time." Anthropological Theory 8: 399-429.

Hoffman, Michael. 2018. The Partial Revolution: Labour, Social Movements and the Invisible Hand of Mao in Western Nepal. New York: Berghahn Books.

Holbraad, Martin. 2004. "Religious 'Speculation': The Rise of Ifá Cults and Consumption in Post-Soviet Havana." Journal of Latin American Studies 36(4): 1-21.

- 2007. "The Power of Powder: Multiplicity and Motion in the Divinatory Cosmology of Cuban Ifá (or Mana Again).” In Thinking through Things: Theorising Artefacts Ethnographically, edited by Amira Henare, Martin Holbraad, and Sari Wastell, 189-225. London: Routledge

- 2012. Truth in Motion: The Recursive Anthropology of Cuban Divination. Chicago: University of Chicago Press.

- 2014. "Revolución o Muerte: Self-sacrifice and the Ontology of Cuban Revolution." Ethnos 79(3): 365-87.

- 2017a. "Cosmogonía y Segunda Naturaleza en la Revolución Cubana." Cuicuilco: Revista de Ciencias Antropológicas 70: 11-30.

- 2017b. "'I Have Been Formed in This Revolution': Revolution as Infrastructure, and the People It Creates in Cuba." Journal of Latin American and Caribbean Anthropology 23(3): 478-95.

- 2019. "How Myths Make Men in Afro-Cuban Divination." In The Culture of Invention in the Americas, edited by Pedro Pitarch and José Antonio Kelly, 53-73. Canon Pyon, Herefordshire: Sean Kingston.

Holbraad, Martin, Bruce Kapferer, and Julia Sauma, eds. 2019. Ruptures: Anthropologies of Discontinuity in Times of Turmoil. London: UCL Press.

Holbraad, Martin, and Morten A. Pedersen, eds. 2013. Times of Security: Ethnographies of Fear, Protest and the Future. New York: Routledge.

Holbraad, Martin, Morten Axel Pedersen, and Eduardo Viveiros de Castro. 2014. "The Politics of Ontology: Anthropological Positions." Cultural Anthropology. Accessed 5 January 2019. https://culanth.org/fieldsights/462-the-politics-of-ontology -anthropological-positions.

Holloway John. 1996. "The Concept of Power and the Zapatistas." Common Sense 19: 20-27.

- 2002. Change the World without Taking Power: The Meaning of Revolution Today. New York: Pluto Press.

Holloway, John, and Elona Pelaez. 1998. Zapatista!: Reinventing Revolution in Mexico. Chicago: Pluto Press.

Humphrey, Caroline. 1997. "Exemplars and Rules: Aspects of the Discourse of Moralities in Mongolia." In The Ethnography of Moralities, edited by Signe Howell, 25-48. London: Routledge. 
1999. Marx
Michigan Press.

- 2003. "Stalin and the Blue Elephant: Paranoia and Complicity in Postcommunist Metahistories." In Transparency and Conspiracy: Ethnographies of Suspicion in the New World Order, edited by Harry G. West and Todd Sanders, 175-203. London: Duke University Press.

- 2008. "Reassembling Individual Subjects: Events and Decisions in Troubled Times." Anthropological Theory 8: 357-80.

- 2014. "Schism, Event, and Revolution: The Old Believers of Trans-Baikalia." Current Anthropology 55(S10): S216-25.

- 2019. "The Guillotine: Reflections of Violent Revolutionary Rupture." In Ruptures: Anthropologies of Discontinuity in Times of Turmoil, edited by Martin Holbraad, Bruce Kapferer, and Julia Sauma, 27-51. London: UCL Press.

Huntington, Samuel P. 1968. Political Order in Changing Societies. New Haven, CT: Yale University Press.

Hyde, Lewis. 1995. Trickster Makes This World. London: Canongate.

Hylton, Forrest, and Sinclair Thompson. 2005. Revolutionary Horizons: Past and Present in Bolivian History. London: Verso.

Højer, Lars. 2018. "Apathy and Revolution." In Recovering the Human Subject: Freedom, Creativity and Decision, edited by James Laidlaw, Barbara Bodenhorn, and Martin Holbraad, 74-94. Cambridge: Cambridge University Press.

Israeli, Raphael. 2017. From Arab Spring to Islamic Winter. Abingdon: Routledge.

Iteanu, Andre. 1983. La Ronde des Changes. Paris: Maison des Sciences de l'Homme.

James, Cyril L. R. 1963. The Black Jacobins: Toussaint L'Ouverture and the San Domingo Revolution, 2nd ed. rev. New York: Vintage.

Jameson, Fredric. 1981. The Political Unconscious. Ithaca, NY: Cornell University Press.

- 1984. " Foreword." In The Postmodern Condition: A Report on Knowledge, J. Lyotard, vii-xxii. Manchester: Manchester University Press.

. 1998. The Cultural Turn. London: Verso Books.

Jean-Marie, Vivaldi. 2019. Vodou Cosmology and the Haitian Revolution in the Enlightenment Ideals of Kant and Hegel. Kingston: University of West Indies Press.

Johnson, Kay A. 1985. Women, the Family, and Peasant Revolution in China. Chicago: University of Chicago Press.

Johnston, Josée. 2003. "We Are All Marcos? Zapatismo, Solidarity and the Politics of Scale." In Global Civil Society and Its Limits, edited by Gordon Laxer and Sandra Halperin. International Political Economy Series. London: Palgrave Macmillan.

Juris, Jeffrey. 2008. Networking Futures: The Movements against Corporate Globalization. Durham, NC: Duke University Press.

Kalb, Don. 2018. "Trotsky over Mauss: Anthropological Theory and the October 1917 Commemoration." Dialectical Anthropology 42: 327-43.

Kantorowitz, Ernst. 2016. The King's Two Bodies: A Study in Medieval Political Theology. Princeton, NJ: Princeton University Press.

Keane, Webb. 2007. Christian Moderns: Freedom and Fetish in the Mission Encounter. Berkeley: University of California Press. 
Keck, Margaret E., and Kathryn Sikkink. 1998. Activists beyond Borders: Advocacy Networks in International Politics. Ithaca, NY: Cornell University Press.

Kharkhordin, Oleg. 1999. The Collective and the Individual in Russia: A Study of Practices. Berkeley: University of California Press.

Khatib, Lina. 2013. Image Politics in the Middle East: The Role of the Visual in Political Struggle. London: IB Tauris.

Khoury, Philip, and Joseph Kostiner. 1990. Tribe and State Formation in the Middle East. Berkeley: University of California Press.

Kimmel, Michael S. 1990. Revolution: A Sociological Interpretation. Philadelphia: Temple University Press.

King, Margaret L. 1978. "The Social Role of Intellectuals: Antonio Gramsci and the Italian Renaissance." Soundings: An Interdisciplinary Journal 61(1): 23-46.

Koselleck, Reinhart. 1985. "Historical Criteria of the Modern Concept of Revolution." In Futures Past: On the Semantics of Historical Time, 39-54. Cambridge, MA: MIT Press.

Kotkin, Stephen. 1997. Magnetic Mountain: Stalinism as a Civilization. Berkeley: University of California Press.

Krøijer, Stine. 2015. Figurations of the Future: Forms and Temporalities of Left Radical Politics in Northern Europe. Oxford: Berghahn Books.

- 2019. "Slow Rupture: The Art of Sneaking in an Occupied Forest." In Ruptures: Anthropologies of Discontinuity in Times of Turmoil, edited by Martin Holbraad, Bruce Kapferer, and Julia Sauma, 157-73. London: UCL Press.

Kropotkin, Peter. 1971. Louise Michel and the Paris Commune. London: Freedom Press.

- 1975. The Essential Kropotkin. Edited by Emile Capouya and Keitha Tompkins. London: Macmillan Press.

Kwon, Heonik. 2013. "Time Consciousness in North Korea's State Security Discourse." In Times of Security: Ethnographies of Fear, Protest and the Future, edited by Martin Holbraad and Morten A. Pedersen. New York: Routledge.

Lacher, Wolfram. 2013. "The Rise of Tribal Politics." In The 2011 Libyan Uprisings and the Struggle for the Post-Qadhafi Future, edited by Jason Pack, 151-74. New York: Palgrave Macmillan.

Laclau, Ernesto. 2005. On Populist Reason. London: Verso.

Laidlaw, James. 2014. The Subject of Virtue: An Anthropology of Ethics and Freedom. Cambridge: Cambridge University Press.

Laidlaw, James, Barbara Bodenhorn, and Martin Holbraad, eds. 2018. Recovering the Human Subject: Freedom, Creativity and Decision. Cambridge: Cambridge University Press.

Lan, David. 1985. Guns and Rain: Guerrillas and Spirit Mediums in Zimbabwe. Los Angeles: University of California Press.

Lancaster, Roger N. 1988. Thanks to God and the Revolution: Popular Religion and Class Consciousness in the New Nicaragua. New York: Columbia University Press.

Landy, Joshua, and Michael T. Saler. 2009. The Re-enchantment of the World: Secular Magic in a Rational Age. Palo Alto, CA: Stanford University Press.

Laruelle, Francois. 2017. Anti-Badiou: The Introduction of Maoism into Philosophy. London: Bloomsbury.

Latour, Bruno. 1993. We Have Never Been Modern. Harlow: Pearson Education.

- 2002. War of the Worlds: What about Peace? Chicago: University of Chicago Press.

2010. On the Modern Cult of the Factish Gods. Durham, NC: Duke University Press. 
Lazar, Sian. 2014. "Historical Narrative, Mundane Political Time, and Revolutionary Moments: Coexisting Temporalities in the Lived Experience of Social Movements." Journal of the Royal Anthropological Institute (N. S.) 20(S1): 91-108.

Lazarte, Jorge. 1991. "Partidos, Democracia, Problemas de Representación e Informalización de la Política (el caso de Bolivia)." Revista de Estudios Políticos 74: 579-614.

Le Goff, Jacques. 1980. Time, Work and Culture in the Middle Ages. Chicago: Chicago University Press.

-1982. Mercaderes y Banqueros de la Edad Media. Buenos Aires: EDUBA.

Lenin, Vladimir Ilyich. [1902] 2008. What Is to Be Done? Burning Questions of Our Movement. Accessed on 7 December 2018. www.marxists.org/archive/lenin/works/1901/witbd/index.htm.

- [1917] 2014. State and Revolution. Chicago: Haymarket Books.

Lévi-Strauss, Claude. 1966. The Savage Mind. Oxford: Oxford University Press.

Lévy-Bruhl, Lucien. 1926. How Natives Think. London: George Allen and Unwin.

Lewis, Rith M. 1977. "Foreword." In Four Men: Living the Revolution-An Oral History of Contemporary Cuba, Oscar Lewis, Ruth M. Lewis, and Susan M. Rigdon, vii-xxx. Urbana: University of Illinois Press.

Leyva Solano, Xochitl. 1994. "De Identidades y Militancias en la Región de Conflicto." La Jornada, February 1.

- 2001. "El Neo-Zapatismo: De Guerrilla a Social Movement Web. In La Guerrilla en las Regiones de México, Siglo XX, 725-47. Mexico City: CIESAS/El Colegio de Michoacán.

Liu, Xin. 2002. The Otherness of Self: A Geneaology of the Self in Contemporary China. Ann Arbor: University of Michigan Press.

2009. The Mirage of China: Anti-Humanism, Narcissism, and Corporeality of the Contemporary World. New York: Berghahn Books.

Loris-Rodionoff, Charlotte. 2019. Of Revolutionary Transformations: Life in Displacement at the Syrian-Turkish Border. PhD thesis submitted to the Department of Anthropology, UCL.

Löwith, Karl. 1949. Meaning in History. Chicago: University of Chicago Press.

Lukács, Georg. 1971. History and Class Consciousness. London: Merlin Press.

Luxemburg, Rosa. 2006. Reform or Revolution and Other Writings. Mineola: Dover.

Lyotard, Jean-François, and Eberhard Gruber. 1999. The Hyphen: Between Judaism and Christianity. Amherst: Humanity Books.

Maeckelbergh, Marianne. 2009. The Will of the Many: How the Alterglobalisation Movement Is Changing the Face of Democracy. London: Pluto Press.

Mahmood, Saba. 2005. Politics of Piety: The Islamic Revival and the Feminist Subject. Princeton, NJ: Princeton University Press.

Malatesta, Errico. 2015. Life and Ideas: The Writings of Errico Malatesta. Edited by Vernon Richards. London: Freedom Press.

Malia, Martin. 2006. History's Locomotives: Revolutions and the Making of the Modern World. New Haven, CT: Yale University Press.

Malinowski, Bronislaw. 1922. Argonauts of the Western Pacific. London: Routledge.

Malmström, Maria Federika. 2012. Have the Arab Uprisings Helped or Harmed Women's Rights? Women and the Arab Revolutions: From Equality in Protest to Backlash in the Transition from Old Regimes to New Governments. Cairo: The Swedish Institute. 
. ed. 2015. Affective Politics in Transitional North Africa: Imagining the Future. Uppsala: The Nordic Africa Institute.

- 2019. The Streets Are Talking to Me: Affective Fragments in Sisi's Egypt. Oakland: University of California Press.

Mamani, Pablo. 2010. El Rugir de las Multitudes: Microgobiernos barriales. La Paz: La Mirada Salvaje.

Mannheim, K. [1936] 200o. Ideology and Utopia, Collected Works, Volume 1. London: Routledge. Marcuse, Herbert. 1969. Soviet Marxism: A Critical Analysis. New York: Columbia University Press.

- 1991. One-Dimensional Man: Studies in the Ideology of the Advanced Industrial Society. London: Routledge.

Marsden Magnus. 2005. Living Islam: Muslim Religious Experience in Pakistan's North West Frontier. Cambridge: Cambridge University Press.

Marusek, Sarah. 2018. Faith and Resistance: The Politics of Love and War in Lebanon. London: Pluto Press.

Marx, Karl. 1970. Critique of Hegel's Philosophy of Right. Cambridge: Cambridge University Press. - 1974. Early Writings. New York: Vintage.

-1993. Grundrisse: Foundations of the Critique of Political Economy. London: Penguin.

- 2007. Economic and Philosophic Manuscripts of 1844. New York: Dover.

— [1852] 2008. The Eighteenth Brumaire of Louis Bonaparte. New York: International.

- [1867] 2011. Capital, Volume 1. New York: Dover.

Marx, Karl, and Friedrich Engels. 1976. Collected Works, vol. 5, Theses on Feuerbach: The German Ideology and Related Manuscripts. New York: International.

- 2001. The German Ideology Part One, with Selections from Parts Two and Three, Together with Marx's "Introduction to a Critique of Political Economy." New York: International.

- [1848] 2005. The Communist Manifesto and Other Writings. New York: Barnes \& Noble.

Maurer, Bill. 2005. Mutual Life, Limited: Islamic Banking, Alternative Currencies, Lateral Reason. Princeton, NJ: Princeton Univ. Press.

Mauss, Marcel. 1990. The Gift. London: Routledge.

[1924-25] 1992. "A Sociological Assessment of the Bolshevism." In The Radical Sociology of Durkheim and Mauss, edited by Mike J. Gane, 165-212. London: Routledge. Mazzini, Giuseppe. 1862. The Duties of Man. London: Chapman \& Hall.

McPhee, Pete. 2012. Robespierre: A Revolutionary Life. London: Yale University Press.

Meeks, Brian. 2002. Caribbean Revolutions and Revolutionary Theory: An Assessment of Cuba, Nicaragua and Grenada. Kingston: University of West Indies Press.

Michelutti, Lucia. 2014. "Kingship without Kings." In Patronage as Politics in South Asia, edited by Anastasia Piliavsky, 283-302. Cambridge: Cambridge University Press.

- 2017. "We Are All Chávez': Charisma as an Embodied Experience." In Latin American Perspectives 212(44): 232-50.

Mignolo, Walter. 2002. “The Zapatistas's Theoretical Revolution: Its Historical, Ethical, and Political Consequences." Review (Fernand Braudel Center) 25(3): 245-75.

Milbank, John, Slavoj Žižek, and Creston Davis, eds. 2010. Paul's New Moment: Continental Philosophy and the Future of Christian Theology. Ada: Brazos Press.

Miller, Daniel. 1997. Capitalism: An Ethnographic Approach. London: Bloomsbury. 
. 2014. "Facebook and the Origins of Religion." In Framing Cosmologies: The Anthropology of Worlds, edited by Allen Abramson and Martin Holbraad, 244-6o. Manchester: Manchester University Press.

Mitchell, Timothy. 1991. Colonising Egypt. Cambridge: Cambridge University Press.

Mittermaier, Amira. 2014. "Bread, Freedom, Social Justice: The Egyptian Uprising and a Sufi Khidma." Cultural Anthropology 29(1): 54-79.

- 2019. Giving to God: Islamic Charity in Revolutionary Times. Berkeley: University of California Press.

Molyneux, Maxine. 1985. "Mobilization without Emancipation? Women's Interests, the State, and Revolution in Nicaragua." Feminist Studies 11(2): 227-54.

Montag, Warren. 1995. "'The Soul Is the Prison of the Body': Althusser and Foucault, 1970-1975." Yale French Studies 88: 53-77.

Montoya, Rosario. 2012. Gendered Scenarios of Revolution: Making New Men and New Women in Nicaragua 1975-200o. Tucson: University of Arizona Press.

Moore, Barrington. 1966. Social Origins of Dictatorship and Democracy: Lord and Peasant in the Making of the Modern World. Harmondsworth: Penguin.

Moore, Carlos. 1989. Castro, the Blacks, and Africa. Berkeley: Center for Afro-American Studies, University of California.

Mosse, George L. 1999. The Fascist Revolution: Toward a General Theory of Fascism. New York: Howard Fertig.

Mottahedeh, Roy. 2000. The Mantle of the Prophet: Religion and Politics in Iran. London: Oneworld.

Murra, John. 1987. “Existieron el tributo y los mercados antes de la invasión europea?” In La Participación Indígena en los Mercados Surandinos: Estrategias y Reproducción Social-Siglos XVII a XX, edited by Olivia Harris, Brooke Larson, and Enrique Tandeter, 51-61. Cochabamba: Ceres.

Nash, June. 1993. We Eat the Mines and the Mines Eat Us: Dependency and Exploitation in Bolivian Tin Mines. New York: Columbia University Press.

— 1997. "Press Reports on the Chiapas Uprising: Towards a Transnationalized Communication." Journal of Latin American Anthropology 2: 42-75.

Nasser, Gamal Abd-el. 1958. Egypt's Liberation: The Philosophy of the Revolution. Washington, DC: US Government Printing Office.

Navaro-Yashin, Yael. 2002. Faces of the State: Secularism and Public Life in Turkey. Princeton, NJ: Princeton University Press.

Nechayev, Sergei. [1869] 2014. The Revolutionary Catechism. Accessed 8 December 2018. www.marxists.org/subject/anarchism/nechayev/catechism.htm.

Needham, Rodney. 1972. Belief, Language, and Experience. Oxford: Blackwell. 1992. Exemplars. Berkeley: University of California Press.

Noueihed, Lin, and Alex Warren. 2013. The Battle for the Arab Spring: Revolution, Counter-Revolution and the Making of a New Era. New Haven, CT: Yale University Press.

Nugent, David. 1997. Modernity at the Edge of Empire: State, Individual and Nation in the Northern Peruvian Andes, 1885-1935. Stanford, CA: Stanford University Press.

Olcott, Jocelyn, Mary Kay Vaughan, and Gabriela Cano, eds. 2006. Sex in Revolution: Gender, Politics, and Power in Modern Mexico. Durham, NC: Duke University Press.

Ortner, Sherry. 2006. Anthropology and Social Theory: Culture, Power and the Acting Subject. Durham, NC: Duke University Press. 
Otto, Jan Michiel, Jessica Carlisle, and Suliman Ibrahim, eds. 2013. Searching for Justice in Post-Gaddafi Libya. Leiden: Van Vollenhoven Institute.

Otto, Ton, and Nils Bubandt, eds. 2010. Experiments in Holism: Theory and Practice in Contemporary Anthropology. Hoboken, NJ: Wiley-Blackwell.

Paige, Jeffrey. 2003. "Finding the Revolutionary in the Revolution: Social Science Concepts and the Future of Revolution." In The Future of Revolution, edited by J. Foran, 19-29. London: Zed Books.

Palmié, Stephan, and Charles Stewart. 2016. "Introduction: For an Anthropology of History." Hau: Journal of Ethnographic Theory 6(1): 207-36.

Paperny, Vladimir. 1993. "Movement-Immobility." In Tekstura: Russian Essays on Visual Culture, edited by Alla Efimova and Lev Manovich, 56-69. Chicago: University of Chicago Press.

Pasolini, Pier Paolo. 2014. Saint Paul. London: Verso.

Patterson, Thomas. 2009. Karl Marx, Anthropologist. Oxford: Berg.

Paz, Octavio. [1950] 2005. The Labyrinth of Solitude. London: Penguin

Pedersen, Morten Axel. 2011. Not Quite Shamans: Spirit Worlds and Political Lives in Northern Mongolia. Ithaca, NY: Cornell University Press

_. 2019. "Inner Revolution: Reaction and Rupture in a Danish Lutheran Movement." In Ruptures: Anthropologies of Discontinuity in Times of Turmoil, edited by Martin Holbraad, Bruce Kapferer, and Julia Sauma, 93-115. London: UCL Press.

Pellegrini, Alessandra. 2016. Beyond Indigeneity: Coca Growing and the Emergence of a New Middle Class in Bolivia. Tucson: University of Arizona Press.

Pérez Jr., Louis A. 2005. To Die in Cuba: Suicide and Society. Chapel Hill: University of North Carolina Press.

Peters, Emrys L. 1990. The Bedouin of Cyrenaica: Studies in Personal and Corporate Power Cambridge: Cambridge University Press.

Pettigrew, Judith. 2013. Maoists at the Hearth: Everyday Life in Nepal's Civil War. Philadelphia: University of Pennsylvania Press.

Pinault, David. 1999. "Shia Lamentation Rituals and Reinterpretations of the Doctrine of Intercession: Two Cases from Modern India." History of Religion 38(3): 285-305.

Plattner, Marc F. 2011. "Comparing the Arab Revolts: The Global Context." Journal of Democracy 22(4): 5-12.

Polanyi, Karl. 1959. The Great Transformation: The Political and Economic Origins of Our Times. Boston: Beacon Press.

Porter, Ross. 2016. “Tricking Time, Overthrowing a Regime: Reining in the Future in the Yemeni Youth Revolution." Cambridge Journal of Anthropology 34(1): 58-71.

- 2017. "Freedom, Power and the Crisis of Politics in Revolutionary Yemen." Middle East Critique 26(3): 265-81.

Postero, Nancy. 2017. The Indigenous State Race, Politics, and Performance in Plurinational Bolivia. Oakland: University of California Press.

Poulantzas, Nikos. 1987. Political Power and Social Classes. London: Verso.

Povinelli, Elizabeth A. 2012. "The Will to Be Otherwise / The Effort of Endurance." South Atlantic Quarterly 111(3): 453-57.

Preve, Costanzo. 2006. Verita' e Relativismo: Religione, Scienza, Filosofia e Politica nell'Epoca delle Globalizazzione. Torino: Alpina Srl.

Putnam, Hilary. 2008. Jewish Philosophy as a Guide to Life: Rosenzweig, Buber, Lévinas, Wittgenstein. Bloomington: Indiana University Press. 
Quo, Quei F. 1988. “Orwell's Nineteen Eighty-Four and Mao's Cultural Revolution.” In George Orwell: A Reassessment, edited by Peter Buitenhuis and Ira Nadel, 126-35. London: Palgrave Macmillan.

Rabinbach, Anson. 1992. "Introduction.” In The Correspondence of Walter Benjamin and Gershom Scholem, 1932-1940, edited by Gershom Scholem, vii-xxxviii. Cambridge, MA: Harvard University Press.

Regalsky, Pablo. 2010. "Political Processes and the Reconfiguration of the State in Bolivia." Latin American Perspectives 37(3): 35-50.

Rehmann, Jan. 2013. Theories of Ideology: The Powers of Alienation and Subjection. Brill: Leiden.

Reinaga, Fausto. [1970] 2010. La Revolución India. La Paz: La Mirada Salvaje.

Ricciardi, Maurizio. 2003. Revolución: Léxico de Política. Buenos Aires: Nueva Visión.

Richards, Robert J. 1993. "Ideology and the History of Science." Biology and Philosophy 8: $103-8$.

Rigdon, Susan M. 1983. The Culture Facade: Art, Science and Politics in the Work of Oscar Lewis. Champaign: University of Illinois Press.

Risager, Bjarke Skærlund. 2016. “The Eventful Places of Occupy Wall Street and Tahir Square: Cosmopolitan Imagination and Social Movements." Globalizations 14(5): 714-29.

Robbins, Joel. 2010. "Anthropology, Pentecostalism, and the New Paul: Conversion, Event, and Social Transformation." South Atlantic Quarterly 109(4): 633-52.

- 2018. "Where in the World Are Values? Exemplarity, Morality, and Social Process." In Recovering the Human Subject: Freedom, Creativity and Decision, edited by James Laidlaw, Barbara Bodenhorn, and Martin Holbraad, 174-92. Cambridge: Cambridge University Press.

Robespierre, Maximilien. 1989. La Scalata al Cielo. Milan: Essedue.

Robinson, Andrew. 2013. "Walter Benjamin: Messianism and Revolution-Theses on History." Accessed 2 November 2014. https://ceasefiremagazine.co.uk/walter-benjaminmessianism-revolution-theses-history/.

Robinson, Cedric J. 2019. An Anthropology of Marxism. Chapel Hill: University of North Carolina Press.

Rodinson, Maxime. 1981. Marxism and the Muslim World. New York: Monthly Review Press.

Rosendahl, Mona. 1997. Inside the Revolution: Everyday Life in Socialist Cuba. Ithaca, NY: Cornell University Press.

Routon, Kenneth. 2009. “The 'Letter of the Year' and the Prophetics of Revolution.” In Cuba in the Special Period, edited by Ariana Hernández-Reguant, 123-42. New York: Palgrave MacMillan.

Rubenstein, Mary-Jane. 2012. "Cosmic Singularities: On the Nothing and the Sovereign." Journal of the American Academy of Religion 8o(2): 485-517.

Sa'adah, Anne. 1990. The Shaping of Liberal Politics in Revolutionary France: A Comparative Perspective. Princeton, NJ: Princeton University Press.

Sabea, Hanan. 2014. "I Dreamed of Being a People: Egypt's Revolution, the People and Critical Imagination." In The Political Aesthetics of Global Protest, edited by Pnina Werbner, Martin Webb, and Kathryn Spellman-Poots, 67-92. Edinburgh: Edinburgh University Press.

Sahlins, Marshall. 1996. “The Sadness of Sweetness: The Native Anthropology of Western Cosmology." Current Anthropology 37(3): 395-428.

- 2013. What Kinship Is-And Is Not. Chicago: University of Chicago Press. 
. 2017. "The Stranger-Kingship of the Mexica." In On Kings, David Graeber and Marshall Sahlins, 223-48. Chicago: Hau Press.

Salazar, Huascar. 2015. "Se han adueñado del proceso de lucha": Horizontes comunitariopopulares en tensión y la reconstitución de la dominación en la Bolivia del MAS. La Paz: Autodeterminación.

Sánchez, Rafael. 2016. Dancing Jacobins: A Venezuelan Genealogy of Latin American Populism. New York: Fordham University Press.

Sande, Mathijs van de. 2013. "The Prefigurative Politics of Tahrir Square: An Alternative Perspective on the 2011 Revolutions." Res Publica 19(3): 223-39.

Santos, Boaventura de Sousa. 2008. Conocer desde el Sur: Para una Cultura Política Emancipatoria. Buenos Aires: CLACSO, CIDES-UMSA, Plural.

Scheele, Judith. 2007. "Revolution as a Convention: Rebellion and Political Change in Kabylia." In Creativity and Cultural Improvisation, edited by Elizabeth Hallam and Tim Ingold, 151-66. Oxford and New York: Berg.

Schielke, Samuli. 2009. "Being Good in Ramadan: Ambivalence, Fragmentation and the Moral Self in the Lives of Young Egyptians." Journal of the Royal Anthropological Institute 15: 24-40.

- 2010. "Second Thoughts about the Anthropology of Islam, or How to Make Sense of Grand Schemes in Everyday Life." ZMO Working Papers 2, Zentrum Moderner Orient, Berlin.

- 2015. Egypt in the Future Tense. Indianapolis: Indiana University Press.

Schmitt, Carl. 2005. Political Theology: Four Chapters on the Concept of Sovereignty. Chicago: Chicago University Press.

Scholem, Gershom. 1971. The Messianic Idea in Judaism and Other Essays on Jewish Spirituality. New York: Schocken Books.

Schram, Stuart R. 1963. The Political Thought of Mao Tse-tung. New York: Frederick A. Praeger.

. 1971. "Mao Tse-tung and the Theory of the Permanent Revolution, 1958-69." China Quarterly 46: 221-44.

Scott, David. 2004. Conscripts of Modernity: The Tragedy of Colonial Enlightenment. Durham, NC: Duke University Press.

Scott, James. 1985. Weapons of the Weak: Everyday Forms of Peasant Resistance. New Haven, CT: Yale University Press.

- 1990. Domination and the Art of Resistance: Hidden Transcripts. London: Yale University Press.

Scott, Peter, and William T. Cavanaugh. 2008. The Blackwell Companion to Political Theology. Malden, MA: Blackwell.

Selbin, Eric. 1999. Modern Latin American Revolutions, 2nd Edition. Boulder, CO: Westview.

Sewell Jr., William H. 1996. "Historical Events as Transformations of Structures: Inventing Revolution at the Bastille." Theory and Society 25(6): 841-81.

Shah, Alpa. 2014. “'The Muck of the Past': Revolution, Social Transformation, and the Maoists in India." Journal of the Royal Anthropological Institute 20(2): 337-56.

Shah, Alpa, and Judith Pettigrew, eds. 2018. Windows into a Revolution: Ethnographies of Maoism in India and Nepal. London: Routledge. 
Shakow, Myriam. 2014. Along the Bolivian Highway: Social Mobility and Political Culture in a New Middle Class. Philadelphia: University of Pennsylvania Press.

Shariati, Ali. 2010. Ali Shariati: The Complete Collection of Works, C.W. 4, "The Return of the Self." Tehran: Shariati Cultural Foundation. CD-ROM.

- 2015. Hajj: The Pilgrimage. Lavergne: CreateSpace.

Siegel, James T. 1997. Fetish, Recognition, Revolution. Princeton, NJ: Princeton University Press

Sieyès, Emmanuel Joseph. [1789] 1963. What Is the Third Estate? London: Pall Mall Press.

Skinner, Quentin. 2008. "A Genealogy of the Modern State." Proceedings of the British Academy 162: 325-70.

Skinner, Quentin, and Bo Stråth, eds. 2003. States and Citizens: History, Theory, Prospects. Cambridge: Cambridge University Press.

Skocpol, Theda. 1979. States and Social Revolutions: A Comparative Analysis of France, Russia, and China. New York: Cambridge University Press.

Smith, S. A. 2017. "China, Revolution and Presentism." Past and Present 234: 274-89.

Sneath, David. 2007. The Headless State: Aristocratic Orders, Kinship Society and Misrepresentation of Nomadic Inner Asia. New York: Columbia University Press.

Sorel, Georges. 2009. Reflections on Violence. Charleston, SC: BiblioBazaar.

Soruco, Ximena, Daniela Franco, and Mariela Durán. 2014. Composición social del Estado: Hacia la descolonización de la burocracia. La Paz: CIS.

Ssorin-Chaikov, Nikolai. 2003. The Social Life of the State in Subarctic Siberia. Stanford, CA: Stanford University Press.

- 2017. Two Lenins: A Brief Anthropology of Time. Chicago: University of Chicago Press.

Starn, Orin. 1991. "Missing the Revolution: Anthropologists and the War in Peru." Cultural Anthropology 6(1): 63-91.

- 1995. "The Revolt against the Revolution: War and Resistance in Peru's Andes." Cultural Anthropology 10(4): 547-80.

Starn, Orin, and Miguel La Serna. 2019. The Shining Path: Love, Madness, and Revolution in the Andes. New York: W. W. Norton.

Starr, John Bryan. 2015. Continuing the Revolution: The Political Thought of Mao. Princeton, NJ: Princeton University Press.

Stedman Jones, Gareth. 1996. "The Determinist Fix: Some Obstacles to the Further Development of the Linguistic Approach to History in the 199os." History Workshop Journal 42: 19-35.

Steinmüller, Hans. 2011. "The State of Irony in China." Critique of Anthropology 31(1): 21-42.

- 2013. Communities of Complicity: Everyday Ethics in Rural China. Oxford: Berghahn Books.

Stengers, Isabelle. 2010. Cosmopolitics. Minneapolis: Minnesota University Press.

Stern, Steve, ed. 1987. Resistance, Rebellion and Consciousness in the Andean Peasant World, 18th to 2oth Centuries. Madison: University of Wisconsin Press.

Stinchcombe, Arthur L. 1999. "Ending Revolutions and Building New Governments." Annual Review of Political Science 2: 49-73. 
Stites, Richard. 1989. Revolutionary Dreams: Utopian Vision and Experimental Life in the Russian Revolution. New York: Oxford University Press.

Stobart, Henry. 2000. "Bodies of Sound and Landscapes of Music: A View from the Bolivian Andes." In Musical Healing in Cultural Contexts, edited by Penelope Gouk, 26-47. Aldershot: Ashgate.

Strathern, Marilyn. 1988. The Gender of the Gift: Problems with Women and Problems with Society in Melanesia. Berkeley: University of California Press.

-1990. "Artefacts of History: Events and the Interpretation of Images." In Culture and History in the Pacific, edited by Jukka Siikala, 25-44. Helsinki: Transactions of the Finish Anthropological Society.

Subcomandante Marcos. 1995. "Ejército Zapatista de Liberación Nacional (EZLN), Comuniqué of May 29, 1994." In Zapatistas! Documents of the New Mexican Revolution. New York: Autonomedia.

Svampa, Maristella, and Pablo Stefanoni, eds. 2007. Bolivia: Memoria, insurgencia y movimientos sociales. Buenos Aires: CLACSO.

Tambiah, Stanley. 1977. "The Galactic Polity: The Structure of Traditional Kingdoms in Southeast Asia." Annals of the New York Academy of Sciences 293: 69-97.

Tassi, Nico. 2010. "The Postulate of Abundance: Cholo Market and Religion in La Paz, Bolivia." Social Anthropology / Anthropologie Sociale 18(2): 191-209.

- 2013. "Things We Grow With: Spirits, Matter and Bodies in La Paz, Bolivia." In Making Spirits: Materiality and Transcendence in Contemporary Religions, edited by Diana Espirito Santo and Nico Tassi, 179-204. New York: IB Tauris.

- 2016. The Native World-System: An Ethnography of Bolivian Aymara Traders in the Global Economy. New York: Oxford University Press.

- Forthcoming. The Margins at the Centre: An Ethnography of Political Transformation among Bolivian Aymara during the "Process of Change."

Tassi, Nico, and María Elena Canedo 2018. Multiactividad, Equidad y Solidaridad: Nuevos Circuitos Económicos. Working paper. La Paz: CIDES-UMSA.

Taussig, Michael. 1980. The Devil and Commodity Fetishism in South America. Chapel Hill: University of North Carolina Press.

-1986. Shamanism, Colonialism and the Wild Man: A Study in Terror and Healing. Chicago: University of Chicago Press.

- 1997. The Magic of the State. London: Routledge.

Tétreault, Mary Ann, ed. 1994. Women and Revolution in Africa, Asia and the New World. Columbia: University of South Carolina Press.

Therborn, Göran. 1999. The Power of Ideology and the Ideology of Power. London: Verso.

Thomassen, Bjørn. 2012. "Notes towards an Anthropology of Political Revolutions." Comparative Studies in Society and History 54(3): 679-706.

Thompson, Edward P. 1991. The Making of the English Working Class. Toronto: Penguin Books.

- 1995. The Poverty of Theory or an Orrery of Errors. London: Merlin.

Thompson, Sinclair. 2002. We Alone Will Rule: Native Andean Politics in the Age of Insurgency. Madison: University of Wisconsin Press.

Tilly, Charles. 1978. From Mobilization to Revolution. New York: McGraw-Hill.

Todorov, Vladislav. 1995. Red Square, Black Square: Organon for Revolutionary Imagination. Albany: State University of New York Press. 
de Tracy, Antoine L.C. Destutt. [1818] 1973. A Treatise on Political Economy, Book 1. Detroit: Center for Health Education.

Trotsky, Leon. [1924] 2005. Literature and Revolution. Edited by William Keach and translated by Rose Strunsky. Chicago: Haymarket Books.

- 2008. History of the Russian Revolution. Chicago: Haymarket Books.

Tse Tung, M. Mao. [1930] 2014. “A Single Spark Can Start a Prairie Fire." In Selected Works of Mao Tse Tung, Volume 1. New York: Pergamon Press.

Tsing, Anna Lowenhaupt. 2004. Friction: An Ethnography of Global Connection. Princeton, NJ: Princeton University Press.

- 2015. The Mushroom at the End of the World: On the Possibility of Life in Capitalist Ruins. Princeton, NJ: Princeton University Press.

Turner, Victor. 1957. Schism and Continuity in an African Society: A Study of Ndembu Village Life. Manchester: Manchester University Press.

- 1969. The Ritual Process: Structure and Anti-structure. London: Routledge \& Kegan Paul.

- 1975. "Hidalgo: History as Social Drama." In Dramas, Fields, and Metaphors: Symbolic Action in Human Society, 98-155. Ithaca, NY: Cornell University Press.

-1990. "Are There Universals of Performance in Myth, Ritual and Drama?" In By Means of Performance, edited by Richard Schechner. Cambridge: Cambridge University Press.

Untoja, Fernando. 2001. El Retorno al Ayllu: Una Mirada Aymara a la Globalización. La Paz: Fondo Editorial de los Diputados.

Urioste, Miguel. 2017. Pluriactividad campesina en tierras altas: "Con un solo trabajo no hay caso de vivir." La Paz: Foro Andino Amazónico de Desarrollo Rural.

Van Gennep, Arnold. 1960. The Rites of Passage. London: Routledge \& Kegan Paul.

Vanderwalle, Diederick J. 2006. A History of Modern Libya. Cambridge: Cambridge University Press.

Varzi, Roxanne. 2006. Warring Souls: Youth, Media and Martyrdom in Post-Revolutionary Iran. London: Duke University Press.

Verdery, Katherine. 1996. What Was Socialism and What Comes Next? Princeton, NJ: Princeton University Press.

-1999. The Political Lives of Dead Bodies: Reburial and Postsocialist Change. New York: Columbia University Press.

- 2018. My Life as a Spy: Investigations in a Secret Police File. Durham, NC: Duke University Press.

Viveiros de Castro, Eduardo. 2014. Cannibal Metaphysics. Minneapolis: Univocal.

Vom Bruck, Gabriele. 2005. Islam, Memory and Morality in Yemen: Ruling Families in Transition. New York: Palgrave Macmillan.

- 2019. Mirrored Loss: A Yemeni Woman's Life History. Oxford: Oxford University Press.

Ward, Colin. 2004. Anarchism: A Very Short Introduction. Oxford: Oxford University Press.

Wartenberg, Thomas E. 1982. "Species-Being and Human Nature in Marx." Human Studies 5(2): 77-95.

Watson, Carolyn. 2010. "Citizenship, Religion, and Revolution in Cuba." Doctoral dissertation submitted to the University of New Mexico. Accessed 8 December 2018. 
https://digitalrepository.unm.edu/cgi/viewcontent.cgi?referer=;www.google.com/\&h ttpsredir $=1 \&$ article $=1080 \&$ context $=$ hist_etds.

Weber, Max. 1968. On Charisma and Institution Building. Edited by S. N. Eisenstadt. Chicago: University of Chicago Press.

Weeden, Lisa. 1999. Ambiguities of Domination: Politics, Rhetorics and Symbols in Contemporary Syria. Chicago: University of Chicago Press.

Weil, Simone. 2004. Gravity and Grace. London: Routledge.

Weinreb, Ameliua Rosenberg. 2009. Cuba in the Shadow of Change: Daily Life in the Twilight of the Revolution. Gainesville: University Press of Florida.

Weismantel, Mary. 2001. Cholas and Pishtakos: Stories of Race and Sex in the Andes. Chicago: University of Chicago Press.

Werbner, Pnina, Martin Webb, and Kathryn Spellman-Poots., eds. 2014. The Political Aesthetics of Global Protest. Edinburgh: Edinburgh University Press.

West, Harry. 2000. "Girls with Guns: Narrating the Experience of War of FRELIMO's 'Female Detachment"' Anthropological Quarterly 73(4): 180-94.

-2005. Kupilikula: Governance and the Invisible Realm in Mozambique. Chicago: University of Chicago Press.

West, Harry, and Parvathi Raman, eds. 2009. Enduring Socialism: Explorations of Revolution and Transformation. Oxford: Berghahn Books.

Williams, Raymond. 1977. Marxism and Literature. Oxford: Oxford University Press.

Wilson, Alice. 2016. Sovereignty in Exile: A Saharan Liberation Movement Governs. Philadelphia: University of Pennsylvania Press.

- 2019. "Revolution." In Cambridge Online Encyclopedia of Anthropology. Accessed online at https://www.anthroencyclopedia.com/entry/revolution on 22 March 2020.

Winegar, Jessica. 2012. "The Privilege of Revolution: Gender, Class, Space, and Affect in Egypt." American Ethnologist 39(1): 67-70.

- 2016 . "A Civilized Revolution: Aesthetics and Political Action in Egypt." American Ethnologist 43: 609-622.

Wolf, Eric. 1969. Peasant Wars of the Twentieth Century. New York: Harper and Row.

Worsley, Peter. 1991. "The Analysis of Rebellion and Revolution in Modern British Social Anthropology." Science \& Society 25(1): 26-37.

Yampara Huarachi, Simón. 1992. “Economía’ Comunitaria Andina.” In La Cosmovisión Aymara, edited by Hans Van den Berg and Norbert Schiffers, 143-86. La Paz: Hisbol/UCB.

Yampara, Simón, Saul Mamani, and Nora Calancha. 2007. La Cosmovisión y Lógica en la Dinámica Socioeconómica del Qhatu/Feria 16 de Julio. La Paz: PIEB.

Yan, Yunxiang. 2016. "Old and New Moralities in Changing China." Anthropology of This Century 16. Accessed 8 December 2018. http://aotcpress.com/articles/moralities -changing-china/.

Yurchak, Alexei. 2006. Everything Was Forever, Until It Was No More: The Last Soviet Generation. Princeton, NJ: Princeton University Press.

- 2015. "Bodies of Lenin: The Hidden Science of Communist Sovereignty." Representations 129(1): 116-57.

Zavaleta, René. 2011. Obra Completa. La Paz: Plurales Editores.

Zedong, Mao. 1976. Quotations from Chairman Mao Tse Tung (also known as "The Little Red Book"). Austin: University of Texas. 
Zegada, María Teresa, and George Komadina. 2017. El Intercambio Político Indígenas/ Campesinos en el Estado Plurinacional. La Paz: Plural.

Zegada, María Teresa, Claudia Arce, Gabriela Canedo, and Alber Quispe. 2011. La Democracia desde los Márgenes: Transformaciones en el Campo Político Boliviano. La Paz: Muela del Diablo/Clacso.

Zharkevich, Ina. 2019. Maoist People's War and the Revolution of Everyday Life in Nepal. Cambridge: Cambridge University Press

Ziadeh, Nicola A. 1958. Sanusiyah: A Study of a Revivalist Movement in Islam. Leiden: Brill. Zibechi, Raul. 2010. Dispersing Power: Social Movements and Anti-State Forces. Edinburgh: AK Press.

Žižek, Slavoj. 1994. “The Spectre of Ideology.” In Mapping Ideology, edited by Slavoj Žižek, 1-33. London: Verso.

- 1995. Looking Awry: An Introduction to Jacques Lacan through Popular Culture. London: MIT Press.

— 1997. "Multiculturalism, or the Cultural Logic of Multinational Capitalism." New Left Review (September-October): 28-51.

- 2003. The Puppet and the Dwarf: The Perverse Core of Christianity. Cambridge, MA: MIT Press.

- 2008. The Sublime Object of Ideology. London: Verso.

- 2009. In Defence of Lost Causes. London: Verso.

- 2012. The Year of Dreaming Dangerously. London: Verso.

- 2013. “Troubles in Paradise." London Review of Books 35(14): 11-12.

Zolberg, Aristide R. 1972. "Moments of Madness." Politics and Society 2(2): 183-207. 



\section{N D E X}

aché, 89-90, 167-68

Adorno, Theodor, 99, 119-20

Afary, Janet, 70, 134-35

Aflaq, Michel, 128

Aliabad (Iran), 54-55

Althusser, Louis, 68-69, 120

altruism, 67

anarchism, 17, 48, 53, 97, 111, 125

Andeanism, 1

Anderson, Kevin, 70, 102

Anglo-Iranian Oil Company, 53

animal sacrifice, $85,88-90,168$

antistructure, 24, 26

Arab Spring, 2, 8, 14-15, 37, 43-44, 75, 129, 135

Arendt, Hannah, 18-19, 35-37, 87, 94, 137-38, 144, 157

Atatürk, Mustapha Kemal, 122

Aymara, 3, 42, 63, 131-32, 149-53, 166-68

Badiou, Alain, 69, 129, 143, 160

Bakunin, Mikhail, 48, 94, 96-97, 144

Bartolina Sisa National Confederation, 41-42

Bayar (Mongolian activist), 92

Benjamin, Walter, 142, 159-63, 165, 167

Bloch, Ernst, 129

Bloch, Maurice, 27-30, 32-34

Bolívar, Simon, 106

Bolivia, 46, 61-65, 93, 131, 149, 152, 165, 167;

Bartolinas, 41-42; proceso de cambio, 41-42, $46,60-63,131,149-50,166$

Bonaparte, Louis, 138 capitalism, 160; Marxist critique of, 129; newness in, 130; time and, 142, 153, 160; uncontrolled growth, 95, 130

Castro, Fidel, 85-89, 97, 169

Catholic Church, 142

Chávez, Hugo, 13-14, 105-7

Cheng, Yinghong, 80

Chernyshevsky, Nikolai, 77

Cherstich, Igor, 39, 57-60, 102-3, 123

China, $18,47,80-81,84-85,90$

Christianity, 9, 21, 74, 76, 143-44, 162, 165

clanship, 3, 7, 42-44, 51-53, 148

colonialism, 31-32, 113, 150, 156

communitas, 24-26

Confucianism, 81-84, 90

cosmogony, 4, 156, 158-59, 161, 163, 169

Cuba, 85-91, 93, 97, 136-37, 165, 167-68; Afro-

Cuban religious practices, 85 ; guerilla movements, 47; Revolution, 14, 85-86, 88, 90, 167-68; revolution as fusion of state and person, 87; Ruth and Oscar Lewis' expulsion from, 11

Dabashi, Hamid, 43-44, 73

Dande, 30-31, 147

Daoism, 84

Donham, Donald, 2, 9, 139, 153

Dumont, Luis, 7, 164-65

Eagleton, Terry, 117-20, 127, 129, 142, 160

Egypt, 2, 37-39; 2011 Revolution, 14, 129 
El Alto market, 61-63, 150-52

Engels, Friedrich, 36, 41, 127, 130, 157; Communist Manifesto, 94; false consciousness, 116; ideology and material circumstance, 117 exomologesis, 74, 76

Fosshagen, Kjetil, 129

Foucault, Michel, 69-76, 78-79, 84, 95, 134-35; Ghamari-Tabrizi on, 70; on Iran, 70-80

FRELIMO, 145-46

French Revolution, 91, 166; anticlericism and, 36, 141 ; as genesis of the nation, 45; as inaugral event of modern era, 19;

Napoleon's claim to be heir of, 98; Tracy on, 116; tragic quality, 19; universalism, 164-65; Zhou's comment to Nixon, 18

Gaddafi, Muammar, 58-59, 102-4, 122-24, $127-28,165-66$

García Linera, Álvaro, 42, 44, 46, 62, 157, 167

Gennep, Arnold von, 24, 27-28

Germany, post-Reformation, 164

Ghamari-Tabrizi, Behrooz, 70-74

Gharbzadegi, 131

Gluckmann, Max, 12-13, 22-24, 28, 33, 35, 45

God-building, 141

Gorki, Maxim, 141

Governance of the Jurist doctrine, 74

Gramsci, Antonio, 20, 118-21, 125, 128, 144

Greece, 43, 78

Guevara, Ernesto "Che", 2, 85-88, 97, 142, 144; death 86

guilds, 53, 137

Habermas, Jürgen, 119

Haiti, $148-49$

Hegel, G.W.F., 44, 46, 94, 129

Hegland, Mary Elaine, 2, 13, 54

Hidalgo, Miguel, 25-26

historical event, 19, 22

history, linear conception, 6

Hobsbawm, Eric, 6, 13, 25

Hoffman, Michael, 52

Holbraad, Martin, 4, 14, 33, 85, 87-89, 155, 167

Holloway, John, 49, 51

humanism, 92-93

Humphrey, Caroline, 11, 33, 75, 83, 87, 92, 107-8

Hussain ibn Ali (grandson of Muhammad), 72, 135

ideology, 85, 115-25, 127-33, 139, 144, 147, 161; communitas as, 25, 27; cultural specificity, 114; as discourse, 114; as false representation,
115, 117; hegemony and, 118; Maoist, 14; Marxist analysis of, 115, 117; Marxist analysis of, material conditions and, 117; Marx on, 113; Napoleon's use of term, 116; as science of ideas, 116; as sensemaking tool, 114; Shi'a, 55; as worldview, 114

Ifá, 88-90

interpellation, 68-69, 120

Iran, 54, 64, 70-74, 76, 84, 90, 115, 125, 131, 135-36; 1979 Revolution, 53-54, 56, 70-72, 74, 90, 134, 136, 163; becomes Islamic Republic, 53-54; Foucault on, 69-80; Khomeini returns to, 54

Islam, 37, 72, 74-75, 128, 130, 134-35, 145; law and jurisprudence, 53, 57, 125, 134; role in revolutionary uprising, 68, 71; Shía, 53-55, 71-74, 76, 90, 126-27, 134-35; Shi'a, martyrdom, 71, 73-74, 76, 135; Sunni, 102, 127; Western culture and, 43

Islamism, 15, 70, 128, 130

Jamahiriya system, 58-60, 102

James, C. L. R., 148

Judaism, 159-63, 165; Jewish mystical temporality, 159-60

Judaeo-Christian traditions, 36-37, 162, 165

Kabylia, 15

Kharchordin, Oleg, 75-77, 80-81, 84

khidma, 37-39, 75

Khomeini, Ruhollah, 53-56, 69-71, 73-75, 125-27, 134-35

Khrushchev, Nikita, 101

kingship, 22-23, 95, 105, 110-11, 144, 156

kinship, 7, 13, 44, 50-51, 53, 56, 64, 78, 92, 165

Kissinger, Henry, 18

Koselleck, Reinhart, 4, 6, 19, 21, 33, 136, 138, 163

Lacan, Jacques, 120-21

Lan, David, 2, 13, 30-31, 35, 50, 147-48

leadership, 38, 55, 61, 82, 95-99, 101-12, 123-25, 140, 144, 165; divine kingship, 105; Iran, 75; kingship, 22-23, 95, 105, 110-11, 144, 156; personality cults, 110, 141; rotational, 45; segmentary organizations, 12-13, 51, 59, 61-62, 64; taifeh-keshi paradigm, 54-56

Le Goff, Jacques, 137

Lenin, Vladimir, 77, 100, 110-11, 125, 139-40, 164; class consciousness and, 69, 77; cult of personality, 110; mummified remains, 109-11; New Man, 67; oblichenie, 76 ; on revolution and the state, 42; on the state, 47-48; What Is to Be Done, 76-77 
Leninism, 101, 110

letra del año, 89

Lévi-Strauss, Claude, 4, 30

Lévy-Bruhl, Lucien, 88

Lewis, Ruth, 11

Liberation Theology, 48, 104, 163

Libya, 3, 12, 56-57, 6o, 64-65, 102-3, 115, 122, 165

liminality, 23-29, 39

lineages, 51-53, 64, 105-6, 138, 147-48

linear cosmology, 16, 158, 162

Liu Shaoqi, 83, 85

Louis XIV of France, 45

Luxemburg, Rosa, 20

Maduro, Nicolas, 106-7

Mamani, Cristina, 61, 150-51

Manchester School, 23

Maoism, 52, 83-84, 146; Confucian ethics and, 83

Maoists, 20, 82, 147

Mao Zedong, 52, 80-83

Marcos, 49, 97

Marcuse, Herbert, 100, 120

Marx, Karl, 19, 117, 128, 161; Communist Manifesto, 94; on global solidarity, 44; on hegemony, 118; historical dialectic, $138,158,160$; historical inevitability of revolution, 94, 109, 129; on ideology, 115-18; on ideology, as unreal, 120; on language and revolution, 138-39; on locality and globalization, 43-44; on religion, $116-17,127-28$, 139; revolution as end of exploitation, 129; revolution as end of ideology, 114-15, 118, 125; revolution as outcome of class conflict, 5 ; revolution as rupture in time, 19, 157; specter, 94-95; on time and the temporal, 130, 159; Tracy and, 116; on tradition, 50; universalism, 166

Marxism, 35, 48, 60, 82, 118-19, 125, 127-32, 162

Marxism-Leninism, 48, 141

Mauss, Marcel, 51, 78, 103, 156

Mencken, H. L. , 6

Mexico, 25-27, 48; Civil War, 25, 113; Zapatism, 48

mhondoro, 31-32, 35-36, 147

Michelutti, Lucia, 13, 105-6

Mittermaier, Amira, 14-15, 37-39, 50, 130

Mongolia, 3, 83, 87, 92

Morales, Evo, 41, 62-63, 150

Mozambique, 31, 136, 145-47, 149

Muedans, 145-47
Mugabe, Robert, 32

Muslim Brotherhood, 37-38, 75

Napoleon Bonaparte, 98, 116

New Culture Movement, 81

New Man, 4, 66-67, 79-81, 85-87, 90-92, 113, $142-45$

New Soviet Man, 77

Nixon, Richard, 18

oblichenie, 76

Occupy movement, 38,43

Pachakuti, 131, 149-51

partial revolution, 52

Paul the Apostle, 69, 142-44, 160

Paz, Octavio, 113

peasant groups, 45, 142

penitence rites, $66,71-72,74-77$

permanent revolution, $80-81,84$

personhood, $2-3,69,72,79-80,85,90-91$; malleable, 84

Peru, 1,52

political instrument, 61

political science, 5-8, 10, 13, 153

possession, 95

post-humanism, 91-93

proceso de cambio, 41-42, 46, 60-63, 131, 149-50, 166

Protestant Reformation, 76

religion, 13, 128, 136, 145, 153; Afro-Cuban, $85,88,167-68$; as domain of revolution, 153; Marxist analysis of, 126-28, 139-40; Marxist borrowing from, 128; Marx on, 116; political theology, 78, 135; revolutionary abandonment of, 141, 143; revolution as analogue of, 67-68; as social bond, 165 ; state co-option of, 89 . See also Christianity; Islam; Judaism; Russian Orthodox Church

ritual, 3-4, 13, 23-24, 26, 28, 34, 89, 145, 148, 153; Bloch's model, 27-29, 32-34; conservatism, 30; critical function, 21; Durkheim on, 27; as event, 21; Gluckman on, 23; liminality, 23-29, 39; as mechanism for social bonding, 23, 29; personhood and, 79; political function, 30; rebellious ritual as distinct from revolution, 22; revolution and, 30, 32; revolutionary rituals, 13, 22; Shi'ia, 74; social change and, 23-24; time and, 34, 147; transformative character, 28-29; Turner's model, 13, 23-27, 29; violence in, 21, 29. See also tradition 
ritual rebellions, 22-23

Robespierre, 46, 67, 95

rupture, 4, 18-20, 36-38, 49, 137, 139, 142, 151, 153;

historical, 4-6

Russia. See Soviet Union

Russian Orthodox Church, 68, 76, 80-81

Saharawi Arab Democratic Republic (SADR), 52

Sahlins, Marshall, 7, 87, 105

Saleh, Abdullah, 130-31

Sánchez, Rafael, 111

Sanusi order, 12, 57

Scheele, Judith, 15, 44, 134, 142

Schielke, Samuli, 11, 15, 37, 75, 124, 129-30

self, the, 14, 67, 75, 112, 120; annihilation of,

135, 144; formation of, 69; Foucault on,

75 ; ideology as illusory image of, 117,119 ;

intrusion of the state into, 77 ; revolutionary

personhood, 70, 72, 77-78, 80, 91-92, 167;

revolution as search for, 113; sacrifice of, 73 ;

suppresion of, 49; technologies of, 73, 77, 79

self-formation, $69-70$

self-reform, $83-84$

self-revelation, $76,80-81$

self-sacrifice, $14,33,67,80,85,87-88,90$

Seyyid family, 55

Shía Islam, 53-55, 71-74, 76, 90, 126-27, 134-35

Shining Path, 1, 140

Shona, 32, 36, 147

socialism, 85-86, 102, 124, 128, 140, 144, 167

Sorel, Georges, 104, 128

Soviet Union, 11, 47, 100; Bolshevik Revolution,

$68,76,80,100,103,110,140-41,143,164$;

China and, 82, 85; God-building, 141;

routinized post-revolutionary period,

100-102; state ideology, 124;

unlearning, 139

soznatelnost, 77

specter, 94-95

spirit mediums, 31-32, 35, 147-48

spirit possession, 13, 31-32, 35, 145, 147, 149

Stalin, Joseph, 68, 76-77, 100-102, 104, 107-10

Starn, Orin, 1-2, 14, 140

state, $42-43,47,51,58-60,64-65,108,125$;

anarchism and, 48; challenges to role of, 61 ; co-option of state power as revolutionary aim, 47, 50, 64; as embodiment of national community, 45; fragmentary approaches, 50-53, 64; indigenous movements and, 131; individual persons and, $86-87$, 95; leaders as personification of, 63, 100-101; Lenin on,
47; Libyan notions, 56; local organizations and, 63; as mediating force for popular will, 125; nonstate power structures replacing, $52,58,165$; overemphasis of role in analysis of revolution, 50; relation to other power structures, 50-51, 56, 58, 64; revolutionary transformation of, 47; tribalism and, 58-59; as unifying structure, 44,64 ; as universalist and revolutionary agent, 46-48; Zapatist attitude to, 49-50

statecraft, 11

statelessness, 56, 58-60

state power, 47,49

stranger-kings, 105

Strathern, Marilyn, 7, 34, 78, 92

structural-functionalism, 23-24

Subcomandante Marcos, 49, 97

subjectivity, 69

Sufism, 37, 39, 126

Tahrir Square, 15, 18, 37-38, 75

taifeh-keshi paradigm, 54-56

Taussig, Michael, 13, 95, 156

temporality. See time

Third Universal Theory of the state, 58

Thomassen, Bjørn, 2, 17, 103-4

time and temporality, 3, 5-6, 21, 34, 100, 162; cosmology and, 136-37; cyclical concept, 33-35; as historical development, 6; Jewish mystical conception, 159-60; linear (Western, Judaeo-Christian) conception, 33-34, 36, 136-37, 160, 162; Marxist ideology and, 128, 139, 142, 160; medieval conception, 137; Pachakuti reconfiguration, 149-50; progress and, 135; revolution as rupture in, 18-19, 38; revolution as time travel, 36 ; ritual and, 22, 33-34, 147; secularization of, 37; transcendence of the divine, 39,137

Tracy, Antoine Destutt de, 115-16

trade unions, 42, 45, 62, 64

traditio, 163

tradition, 81, 90, 96, 101, 134, 136, 138, 140, $142-43,153,162-63$; as inverse of modernity, 23; revolutionary movements drawing from, 140, 142, 153; revolution as break from, 81, 134, 136, 138, 143

tribes, 12-13, 41-45, 51-53, 56-60, 64-65

trickster archetype, 103-5

Trotsky, Leon, 66-67, 77, 81, 96, 144

Turkey, 122

Turner, Victor, 13, 23-27, 29 
uwawi, 145-46

Van Gennep, Arnold, 24, 28

Varzi, Roxanne, 11, 14, 74, 125-26

violence, 27-34, 73, 87

Virgin Mary, 106

Virgin of Guadalupe, 25-26

voodoo, 148

Weber, Max, 97-100, 104, 106

West, Harry, 145

Wilson, Alice, 52
Yan'an, 82-84

Yemen, 38, 52, 130-31

Yurchak, Alexei, 11, 47, 85, 100-101, 109-11, 124, 132, 139, 141

Zapatism, 48-50, 53, 97

Zhou Enlai, 18

Zibechi, 49, 61, 150

Zimbabwe, 36, 79, 147-48

Zimbabwe African National Liberation Army (ZANLA), 30-32, 35-36, 147-48

Žižek, Slavoj, 17, 43, 51, 120-23, 125, 127-28, 160-61 
Founded in 1893 ,

UNIVERSITY OF CALIFORNIA PRESS

publishes bold, progressive books and journals

on topics in the arts, humanities, social sciences, and natural sciences - with a focus on social justice issues-that inspire thought and action among readers worldwide.

The UC PRESS FOUNDATION

raises funds to uphold the press's vital role as an independent, nonprofit publisher, and receives philanthropic support from a wide range of individuals and institutions - and from committed readers like you. To learn more, visit ucpress.edu/supportus. 


\section{ANTHROPOLOGY}

WHAT CAN ANTHROPOLOGICAL THINKING contribute to the study of revolutions? The first book-length anthropological approach to revolutions, Anthropologies of Revolution proposes that revolutions should be seen as concerted attempts to radically reconstitute the worlds people inhabit. Viewing revolutions as all-embracing, world-creating projects, the authors ask readers to move beyond the idea of revolutions as acts of violent political rupture, and instead regard them as processes of societal transformation that penetrate deeply into the fabric of people's lives, unfolding and refolding the coordinates of human existence.

"With insightful references to cases around the world, this book advances a brilliant holistic theory that offers credibility and significance to the ways revolutions unfold in culturally specific practices without diminishing their political impact and universal aspirations."

BEHROOZ GHAMARI-TABRIZI, author of Foucault in Iran: Islamic Revolution after the Enlightenment

"This fascinating volume opens up new horizons in the study of revolutionary practice. It is difficult to imagine a more important or original work."

DAVID NUGENT, author of The Encrypted State: Delusion and Displacement in the Peruvian Andes

"This book is a truly original (in all senses of the term) contribution to understanding the global and human condition of far-reaching political, social, and cosmological change."

BJWRN ENGE BERTELSEN, author of Violent Becomings: State Formation, Sociality, and Power in Mozambique

IGOR GHERSTIBH is Teaching Fellow in Social Anthropology at University College London. He is coeditor of the special issue "The Multiple Narratives of the Libyan Revolution," Middle East Critique.

MARTIN HOLBRAAD is Professor of Social Anthropology at University College London. He is author of Truth in Motion: The Recursive Anthropology of Cuban Divination and coauthor of The Ontological Turn: An Anthropological Exposition.

NIBO TASSI is Research Associate at the Universidad Mayor de San Andrés in La Paz, Bolivia, and author of The Native World System: An Ethnography of Bolivian Aymara Traders in the Global Economy.

\section{UNIVERSITY OF GALIFORNIA PRESS WWW.UCPRESS.EDU}

A free ebook version of this title is available through Luminos, University of California Press's Open Access publishing program for monographs. Visit www.luminosoa.org to learn more. 